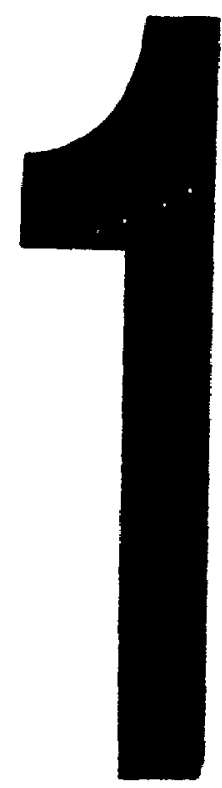

PM-1 31'1" $\times 4$ " PHOTOGRAPHIC MICROCOPY TARGET NES 1010a ANSI/ISO \#2 EQUIVALENT

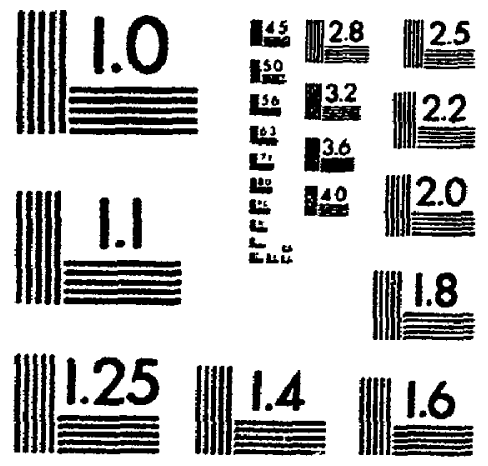

PRECISION ${ }^{S M}$ RESOLUTION TARGETS

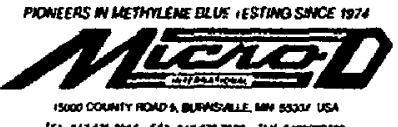


Ottawa. Canada

KIA ON4
NOTICE

The quality of this microform is heavily dependent upon the quality of the original thesis submitted for microfilming. Every effort has been made to ensure the highest quality of reproduction possible.

If pages are missing. contact the university which granted the degree.

Some pages may have indistinct print especially it the original pages were typed with a poor typewriter ribbon or if the university sent us an inferior photocopy.

Reproduction in full or in part of this microform is governed by the Canadian Copyright Act, R.S.C. 1970. C. C-30, and subsequent amendments.

\begin{abstract}
AVIS
La qualité de cette microłorme dépend grandement de la qualité de la thèse soumise au microfitmage. Nous avons tout fait pour assurer une qualité supérieure de reproduction.

S'il manque des pages, veuillez communiquer avec luniversité qui a conféré le grade.

La qualité d'impression de certaines pages peut laisser à désirer, surtout si les pages originales ont été dactylographiées à raide d'un ruban usé ou si l'université nous a fait parvenir une photocopie de qualité inférieure.
\end{abstract}

La reproduction, méme partielle, de cefte microforme est soumise a la Loi canadienne sur le droit d'auteur. SRC 1970, c. C-30, et ses amendements subséquents. 


\title{
CHARACTERIZATION OF CHROMOSOMAL SITES OF T-DNA INTEGRATION BY ACTIVATION OF A PROMOTERLESS B-GLUCURONIDASE (GUS) GENE LINKED TO THE T-DNA RIGHT BORDER REPEAT
}

\author{
BY
}

PIERRE R. FOBERT

A Thesis Submitted to

The Faculty of Graduate Studies and Research

in Partial Fulfilment of

the Requirements for the Degree of

Doctor of Philosophy

Department of Biology

Carleton University

Ottawa, Ontario

January 10, 1992

(C) copyright 1992, Pierre R. Fobert 
National Library

of Canada

Canadian Theses Service

Ottawa. Canada

KIA ON4
Bibfiothèque nationale

du Canada

Service des theses canadiemes
The author has granted an irrevocable nonexclusive licence allowing the National Librery of Canada to reproduce, loan, distribute or sell copies of histher thesis by any means bad in any form or format, making this thesis avaliable to interested persons.

The author retains ownership of the copyright in his/her thesis. Neither the thesis nor substantial extracts from it may be printed or otherwise reproduced without his/her permission.
L'auteur a accordé une licence irrévocable et non exclusive permettant à la Bibliothéque nationale du Canada de reproduire, preter. distribuer ou vendre des coples de sa these de quelque manière et sous quelque forme que ce soit pour mettre des exemplaires de cette thèse à la disposition des personnes intěressées.

L'auteur conserve la propriété du droit d'auteur qui protège sa thèse. Ni la thèse ni des extraits substantiels de celle-ci ne dolvent stre imprimés ou autrement reproduits sans son autorisation. 
Thesis containg black \& white photographe \&/or explanatory tables which when microfilmed may lose their aignificance. The hardcopy of the thesis is available upon request from Carleton University Library. 
The undersigned hereby recommend to

the Falcuty of Graduate Studies and Research

acceptance of the thesis,

\section{CHARACTERIZATION OF CHROMOSOMAL SITES OF T-DNA INTEGRATION BY ACTIVATION OF A PROMOTERLESS B-GLUCURONIDASE (GUS) GENE LINKED TO THE T-DNA RIGHT BORDER REPEAT}

submitted by

PIERRE R. FOBERT, B.Sc.(Honours), M.Sc.

in Partial Fulfilment of the Requirements

for the Degree of Doctor of Philosophy

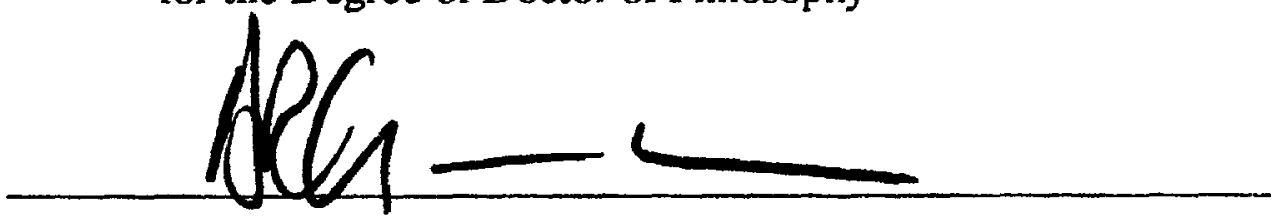

Chair, Department of Biology

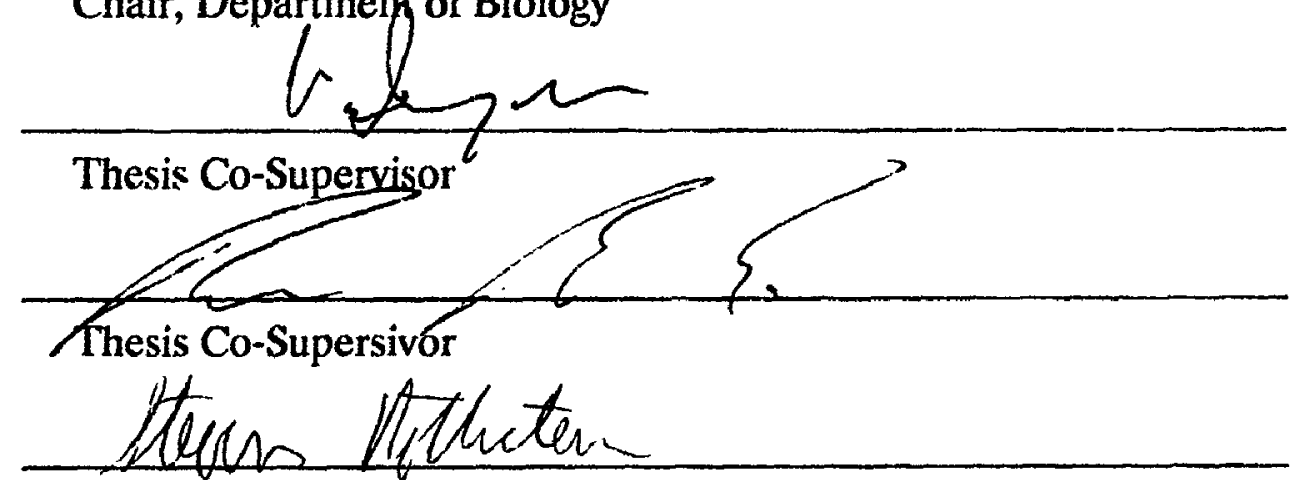

External Examiner

Carleton University

January 16, 199? 


\begin{abstract}
A binary vector, pPRF120, was designed to detect T-DNA insertions within transcribed regions of the plant genome. Linked to the right border repeat, the vector contains a promoterless $B$-glucuronidase (GUS) gene which can, upon integration into chromosomes, be activated by endogenous cis-acting regulatory elements. The vector also incorporates a chimaeric marker gene conferring resistance to kanamycin to ensure recovery of gene fusions regardless of the extent of their tissue-specific or developmentally-regulated expression, and to permit analysis of the frequency of plants which express the promoterless reporter. Analysis of 52 tobacco plants harbouring pPRF120 indicates that more than $80 \%$ contain single, intact copies of the T-DNA. Screening of leaf tissue from 940 transformants revealed that $57(6 \%)$ contained GUS activity. Analysis of seeds from 220 plants which did not express GUS in leaves revealed the presence of an additional 5 gene fusions. Fluorogenic and histological GUS assays were used to visualize and quantify tissue- and cell-specific gene expression. Preliminary analysis of all 62 plants expressing GUS, and more detailed analysis of 18 plants indicates that the most prevalent patterns of expression are those where GUS activity is detected in 2 or several, but not all organs. Levels of GUS activity differed considerably amongst different organs, as did the tissue-specificity of expression. One fusion was expressed in all the tissues and organs screened, which included the vegetative and floral organs, and seeds harvested at 10 and 20 days post-anthesis. Gene fusions expressed in a highly tissue-specific manner were also identified, including vascular-, endosperm-, seed coat-, and embryo-specific patterns. The promoterless GUS gene along with $2.5 \mathrm{~kb}$ of upstream, flanking chromosomal DNA was isolated from a plant (T218) which expresses GUS specifically in the seed coat. Reintroduction of this fragment in tobacco by T-DNA-mediated transformation indicates that it contains the sequences responsible for the spatial and temporal
\end{abstract}


pattern of GUS expression observed in plant T218. Data obtained suggests that TDNA integration occurs preferentially within transcribed regions of the plant genome. This conclusion is based on the high frequency at which gene fusions were observed relative to the proportion of the tobacco genome which is transcribed. There does not appear to be a need for a chromosomal region to be transcriptionally active for T-DNA integration to occur, although the frequency of obtaining gene fusions in the infected tissue was three times higher than in tissues which were not present during Agrobacterium co-cultivation. T-DNA-mediated gene fusions may also be useful for detecting novel gene regulatory signals in planta. 


\section{ACKNOWLEDGEMENTS}

I would first like to thank my supervisors, Dr. V.N. Iyer and Dr. Brian Miki for their help, advice and support during all the stages of this project. I am also grateful to Dr. Miki and the Plant Research Centre, Agriculture Canada, for allowing me to use their research facilities. The advice of Dr. V. Seligy of the National Research Council is also gratefully acknowledged.

I would like to thank Dr. S. Rothstein of the University of Guelph for accepting to act as the external examiner on such short notice.

The help, advice, encouragement and friendship of the people from Drs. lyer's and Miki's labs, past and present, is well appreciated. Special thanks to Amy Wheeler, Trudy Weeri, Elizabeth Ricciuto, Hélène Labbé, and John Cosmopoulos for their help with plant transformation and GUS assays, Dr. Jiro Hattori for pnosGUS and synthesizing sequencing primers, and Janice DeMoor for, amongst other things, Figure 2.2. In addition, I would like to thank the greenhouse staff at the Central Experimental Farm for maintaining the large number of plants generated in this study.

I would like to acknowledge the financial support of the Natural Sciences and Engineering Research Council of Canada and Carleton University.

Finally, I wish to thank my family for their continued support of my studies and career. Very special thanks to my wife, Jocelyn, who helped and supported me in so-0-o many ways...so there! (Hi Jennifer). 


\section{TABLE OF CONTENTS}

Abstract

Acknowledgements

Table of Contents

List of Tables

List of Figures

List of Abbreviations

INTRODUCTION

\section{CHAPTER 1}

\section{LITERATURE REVIEW}

1.A. Size and Organization of Plant Genomes

1.A.1. Size and sequence organization of plant genomes

1.A.2. Structure of plant chromatin

1.B. Patterns of Gene Expression during Plant Development

1.B.1. Overview of plant gene expression

1.B.2. Expression patterns of cloned genes

1.B.3. Significance of differential gene expression

ii

$x$

$\mathbf{x i}$

1.C. Regulation of Plant Gene Expression 1.C.1. cis-acting factors involved in transcriptional regulation of plant genes

1.C.2. trans-acting factors involved in regulating gene transcription

1.C.3. Models of transcriptional gene regulation

1.C.4. Post-transcriptional control of gene expression

1.D. Gene Fusions and Reporter Genes

1.E. Agrobacterium-Mediated Gene Transfer

1.E.1. Molecular basis of gene transfer and the development of transformation systems

1.E.2. Events within the bacterial cell:

a model for T-DNA transfer

1.E.3. Events within the plant cell

1.E.3.a. Early events within the plant cell

1.E.3.b. Genetic analysis of T-DNA inheritance

37

38

41

1.E.3.c. Structure and organization of the integrated T-DNA

1.E.3.d. Localization of T-DNA insertions

43

48

1.E.3.e. Analysis of T-DNA/plant DNA junctions and target sites of T-DNA integration

50

1.E.3.f. Models of T-DNA integration

52

55

1.E.4. Gene expression in transgenic plants

1.F. Agrobacterium-Mediated Gene Transfer as a Means of Studying Plant Genes in vivo

60

1.F.1. Assessment of T-DNA as an element to manipulate genes in vivo

1.F.2. Strategies for generating T-DNA-mediated gene fusions

1.F.2.a. T-DNA-mediated genes fusions to promoterless selectable markers

1.F.2.b. T-DNA-mediated genes fusions to promoterless reporter genes

1.F.2.c. T-DNA-mediated enhancer fusions

1.F.3. Molecular cloning and functional testing of T-DNA-mediated gene fusions

1.G. Rationale of the Present Study 
CHAPTER 2

MATERIALS AND METHODS

2.A. Bacterial Strains and Plasmids $\quad 79$

2.A.1. Growth and storage conditions 79

2.B. Bacterial Conjugation $\quad 84$

2.B.1. Conjugation between $E$. coli strains $\quad 84$

2.B.2. Transfer of binary plasmids from $E$. coli to A. tumefaciens GV3101 84

2.B.3. Transfer of pPRF120 from Agrobacterium to E. coli 85

2.C. Preparation of Competent Cells and Bacterial Transformation 86

2.C.1. Preparation of competent cells (Cohen et al., 1972) 86

2.C.2. Preparation of competent cells (Hanahan, 1985) 86

2.C.3. Transformation of competent cells 87

2.D. DNA Extraction Protocols $\quad 88$

2.D.1. Rapid extraction of plasmid DNA 88

2.D.1.a. Holmes and Quigley's boiling method 88

2.D.1.b. Rapid DNA isolation by alkaline lysis 88

2.D.2. Large scale plasmid DNA extraction $\quad 89$

2.D.2.a. Large scale isolation of high-copy number plasmid DNA $\quad 89$

2.D.2.b. Large scale isolation of wide host-range plasmid DNA 90

2.D.3. Isolation of lambda DNA 90

2.D.4. Isolation of total plant DNA 92

2.D.5. Isolation of DNA fragments

2.D.5.a. Isolation of DNA using GENECLEAN 93

2.D.5.b. Isolation of DNA using low-melting-temperature agarose $\quad 93$

2.E. Ethanol Precipitation of DNA 93

2.F. Restriction Digestion 94

2.F.1. Restriction digestion of plasmid DNA

2.F.2. Restriction digestion of plant DNA 94

2.G. Ligation of DNA 94

2.H. DNA Sequencing 95

2.I. Preparation of Radioactive Probes 96

2.J. DNA Hybridization Techniques 96

2.J.1. Southern blot hybridization $\quad 96$

2.J.1.a. Agarose gel electrophoresis and Southern blotting 96

2.J.1.b. Hybridization and autoradiography 97

2.J.2. Plaque Hybridization $\quad 98$

2.K. Construction of a Partial Genomic Library from Transgenic Plant T218 99

2.L. Vector Construction 99

2.L.1 Construction of pPRF120 100

2.L.2. Construction of vectors for sequencing T218 gene fusion $\quad 102$ $\begin{array}{ll}\text { 2.L.3. Construction of binary vectors for functional testing of the T218 } & 102 \\ \text { gene fusion }\end{array}$

2.M. Growth and Transformation of Plant Tissues 104

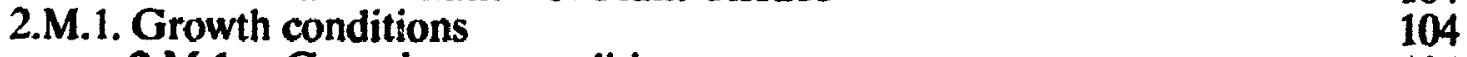

2.M.1.a. Greenhouse conditions 104

2.M.1.b. In vitro growth conditions 105

2.M.2. Tissue Culture 105

2.M.2.a. Media composition 105

2.M.2.b. Shoot culture 106

2.M.2.c. Cell suspension culture $\quad 106$

2.M.3. Agrobacterium-mediated transformation $\quad 107$

2.M.4. Seedling germination and analysis of kanamycin segregation $\quad 107$

2.N. Plant Pollination 
2.O. B-Glucuronidase Assays 108

2.O.1. Fluorogenic assay 108

2.O.1.a. Tissue collection 108

2.0.1.b. Tissue homogenization 109

2.0.1.c. GUS assay protocol 111

2.0.1.d. Determination of GUS activity 111

2.O.2. Histological GUS assay 111

CHAPTER 3

RESULTS 113

3.A. Design and Construction of pPRF120:

A Binary Vector Capable of Identifying T-DNA Insertions into

Transcribed DNA.

3.B. Occurrence of T-DNA-mediated gene fusions in tobacco plants transformed with pPRF120

3.B.1. Screening for cold-inducible T-DNA-mediated gene fusions

3.B.2. Screening for T-DNA-mediated gene fusions differentially expressed during plant development

3.C. Analysis of pPRF120 T-DNA Segregation and Structure in

Transgenic Plants

120

3.C.1. Segregation of kanamycin resistance

122

3.C.2. Copy number and organization of pPRF120 T-DNA

125

3.C.3. Kanamycin segregation and Southern blot analysis of pBIN19 derivatives

3.D. Analysis of T-DNA-Mediated Gene Fusion Expression

3.D.1. Preliminary analysis of GUS expression

3.D.1.a. Histological analysis of GUS activity in seedlings

3.D.1.b. Quantitative analysis of GUS activity in vegetative organs of pPRF120 transformants

3.D.2. Detailed expression analysis of T-DNA-mediated gene fusions

3.D.2.a. Gene fusions expressed in an unrestricted pattern

3.D.2.b. Gene fusions expressed in a restricted pattern

3.D.2.c. Tissue-specific patterns of gene fusion expression

156

3.D.2.c.i. Vascular-specific gene fusion expression

156

3.D.2.c.ii. Embryo-specific gene fusion expression

157

3.D.2.c.iii. Endosperm-specific gene fusion expression

159

3.D.2.c.iv. Seed coat-specific gene fusion expression

159

3.D.3. Further characterization of the T218 gene fusion expression 160

3.D.3.a. Genetic analysis GUS expression in T218 seeds

160

3.D.3.b. Time course of GUS expression in T218 seeds

162

164

3.E. Molecular Analysis of the T218 Gene Fusion

3.E.1. Mo!ecular cloning of the T218 gene fusion by T-DNA tagging

3.E.2. Sequence analysis of the $T 218$ gene fusion

164

168

3.E.3. Structural organization of the T218 locus in untransformed tobacco plants

3.E.4. Expression analysis of the cloned $T 218$ gene fusion in transgenic plants

3.E.4.a. Experimental design and vector construction

3.E.4.b. Expression analysis of the full-length T218 gene fusion in transgenic plants

3.E.4.c. Deletion analysis of the seed coat-specific promoter 
4.A. Characteristics of pPRF120

4.B. Characterization of Chromosomal Sites of T-DNA Integration Based on Promoterless Gene Activation

4.B.1. Frequency of T-DNA integration within transcriptionally active DNA

4.B.2. Expression patterns of sites of T-DNA integration

4.B.3. Additional questions relating to T-DNA integration specificity

4.B.3.a. Why were no cold-inducible gene fusions detected?

4.B.3.b. Why were no gene fusions detected by analyzing flowers of PPRF120?

4.B.3.c. Does the T-DNA show any site-specificity within transcribed DNA?

4.B.3.d. What effect does kanamycin selection have on the distribution of T-DNA insertion?

4.B.5.e. Is there a correlation between the frequency of T-DNA-mediated gene fusions and that of T-DNAinsertional mutagenesis?

4.B.3.f. Is it possible to resolve T-DNA-mediated gene fusions within transcribed regions which do not encode structural genes?

4.B.3.g. How could vectors for generating T-DNA-mediated gene fusions be improved?

4.C. Possible Influences of Flanking Chromosomal Sequences on Transgene Expression

4.D. Use of T-DNA-Mediated Gene Fusions to Uncover Novel cis-Acting

Elements.

4.D.1. Examples of novel patterns of gene expression revealed by T-DNA-mediated gene fusions

4.D.2. Analysis of gene fusion $\mathrm{T} 218$ at the molecular level 


\section{LIST OF TABLES}

TABLE

DESCRIPTION

PAGE

1.1. Summary of analyses of T-DNA segregation in transgenic plants

1.2. Summary of features of vectors designed to generate

T-DNA-mediated gene fusions and results obtained with these vectors

2.1. List of bacterial strains used in this thesis

2.2. List of plasmids used in this thesis

2.3. Concentration of antibiotics used with $E$. coli and Agrobacterium tumefaciens

3 1. Summary of results from initial screening of pPRF120 transformants for GUS activity

3.2. Analysis of pPRF120-encoded kanamycin resistance in the progeny of Group 1 plants

3.3. Analysis of pPRF120-encoded kanamycin resistance in the progeny of Group 2 plants

3.4. Analysis of pPRF120-encoded kanamycin resistance in the $\mathbf{R} 2$ generation of plant $\mathrm{T} 819$

3.5. Summary of pPRF120 integration patterns

3.6. Analysis of kanamycin resistance in the progeny of plants transformed with the pBIN19 derivatives pBI101, pBI121 and pnos-GUS

3.7. Summary of analysis of T-DNA integration in plants transformed with pBIN19 derivatives

3.8. Patterns of GUS staining in kanamycin-resistant R1 seedlings of pPRF120 transformants

3.9. GUS activity (pmole $\mathrm{MU} /$ minute/mg protein) in different vegetative organs of untransformed tobacco plants and the progeny of seven plants transformed with pPRF120

3.10. GUS activity in the leaves of progeny from independent transformants harbouring either pBI101, pnos-GUS, or pBI121

3.11. Summary of histological analyses 


\section{LIST OF FIGURES}

FIGURE

DESCRIPTION

PAGE

0.1. Generation of a T-DNA-mediated gene fusion

2.1. Construction of pPRF120

2.2. Development of zygotic embryos in tobacco

3.1. Sequence of the T-DNA right border area of pPRF120

3.2. Flow diagram illustrating the strategy employed to screen pPRF120 transformants for the presence of T-DNA-mediated GUS gene fusions

3.3. Map of the T-DNA portion of pPRF120

3.4. Southern blot analysis of Group 1 plants

3.5. Southern blot analysis of Group 2 plants

3.6. Southern blot analysis of plants transformed with derivatives of pBIN19

3.7. Effect of saccharo lactone on fluorescence production

(nM methylumbelliferone) from transformed and untransformed leaf extracts

3.8. Patterns of GUS expression in the progeny of plants transformed with pPRF120

3.9. Histological analysis of GUS expression in seedlings of pPRF120 transformants showing variation in expression patterns

3.10. Fluorogenic and histological analyses of GUS expression in plants T1275, T777, and T30

3.11. Quantitative analysis of GUS expression in plants containing T-DNA-mediated gene fusions expressed in a restricted pattern

3.12. Fluorogenic and histological analyses of GUS expression in plants T1041, T612, and T804

3.13. Quantitative analysis of GUS expression in three Class I plants containing T-DNA-mediated gene fusions expressed in a restricted pattern and one plant containing a Class II gene fusion (T62)

3.14. Fluorogenic and histological analyses of GUS expression in plants T418. T165, and T218

3.15. Analysis of promoterless GUS expression during seed development in plant $\mathrm{T} 218$ 
3.16. Southern blot analysis and restriction map of chromosomal

DNA adjacent to the T-DNA in plant T218

3.17. Restriction map and strategy used to sequence the cloned T218 gene fusion

3.18. Nucleotide sequence of the T-DNA-mediated gene fusion T218

3.19. Localization of putative cis-acting elements within the promoter region of the T218 gene fusion

3.20. Southern blot analysis of tobacco, $N$. sylvestris, and $N$. tomentosiformis DNA using a probe derived from tobacco chromosomal DNA flanking the T218 right border repeat

3.21. Schematic drawings of vectors used to functionally test the T218 gene fusion promoter

3.22. Southern blot analysis of tobacco plants transformed with pT218-C4-2 178

3.23. Southern blot analysis of tobacco plants transformed with pT218-C5-3 180 


\section{LIST OF ABBREVIATIONS}

A

aph

bp

C

$c a b$

CaMV

dATP

DNA

dTTP

EDTA

g

G

GUS

$\mathrm{kb}$

$\mathrm{Km}$

LB

luc

lux

$\mu \mathrm{E}$

mRNA

MU

MUG

nos

$n p t \mathbf{l l}$

ocs adenine

gene encoding amino glycoside phosphotransferase

base pair

cytosine

gene encoding chlorophyll $\mathrm{a} / \mathrm{b}$ binding protein

cauliflower mosaic virus

deoxyadenosine triphosphate

deoxyribonucleic acid

deoxythymidine triphosphate

ethylenediaminetetra acetic acid

gram or centrifugal force

guanine

B-glucuronidase and gene encoding B-glucuronidase

kilo base pair

kanamycin

T-DNA left border repeat

gene encoding firefly luciferase

gene encoding Vibrio haveyi luciferase

micro Einstein

messenger RNA

methyl umbelliferone

methyl umbelliferyl glucuronide

gene encoding nopaline synthase

gene encoding neomycin phosphotransferase

gene encoding octopine synthase 
PCR

RB

rbsC

RFLP

RNA

rRNA

SDS

$\mathrm{T}$

T-DNA

$\mathrm{Ti}$

tRNA

vir

$\mathrm{v} / \mathrm{v}$

$w / v$

X-GLUC polymerase chain reaction

T-DNA right border repeat

gene encoding the small subunit of ribulose bisphosphate carboxylase oxygenase

restriction fragment length polymorphism

ribonucleic acid

ribosomal RNA

sodium dodecyl sulfate

thymine

transferred DNA

tumour-inducing

transfer RNA

Agrobacterium virulence genes

volume/volume

weight/volume

5-bromo-4-chloro-3-indolyl-B-D-glucuronide 


\section{INTRODUCTION}

The soil bacterium Agrobacterium tumefaciens has the natural ability to transfer specific segments of DNA (T-DNA) to the chromosomes of susceptible plant cells (section 1.E.). Basic knowledge of this process, accumulated over the past 10-15 years, has enabled molecular biologists to exploit this unique phenomenon and develop highly efficient systems for the genetic transformation of plants (Klee et al., 1987; Rogers and Klee, 1987). Recently, applications for Agrobacterium-mediated gene transfer have become more creative, extending beyond "simple" gene transfer to include genetic complementation (Yanofsky et al., 1990), insertional mutagenesis (Feldmann, 1991) and the generation of genetic fusions between sequences located on the trariferred DNA and endogenous plant chromosomal cis-acting regulatory elements (T-DNA-mediated gene fusions; Koncz et al., 1989). Despite such developments, our understanding of many aspects of Agrobacterium-mediated gene transfer remains limited. This is especially true for events occurring within the plant cell.

The goal of this thesis was to develop a strategy for characterizing chromosomal regions into which the T-DNA has integrated based on their expression properties. This was accomplished by generating, upon insertion of the T-DNA into plant chromosomes, in vivo gene fusions between a reporter gene devoid of cis-acting regulatory elements (i.e. promoterless) located at the end of the T-DNA, and endogenous promoters residing in the chromosome. The concept of TDNA-mediated gene fusions is illustrated in Figure 0.1. In this thesis, the relative frequency of insertions into transcriptional units was estimated by the proportion of transformants expressing the promoterless gene, while spatial and temporal 
Figure 0.1. Generation of a T-DNA-mediated gene fusion. A) represents the TDNA portion of a specially designed vector containing a promoterless reporter gene (reporter) linked to one of the border repeats (shown as triangles). A constitutivelyexpressed selectable marker (selectable) is also ircluded to recover transgenic plants regardless of their ability to express the promoterless reporter gene. B) shows the structure of a hypothetical plant gene $(X)$ which contains a protein coding region (coding gene $\mathrm{X}$ ) under the transcriptional control of promoter $\mathrm{X}(\mathrm{pX})$. Gene $\mathrm{X}$ resides in the plant chromosome. $\mathrm{C}$ ) insertion of the T-DNA within gene $\mathrm{X}$ resulting in a gene fusion between the promoterless reporter gene and the promoter of gene X. Expression of the reporter gene is now under the transcriptional control of $\mathrm{pX}$, and can be detected by enzyme assay. In this specific example, insertion of the T-DNA within gene $X$ also results in loss of expression of this gene. D) insertion of the T-DNA within the plant genome not yielding a gene fusion. The reporter gene has not integrated downstream of an endogenous promoter and therefore is not expressed. The selectable marker, under the control of its own promoter (pS), continues to be expressed in such plants. The relative proportion of the transgenic plants expressing the promoterless reporter gene will be used to estimate the frequency at which the T-DNA integrates within transcriptionally active regions of the genome. 
A) Dipler psectable

B)

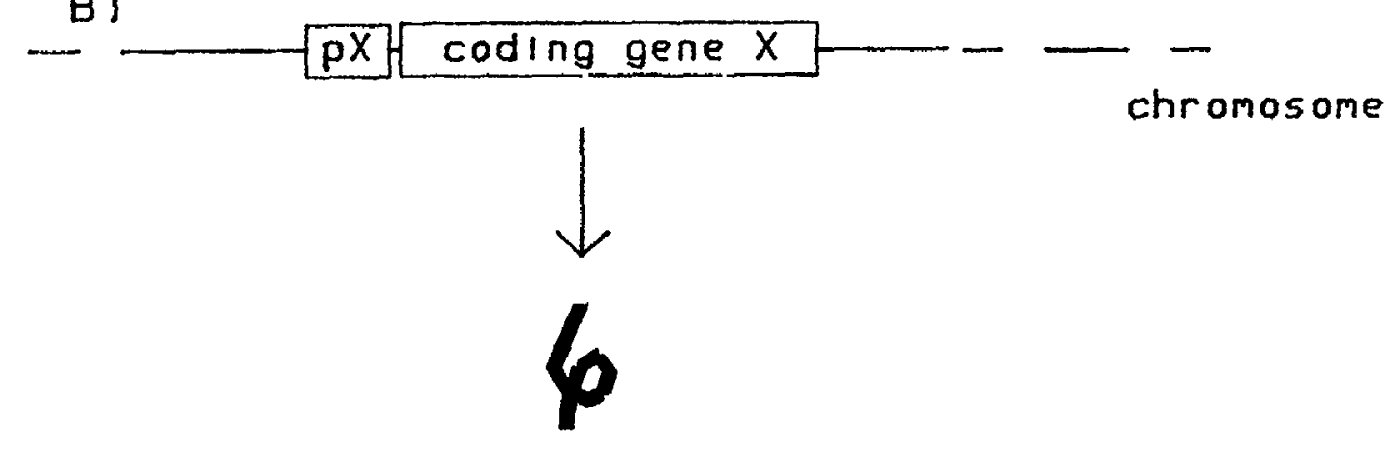

C)

T-DNA
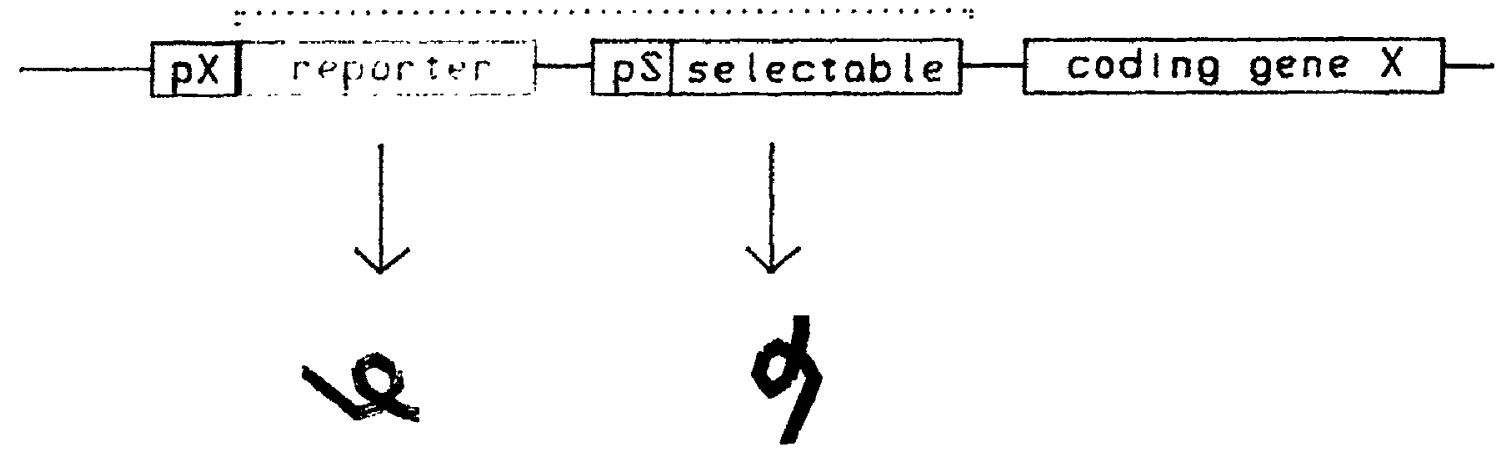

D) T-DNA

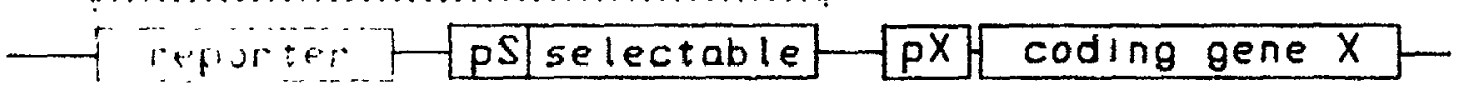
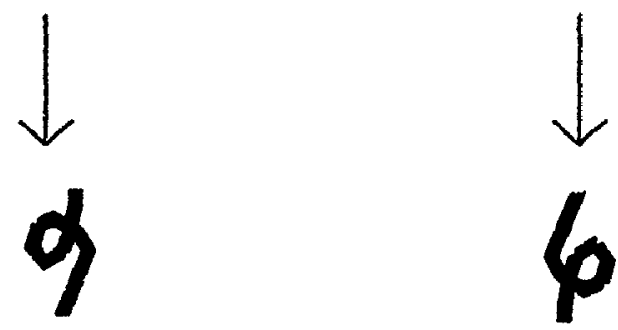
expression of the T-DNA integration loci were assessed directly in planta by patterns of promoterless gene activation. Results obtained could be interpreted in the context of the vast body of literature made availablein recent years on plant gene expression and genome complexity (Okamuro and Goldberg, 1989).

Although the proposed strategy does not include the recovery of plant chromosomal segments flanking the T-DNA for characterization of integration sites, such manipulations are still possible by use of the T-DNA as a molecular tag. Further analysis of flanking sequences at the molecular level may be warranted to demonstrate, through functional testing in transgenic plants, that the expression patterns associated with specific gene fusions are, in fact, due to the location of $T$ DNA integration, and to isolate the wild-type (untransformed) locus into which the T-DNA has integrated. It was also foreseen that unique patterns of gene expression may be revealed by such T-DNA gene fusions. These include patterns which would be difficult to uncover by other methods of gene isolation such as differential cDNA hybridization. Thus, T-DNA-mediated gene fusions, coupled with T-DNA tagging, could also be used to recover genes with novel expression properties, and corresponding cis-acting regulatory elements.

Analysis of the expression patterns of chromosomal sites of T-DNA insertion was accomplished with the following experimental steps:

1. A specialized transformation vector capable of generating T-DNA-mediated gene fusions vas designed and engineered. A vector which would integrate into the genome of plants as single, intact copies, and allow rapid and sensitive detection of promoterless gene activation in any tissue, at any time in development was sought.

2. A population of transgenic plants harbouring this vector was regenerated and different organs assayed for the presence of T-DNA-mediated gene fusions. In order to determine the distribution of T-DNA integration throughout the 
genome, the observed frequencies of promoterless gene activation were compared to the fraction of the plant genome which has been estimated to be transcriptionally active.

3. Detailed spatial and temporal analysis of gene fusion expression in several transgenic lines was carried out to determine how these compare with the overall patterns of plant gene expression observed by Okamuro and Goldberg (1989) and to identify candidates for further analysis at the molecular level.

4. A T-DNA-mediated gene fusion (i.e. the integrated promoterless 1 sporter gene and adjacent chromosomal sequences thought to contain cis-acting regulatory elements) was isolated by T-DNA tagging, further characterized at the molecular level, and reintroduced into non-transformed plants for functional testing. Results were used to confirm that sequences controlling GUS expression were confined to the chromosomal DNA flanking the T-DNA, and to characterize novel cis-acting regulatory elements.

It will be proposed that the approach undertaken herein could provide clues into the mechanism of T-DNA integration which may lead to the development of more efficient and versatile transformation strategies. More specifically, an understanding of patterns of T-DNA integration may help predict the location of TDNA inserts and ultimately allow for gene targeting. Furthermore, analyzing the expression properties of sequences flanking the T-DNA is essential for understanding the relative influences of chromatin structure and nearby cis-acting gene regulatory elements on the levels and patterns of transgene expression predicated by theories of position effect (Weising et al., 1988). 


\section{CHAPTER 1 - LITERATURE REVIEW}

In this chapter, the literature bearing on plant genome structure and organization, plant genes and their expression is first reviewed. This is followed by a review of our current knowledge of the process and mechanism of T-DNA integration, as this and a critical evaluation of plant reporter genes and selectable markers influenced the T-DNA vector design. Other examples of methods used to manipulate plant genes, including T-DNA-mediated gene fusions are also presented for comparison.

\section{A. Size and Organization of Plant Genomes}

The end result of Agrobacterium-mediated gene transfer is the stable integration of the T-DNA into the plant genome (reviewed in section 1.E. and Zambryski, 1988). However, plant genomes are not homogeneous: they vary in size and organization, and contain DNA sequences which differ with respect to the number of times they are reiterated within the genome, and in thei gotential to encode genes. The following section will review features of the plant nuclear genome with the purpose of highlighting those properties which may affect T-DNA integration and the ability to uncover T-DNA-mediated gene fusions. Whenever possible, information on Nicotiana tabacum and Arabidopsis thaliana will be presented as T-DNA-mediated gene fusions have been generated in these two species (Herman et al., 1990; Kertbundit et al., 1991; Koncz et al., 1989; Topping et al., 1991). Although genetic material is also contained within two plant organelles, mitochondria and plastids, their characteristics are not discussed, as they do not appear to be major targets for T-DNA integration. 


\section{A.1. Size and sequence organization of plant genomes}

Given a random distribution of T-DNA inserts throughout the plant genome, two factors which could considerably influence the ability of the T-DNA to integrate into transcribed DNA are the genome size and the fraction of genome which encodes genes. The DNA content of plant nuclei varies considerably amongst different species, and ranges between $10^{5}$ and $10^{7} \mathrm{~kb}$ (Okamuro and Goldberg, 1989). Arabidopsis thaliana has the smallest genome characterized to date (Leutwiler et al., 1984). At $7 \times 10^{4} \mathrm{~kb}$, it is only 5 times larger than that of baker's yeast. The most recent estimate of $N$. tabacum genome size is $2.4 \times 10^{6} \mathrm{~kb}(2.6 \mathrm{pg})$ per haploid genome (Okamuro and Goldberg, 1985). This is approximately 25 times larger than the $A$. thaliana genome and is similar to the size of the haploid human genome (2.0 X $10^{6} \mathrm{~Kb}$; Okamuro and Goldberg, 1989). However, whereas Homo sapiens and $A$. thaliana are diploid species, N. tabacum is an allotetraploid, resulting from the interspecific hybridization of two diploid progenitors, Nicotiana sylvestris and Nicotiana tomentosiformis (Okamuro and Goldberg, 1985).

The fraction of the plant genome which is expressed also varies between species, but is generally quite small. Okamuro and Goldberg (1989) estimated that only $18 \%$ of the tobacco genome is expressed throughout the entire life cycle. More than $75 \%$ of these sequences are restricted to the nucleus and were never detected on cytoplasmic polysomes. Thus the proportion of the genome which actually encodes structural genes is much smaller than $18 \%$ and has been estimated at $4.6 \%$ (Kamalay and Goldberg, 1980; Okamuro and Goldberg, 1989). Although the proportion of the $A$. thaliana genome which is expressed has not been assessed experimentally, it has been proposed to be greater than the one calculated in tobacco (Koncz et al., 1989). Pang and Meyerowitz (1987) have speculated that up to $25 \%$ of the $A$. thaliana genome may encode mRNA. 
Most of the DNA sequences encoding structural genes are present only once per genome (Okamuro and Goldberg, 1989). However, several sequences are repeated several times in the genome. With the exception of multigene families and sequences encoding ribosomal RNA, the vast majority of repetitive DNA does not encode genes. In tobacco, $60 \%$ of the DNA content is reiterated (Okamuro and Goldberg, 1985; Okamuro and Goldberg, 1989). The dominant classes of repetitive sequences found in plant genomes are those which are present at low (10-100 times) or moderate (100-1000 times) frequency, although some sequences are reiterated more than 10,000 times (Walbot and Goldberg, 1979). Repetitive and single copy DNA may be organized in short period interspersion patterns, with alternating stretches of relatively short (200-400 bp) moderately repetitive sequences and single copy DNA stretches of 1,000 to 4,000 bp, or in long period interspersion patterns, where larger segments of single copy DNA (35,000 bp) are separated by correspondingly longer stretches of repetitive DNA $(5,000$ to $10,000 \mathrm{bp})$. In tobacco, approximately 55\% of the DNA is organized in the former pattern (Okamuro and Goldberg, 1989), while the latter pattern may constitute from 25 $80 \%$ of the repeated DNA fraction found in plant cells (Walbot and Goldberg. 1979). In contrast, the genome of Arabidopsis is comprised mostly of single copy DNA. Repeated sequences account for only 10-14\% of its DNA content (Leutwiler et al., 1984, Pang and Meyerowitz, 1987).

\section{A.2. Structure of plant chromatin}

DNA found in plant nuclei is intimately associated with various proteins to form chromatin (Jordan et al., 1980; Kahl et al., 1987). As a result, the DNA becomes tightly packaged and organized into higher-order structures commonly referred to as nucleosomes, solenoids, and finally, looped domains. The extent of DNA packaging within chromatin is not consistent. Large sections of 
transcriptionally inert DNA are highly condensed into heterochromatin, while transcriptionally active sequences are contained within the more diffuse euchromatin. Even within euchromatin, the bulk of the DNA is packaged so tightly that it is thought to be not readily accessible to proteins involved in DNA transcription (Kahl et al., 1987). Activation of gene expression is usually correlated with an increased sensitivity of the surrounding chromatin to digestion by nucleases (Kahl et al., 1987). This phenomenon is presumably the result of a locally more relaxed, or "open" chromatin conformation, which renders the DNA template more accessible to macromolecules in general, and more specifically, to regulatory proteins and proteins involved in RNA transcription (Jordan et al., 1980; Kahl et al., 1987). As T-DNA integration into the plant chromosome is an enzyme-mediated process (Gheysen et al., 1991; Mayerhofer et al., 1991), differential accessibility of the target site to the specific polypeptides involved, brought about by chromatin conformation, is yet another factor which may influence integration patterns.

\section{B. Patterns of Gene Expression during Plant Development}

Although only a small fraction of the plant genome has the potential to be transcribed, analysis of plant gene expression at the RNA population level and at the level of individual genes has revealed that it is complex and highly regulated. RNA/DNA reassociation studies have been used to determine the magnitude of gene activity in different plant organs, and to characterize overall changes in RNA populations throughout the life cycle. Results from such studies provide an indication of the types of expression patterns which may be uncovered by T-DNAmediated gene fusions. Analysis of gene expression using cloned genes complements studies carried out on large populations of RNA by providing more detailed information on the expression of individual genes or gene families. This 
approach has also been extensively exploited to characterize sequences involved in regulating gene expression.

\section{B.1. Overview of plant gene expression}

The number of structural genes which are expressed in a mature tobacco plant has been estimated to be at least 60,000 to 80,000 (Okamuro and Goldberg. 1989). In light of this finding, it is clear that an accurate assessment of the overall changes in gene expression occurring during plant development cannot be achieved by analyzing the expression of individual cloned genes. Instead, methods which measure differences in large populations of RNA, such as DNA/RNA hybridization techniques have been used to characterize patterns of gene expression in mature tobacco plants (Goldberg et al., 1978; Goldberg et al., 1989; Kamalay and Goldberg, 1980; Kamalay and Goldberg, 1984; Okamuro and Goldberg, 1985; Okamuro and Goldberg, 1989). Such studies have revealed that the majority of transcripts detected in tobacco plants are present at only a few molecules per cell per sequence. Although, more than $95 \%$ of the tobacco sequence diversity is represented in this mRNA class, rare transcripts constitute less than $25 \%$ of the mRNA mass (Okamuro and Goldberg, 1989). Many of the rare class transcripts are developmentally regulated. Howeve, little is known about the nature or the function of most of these mRNAs. Superabundant and abundant transcripts make up the remaining $5 \%$ of sequence complexity while contributing up to $75 \%$ of the mRNA mass. Superabundant transcripts are most often restricted to highly specialized cell types and include genes encoding the small subunit of ribulosebisphosphate carboxylase oxygenase ( $r b c S$ ) and seed storage proteins.

Each organ of a tobacco plant expresses between 10,000 and 30,000 different structural genes. These estimates are comparable to the number of genes found in mammalian organs (Okamuro and Goldberg, 1989). Different organs contain 
distinct populations of mRNA. Twenty-three to $40 \%$ of transcripts are organspecific while up to $30 \%$ are detectable in all organ types (housekeeping genes). The remaining fraction of mRNA represents transcripts which are shared by 2 or several organs. Transcripts which are detected in more than one organ may vary in concentration from organ to organ (Okamuro and Goldberg, 1989). It is noteworthy that changes in nuclear RNA populations have also been noted during tobacco development (Goldberg et al., 1978; Kamalay and Goldberg, 1984).

The extent of gene expression in gametophytic tissues and in zygotic embryos have also been estimated, although not in tobacco. In Tradescantia paludosa and maize pollen (the male gametophyte), approximately 20,000 different genes are expressed (reviewed in Mascarenhas, 1989). A similar number of transcripts were observed in soybean embryos analyzed at different stages of development (Goldberg et al., 1981). As in the tobacco sporophyte, mRNA species detected in these tissues could be divided into different classes based or their relative abundance. Comparison of mRNA pools in polleri grains or embryos with those present in leaves or shoots revealed a large overlap in gene expression between the sporophytic and gametophytic generation in one case (shoot vs. pollen) and different sporophytic generations in the other (leaf vs. embryo). Perhaps more importantly, these studies show that plant tissues which differ considerably in structure and function express between 60 to $75 \%$, and perhaps up to $90 \%$, of the same genes (Mascarenhas, 1989). It is noteworthy that little overlap occurred between the superabundant mRNA class of the leaf and embryo; most of the common sequences comprised rare class transcripts (Goldberg et al., 1981).

In addition to developmental and organ-specific regulation, plant gene expression is also altered by endogenous or environmental signals, such as hormones (Klee and Estelle, 1991; McClure et al., 1989; Theologis, 1986), circadian rhythms (Giuliano et al., 1988), light (Pean et al., 1989; Thompson and White, 
1991), and a variety of stresses including heat shock, anaerobism, high salt levels (Sachs and Ho, 1986), chilling (Thomashow, 1990), mechanical and pathogeninduced wounding (Collinge and Slusarenko, 1987; Dixon and Lamb, 1990; Stanford et al., 1989) and U.V. radiation (Schulze-Lefert et al., 1989a; Schulze-Lefert et al., 1989b). In response to these stimuli, plant gene expression may be induced or suppressed. With the possible exception of light, the number of genes whose regulation is affected by these conditions is modest. On two dimensional polyacrylamide gels, less than 100 new polypeptides can usually be resolved (Sachs and Ho, 1986). Analysis of gene expression at this level, however, almost certainly underestimates the number of genes which are induced.

\section{B.2. Expression patterns of cloned genes}

Numerous plant genes have been isolated using a variety of methods, including differential cDNA hybridization (Conkling et al., 1990; Medford et al., 1991; Smith et al., 1990), subtractive hybridization (Sommer et al., 1990), hybridization with heterologous probes (Rutledge et al., 1991) or degenerate oligonucleotides (Hata et al., 1991), polymerase chain reaction (PCR) amplification from degenerate oligonucleotide primers (Ferreira et al., 1991), genetic complementation (Izui et al., 1986), T-DNA tagging (Koncz et al., 1990; Herman and Marks, 1989; Yanofsky et al., 1990) and transposon tagging (Coen et al., 1990; Hake et al., 1989). The availability of cloned DNA segments enables one to exploit them as hybridization probes, or to study their expression after reintroducing them into plant cells via one of several available genetic transformation techniques. In order to facilitate analysis of gene activity in transgenic plants, genes are usually modified in vitro prior to transfer. This generally consists of substituting the coding region from the gene of interest with a reporter gene, which encodes a readily assayed enzymatic activity (see section 1.D. for more details on gene fusions and 
reporter genes). Details of the spatial and temporal expression patterns of several cloned genes have been recently reviewed (Benfey and Chua, 1989; Dixon and Lamb, 1990; Edwards and Coruzzi, 1990; Okamuro and Goldberg, 1989; Weising et al., 1988). Numerous examples of cell-, tissue- and organ-specificity, as well as inducible gene regulation are included within these analyses. It is noteworthy that most of the genes which have been isolated and characterized to date encode mRNA which belong to the abundant or super-abundant transcript classes (Okamuro and Goldberg, 1989).

\section{B.3. Significance of differential gene expression}

The coordinated expression of different tissue-specific and developmentallyregulated sets of genes throughout the plant life cycle is required for normal growth and differentiation. Housekeeping genes are thought to encode basic functions which are essential to all cell types, including respiration, cell division, and gene expression, while organ-specific genes have been postulated to be required for the establishment and maintenance of the differentiated state of that organ (Okanuro and Goldberg, 1989). Environmentally-induced genes are suspected to allow the plant to re-adjust to its surroundings (Sachs and Ho, 1986) or be involved in the defense mechanisms against pathogen attack (Dixon and Lamb, 1990).

Specific functions have yet to be attributed to all genes which have been identified, especially those which were isolated by differential or subtractive hybridization. In contrast, genes isolated by T-DNA or transposon tagging were first identified on the basis of structural, biochemical of morphological mutations, and thus encode functions necessary for normal plant development. 


\section{C. Regulation of Plant Gene Expression}

Characterization of sequences involved in regulating gene expression has been a major focal point of plant molecular biology in recent years. Such analyses have been greatly facilitated by the development of efficient genetic transformation systems, which allow functional testing of intact and modified gene constructs in differentiated plant tissues. Studies with transgenic plants have established that, although plant gene expression is regulated at both the transcriptional and posttranscriptional levels, the spatial and temporal regulation of most of the cloned genes analyzed to date is controlled primarily at the level of transcription. Specific cis- and trans-acting factors involved in regulating gene transcription have now been isolated and characterized for a limited number of plant genes. Since it is proposed that activation of promoterless reporter genes located at the extremity of the integrated T-DNA is mediated by cis-acting regulatory elements residing in the flanking chromosomal DNA, the properties of such cis-acting factors and the proposed mechanisms by which these interact with each other and with trans-acting factors to control gene expression are reviewed in the following sections.

\section{C.1. cis-acting factors involved in transcriptional regulation of plant genes}

Transcriptional regulation of plant genes has been frequently demonstrated by showing that non-transcribed sequences located at the 5' end of most genes are, by themselves, sufficient to confer proper tissue-specific and developmentalregulated expression on a reporter gene in transgenic plants. As sequences involved in post-transcriptional regulation must, by definition, reside within the gene transcript, the above results strongly suggest that post-transcriptional control does not play a major role in determining the expression pattern of these genes. Posttranscriptional regulation has, however, been implicated in quantitative expression of several cloned genes, and will be discussed in another section. For the remainder 
of this thesis, the term "promoter" is used to functionally define the assemblage of 5 , cis-acting transcriptional regulatory elements required to achieve wild-type patterns of gene expression.

A variety of approaches, including comparison of DNA sequence homology, mutagenesis - followed by functional testing in transgenic plants, and protein binding assays have been used to define and dissect promoters from several plant genes. Based on these studies, it has been proposed that promoters constitute a collection of recognition sites for sequence-specific DNA binding proteins, some of which have been identified as transcriptional activators. Regulation of plant gene expression would thus be controlled by interactions between specific trans-acting protein factors and the particular set of cis-acting elements residing within the promoter area of a given gene.

One implication of the above model is that promoters are modular and contain several cis-acting elements. Operationally, two classes of cis-acting elements can be distinguished; the "promoter-proper" and the enhancer (Dynan, 1989; Maniatis et al., 1987; Weising and Kahl, 1990). Both elements are composed of several recognition sites and function by binding specific proteins (Dynan, 1989; Weising and Kahl, 1990). Components of the promoter-proper are localized within $100 \mathrm{bp}$ from the transcriptional start site and act in a position-dependent manner. These include the TATA box, located approximately $30 \mathrm{bp}$ from the start site, which is involved in determining the precise start site of transcription (Elliston and Messing, 1988). Other elements within the promoter-proper modulate levels of transcription. The best known of these elements is the CAAT box. However, not all plant promoters analyzed contain this element (Elliston and Messing, 1988). In addition, the presence of a CAAT box at the proper distance from the transcriptional start site does not imply that it is necessary for gene expression. For example, Morelli et al. (1985) found that deletion of a CAAT consensus sequence at 
position -85 of the pea $r b c$ S-E9 gene did not reduce levels of gene expression or alter photoregulation. Similarly, site-directed mutations within 2 CAAT motifs located between -85 and -58 of the $35 \mathrm{~S}$ promoter of cauliflower mosaic virus (CaMV) were found to have no dramatic effect on levels of gene expression in leaves, stems and roots of transgenic plants (Lam et al., 1989). Other consensus sequences found within the promoter-proper include the AGGA box found in the promoter of zein genes (Elliston and Messing, 1988) and the GATA box, found between the TATA and CAAT boxes of several photoregulated gene promoters (Gidoni et al., 1989; Gilmartin et al., 1990). Elements located within the promoterproper can also confer organ-specific (Stougaard et al., 1987) or light-inducible (Kuhlemeier et al., 1989; Lipphardt et al., 1988; Schulze-Lefert et al., 1989a; Sheen, 1991) regulation upon a constitutive enhancer. Thus, promoter-proper regions from different genes are not functionally equivalent, and cannot always be substituted by corresponding sequences from a different promoter (Castresana et al., 1988).

The promoter-proper by itself is usually insufficient to initiate gene transcription (An et al., 1986; Bustos et al., 1991; Fraley et al., 1986; Kuhlemeier et al., 1989; Stougaard et al., 1987). The additional cis-acting elements required to potentiate transcription are generally referred to as enhancers. It is noteworthy that enhancers, in the absence of promoter-proper elements, are also unable to activate gene transcription. Unlike promoter-proper elements, enhancers function in a position- and orientation-independent manner when present 5 ' of the coding sequence (Dynan, 1989; Maniatis et al., 1987). In some cases, enhancers and promoter-proper elements have been shown to overlap (Benfey et al., 1989;

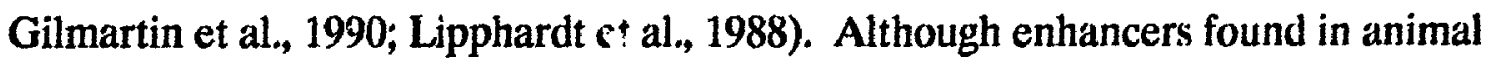
gene promoters are able to regulate gene transcription when located 3' of the coding region (Dynan, 1989; Maniatis et al., 1987), most plant enhancers characterized to date have either weak (Fang et al., 1989) or no activity when positioned 3' of a 
coding region, or have not been tested in this context (see, for example, Donald and Cashmore, 1990). This prompted Okamuro and Goldberg (1989) to refer to distal regulatory elements found in plants as "enhancer-like", and propose that plant "enhancers" may be functionally more related to upstream activation sites (UASs) found in yeast (Guarente, 1988; Struhl, 1987).

Enhancers may be functionally organized into a hierarchical structure. The basic unit capable of forming a binding site for a trans-acting factor is referred to as the "core" motif or enhanson (Ondek et al., 1988). Individual core motifs, tandemly repeated motifs or two non-identical motifs combine to form the next level of organization, referred to as a domain (Wasylyk, 1988), element (Ondek et al., 1988) or module (Dynan, 1989). Specific combinations of one or several enhancer modules then interact to form an active enhancer. Several enhancers, potentially having different cell- or developmental-specificity may be present in the promoter of a gene. Although this model was originally proposed for animal enhancers, analysis of plant enhancers indicates that they are organized in a similar fashion. However, due to differences in nomenclature and experimental approaches, and the availability of limited data in several cases, it is often difficult to interpret results within the exact context of the above model. Consequently, emphasis will not be focused on determining the precise organizational level of a particular cis-acting element, but rather on illustrating the modular nature of plant enhancers and how interactions between cis-acting elements at different levels may regulate gerie expression.

There is ample evidence in the literature to demonstrate that sequences located within plant enhancers have the ability to bind nuclear factors. The most direct method of identifying such sequences is by binding assays. These may be performed in vitro or in vivo, although results obtained by the two approaches are not always similar. Studies in plants (McKendree et al., 1990) have established that 
sequences which bind protein factors in vitro do not always do so in vivo.

Presumably the presence of a trans-acting factor in a cell or tissue is not directly correlated to its ability to bind at a recognition site within the promoter of any particular gene (McKendree et al., 1990). Based on in vitro and in vivo studies, a variety of consensus motifs have been catalogued (for a partial list, see Weising and Kahl, 1990). These are usually 8 to $30 \mathrm{bp}$ in length and may include "AT" rich sequences, short palindromes, and stretches of alternative purines and pyrimidines capable of adopting a Z-DNA conformation (Gilmartin et al., 1990; Okamuro and Goldberg, 1989; Weising and Kahl, 1990). Several of these sequences show homology to core animal/viral enhancers (Kuhlemeier et al., 1987b; Okamuro and Goldberg, 1989). Some of the consensus motifs have now been shown to actually contain more than one binding site for trans-activating factors. Motifs with dyad symmetry, in particular, may consist of 2 "half sites", each capable of binding transacting factors. The two factors bound at such sites presumably interact as either homo- or hetero-dimers. One such sequence is the ocs element found in the octopine synthase enhancer. This element consists of a $16 \mathrm{bp}$ palindrome which contains 2 recognition sites (Tokuhisa et al., 1990). A protein factor capable of binding the ocs element was isolated and found to contain a region of basic amino acids and potential leucine zipper motif characteristic of a class of transcriptional factors known as bZIP proteins (Vinson et al., 1989; Singh et al., 1990). Proteins with bZIP domains have been shown to bind DNA in a sequence-specific manner when dimerized (Talanian et al., 1990). Consistent with this model, Tokuhisa et al. (1990) reported that both binding sites of the ocs element had to be occupied as a prerequisite to transcriptional activation. Other trans-acting factors possessing bZIP domains have been isolated from plant tissues. A partial list of these factors, their sources, and the DNA sequences to which they bind is presenied in Oeda et al. (1991). In addition, consensus sequence motifs located in the promoter regions of 
several plant genes including $r b c S$, chalcone synthase, and the maize Bronze-1 gene show sequence similarity to those capable of binding animal myb proto-oncogenes and myc proteins (Roth et al., 1991), which are also transcriptional activators that must dimerize in order to bind DNA (Johnson and McKnight, 1989). Proteins homologous to myc, myb and other proto-oncogenes have been identified in plants (Hartings et al., 1989; Jackson et al., 1991; Paz-Ares et al., 1987; Roth et al., 1991). These include the regulatory genes known to control the expression of Bronze-1 (Roth et al., 1991). It is noteworthy that a recognition site does not have to possess dyad symmetry in order to bind dimerized transcriptional regulators (McKnight, 1991). As the techniques usually used to study DNA binding of nuclear factors (e.g. gel retardation and DNase footprinting) cannot resolve whether the factors act as dimers, it is not possible, based solely on these analyses, to determine whether a recognition motif represents more than one binding site. In the absence of such data, the distinction between core motifs (an individual binding site) and enhancer modules (a group of core motifs) becomes obsolete. Consequently, a short stretch of nucleotides having the potential to bind nuclear factors will simply be referred to as a motif or box. Nevertheless, the above data emphasizes that even at the level of 8-30 bp sequences, there is the potential for interactions between cis-acting elements, between cis- and trans-acting factors, and finally between trans-acting factors.

Specific motifs may be reiterated several times within a promoter. Interestingly, the promoter region of genes having drastically different expression patterns may contain several identical or related consensus motifs (Oeda et al., 1991; Roth et al., 1991; Schindler and Cashmore, 1990; Schulze-Lefert et al., 1989b). In contrast, it is possible for genes having similar expression properties to lack any significant sequence similarity in the promoter region (Paul and Ferl, 1991; Schäffner and Sheen, 1991) and even to bind different nuclear factors (Paul and 
Ferl, 1991). Working with the light-regulated promoter of the chlorophyll $a / b$ binding protein ( $c a b)$ gene, Schindler and Cashmore (1990) found that sequences related to 4 of the 5 binding sites they studied could be identified in the promoter region of non-photoregulated genes. In addition, the trans-acting nuclear factors which bound to these sites had also been implicated in the regulation of nonphotoregulated genes. A related experimental finding which also reveals the complexity of DNA binding sites is that, at least in vitro, a recognition site may bind more than one type of trans-acting factor (Datta and Cashmore, 1989; Johnson and McKnight, 1989). It has been proposed that families of related proteins, each recognizing slightly different DNA sequences, or having different tissue or developmental specificities may exist in plant cells (Forde et al., 1990; Gilmartin et al., 1990; Oeda et al., 1991; Weisshaar et al., 1991).

The ability to bind nuclear factors does not imply that a sequence is important for gene activation. Although deletion analysis has been successfully used to delineate promoter regions required for gene activation, they cannot resolve which specific sequences within the promoter are involved in binding nuclear factors or their role in controlling gene transcription. Other methods such as site-directed mutations or short, internal deletions, have consequently been exploited to correlate the binding of nuclear factors and the ability to activate gene transcription in vivo. In plants, this has been demonstrated for only a few sequence motifs (see, for example, Block et al., 1990; Donald and Cashmore, 1990; Gilmartin et al., 1990; Lam et al., 1989). In addition, gain-of-function experiments, where a sequence suspected of having regulatory properties is added to a non-active promoter fragment, have been used to test whether a certain motif is required for the initiation of gene transcription. One advantage of the latter approach is that it can demonstrate whether a motif by itself is sufficient for transcriptional activity. Thus, within the enhancer region of the pea $r b c S$ promoter there are several sequence 
motifs, designated GT-1 sites, which bind nuclear factors. Deletion or site-directed mutations within these boxes result in loss of transcriptional activity (Kuhlemeier et al., 1987b), indicating a functional role for GT-1 binding. A gain-of-function experiment was carried out by ligating a tetramer of GT-1 motifs to the promoterproper of a rbcS gene or the CaMV 35S transcript. Such constructs could not activate transcription, indicating that GT-1 binding is necessary, but not sufficient for initiating gene transcription (Gilmartin et al., 1990). Presumably, these GT-1 sequences must interact with other elements within the $r b c S$ enhancer.

The importance of interactions between GT-1 motifs and other cis-acting elements has been demonstrated using similar gene fusions to the ones described above. Lam and Chua (1990) ligated the GT-1 tetramer to the "A" domain of the CaMV 35S enhancer, and also inserted the tetramer within the full-length CaMV 35S promoter. As outlined below, the "A" domain of the CaMV 35S enhancer overlaps the promoter-proper and contains only $34 \mathrm{bp}$ more than the promoterproper construct used in the above experiment (Benfey et al., 1989). Within the context of either of these gene fusions, the GT-1 tetramer potentiated transcription in a light-regulated fashion (Kuhlemeier et al., 1987b; Lam and Chua, 1990). The mechanism by which the tetramer affected gene regulation in these cases had to be drastically different. When fused to the "A" domain, which is not expressed in the leaves and stems, the GT-1 tetramer acted as a positive regulatory element. However, in the context of the constitutively expressed full-length CaMV 35S promoter, the tetramer had to shut down expression in the dark to render the construct photo-responsive. It is noteworthy that a unique GT-1 motif inserted into the CaMV 35S promoter did not alter the pattern of gene expression (Kuhlemeier et al., 1987b). The need to duplicate an element before it becomes biologically active is reminiscent of the enhancer modules of SV40, which can potentiate gene transcription only after duplication (Dynan, 1989). Thus, the GT-1 box has different 
regulatory properties depending on the nature of other cis-acting elements found within the same promoter. This is illustrated quite well by the results obtained with gene fusions to the CaMV $35 S$ promoter-proper and "A" domain. As mentioned above, the CaMV 35S "A" domain is only 34 bp longer than the promoter-proper. However, the GT-1 motif is only functionally active when fused to the "A" domain. This presumably results from interactions with a binding site which has been identified at position -75 of the CaMV 35 S promoter (Lam et al., 1990). Introduction of site-directed mutations within this site, in the context of the full length promoter, caused a 50\% drop in gene expression (Lam et al., 1989).

The above results clearly show that a binding motif interacts with other elements to regulate transcription. Other examples of interactions between binding motifs have been published. For example, Lam et al. (1990) found that a tetramer of the rbcs Box VI motif, which binds a transcriptional factor called 3AF-1, is active when fused to the "A" domain of the CaMV 35S promoter. Like the GT-1 motif, the Box VI tetramer could not potentiate transcription from the CaMV 35S promoterproper (Lam et al., 1990). However, unlike the GT-1 motif, the Box VI tetramer fused to the "A" domain did not activate gene expression in a light-dependent fashion. Using a different approach to demonstrate inieractions between binding motifs, Gilmartin et al. (1990) and Block et al. (1990) tested the requirements for exact spacing between adjacent boxes. Their results clearly showed that proper spacing is important of gene activation. A recent example which demonstrates the need for proper orientation and spacing between core binding motifs comes from the study of thyroid hormone, retinoic aci, and estrogen responsive genes in human cell cultures (Näär et al., 1991). Cis-acting elements responsive to these factors all contain the consensus core motif "TCAGGTCA" in different orientations and combinations. Mutational analyses performed by Näär et al. (1991) demonstrate that differences in orientation and spacing of the core sequence within responsive 
elements by themselves are sufficient to impose transcriptional selectivity.

The most compelling evidence for interactions between different elements of an enhancer comes from a series of publications on the CaMV 35S promoter by Benfey et al. (1989; 1990a; 1990b). These authors demonstrated that it was possible to dissect a constitutively-expressed promoter into several domains and subdomains, each of which possessed different tissue and developmental specificities. For example, the " $\mathrm{A}$ " domain was found to be responsible for expression in the roots, while the more distal " $\mathrm{B}$ " domain is primarily responsible for expression in non-root tissues (Benfey et al., 1989). The combined expression pattern of the "A" and "B" domains when fused separately to a reporter gene (in this case GUS) did not add up to that of the intact promoter, strongly suggesting that synergistic interactions occur between the 2 domains. The " $\mathrm{B}$ " domain was subsequently divided into 5 subdomains, each of which were fused either to the promoter-proper or to the "A" domain. The resulting expression patterns were analyzed in seeds, seedlings, and mature plants (Benfey et al., 1990a; Benfey et al., 1990b). Different subdomains were found to be responsible for gene activity in distinct cell types. Patterns varied depending on whether the subdomains were fused to the promoterproper or the "A" domain, once again demonstrating the potential involvement of the $-\mathbf{7 5}$ binding site in gene regulation. However, the patterns of expression of the " $\mathrm{A}$ " domain fused to the "B" subdomains were all different from that of the " $\mathrm{A}$ " domain itself. When 2 or the "B" subdomains were fused together, the resulting pattern of gene expression was unlike that of either subdomain alone. Just as the sum of the expression of the "A" and "B" domains tested separately did not equal that of the intact promoter (Benfey et al., 1989), the sum of the expression of all the 5 "B" domains do not add up to that of the intact "B" domain (Benfey et al., 1900a; Benfey et al., 1990b). Thus the "B" sabdomains interact synergistically amongst themselves, as well as with the "A" subdomain and the promoter-proper elements. 
Unfortunately, the amount of information available on the nuclear factor binding sites within the CaMV 35S promoter (Lam et al., 1989; Prat et al., 1989) is not as advanced as the functional analysis in vivo. Consequently, with the exception of interactions with the -75 element, it is impossible to correlate the various synergistic interactions listed above with the binding of trans-acting factors.

It is noteworthy that Benfey et al. (1989) refer to the entire promoter region outside the promoter-proper as the CaMV 35S enhancer. However, several of the domains and subdomains within this enhancer were capable of potentiating gene transcription when fused to the promoter-proper (Benfey et al., 1989; Benfey et al., 1990a; Benfey et al., 1990b). Thus, according to the functional definition adopted by other researchers, these domains could be classified as enhancers. In other cases, the "B" subdomains could not activate gene transcription in the presence of the promoter-proper and therefore do not represent enhancers. Nevertheless, in combination with other domains or subdomains they were able to alter patterns of gene expression.

By defining an enhancer as a segment of DNA capable of activating gene expression in an orientation- and position-independent fashion, a promoter may be shown to consist of several enhancers having potentially different regulatory properties. Thus general enhancers, capable of potentiating transcription in all cell types (Bustos et al., 1989; Castresana et al., 1988; Fang et al., 1989; Lipphardt et al., 1988; Stougaard et al., 1987), tissue- and organ-specific (Bustos et al., 1991; Fromm et al., 1989; Kuhlemeier et al., 1989), developmentally regulated (Bustos et al., 1991; Fromm et al., 1989), and photoregulated (Castresana et al., 1988; Lipphardt et al., 1988; Nagy et al., 1987) enhancers have now been identified. In addition, distal ciselements capable of reducing rates of transcription also exist. From an organizational and operational level, these elements, often termed silencers, are analogous to enhancers and may also function under specific developmental 
conditions or in certain call types (Bustos et al., 1991; Castresana et al., 1988; Kuhlemeier et al., 1987a; Kuhlemeier et al., 1987b). As an example, promoters from two photoregulated genes ( $c a b$-E promoter, Castresana et al., 1988; chalcone synthase promoter, Lipphardt et al., 1988) contain distinct positive regulatory elements (PRE), negative regulatory elements (NRE) and light regulated elements (LRE). Each of these "elements" being analogous to an enhancer. Combined, they regulate gene transcription in a developmental and photoregulated manner.

\section{C.2. trans-acting factors involved in regulating gene transcription}

A detailed review of trans-acting factors is beyond the scope of this literature review. However, it is worth noting that interactions between trans-acting factors are important for gene regulation. One example which has already been described is the formation of dimers. Analysis of transcriptional activators in animal systems has revealed that several are inactive as monomers; dimerization being a critical step for binding DNA in a sequence-specific manner (Johnson and McKnight, 1989; McKnight, 1991). Studies with animal promoters have also established that protein binding to every recognition motif of a gene is required, but not necessarily sufficient to initiate gene transcription. Specific interactions between regulatory proteins bound to neighbouring sites, and to proteins which do not bind DNA, are also required for gene activation (McKnight, 1991). Ultimately, the sequence of recognition motifs within a promoter and the availability of a trans-acting factor within a specific tissue (Datta and Cashmore, 1989; Benfey et al., 1990b) will play a major role in determining the intcractions between bound trans-acting factors.

\section{C.3. Models of transcriptional gene regulation}

The information reviewed in the above sections demonstrate that there are 
no specific control elements responsible for a given pattern of regulated gene expression. For example, promoters from light-regulated genes do not possess a unique light-regulated consensus sequence or bind to one specific transcriptional factor which confers light-regulated expression. Instead, the different patterns of gene expression appear to be regulated by a relatively small number of DNA recognition sites, arranged in a non-random fashion, which bind families of transacting factors. Given the modular nature of promoters, Okamuro and Goldberg (1989) have speculated that only a small number of positive and negative cis-acting elements are needed to account for all the diversity of expression patterns observed in plants. The ability of trans-acting proteins to form hetero-dimers has been proposed to represent a means of expanding the number of possible regulatory patterns which may be dictated by a limited number of recognition motifs (McKnight, 1991). Johnson and McKnight (1989) compare a promoter, and the trans-acting factors bound to it, to a jigsaw puzzle: Every piece of the puzzle must fit into a precise three-dimensional arrangement and the puzzle is not comvlete unless every piece is in place. Thus it is not sufficient for a trans-acting factor to bind a recognition motif, it must fit into the framework of the promoter and interact with other trans-acting factors. Furthermore, the model predicts that in the absence of only 1 piece (i.e trans-acting factor), gene activation cannot occur.

\section{C.4. Post-transcriptional control of gene expression}

Post-transcriptional regulation of gene expression may take place at several different stages, including RNA splicing, processing, transport, and turnover (Okamuro and Goldberg, 1989). Additionally, regulation at the level of protein translation, post-translational processing and targeting, also occur, by definition, at the post-transcriptional level.

Factors controlling plant gene expression at the post-transcriptional level 
have not been analyzed as intensely as those involved in transcriptional regulation. This does not imply that post-transcriptional processes are not important for controlling plant development. In fact, the observation that only $25 \%$ of the sequence complexity detected in nuclear RNA can be found in the cytoplasmic RNA populations (Goldberg et al., 1978; Kamalay and Coldberg, 1984) demonstrates that post-transcriptional regulation plays a major role in establishing the mRNA pools found in the various organs of a plant.

Results obtained with cloned genes suggest that post-transcriptional regulation mostly influences the quantitative expression of a gene. Dean et al. (1989) studied factors affecting post-transcriptional regulation of different members of the Petunia rbcS gene family by exchanging sequences downstream of the translation start site from the gene expressed at the highest levels to the one expressed at the lowest levels. Their results indicated that sequences located 3' of the start site, and probably $3^{\prime}$ of the coding segment could influence the relative transcription rate of the $r b c S$ genes. Most studies of post-transcriptional regulation with cloned plant genes have been carried out with gene fusions. In addition to simplifying measurements of gene activity, the use of defined gene fusions enables researchers to assess the role of various DNA fragments on gene expression by adding and removing these sequences, or modified versions of them, to a standard reference gene construct. Using gene fusions, several "gene components" such as the 5 ' cap site (Gallie et al., 1991), leader sequences (Futterer et al., 1990; Gallie et al., 1991), initiation codons (Taylor et al., 1987), introns (Callis et al., 1987; Mascarenhas et al., 1990), 3' untranslated regions (Gallie et al., 1991) and polyadenylation sites (Ingelbrecht et al., 1989; Thornburg et al., 1987) have been shown to influence levels of gene expression. In at least one case, the presence of different 3 ' segments on a chimaeric CaMV 35 S promoter-luciferase fusion altered the spatial expression of the reporter gene (Barnes, 1990). 


\section{D. Gene Fusions and Reporter Genes}

Simply stated, a gene fusion is a chimaeric DNA construct containing sequences from more than 1 gene. Gene fusions may be created in vitro, using standard recombinant DNA technology, or in vivo, by insertions of mobile genetic elements within intact genes. Most of the studies with gene fusions have exploited constructs created in vitro which contain the coding region from a reporter gene or selectable marker (e.g. resistance to an antibiotic). Two types of gene fusions are generally recognized. Transcriptional fusions contain the coding region of the reporter gene only, while translational fusions encode chimaeric proteins containing segments from both the reporter and the gene of interest. In both cases, however, the mRNA may contain sequences from both the reporter and the gene of interest (Jefferson, 1987). As will be discussed in another section, vectors capable of generating T-DNA-mediated gene fusions may be designed to create either, or both types of fusions.

Many of the advantages to using a gene fusion rely on the properties of the reporter gene. An ideal reporter gene shou:d encode an erizymatic function which c: $n$ be detected rapidly and inexpensively with great sensitivity. Inherent in this dofinition is that the host organism being studied must possess little or no associated enzyme activity which could obscure results. Enzyme assays used to detect reporter activity should be quantitative and permit the spatial analysis of gene expression. An additional, important feature of a reporter is enzyme stability, including the ability to trerate a $: x_{i}$ ino te minal fusions, and varying ionic and $\mathrm{pH}$ conditions (Jefferson, 1987).

3. eral remorte; genes have been developed for use in plants. All but one of these, the firefly lucife' ase gene, come from bacterial sources. Genetic transformation studies have estabiished that cis-acting gene regulatory signals from bacterial or animal sources are not recognized in plants (Fraley et al., 1983; Fraley 
et al., 1986). Consequently, expression of these genes in plants requires that appropriate regulatory elements be added to the coding regions. The most frequently used 3' signals are those of the nopaline synthase (nos) and octopine synthase (ocs) genes. Although necessary for proper gene expression, it has been generally assumed that these 3 ' sequences do not contribute to the spatial and temporal regulation of the reporter gene. However, as reported in a previous section, genetic elements $3^{\prime}$ of the coding region do have the potential to influence gene expression in both a qualitative and quantitative manner. The choice of 5 regulaiory signals to be added to a marker gene has received much more attention. The two most commonly used promoters for the recovery and identification of transgenic plants have been those derived from nos and the CaMV 35S transcript. The CaMV 35S promoter is expressed at high levels in transient assays and transgenic plants, and has been estimated to be approximately 30 times stronger than the nos promoter (Sanders et al., 1987). Although reporter genes under the control of these promoters are activated in most plant tissues, their expression cannot be considered as constitutive. Histological localization of CaMV $35 S$ promoter activity in tobacco (Jefferson et al., 1987) and rice (Terada and Shimamoto, 1988) using the GUS reporter gene (see below) revealed that it is predominantly expressed in vascular tissues. However, more detailed analyses indicate that this promoter is also active in several other cell types in both dicotyledonous (Benfey et al., 1989) and monocotyledonous (Battraw and Hall, 1990) plants. The nos promoter is regulated in an organ-specific, developmental, and wound-inducible fashion (An et al., 1988; Teeri et al., 1989). Meaningful in situ localization has yet to be carried out for the nos promoter.

Reporter genes which have been widely used in plants - mclude Agrobacterium genes involved in opine synthesis, ocs (De Greve et al., 1982) and nos (Zambryski et al., 1983), the transposon Tn5-encoded neomycin phosphotransferase II gene (npt II; 
De Block et al., 1984; Fraley et al., 1983), the chloramphenicol acetyltransferase (cat) gene from $\mathrm{Tn} 9$ (Herrera-Estrella et al., 1983; Herrera-Estrella et al., 1984; Morelli et al., 1985), the firefly luciferase gene (luc; Schneider et al., 1990; Ow et al., 1986), the Vibrio harveyi luciferase genes (lux; Koncz et al., 1987), and the GUS gene (E. coli uidA locus, herein referred to as GUS, Jefferson et al., 1986; Jefferson et al., 1987). Corresponding enzymatic activities encoded by these genes will be referred to as OCS, NOS, NPT II, CAT, LUC, LUX, and GUS, respectively. Most plant tissues have little or no background activity for the above markers. However, as is discussed below, their detection may be hampered by the presence of interfering compounds or enzymatic activities.

The most popular reporter gene in bacterial systems is the Escherichia coli lac $Z$ gene which encodes a $B$-galactosidase (Teeri et al., 1989). Although numerous substrates and efficient fluorogenic and histological assays have been developed for this reporter, it is not suitable for plant studies due to the high endogenous galactosidase levels found in many tissues (Bhalla and Dalling, 1984; Helmer et al., 1984; Teeri et al., 1989). In order to circumvent this problem, Teeri et al. (1989) developed protocols for separating endogenous plant activity from the bacterial activity. Regardless of these new developments, lac $Z$ has not been widely used as a reporter gene, not even by the groups that developed the assays.

Opine synthesis reporters were popular after Agrobacterium-based transformation systems were first developed since they are naturally found within wild-type T-DNA and were easily incorporated into early transformation vectors (e.g. pGV3850; Zambryski et al., 1983). However, assays for these reporters are hard to quantify and may be plagued by interference from co-migrating compounds and lack of reproducibility. Consequently, they are now rarely used. The remaining reporters have either been used to detect T-DNA-mediated gene fusions, or were considered as possible reporter genes for the present study. Therefore, the 
properties of NPT II, CAT, GUS, LUC and LUX, and of the assays used to detect their activity will be considered in more detail.

NPT II catalyzes the transfer of a phosphate moiety from ATP to aminoglycoside antibiotics, thus inactivating them. It has accordingly been used as a selectable marker for recovery of transgenic plants (Bevan, 1984; Horsch et al., 1985; Koncz and Schell, 1986). NPT II activity may also be sensitively assayed in vitro by measuring the incorporation of radiolabelled ${ }^{32} \mathrm{P}$ into kanamycin. Although $n p t$ II has not been frequently exploited as a reporter gene, it has been used in this capacity to detect T-DNA-mediated gene fusions to promoterless $n p t$ II constructs (Koncz et al., 1987; Koncz et al., 1989). The cat gene may also be used both as a selectable marker or a reporter gene. Unlike NPT II, CAT is not well-suited as a selectable marker in plants and has been predominantly used as a reporter. CAT catalyzes the acetylation of chloramphenicol, an activity which can be measured using radiolabelled chloramphenicol as substrate. Acetylated products must be resolved from the substrate by chromatography in order to be detected and quantified. For the NPT II assays, extract separation, either by chromatography or electrophoresis, is also needed to separate the radiolabelled kanamycin not only from the unreacted ${ }^{32} \mathbf{P}$, but also from other molecules which have been labelled as a result of contaminating esterase, phosphatase and kinase activity present in the extract. Thus, the major disadvantages of these reporter gene assays are the need for radioactivity, which increases costs and introduces risks, and the involvement of numerous manipulations, which limit the number of samples that can be analyzed in a given time. Furthermore, assays for neither reporter allow meaningful quantification of results, nor do they permit the spatial analysis of enzyme activity in vivo.

Several of the disadvantages associated with NPT II or CAT may be overcome by use of GUS or luciferase as reporters. Assays for both these reporters 
can be quantified, do not require radioactivity, and although the tissue may need to be homogenized, the extracts do not have to be separated by electrophoresis or chromatography. GUS and luciferase activity may also be localized in situ. Regardless of the apparent advantages of both these reporter systems, GUS is, by far, the reporter of choice in the current literature. GUS is a hydrolase which catalyzes the cleavage of a variety of $B$-glucuronides. Several synthetic substrates for GUS are commercially available and may be used in conjunction with fluorogenic or histological assays (Jefferson, 1987; Jefferson et al., 1986). The former assay allows sensitive, quantitative measurement of GUS activity, while histological staining of GUS with an appropriate chromogenic substrate, usually 5-bromo-4-chloro-3-indolyl glucuronide (X-GLUC; Jefferson et al., 1987) can resolve enzyme activity to individual cells within a tissue or organ. One disadvantage of the GUS assays is that the tissue is killed by the procedure. It is noteworthy that several plant tissues have been reported to contain endogenous GUS activity, or fluorescent compounds which interfere with fluorogenic assays (Hu et al., 1990). Of particular relevance to the present study is the repor that tobacco anthers and pollen contain endogenous GUS activity (Piegt and Bino, 1989).

The LUC enzyme catalyzes the ATP-dependent oxidation of the substrate luciferin to produce light (Schauer, 1988; Schneider et d., 1990). As with GUS, LUC activity may be quantitatively assayed in cell-free extracts with great sensitivity. However, unlike the fluorometers used to detect GUS activity, equipment which measure bioluminescence cannot be calibrated (Brasier, 1990), thus making it difficult to compare results obtained in different laboratories. Spatial patterns of gene activity obtained with LUC can be visualized using contact photography or enhancing video systems (Barnes, 1990; Schauer, 1988; Schneider et al., 1990). However, the resolution of these assays is not as great as that of the histological GUS assay. It is rarely possible to locate luciferase activity to individual cells. 
Although the patterns of LUC activity observed in whole plants and excised plant organs fed the substrate luciferin accurately reflects the distribution of enzyme activity, it is biased by the uptake and distribution of luciferin (Schneider et al., 1990). Problems associated with substrate availability may be overcome by using the bacterial lux gene. The enzyme encoded by lux produces light from the oxidation of long-chain aldehydes using $\mathrm{FMNH}_{2}$ as energy (Schauer, 1988). Unlike luciferin, the aldehydes used in this assay are volatile and readily pass through plant tissues (Koncz et al., 1987; Schauer, 1988). One advantage of luciferase over GUS is that the spatial expression of both LUC and LUX may be studied in live tissues.

There are at least two additional disadvantages to using luc as a reporter gene. First, LUC is targeted to peroxisomes in transgenic plants (Schneider et al., 1990). It has been proposed that the distribution of peroxisomes within different plant tissues may influence patterns of expression. However, Schneider et al. (1990) were able to target LUC to the chloroplast without greatly affecting the pattern of gene expression, indicating that the subcellular localization of LUC may not be as important as some researchers had speculated. GUS does not appear to be targeted to any specific subcellular compartment in plant cells and is presumably a cytoplasmic protein (Iturriaga et al., 1989). However, GUS may be targeted to the nucleus (Carrington et al., 1991) or the chloroplast (Kavanagh et al., 1988) without loss of activity. In contrast, targeting GUS to the endoplasmic reticulum abolishes acivity, presumably as a result of glycosylation (Iturriaga et al., 1989). A modified GUS enzyme lacking potential glycosylation sites was recently found to retain activity when targeted to the endoplasmic reticulum (Farrell and Beachy, 1990). The other potential disadvantage of luciferase is that it is somewhat labile and cannot tolerate amino terminal fusions. In contrast, the GUS enzyme is very stable, and can tolerate large amino terminal fusions (Jefferson, 1987). Finally, the need for specialized video imaging equipment or a luminometer, and the widespread 
availability of GUS vectors and substrates are practical factors which may deter researchers from using luciferase.

\section{E. Agrobacterium-Mediated Gene Transfer}

Several genetic transformation systems have now been developed for plant cells. These include methods of direct gene transfer such as electroporation, microinjection, microprojection (biolistic), and macroinjection (reviewed in Potrykus, 1991), and an indirect method mediated by species of the soil bacterium Agrobacterium (Zambryski, 1988; Zambryski et al., 1989). Agrobacterium-mediated transformation represents the most efficient and widely used means of stably introducing genes into dicotyledonous plants. The remaining methods are consequently used mostly for monitoring transient gene expression, or for transformation of species which are not amenable to Agrobacterium infection. These include several economically important crops, and in particular the cereals (Binns and Thomashow, 1988; Potrykus, 1991).

The development of efficient Agrobacterium-mediated gene transfer systems can be directly correlated to our understanding of the genetic components involved in the process. However, many aspects of Agrobacterium-mediated gene transfer remain largely unknown. This is especially true for events occurring following transfer to the plant cell (Binns and Thomashow, 1988; Zambryski, 1988). It is not unreasonable to assume that increased knowledge of these events could be applied to the development of more efficient transformation protocols, including strategies which extend beyond "simple" gene transfer. 
1.E.1. Molecular basis of gene transfer and the development of transformation systems

Species of the genus Agrobacterium are phytopathogenic bacteria capable of producing crown gall tumours (A. tumefaciens) or hairy roots (A. rhizogenes) at wound sites of susceptible plant species (Binns and Thomashow, 1988; Nester et al., 1984; Schell and Van Montagu, 1983). The molecular and biochemical basis of these diseases lie in the transfer of specific segments of DNA, called the T-DNA (Transferred DNA), from large (ca. $200 \mathrm{~kb}$ ) tumour-inducing (Ti) or root-inducing (Ri) plasmids found in virulent strains of Agrobacterium to the plant genome. Following transfer, a series of so-called oncogenes (onc) contained on the T-DNA are expressed, resulting in the synthesis of enzymes involved in the metabolism of the plant growth hormones auxin and cytokinin. Plant cell growth and division are thereby stimulated, eventually leading to the production of tumours or roots. Transformed tissues can be cultured in vitro in the absence of exogenous growth regulators and also have the ability to synthesize novel metabolites called opines (Binns and Thomashow, 1988; Nester et al., 1984; Zambryski et al., 1989). Although these compounds are important sources of energy for the bacteria and their production has many interesting evolutionary implications, they are not invoived in T-DNA transfer per se (Binns and Thomashow, 1988; Schell and Van Montagu, 1983; Zambryski, 1988; Zambryski et al., 1989). In fact, none of the genes encoded by the T-DNA are necessary for gene transfer. The only cis-acting elements required for the transfer process are the $25 \mathrm{bp}$ direct repeats which flank the $\mathrm{T}$ DNA (Zambryski, 1988). These observations led to the development of nononcogenic, or disarmed T-DNA vectors which permit the transfer of foreign DNA to plant ceils and the subsequent regeneration of these cells into otherwise normal, often fertile transgenic plants (Fraley et al., 1985; Klee et al., 1987; Schell and Van Montagu, 1983). In the absence of tumour formation, chimaeric marker genes 
conferring selective growth advantages to transformed cells had to be incorporated into T-DNA vectors to facilitate the recovery of transgenic plants (Klee et al., 1987; Rogers and Klee, 1987).

All other genetic components required for T-DNA transfer act in trans to the border repeats (Binns and Thomashow, 1988; Klee et al., 1987; Zambryski, 1988). These include the Ti plasmid-encoded virulence (vir) genes and the chromosomal virulence $(c h v)$ genes. Consequently, it is possible to separate physically the components of the Ti plasmid needed for T-DNA transfer; the T-DNA itself and the vir genes. Based on these observations, binary gene transfer systems were developed in which the vir functions are located on a deleted derivative of a Ti plasmid lacking the T-DNA, and the T-DNA is contained on a smaller, wide-host range cloning vector (Bevan, 1984; Koncz and Schell, 1986; Rogers and Klee, 1987). The alternative to binary vectors are co-integrate Ti plasmids, which consist simply of disarmed Ti plasmids containing sequences from a commonly used cloning vector within the T-DNA portion (Klee et al., 1987; Zambryski et al., 1983). Foreign genes to be introduced within the T-DNA of co-integrate vectors are first inserted into an appropriate narrow host-range cloning vector containing homology to T-DNA sequences, but incapable of replication within Agrobacterium, and subsequently incorporated into the T-DNA by homologous recombination. The co-integrate system is principally limited by the low frequency of homologous recombination $\left(10^{-5}\right.$ to $10^{-7}$; Klee et al., 1987). In contrast, the binary system is limited by the efficiency of bacterial conjugation, which is several orders of magnitude higher than the frequency of homologous recombination (Klee et al., 1987; Koncz and Schell, 1986). Additional advantages of the binary system include the ability to introduce genes directly into the T-DNA, thus reducing the probability of genetic rearrangements within the genes of interest, and the flexibility to exploit different combinations of T-DNA and Ti plasmids (Klee et al., 1987). 


\section{E.2. Events within the bacterial cell: a model for T-DNA transfer}

The vir region is organized into 6 complementation groups, most of which are absolutely required for T-DNA transfer (Binns and Thomashow, 1988; Zambryski, 1988). The most widely accepted model of how the vir genes function to process and transfer the T-DNA to plant cells proposes that the early steps are analogous to bacterial conjugation, while latter events are more comparable to those involved in viral infection (Howard and Citovsky, 1990; Zambryski, 1988). Specific experimental evidence in support of this hypothesis is included in Howard and Citovsky (1990), Zambryski (1988) and Zambryski et al. (1989). Only the salient features of the model are presented below.

In response to phenolic compounds released from wounded plant cells, bacteria migrate towards the wound site and several vir genes are induced. A protein encoded by the virA locus is the best candidate for a chemoreceptor to sense the wound phenolics. The signal perceived by VIR $A$ activates a transcriptional activator encoded by the virG operon, which in turn induces the expression of the other vir genes. Enzymes encoded by the 5 ' half of the virD operon (VIR D1 and VIR D2) have been identified as site-specific endonucleases that recognize and cleave the lower strand (as depicted in standard schematic drawings) of the T-DNA border repeats. As a result of the nicks introduced in the border repeats, a linear single-stranded copy of the lower T-DNA strand is generated. This molecule (Tstrand) is produced at about one copy per bacterium and has been proposed to be the transferred intermediate. The VIR D2 protein is covalently bound to the 5' end of the T-strand and may act as a pilot protein to guide the T-strand to the plant cell and protect it against nuclease digestion. In addition, the longest virE operon (virE2) encodes a single-stranded binding protein which has been proposed to coat the T-strand, thus forming a DNA:protein complex called the T-complex (Howard and Citovsky, 1990). 
Little is known about the remaining steps in the transfer process. By analogy to bacterial conjugation, it would be expected that some form of pilus or pore structure exists at the bacterial surface to mediate the transfer of the T-complex to plant cells. Proteins encoded by virB, which are present at very high levels and can be localized to the cell envelope, are the most likely candidates to carry out such functions (Christie et al., 1989; Zambryski, 1988). It is noteworthy that none of the putative proteins encoded by the virB operon show significant amino acid homology with known pili proteins. However, vir B proteins do contain long stretches of hydrophobic residues, a feature which would be expected of integral membrane proteins (Howard and Citovsky, 1990).

The conjugation model is not sufficient to explain the entire process of $T$ DNA transfer. Many of the potential discrepancies lis in steps occurring or thought to occur outside the bacterial cell. These include penetration of the plant cell membrane and nuclear membrane and integration into the plant genome. Events within the plant cell may be more comparable to those involved in virus-cell interactions and will be considered in more detail in the following sections.

\section{E.3. Events within the plant cell}

Most of the information available on the fate of the T-DNA in plant cells consists of analyses of T-DNA molecules stably integrated into the plant genome. Consequently, models of how transfer and integration occur are based, to a large extent, on the structure and organization of the end products of T-DNA transformation. There are, however, several possible shortcomings to such an approach. First. T-DNA structure has usually been analyzed in population of cells which have been subjected to selective pressures and undergone hundreds or even thousands of cell divisions. Consequently, only those events leading to the formation of tumours or transgenic plants have been analyzed. In addition, within 
such cells, the structure of the T-DNA may not be representative of the primary, or initial integration event (Miki and Iyer, 1990; Zambryski et al., 1982). A better understanding of the transfer process may thus be obtained by characterizing the structure of transfer intermediates, or of initial integration events. A second aspect of T-DNA transfer which has been largely overlooked is the analysis of chromusomal locations at which integration may occur. Although different approaches have been used to physically localize such sites, including in situ hybridization and genomic mapping, only a limited amount of data have been obtained to date.

\section{E.3.a. Early events within the plant cell}

Early events may be defined as those occurring prior to T-DNA integration within the genome. Analysis of the T-DNA during this phase of transfer has proven to be particularly difficult, as transformed cells may initially represent only a small fraction of the total number of cells present. Furthermore, within the population of transformed cells, each transformation event is unique and methods sufficiently sensitive to study events occurring within single cells have yet to be developed. Potentially, a method such as the PCR may prove useful to analyze early steps in TDNA transfer.

Although no intermediate of T-DNA transfer has yet been detected in plant cells (Binns and Thomashow, 1988), at least one attempt was made to study the fate of the T-DNA shortly following Agrobacterium infection. Virts and Gelvin (1985) disrupted the infection process at various time intervals (up to 24 hours) and analyzed T-DNA structure using Southern blot hybridization. Their results indicated that the T-DNA is transferred rapidly (2-6 hours) after inoculation, that the T-DNA may be rearranged shortly after transfer, and that regions of the Ti plasmid outside the T-DNA are also transferred to the plant cells. Unfortunately, 
results of this study have not been confirmed or expanded upon. They have been described as inconclusive (Koukoliková-Nicola et al., 1987) and are notably absent from most review articles of T-DNA transformation. As suggested above, this may be related to technical difficulties and the general lack of sensitivity of the methods available at the time the study was performed.

As an alternative to identifying intermediates of the transfer process, Janssen and Gardner (1989) studied the expression of a T-DNA-encoded GUS gene in Petunia leaf discs shortly after Agrobacterium infection. Data provided demonstrated that GUS activity is detectable in a large proportion of leaf disc cells as early as 2 days following infection. Expression of GUS in most of the cells was transient, with only a small fraction of the cells eventually being stably transformed. It was estimated that the frequency of stable integration was at least 1,000 times lower than that of T-DNA transfer (Janssen and Gardner, 1989). Although the design of the above study was relatively simple, it provides several important conclusions to be drawn. First, the results strongly suggest that the limiting step in T-DNA transfer to plant cells is not the establishment of effective bacterial/plant interactions, but rather the process of T-DNA integration itself. This conclusion contradicts one reached by Depicker et al. (1985) who postulated, based on the frequency with which plant cells are co-transformed with different T-DNAs, that transformation was limited more by the establishment of effective bacterial/plant cell interactions than by the process of T-DNA integration or by the number of competent plant cells capable of being transformed. Second, the transient expression of GUS reported by Janssen and Gardner (1989) implies that DNA transferred to plant cells via Agrobacterium exists in a transcriptionally competent double-stranded form shortly after transfer. Thus, if the transferred intermediate is the single-stranded T-complex, as proposed by Howard and Citovsky (1990) and Zambryski (1988; 1991), then it must be rapidly converted to double-stranded DNA. 
Consistent with this view is the observation that 2 non-complementary T-DNAs cointroduced within tobacco protoplasts may recombine extrachromosomally (Offringa et al., 1990). Such an event could only occur if at least one T-DNA intermediate is converted to a double-stranded form prior to integration into the genome. Finally, results from Agroinfection, where the genome of plant viruses are introduced between T-DNA border repeats and transferred to plant cells via Agrobacterium infection (Bakkeren et al., 1989; Grimsley et al., 1987), also indicate that the T-DNA does not need to be integrated into the genome to be converted to a double-stranded molecule. It is noteworthy that Janssen and Gardner (1987) speculate that the high efficiency of Agroinfection may be related to the fact that, in such cases, T-DNA integration is not required for subsequent virus replication and infection.

One final aspect of early T-DNA transfer to plant cells which merits consideration is the potential involvement of Agrobacteriim-encoded vir gene products. The efficiency and precision of T-DNA transfer has led many to speculate a role for vir gene products within the plant cell (see, for example, Mayerhofer et al., 1991; Offringa et al., 1990). Recently, Zambryski (1991) demonstrated a potential role for VIR D2 and VIR E2 within plant cells. Protein fusions between GUS and the carboxyl terminal of VIR D2 resulted in nuclear compartmentalization of GUS activity in plant cells. Similar fusions between GUS and VIR E2 also demonstrated that this protein has the potential to target GUS to the nucleus. Based on these observations, Zambryski (1991) postulated that the VIR proteins remain associated with the T-strand following transfer to the plant cell and play an essential role in targeting the T-DNA to the nucleus. A potential role for VIR E2 within plant cells was also demonstrated by showing that expression of this protein in transgenic plants can complement Agrobacterium strains containing mutations at the virE2 low'us (Zambryski, 1991). It is noteworthy that although the above study would 
appear to imply that VIR E2 plays an essential role in T-DNA transfer, the virE operon is not absolutely required for virulence (Koukoliková-Nicola et al., 1987). The reasons for this apparent discrepancy are not fully understood.

\section{E.3.b. Genetic analysis of T-DNA inheritance}

Once the T-DNA has stably integrated within the genome and transgenic plants have been regenerated, segregation of the T-DNA in the transformed progeny may be easily studied by exploiting the presence of marker genes originally used to select for transformants. Table 1.1 summarizes the results obtained in 5 studies which analyzed the inheritance of the T-DNA in relatively large populations of transgenic plants. Examples from both co-integrate and binary vectors are included, although direct comparison between plants transformed with both vector types was addressed in only one case (Heberle-Bors et al., 1988). With the exception of one study (Deroles and Gardner, 1988a), the T-DNA integrated within most plants segregated as one or a few dominant Mendelian loci. In all cases, however, a certain fraction of the transformants con:ained insertions which segregated in a non-Mendelian fashion. Included within these cases were plants which failed to segregate for the presence of the $\Gamma$-DNA, tiose which segregated for a homozygous T-DNA insertion, those which appeared to contain homozygouslethal copies of the T-DNA, and those which segregated for the presence of the TDNA at low frequency. Such results may be explained, at least in part, by inactivation of T-DNA-encoded markers. In a recent study, plants which failed to segregate in a Mendelian fashion for hygromycin resistance were shown to segregate according to Mendelian principals when the progeny was analyzed by Southern blot hybridization (Scheid et al., 1991). Although the above study was performed on individuals transformed by direct gene transfer, there have been several reports of T-DNA gene inactivation (e.g. Jorgensen, 1990; Matzke and 


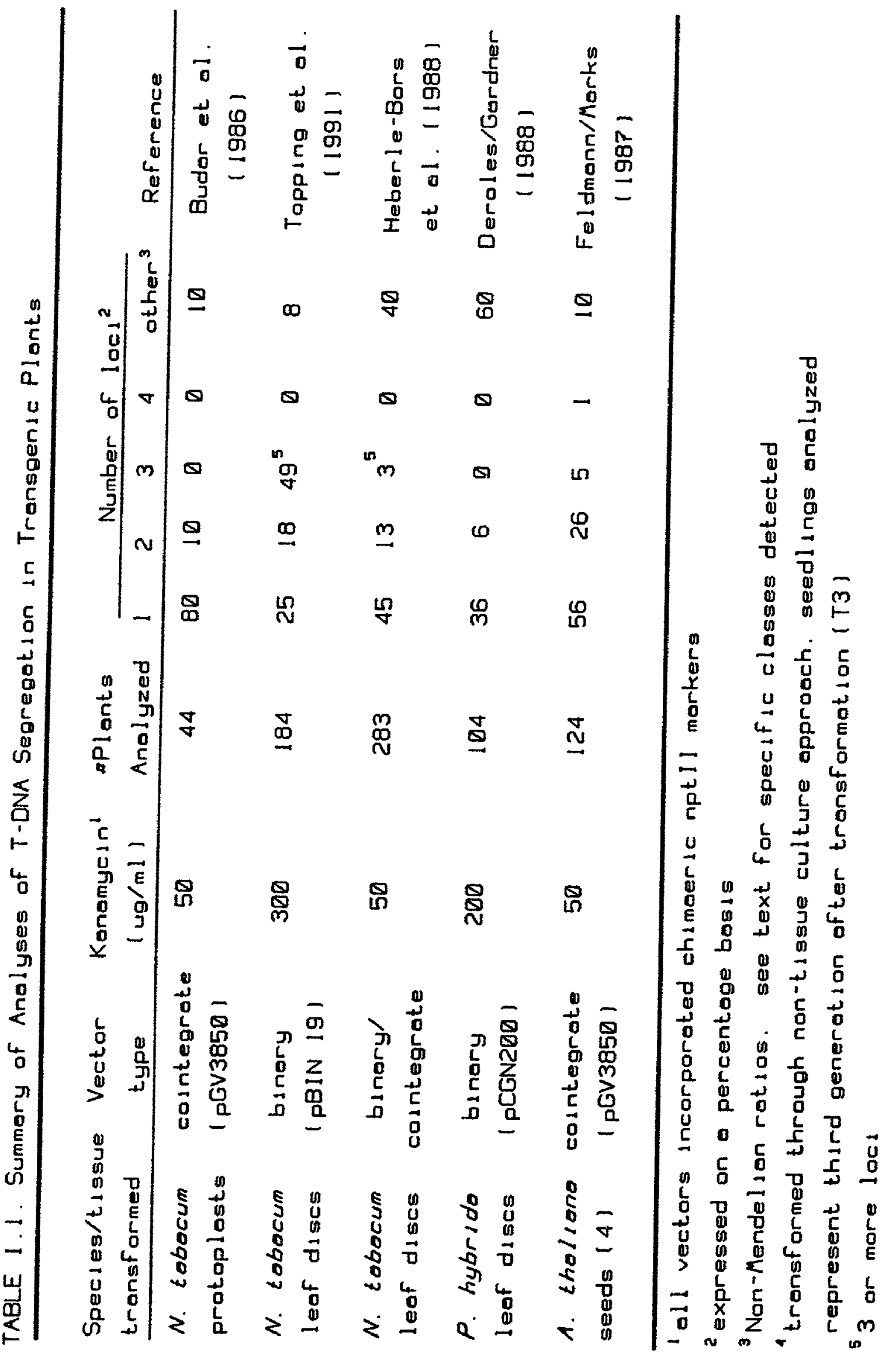


Matzke, 1990; Matzke et al., 1989), and thus a similar mechanism may also expiain the non-Mendelian inheritance patterns observed with Agrobacterium transformation. In the one study which analyzed the segregation of T-DNA derived from co-integrate and binary vectors, an approximately equal fraction of the population segregated for single insertions with each vector type ( $81 \%$ for the cointegrate vector vs. $72 \%$ for the binary vector; Heberle-Bors, 1988).

\section{E.3.c. Structure and organization of the integrated T-DNA}

Sequences contained within the T-DNA are usually well-characterized. Consequently, it is relatively straightforward to use these as hybridization probes to study the structure of integrated T-DNA molecules. In addition to providing a means of estimating copy number, this approach enables one to characterize rearrangements which may have occurred in the T-DNA prior to, during, or after integration into plant chromosomes. As suggested by Jorgensen et al. (1987) and Zambryski et al. (1982), any model of T-DNA transfer and integration must account for the various rearrangements observed in the integrated T-DNA molecules.

Although some degree of T-DNA analysis is performed in most transformation studies, detailed characterization of T-DNA structure has been reported in only a few cases (e.g. Czernilofsky et al., 1986; Deroles and Gardner, 1988b; Jones et al., 1987; Jorgensen et al., 1987; Spielmann and Simpson, 1986). As a consequence, only limited data on a small number of plants is presented in many cases. Comparison of results from different studies is complicated by the fact that several factors other than vector type influence patterns of T-DNA integration. Some of these variables include the species used, explant source, age and preconditioning, tissue culture and regeneration protocols, and the selection regime (Deroles and Gardner, 1988b; Gheysen et al., 1990; Heberle-Bors et al., 1988; Sukhapinda et al., 1987). Nevertheless, several conclusions regarding T-DNA 
integration can be drawn from the existing literature.

Southern blot analysis and sequencing of T-DNA/plant DNA junctions from crown galls and transgenic plants regenerated following infection with co-integrate or binary vectors has revealed that T-DNA integration into plant chromosomes is a very precise event. The endpoints of many integrated T-DNA molecules are located within or less than 10 bp away from the right border repeat (Gheysen et al., 1991; Jorgensen et al., 1987; Koukoliková-Nicola et al., 1987; Mayerhofer et al., 1991). Integration at the left T-DNA end does not appear to be as precise. In most studies, only 1 or a few copies of the T-DNA were detected. Based on the literature available at the time, Zambryski (1988) estimated the average copy number of TDNA present in transformed cells to be 3 . In cases where multiple copies of the TDNA were observed, these were present either as tandem arrays (see below) or as unlinked loci (Jorgensen et al., 1987; Zambryski, 1988). Consequently, the copy number of the T-DNA may equal or surpass the number of genetic loci segregating for the presence of the T-DNA. There is no conclusive evidence to suggest that plants transformed with co-integrate vectors contain fewer copies of the T-DNA than those transformed with binary vectors (Sukhapinda et al., 1987). However, plants transformed with certain binary vectors do appear to contain several copies of the T-DNA. This may be true of systems based on the vector pBIN19 (Bevan, 1984). In the original study, Bevan (1984) analyzed 4 plants transformed with pBIN6, a prototype of pBIN19 and found copy numbers ranging from 5 to 20 . Similarly, Jefferson et al. (1987) engineered derivatives of pBIN19 containing various GUS gene fusions and reported that the number of T-DNA copies observed in 4 plants ranged from 2 to 7 . As reported in the above section, Topping et al. (1991) found that approximately $50 \%$ of the plants they transformed with pBIN19 derivatives contained T-DNA integrated at 3 or more loci.

Although internal rearrangements have occasionally been observed in crown 
gall T-DNA (Peerbolte et al., 1986a; Peerbolte et al., 1986b; Van Lijsebettens et al., 1986), few have been reported in disarmed T-DNA contained within transgenic plants (Deroles and Gardner, 1988b; Koukoliková-Nicola et al., 1987; Zambryski, 1988). The most common type of rearrangements observed in such plants appear to be deletions at the extremities of the T-DNA (Deroles and Gardner, 1988b; Gheysen et al., 1990; Jorgensen et al., 1987; Spielmann and Simpson, 1986). In onc study (Deroles and Gardner, 1988b), 40\% of the T-DNA molecules analyzed contained deletions at either ends of the T-DNA. The frequency of deletions observed at the right and left borders was roughly equal. The endpoints of the deletions were distributed randomly along the T-DNA with no evidence of clustering at one preferred site. Although it has been proposed (Van Lijsebettens et al., 1986) that sequences sharing homology to the T-DNA border repeats (pseudoborders) may be involved in generating deletion events, more recent studies (Deroles and Gardner, 1988b; Gheysen et al., 1990) found no correlation between the presence of pseudo-borders and T-DNA deletion endpoints. In fact, Herman et al. (1990) demonstrated that an intact right border repeat was needed in cis to obtain the transfer of truncated T-DNAs, suggesting that deletions occur after the formation of the transfer intermediate. The observation that break points within inverted repeats are always identical (Jorgensen et al., 1987) may indicate that the deletions occur prior to, or during T-DNA integration. In other cases, the extent of T-DNA rearrangements detected in crown gall tumours has been proposed to be linked to the length of time for which these had been maintained in culture (Deroles and Gardner, 1988b; Koukolikova-Nicola et al., 1987), implying that structural changes in the T-DNA may also occur following integration into the chromosomes. In at least one case, structural changes not apparent in the original transformant were detected in some of its progeny, indicating genetic instability of the T-DNA following integration (Chyi et al., 1986). 
Integrated T-DNA molecules are commonly observed as tandem repeats. This type of organization has been reported in octopine and nopaline crown gall tumours (Kwok et al., 1985; Lemmers et al., 1980; Ooms et al., 1982; Zambryski et al., 1980), and in plants transformed with co-integrate (Feldmann and Marks, 1987; Frale, et al., 1985; Jones et al., 1987; Jorgensen et al., 1987) and binary (Bevan, 1984; Spielmann and Simpson, 1986; Sukhapinda et al., 1987) T-DNA vectors. Jones et al. (1987) and Jorgensen et al. (1987) reported that more than 50\% of the transgenic plants they analyzed contained inverted repeats. This was observed in tomato, petunia, tobacco and Arabidopsis. Within a tandem array, both inverted and direct repeats, centered on either the right or left border may exist. In general, the number of T-DNA copies in such array is quite small (2-4). Larger arrays of input DNA have been observed in plants regenerated following direct methods of gene transfer (Czernilofsky et al., 1986; Paszkowski, 1989; Riggs and Bates, 1986). In animal systems, up to 100 copies of the introduced DNA may be present in one tandem array (Allen et al., 1988). It is noteworthy that in some studies of T-DNA transformation, no evidence of tandem repeats was uncovered. These include studies which analyzed close to 100 (Deroles and Gardner, 1988b) or 50 (Koncz and Schell, 1986) independent transformants.

Jorgensen et al. (1987) speculated about the mechanism by which T-DNA repeats may arise. As these authors observed predominantly inverted repeats, they proposed that simple, intermolecular ligation of different T-DNA copies in the bacterial or plant cell prior to integration was inconsistent with their results. According to such a mechanism, equal numbers of direct and inverted repeats should be generated. An alternative mechanism based on replication of the T-DNA was also proposed. According to such a model, inverted repeats may be generated as a result of strand-switching by the polymerase during replication of the T-DNA (Jorgensen et al., 1987). Presumably, replication of the T-DNA occurs in the plant 
cell, either prior to or during integration, as Zambryski (1988) reports that no multimeric form of the T-DNA has been observed in vir-induced Agrobacterium. Models of tandem repeat formation based on T-DNA replication may explain the observation that deletions within inverted repeats are identical (Jorgensen et al., 1987). Depicker et al. (1985) also proposed that most of the T-DNA copies found in plant cells co-transformed with 2 different Agrobacterium strains are derived from only one original T-DNA which had been multiplied (via replication). Similarly, Van Lijsebettens et al. (1986) detected several copies of the same truncated T-DNA at different chromosomal sites and proposed that replication of a single T-DNA molecule early in the infection process could account for this observation. Finally, Zambryski et al. (1982) also proposed that tandem repeats may occur by a recombination/repair mechanism. It is noteworthy that these authors detected DNA sequences of unknown origin between individual T-DNA copies within an inverted repeat, while Holsters et al. (1983) reported that tandemly repeated TDNA may contain sequences of plant origin. Both these observations strongly suggest that T-DNA tandem arrays are formed only after initial integration within the plant chromosome. Thus, tandem repeats of T-DNA do not appear to be generated by homologous recombination between different copies of the input DNA during transformation, a mechanism which is thought to be responsible for producing tandem arrays of microinjected DNA (into mouse embryos, Palmiter and Brinster, 1986; into Caenorhabditis elegans, Mello et al., 1991) and DNA introduced by liposome-mediated transformation (into tobacco protoplasts, Deshayes et al., 1985).

Results obtained in a recent study (De Block and Debrouwer, 1991) appear to be inconsistent with the recombination and repair models proposed above. These authors transformed Brassica napus with two Agrobacterium strains harbouring different T-DNA and observed that a high proportion of the transgenic 
plants (39\%-85\%, depending on cultivars used) were co-transformed with both TDNA. In 57\% of the cases, the two T-DNA were linked, usually as inverted repeats separated by non-T-DNA sequences. De Block and Debrouwer (1991) offer no explanation for these observations, except to state that they cannot be accounted for by any of the current models of T-DNA integration.

Jorgensen et al. (1987) also speculated that the high frequency of inverted repeats which they observed was linked to transformation with the nopaline strain C58 in combination with pGV3850-derived vectors. Use of disarmed octopine strains and vectors (e.g. LBA4404) presumably yields 5 times fewer inverted repeats. Although such a hypothesis has not been vigorously tested, it is perhaps noteworthy that the binary system engineered by Koncz and Schell (1986), which does not yield any tandem repeats, is based on strain C58/pMP90. Plasmids pGV3850 and pMP90 are closely related and both derived from the oncogenic Ti plasmid pTiC58 (Koncz and Schell, 1986).

\section{E.3.d. Localization of T-DNA insertions}

Segregation of T-DNA markers and DNA hybridization techniques may also be exploited to localize sites of T-DNA integration. In situ hybridization of metaphase chromosomes (Ambros et al., 1986) revealed that the T-DNA may integrate into different chromosomes of Crepis capillaris. Segregation of kanamycin resistance and NOS activity with isozyme markers was used to map the location of the T-DNA in the progeny of 6 independent Petunia hybrida transformants (Wallroth et al., 1986). Isozyme markers, as well as restriction fragment length polymorphisms (RFLPs) were also used to map the chromosomal location of the TDNA in 10 transformed lines of Lycopersicon (Chyi et al., 1986). Based on results from these studies, it was proposed that T-DNA integration is random at the chromosomal level (Ambros et al., 1986; Chyi et al., 1986; Wallroth et al., 1986, 
Zambryski, 1988).

Using the T-DNA as a molecular tag, it is possible to recover integrated TDNA molecules and the chromosomal sequences which flank them (e.g. Holsters et al., 1983; Zambryski et al., 1980; Zambryski et al., 1982). The flanking DNA may subsequently be used as a hybridization probe to analyze the nature of the plant DNA into which the T-DNA has integrated. Such studies have revealed that the TDNA may integrate within single copy as well as repeated genomic sequences (Binns and Thomashow, 1988; Gheysen et al., 1987; Holsters et al., 1983; Thomashow et al., 1980; Yadav et al., 1980; Zambryski et al., 1982). Many of the above T-DNAs were recovered from tobacco cells, and as previously reviewed (section 1.A.1.) much of the tobacco DNA is organized as short stretches of alternating unique and repetitive DNA. More precise determination of flanking chromosomal sequences has, in some cases, revealed that the T-DNA is integrated within such regions (Gheysen et al., 1987; Thomashow et al., 1980).

Yet another means of characterizing the chromosomal location at which $\mathrm{T}$. DNA integration may occur is on the basis of chromatin structure. The relative sensitivity of integrated T-DNA sequences to nucleases has been determined in crown galls (Coates et al., 1987; Kahl et al., 1987) and transgenic plants (Weising et al., 1990), although only a few cases have been analyzed to date. In all cases, data indicate that the T-DNA is in an open chromatin conformation, regardless of whether the specific sequences used as probes contained genes, or encoded genes which were transcriptionally active in the tissues assayed (Weising et al., 1990). Based on these results, Weising et al. (1990) postulated that the conformation of the integrated T-DNA is determined by the surrounding chromatin into which it has integrated - which has been "open" for all integrated T-DNA copies studied thus far - or alternatively, that information carried on the T-DNA itself controls the chromatin structure following in เzgration. Of these 2 hypotheses, Weising et al. 
(1990) favour the first, and further speculated that preferential integration of the TDNA into open chromatin may be linked to the fact that insertions into such sites are more favorable to expression of selectable markers used to recover transgenic plants. Such a model for T-DNA integration would also have to take into account the observation that T-DNA inserts found within crown galls, which have not been selected for resistance to antibiotics, are also in an open chromatin conformation (Coates et al., 1987; Kahl et al., 1987). However, development of a crown gall requires the expression of T-DN $\Lambda$-encoded onc genes (Nester et al., 1984), and thus it could be argued that a form of selection pressure to integrate within areas of the plant genome favorable to gene expression was also imposed on these cells.

\section{E.3.e. Analysis of T-DNA/plant DNA junctions and target sites of T-DNA integration}

Chromosomal sites of T-DNA integration may also be analyzed on the basis of nucleotide sequence. Early studies of this type on T-DNA/plant DNA junctions were designed to define the ends of the transferred DNA, to determine whether there was any sequence/site specificity of integration, or to confirm that the T-DNA was covalently bound to nuclear DNA. Although some of the conclusions derived from these studies have already been discussed in previous sections, it is noteworthy to add that there is little evidence to indicate the role of specific sequences for $\mathrm{T}$ DNA integration (a possible exception is discussed below). Sequences flanking the T-DNA are often (Gheysen et al., 1987; Zambryski et al., 1982) but not always (Gheysen et al., 1991; Mayerhofer et al., 1991) rich in A and T. In addition, data obtained demonstrate that sequences at the end of the T-DNA, as well as within the flanking chromosomal DNA may undergo rearrangements as a result of integration (Zambryski et al., 1982; Simpson et al., 1982). Direct and inverted repeats are commonly detected at or near T-DNA/plant DNA junctions. 
Further insights into the mechanism of T-DNA integration may be obtained by analyzing the structure of the plant DNA before and after integration. The availability of cloned DNA segments flanking the T-DNA provides a means of isolating the corresponding wild-type sequences. Data obtained from such studies indicate that integration of the T-DNA causes few major rearrangements in flanking DNA (Gheysen et al., 1991; Matsumoto et al., 1990; Mayerhofer, 1991). The only alteration consistently observed in the plant chromosomal DNA are short (13-73 bp) deletions. Mayerhofer et al. (1991) refer to such deletions as target sites. Other rearrangements were also occasionally detected, including base pair substitutions and insertions. In one case, T-DNA integration generated a direct repeat of $158 \mathrm{bp}$ at the left and right T-DNA junction (Gheysen et al., 1987), while in another it resulted in a duplication of more than $3 \mathrm{~kb}$ (Gheysen et al., 1991). At least one additional major rearrangement of 1 to several $\mathrm{kb}$ was reported by Gheysen et al. (1991).

Short stretches of repeated sequences in the flanking DNA were commonly found near the target site (Gheysen et al., 1991; Matsumoto et al., 1990; Mayerhofer et al., 1991). Such repeats have been proposed to be generated by imprecise integration events (see below) in which "fill ar" DNA was used to join the T-DNA and chromosomal DNA. Although the filler DNA is different from the plant target site and the T-DNA ends, it is usually identical to sequences found in the nearby flanking DNA, thus resulting in direct or inverted repeats (Gheysen et al., 1991; Mayerhofer et al., 1991). In addition to imprecise junctions, precise junctions, in which no filler DNA can be detected have also been observed (Mayerhofer et al., 1991).

Although there was little or no homology between the different target sites which have been studied, short stretches ( $<10 \mathrm{bp}$ ) of partial homology (20-40\%) could be detected between target sites and the ends of T-DNA molecules (Gheysen 
et al., 1991; Mayerhofer et al., 1991). Mayerhofer eı 2l. (1991) observed that the size of the target deletion and the extent of deletion in the T-DNA ends are defined by the location of these short stretches of partial homology and proposed that these sequences play a role in the initial interaction of the T-DNA ends with plant target sites.

The involvement of a more significant region of homology between T-DNA ends and chromosomal sequences has been proposed by Matsumoto et al. (1990). These authors analyzed the integration site of a truncated T-DNA molecule recovered from a tobacco crown gall tumour. Deletions of more than $7 \mathrm{~kb}$ at the right border and $0.35 \mathrm{~kb}$ at the left border were detected. A region of more than $70 \%$ sequence homology was shared between the target site and T-DNA sequences which flanked, but were not present, in the integr.:ed T-DNA molecule. Based on these results, Matsumoto et al. (1990) proposed that the integration event they characterize $I$ was generated by homologous recombination. Other examples of TDNA integration via homologous recombination have been reported (Offringa er al., 1990; Lee et al., 1990). However, such events occurred at a very low frequency ( 1 in $3 \times 10^{4}$, Offringa et al., $1990 ; 8.4 \times 10^{-5}$, Lee et al., 1990) and could only be detected by selection of phenotypes diagnostic of homologous recombination.

\section{E.3.f. Models of T-DNA integration}

From all the data available on T-DNA integration, it appears that the process cannot be fully accounted for by either of the 2 mechanisms known to be responsible for DNA insertion into eukaryotic genomes (outlined in Gheysen et al., 1987). Integration of transposable elements or retroviruses into the genome (Type I system) is catalyzed by both element- and host-encoded functions and is very efficient. Although T-DNA integration is effirient, it generates more rearrangements than Type I integrations, which usually produce only short 
duplications of chromosomal sequences at the end of the element. The presence of tandem repeats, deletions within the element or in the target sequence, and the presence of filler DNA (all of which have been detected in T-DNA integration events) are not characteristic of Type I integration events. Furthermore, no TDNA-encoded enzymes are needed for integration, although it is still questionable whether any of the Agrobacterium-encoded vir gene products are involved in the process. Integration of foreign DNA introduced by direct gene transfer methods such as electroporation or micro,njection into the host genome is calalyzed entirely by host-encoded enzymes usually involved in DNA replication, recombination and repair (Type II system). Several of the features of T-DNA integration are characteristic of Type II systems, however, T-DNA integration is more efficient and the extent of rearrangements observed in the T-DNA and the target sequences are usually much less drastic (for consideration of the efficiency of direct gene transfer methods in plants, and of the types of rearrangements detected see Christou et al., 1989; Deshayes et al., 1985; Hain et al., 1985; Paszkowski, 1989; Potrykus, 1991; Potrykus et al., 1985a; Potrykus et al., 1985b; Potrykus et al., 1985c; Riggs and Bates, 1986; Saul and Potrykus, 1990). T-DNA integration thus appears to share features of both Type I and Type II systems. Such observation could be explained by a process largely catalyzed by host-encoded enzymes, with a limited role for vir products, perhaps in targeting the T-complex to the nucleus and protecting the DNA from degradation by nucleases (Gheysen et al., 1987; Gheysen et al., 1991; Mayerhofer et al., 1991; Zambryski, 1988). Additional functions for VIR D2 and VIR E2 during the integration process have also been proposed, including recognition and nicking of the plant DNA, mediating the formation of precise junctions at the right border end, and unwinding of the target DNA (Mayerhofer et al., 1991). These features are consistent with those of an "integrase", an enzymatic function that Howard and Citovsky (1990) postulated may be encoded by enzymes 
within the T-complex.

Detailed models for T-DNA integration based on illegitimate recombination are presented by Gheysen et al. (1991) and Mayerhofer et al. (1991). These models are similar to each other, and to those previously published by Gheysen et al. (1987) and Zambryski (1989). They are aiso consistent with data obtained by Southern blot analysis of integrated T-DNA molecules and can account for all the various structural rearrangements which have been detected in the T-DNA and flanking chromosomal DNA. Integration of both double-stranded and single-stranded intermediates is considered by Mayerhofer et al. (1991) while Gheysen et al. (1991) propose a model solely based on the integration of a single-stranded molecule. It is noteworthy that if VIR proteins are to play a role in the integration process itself, the substrate must be a single-stranded molecule. The following is a summary of the salient features of the models.

As a result of DNA replication, recombination, or repair, a nick or gap (for the single-stranded model) or a break (for the double-stranded model) is introduced into the chromosomal DNA. Limited base pairing between single-stranded regions of the plant target site and the ends of the T-DNA results in the formation of a heteroduplex. The small size of the target sites suggest that the ends of the T-DNA are located close to one anothcr during this phase. Overhanging ends, if they exist, are removed by exonucleases (possibly explaining the origin of deletions at the end of the T-DNA), and the processed ends are repaired and ligated (possibly generating repeated sequences). If the T-intermediate is single-stranded, then a nick must be introduced in the second strand of chromosomal DNA prior to repair synthesis of this strand using the T-DNA strand as template. Modified versions of these models have been formulated to include involvement of the VIR D2 protein. 


\section{E.4. Gene expression in transgenic plants}

Several aspects of plant gene expression have already been discussed in earlier sections. However, now that the process of Agrobacterium-mediated gene transfer has been reviewed, peculiarities of gene expression in transgenic plants warrants a more detailed consideration.

Although the spatial and temporal expression of transgenes usually parallel those of the original gene, levels of expression often vary considerably (more than 200 fold) between independent transformants regenerated following infection with identical T-DNAs (for recent overviews, see Hobbs et al., 1990; Peach and Velten, 1991). There have also been reports of altered patterns of gene expression in transgenic plants (De Almeida et al., 1989; Barnes, 1990). As maximal levels of faithful gene expression are desirable for most potential applications of transgenic plants, a better understanding of factors responsible for the above-mentioned phenomena would be of both economic and biological significance.

Although several factors have been proposed to account for the variability of gene expression observed in different transformants (see below) the copy number of T-DNA inserts is usually not correlated with levels of expression. When correlations between levels of gene expression and T-DNA copy number have been observed, they were usually negative ones. For example, although Jones et al. (1987) and Jorgensen et al. (1987) found that localization of a gene within an inverted repeat did not preclude its expression, the presence of numerous T-DNA copies in a plant, arranged in multiple, complex tandem arrays appeared to have a negative effect on gene expression. Hobbs et al. (1990) also reported a negative correlation between levels of gene expression of a CaMV 35S promoter-GUS construct and T-DNA copy number. Their data indicate that even plants with $2 \mathrm{~T}$ DNA copies do not express GUS to levels comparable of plants containing single inserts. A negative effect of multiple T-DNA copies was also demonstrated by 
analysis of GUS expression in the transformed progeny. When 2 independent TDNA copies segregated away from each other, higher levels of GUS were detected.

The reasons why multiple copies of a gene would have negative influences on its expression are largely unknown. Matzke et al. (1990) and Matzke and Matzke (1991) observed that sequential transformation of plants with different T-DNAs may lead to the inactivation of genes on the original T-DNA, a phenomenon which was correlated with methylation of promoter sequences. However, inactivation was not observed in all doubly transformed plants; up to 50\% of transformants expressed markers on both T-DNAs. Reactivation of genes in the original T-DNA occurred wher the different T-DNAs segregated away from each other in the progeny of doubly transformed plants (Matzke et al., 1990; Matzke and Matzke, 1991). Although the different T-DNAs were used in the above studies, they did share regions of homology. Matzke and Marzke (1990) proposed that these sequences were somehow involved in the suppression phenomenon. The involvement of homologous sequences in suppressing gene activity was demonstrated by Goring et al. (1991) who transformed transgenic tobacco plants harbouring a nos gene with a partial nos gene. Although the original plant was $\mathrm{NOS}^{+}$, none of the 9 independent transformants containing the partial nos gene contained NOS activity. Transformation of the $\mathrm{NOS}^{+}$plant with a related vector lacking the partial nos gene did not suppress NOS activity. As observed by Matzke et al. (1989), segregation of the nos gene from the partial gene resulted in nopaline synthesis (Goring et al., 1991).

The above studies indicate that it is possible to suppress resident transgene expression by transforming plants with a second T-DNA containing homolngous sequences. It is also possible for transgenes to inactivate endogenous plant genes (Napoli et al., 1990; van der Krol et al., 1990). In such cases, both the endogenous gene and the transgene are both inactivated, leading researchers to refer to the 
underlying mechanism resfonsible for the phenomenon as co-suppression (Jorgensen, 1990), or trans-inactivation (Jorgensen, 1991). As reported for plants sequentially transformed with different T-DNAs, co-suppression is not observed in all transformants and is reversible. In all cases, reactivation of the transgene was correlated with activation of the endogenous genes. This process occurred somatically, and was not due to loss of the transgene. Thus, co-suppression appears to be an epigenetic phenomenon (Jorgensen, 1990). The observation that the inactivation of endogenous genes or transgenes by other transgenes occurs in only a fraction of the transformants led Jorgensen (1990) and Matzke and Matzke (1990) to propose that the interaction between these genes (trans and endogenous) is determined, at least in part, by their relative chromosomal locations.

It is also noteworthy that rearrangements or modifications to the T-DNA may also account for some of the observed plant to plant variability in gene expression levels. As outlined in previous sections, structural analysis of integrated T-DNA has revealed that rearrangements occur at different frequencies in transgenic plants. Although it is relatively straightforward to determine the structure of integrated T-DNA, this is not always accomplished. For example, Ebert et al. (1987), Jefferson et al. (1990) and Keller et al. (1989) all compared the expression of transgenes in multiple independent transformants, but fail to mention whether the material was also analyzed by Southern blot hybridization. Clearly, such analyses should be a prerequisite to any detailed study of transgene expression.

Hypotheses linking variability of transgene expression to integration sites had been postulated long before the phenomenon of co-suppression was reported in plants. Such theories proposed that transgene expression could be influenced by the chromatin structure, and the presence of endogenous promoters and enhancer sequences adjacent to the integrated T-DNA (Jones et al., 1985; Jones et al., 1987; Weising et al., 1988). As T-DNA integration into the plant genome appears to be 
random, each integrated T-DNA molecule should be flanked by different chromosomal sequences, each having distinct properties. Positional effects may also influence the expression of foreign genes introduced into plants (Saul and Potrykus, 1990) or animal (Bonnerot et al., 1990; Reuter et al., 1990) cells by methods of direct gene transfer. It has recently been shown that foreign genes introduced into Drosophila cells can be insulated from positional effects by incorporating, into the transformation vectors, sequences which act to delineate chromosomal domains (Kellum and Schedl, 1991). It would be interesting to determine whether such sequences could also reduce variability of transgene expression in plants. However, Dean et al. (1988) reported that insulating a transgene with large segments of plant DNA (up to $23 \mathrm{~kb}$ ) did not reduce the variability of gene expression amongst the transformants.

One method which has been exploited to compensate for position effects is to add a reference gene within the T-DNA. By comparing the expression of the test gene with that of the reference gene, variability amongst different transformants may be significantly reduced (e.g. Fang et al., 1989; Kuhlemeier et al., 1987b). However, in several instances, expression of linked transgenes was shown to vary independently from one another (Jones et al., 1985; Gidoni et al., 1988; Peach and Velten, 1991). In one report, the ratio of CAT to GUS activity, when expressed from the divergent mannopine synthase (mas) promoters, 1' and 2', varied from 0.05 to 49 (Peach and Velten, 1991). Should these differences in levels of expression be due to positional effects, the influences of flanking DNA must vary considerably over short distances. Gidoni et al. (1988) reported that levels of transgenes expressed from a divergent $C a b 22$ promoter varied independently when inserted near the right border repeat of the T-DNA, while levels of the same gene construct varied coordinately when inserted near the left T-DNA border repeat, presumably because there were no adjacent gene regulatory elements in the adjacent T-DNA 
sequences. Thus, the expression of transgenes may also be influenced not only by its positioning within the plant genome, but also by its position within the T-DNA.

Although it is reasonable to assume that sequences flanking the T-DNA could alter levels of gene expression, this has yet to be directly proven in plants. Even if positional effects are real, the magnitude of their influence on gene expression may be overestimated by spatial and temporal differences in gene expression related to physiological and developmental differences in the material analyzed. For example, repeated analysis of clonal material transformed with the $T$. DNA harbouring CAT and GUS genes expressed from the divergent mas l' 2' promoters yielded activity ratios ranging from 4.8 to 21 (Peach and Velten, 1991). Most plant genes isolated to date show some degree of tissue-specificity and developmental regulation. These include genes which were originally thought to be constitutive, such as those naturally found on the T-DNA (e.g. An et al., 1988; Koncz and Schell, 1986; Teeri et al., 1989) and the CaMV 35S transcript (Benfey et al., 1989). Several reports have now demonstrated that gene expression may be greatly influenced by the developmental stage of a tissue or organ, and its location on the plant. For example, expression of a nos promoter-CAT gene fusion varied almost 300 fold between leaf tissue harvested from the bottom and top of tobacco shoots (An et al., 1988). Similarly, Castresana et al. (1990) found that a gene fusion between the $\beta-1,3-g l u c a n a s e$ gene $(g \ln 1)$ promoter and GUS was expressed only in older leaves of transgenic tobacco. Jones et al. (1987) observed diurnal fluctuations in the expression of the nos gene and a cab promoter-ocs fusion, and reported that it was essential to harvest all material at the same time of day in order to reduce variability. Although it is impossible to eliminate all variables which affect plant growth and physiology, differences in gene expression levels can be minimized by collecting tissues of corresponding developmental stages from plants grown under similar, if not identical conditions. This was demonstrated in a recent study by 
Hoibs et al. (1990). These authors analyzed the expression of GUS in physiologically synchronized $\mathbf{R}_{\mathbf{1}}$ and $\mathbf{R}_{\mathbf{2}}$ progeny (the original transformant being the $R_{(0)}$ generation; Potrykus et al., 1985a) containing intact T-DNA inserts and found little evidence for positional effects.

\section{F. Agrobacterium-Mediated Gene Transfer as a Means of Studying Plant Genes in vivo}

Genetic elements capable of inserting themselves at different sites within a genome can be exploited to manipulate genes in vivo (Kleckner et al., 1977). In plants, insertions of mobile genetic elements, principally transposons, next to or within promoters and coding regions have been used to study gene structure, expression and function (Balcells et al., 1991; Carpenter and Coen, 1990; SchwarzSommer and Saedler, 1987; Weil and Wessler, 1990). A major advantage of gene characterization by in vivo approaches is that little or no information on the location, sequence, function or expression of a gene is required a priori. Gene function and expression are deduced from the phenotypic effects induced by integration and excision of the transposon. The nature and location of genes may also be assessed by using the transposon as a molecular tag to first clone flanking chromosomal sequences and subsequently identify the wild-type gene, and to map sites of integration. These characteristics of in vivo manipulations make them well suited for identifying and analyzing regulatory genes, low abundance genes, as well as geres involved in controlling plant development and morphogenesis (Balcells et al., 1991; Carpenter and Coen, 1990; Chandlee, 1991; Feldmann, 1991; Sheridan, 1988).

Many of the properties of the T-DNA suggest that it can also be exploited for gene manipulation in vivo (Feldmann, 1991; Klee et al., 1987). In the last few years, 
several T-DNA-induced mutations have been generated (Errampalli et al., 1991; Feldmann, 1991; Feldmann et al,, 1989; Koncz et al., 1990; Van Lijsebettens et al., 1991). Some of the wild-type genes into which the T-DNA had inserted have also been characterized (Koncz et al., 1990; Oppenheimer et al., 1991; Roe et al., 1991; Yanofsky et al., 1990). In addition, transformation of plant cells with vectors containing a promoterless reporter gene linked to the ends of the T-DNA can result in the creation of in vivo gene fusions when T-DNA integration occurs downstream of endogenous cis-acting regulatory elements (André et al., 1986; Herman et al., 1990; Kertbundit et al., 1991; Koncz et al., 1987; Koncz et al., 1989; Teeri et al., 1986; Topping et al., 1991). Such an approach provides a means of directly studying gene expression in planta. Use of the T-DNA as a tag permits the recovery of developmentally regulated genes and cis-acting elements controlling their expression (Kertbundit et al., 1991; Koncz et al., 1989).

Vectors for generating in vivo gene fusions based on plant transposons have yet to be developed. Comparable gene fusion systems, based on transposons, exist for bacteria (Casadaban and Cohen, 1979; Kroos and Kaiser, 1984; Stachel et al., 1985), while strategies for generating in vivo gene fusions in mammalian cells are based on retroviruses (Brenner et al., 1989; Friedrich and Soriano, 1991) or microinjected DNA (Friedrich and Soriano, 1991; Gossler et al., 1989).

\section{F.1. Assessment of T-DNA as an element to manipulate genes in vivo}

Stable genetic transformation of eukaryotic cells usually depends on the integration of foreign DNA into their genomes (Palmiter and Brinster, 1986; Potrykus, 1991; Zambryski, 1988). By all indications, such insertions occur at different chromosomal locations. Consequently, DNA introduced by methods of direct gene transfer or Agrobacterium-mediated transformation may be used to manipulate genes in vivo. Several reports have appeared in which DNA introduced 
by direct gene transfer into mammalian cells was exploited to generate insertional mutations (Jaenisch, 1988; Palmiter and Brinster, 1986; Xiang et al., 1990), generate in vivo gene fusions (Friedrich and Soriano, 1991; Gossler et al., 1989) or enhancer fusions (defined in section 1.F.2.; Allen et al., 1988; Friedrich and Soriano, 1991; Hamada, 1986a; Hamada, 1986b). Corresponding transformation methods have yet to be successfully used to manipulate plant genes in vivo. However, as the efficiency and precision of T-DNA transformation are much higher than those of direct gene transfer (reviewed in sections 1.E.3. and 1.E.4.), it would appear to represent the better genetic element :or in vivo gene manipulation. Minimal rearrangements in the transferred DNA and the flanking chromosomal DNA are particularly important if in vivo gene fusions are to be generated. Deletions or rearrangements in the transferred reporter gene would significantly reduce the chances of obtaining active gene fusions, while rearrangements in the flanking DNA could potentially alter the regulatory properties of cis-acting elements contained therein. Due to the modular nature of promoters, the importance of interactions between cis-acting elements, and the requirement for exact spacing between promoter elements (reviewed in 1.C.), even the effects of minor rearrangements at the site of integration should not be underestimated.

Transposons are well-defined DNA segments which can move from one location to another in an organism's genome (Federoff, 1984). Although transposons are a structurally diverse group of genetic elements (for reviews of plant transposon structure, see Gierl et al., 1989; Sommer et al., 1988; Weil and Wessler, 1990), they all encode functions required for their transposition (transposases) which recognize specific sequences at the ends of the transposons (Federoff, 1984; Federoff, 1989; Gierl et al., 1989). Full-length (autonomous) elements, as well as shorter, deleted (non-autonomous) elements are thought to be ubiquitous components of all genomes (Federoff, 1989). However, specific transposons or 
families of related transposons have been characterized in only a few plant species, including maize (Federoff, 1984; Gierl et al., 1989), Antirhinum majus (snapdragon; Sommer et al., 1988), tobacco (Grandbastien et al., 1989; Poutealt et al., 1991), Arabidopsis (Konieczny et al., 1991), parsley (Herrmann et al., 1988), Glycin' max (soybean; Rhodes and Vodkin, 1988) and Pisum sativum (pea; Bhattacharyya et al., 1990). Furthermore, applications for transposon-based in vivo gene manipulations have only been possible in maize and Antimhinum (e.g. Balcells et al., 1991: Carjenter and Coen, 1990; Chandlee, 1991; Cone et al., 1988; Weil and Wessler, 1990). Consequently, host-range limitations must be a practica! consideration when developing strategies based on these genetic elements. It is noteworthy that neither maize nor Antimhinum are efficiently transformed by existing Agrobucteriummediated methodology. If one wished to generate in vivo gene fusions, such manipulations would be required to introduce transposon derivatives containing promoterless reporter genes into the plant genome. A potential solution to the host-range and transformation problems may be achieved by introducing transposons from maize or Antirrhinum into heterologous hosts such as Arabidopsis, carrot, Petunia, tobacco, tomato (for recent reviews, see Balcells et al., 1991; Haring et al., 1991a), and rice (Murai et al., 1991). Available data demonstrate that plant transposons continue to be active in these species, and although some of their transposition properties are maintained, others are not (Haring et al., 1991b; HehI and Baker, 1990; Jones et al., 1990; Yoder, 1990). A better understanding of transposon behaviour in heterologous hosts will be required in orde. to assess the feasibility of exploiting such systems for generating insertional mutations or gene fusions in planta.

Unlike transposons, the T-DNA does not encode any functions required for its transfer and integration into the plant genome. This basic difference has several implications with respect to genetic manipulations, and more specifically to the 
development of in vivo gene fusion systems. First, any sequences may be introduced between the T-DNA border repeats and transferred to plant cells. This is not the case for transposons, where integrity of internal sequences is important for transposition. Use of a defective element, which can be trans-activated by another element, may circumvent this problem, and provides a system in which the frequency of transposition can be better controlled (Balcells et al., 1991; Haring et al., 1991b). Second, the T-DNA is not a mobile genetic element. Once integrated at a chromosimal location, it remains there. Thus, the copy number of the T-DNA in a genome is usually small. In contrast, numerous copies of different families of transposable elements have been identified in maize and Antirhinum (Coen et al., 1990; Cone et al., 1988). Similarly, once transferred to heterologous hosts, these elements may rapidly proliferate, going from 1 to more than 15 copies per genome in 2 generations (Yoder, 1990). High copy number of a transposon complicates identification of the specific element responsible for the observed phenotype, be it a mutation or gene fusion (examples of strategies which have been developed to tag and isolate elements responsible for insertional mutations in maize and Antirhinum can be found in Coen et al., 1990; Cone et al., 1988; McLaughlin and Walbot, 1987; Schmidt et al., 1987; Theres et al., 1987). Controlled transposition using a 2 component system such as the one described above should also limit the copy number of a transposon (Balcells et al., 1991). In some circumstances, mobility of transposons is advantageous. For example, excision of transposons inserted into genes create unstable mutations, a phenotype which is often used as an indication that a particular mutation is in fact transpos'sn-induced (Carpenter and Coen, 1990; Dïring and Starlinger, 1986; Federoff, 1984). Excision of a transposon may also be exploited to identify which specific element caused an insertional mutation, and eventually to isolate the wild-type gene which has been mutated (Coen et al., 1990). Although excision of a transposon per se cannot be seen as advantageous to the 
researcher interested in generating in vivo gene fusions, subsequent integration of an element at new chromosomal locations could significantly reduce the time and effort needed to transform and regenerate plants. Theoretically, once a limited number of plants containing a modified element have been regenerated, these may be propagated to allow element transposition and subsequently assayed for in vivo gene fusions. This is not the case with gene fusions mediated by Agrobacterium integration, where every plant analyzed represents an independent transformant. Use of a transposon-based strategy would consequently also reduce the probability of creating tissue culture-induced phenotypic changes (somaclonal variation). This is of particular importance if T-DNA integration is to be used to generate insertional mutations. It is noteworthy that a non-tissue culture transformation protocol, which reduces the occurrence of somaclonal variations, is available for Arabidopsis (Feldmann and Marks, 1987; Feldmann, 1991).

\section{F.2. Strategies for generating T-DNA-mediated gene fusions}

The precision of T-DNA integration into the plant genome allows one to predict that sequences near the right and left burder repeats will be juxtapositioned to plant chromosomal DNA following insertion. Similarly, analysis of plant gene structure reveals that sequences required for transcriptionally regulating gene expression are localized immediately $S^{\prime}$ to the coding region. Consequently, by incorporating a gene devoid of cis-acting transcriptional and translational expression signals (i.e. promoterless) next to one of the border repeat and with the 5 ' end nearest to the T-DNA extremity, random chromosomal sequences will be placed directly upstrtam to the initiation codon of the coding segment upon T-DNA integration into ihe genome. Insertion of such a T-DNA construct adjacent to, and downstream of endogenous plant promoters leads to the creation of a gene fusion which may result in activation of "promoterless" gene expression. Such gene fusions, 
mediated by T-DNA integration, consist of unknown and thus very likely uncharacterized plant promoters residing at their natural location within the chromosome and the coding segment of a gene, usually a selectable marker or reporter, located on the inserted T-DNA. Expression of T-DNA-mediated gene fusions may be used as a means of selecting for gene fusions and to characterize the regulatory properties of the endogenous plant promoters into which the T-DNA has integrated. Such promoter elements may subsequently be isolated from the chromosome by using the T-DNA as a tag. Alternatively, it is also possible to incorporate a bacterial origin of replication (oriV) and a bacterial selectable marker into the T-DNA and use these to recove: integrated T-DNA and flanking chromosomal sequences thought to contain promoters by plasmid rescue (Kertbundit et al., 1991: Koncz et al., 1989).

Several vectors capable of generating T-DNA-mediated fusions to promoterless genes have been designed. These are listed in Table 1.2 and are described in more detail in the following sections. The types of gene fusions which may be generated using these vectors can be ciassified according to various criteria. First, gene fusions may be generated to selectable markers or reporter genes. Activation of these fusions may subsequently be identified on the basis of resistance to an antibiotic or enzymatic assay, respectively. Second, vectors capable of generating transcriptional, translational or both types of gene fusions exist. Lastly, in a variation of the strategy described above, vectors have been designed which are capable of generating ftisions to endogenous plant enhancer elements (Goldsbrough and Bevan, 1991; Topping et al., 1991). Specific examples of studi;s of selectable promoterless gene fusions, screenable promoterless gene fusions, and enhancer fusions, as well as the advantages/disadvantages of these approaches are considered in the following subsections. 


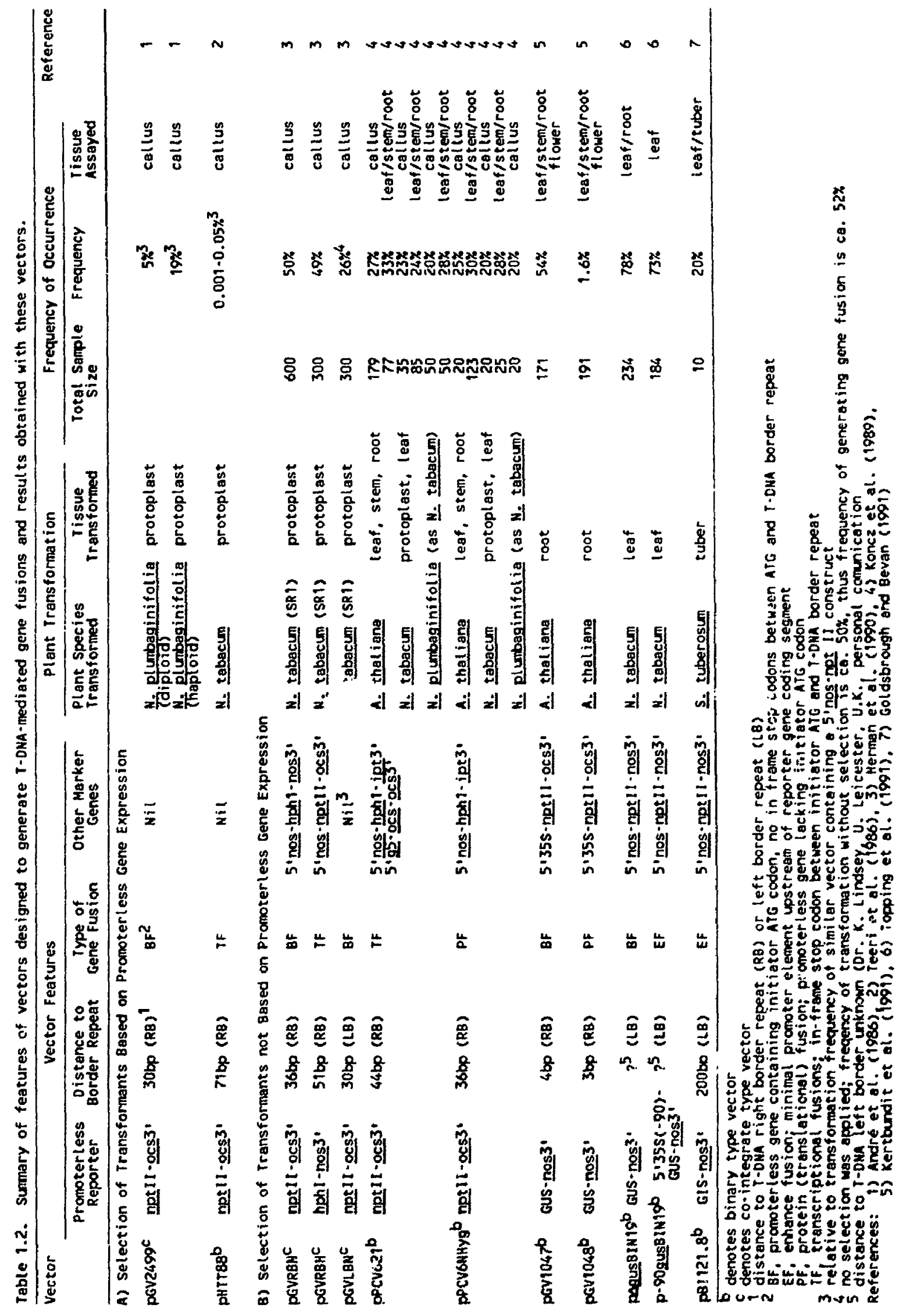




\section{F.2.a. T-DNA-mediated gene fusions to promoterless selectable markers}

The feasibility of generating gene fusions to promoterless genes located at the extremity of the T-DNA was first demonstrated by Andre et al. (1986) and Teeri et al. (1986). In these studies, protoplasts were infected with Agrobacterium strains harbouring vectors containing promoterless $n p t$ II constructs linked to the T-DNA right border repeat. Calli expressing T-DNA-mediated gene fusions were identified by their ability to grow in the presence of kanamycin. Subsequently, NPT II assays were used to show the organ-specificity of the gene fusions in calli and regenerated vegetative tissues. The promoterless npt II construct incorporated in one vector (pGV2499; André et al., 1986) contained an initiation (ATG) codon and was separated from the right border repeat by a stretch of sequences which did not contain translational stop codons. Thus, integration of this T-DNA into a transcription unit may generate either transcriptional or translational fusions, depending on the specific site of insertion. NPT II gel assays of several transformed calli revealed the presence of bands (o-migrating with the native NPT II enzyme as well as bands of slower mobility, suggesting that both types of gene fusions had been isolated. In contrast, the vector designed by Teeri et al. (1986; pHTT88) contained a stop codon in-frame with the npt II coding sequence, thus permitting only the creation of transcriptional gene fusions.

Since both André et al. (1986) and Teeri et al. (1986) selected for the presence of gene fusions, it was impossible to estimate directly the proportion of transformants which expressed T-DNA-mediated gene fusions. However, estimates were obtained by comparing the transformation frequency with promoterless vectors to those observed using similar vectors incorporating chimaeric 5'nos-npt II-ocs 3' genes. The frequency of gene fusions generated using pGV2499 was considerably higher than that with pHTT88 (5\% vs. $0.05-0.001 \%)$. It is noteworthy that in one study (André et al., 1986) several plants regenerated from kanamycin-resistant calli 
possessed morphological abnormalities. Although not reported in the literature, none of the mutations were caused by T-DNA insertion (J.P. Hernalsteens, Vrie Universiteit Brussel, personal communication).

The major advantage of the above approach is that selection for the presence of T-DNA-mediated gene fusions greatly facilitates identification of desired transformants. This becomes especially important when gene fusions are generated at low frequencies, such as those observed by Teeri et al. (1986). However, there are several disadvantages to using $n p t$ II for the study of gene expression (see section 1.D.), thus limiting detailed characterization of the endogenous cis-acting elements next to which the T-DNA has integrated. More importantly, direct selection for in vivo gene fusions limits the scope of regulatory elements which may be uncovered to those expressed in the specific tissues undergoing selection. and induces reärrangements within the T-DNA, thus complicating future genetic analysis of these fusions (Koncz et al., 1989).

Two alternative strategies, both based on selection of gene fusions, have been devised to eliminate some of these problems. First, a chimatric npt II-GUS protein fusion was constructed and used as promoterless reporter to which gene fusions could be generated (Datla et al., 1991). Using this reporter gene, it is possible to select for the presence of gene fusions and also characterize their expression patterns in detail by GUS assay. However, use of this vector does not solve problems associated with direct selection of promoterless gene activity. Theoretically, this should be possible by initially regenerating calli and plants in the absence of selection pressure and subsequently selecting for promoterless gene activation in various tissues of the regenerated plants. Alternatively, transgenic plants may be recovered by use of a separate, constitutively-expressed marker gene prior to selection for the presence of T-DNA-mediated gene fusions. Such vectors were designed by Herman et al. (1990). Calli were either regenerated in the 
absence of antibiotics, and subsequently transferred to medium containing kanamycin to identify cells expressing a "promoterless" npt II-ocs3' construct or were selected on the basis of resistance to hygromycin using a 5'nos-hph 1-nos3' marker, and then transferred to kanamycin-containing media to select for promoterless $\boldsymbol{n p t}$ II gene activation. In addition, a vector containing a chimaeric 5'nos-npt II-ocs3' marker and a promoterless hph 1-nos3' gene was also tested. It is noteworthy that the vector which was used in absence of selection (pGVLBN) contains the promoterless npt II gene linked to the T-DNA left border, while in the other 2 vectors, the promoterless markers are at the right border repeat. Using this system, it is possible to determine how many of the transformed calli express the promoterless marker, and thus contain T-DNA insertions into transcriptionally active DNA. Regardless of the vector tested, it was estimated that approximately $50 \%$ of wansformants expressed promoterless genes when linked to T-DNA border repeats (Herman et al., 1990; also see Table 1.2). In contrast, promoterless marker genes located in the central portion of the T-DNA were activated in only $0.2 \%$ of the calli. As argued by Herman et al. (1990) and others (Koncz et al., 1989) activation of a promoterless gene probably underestimates the number of T-DNA insertions within transcriptional units. This is because the assay systems developed to detect the T-DNA-mediated gene fusions require that the promoterless gene be translated into a functional enzyme. Consequently. T-DNA insertions in which the promoterless gene has integrated into transcriptional units, but in the opposite direction of transcription (see Koncz et al., 1990 for an example of this), or in a different reading frame relative to that of the endogenous coding region, will not be detected. In light of these possibilities, Herman et al. (1990) conclude that at least $70 \%$ to $100 \%$ of the calli they tested contained at least one T-DNA insertion into Iranscriptionally active regions of the genome. Although the approach of Herman et al. (1990) was better-suited for detecting gene fusions expressed in cell types not 
present during the tissue culture phase of development, the only tissues analyzed were calli. It is noteworthy that the primary goal of these authors was to characterize factors involved in T-DNA deletions, and not the identification of novel plant promoters per se.

\section{F.2.b. T-DNA-mediated gene fusions to promoterless reporter genes}

Identification of T-DNA-mediated gene fusions on the basis of in vitro enzyme assays rather than phenotypic selection of promoterless gene activation was first reported by Koncz et al. (1989). Using a system similar to the one described by Herman et al. (1990), these authors used : shimaeric selectable marker (5'nos - $h$ ph 1-ipt3') for recovery of transgenic calli and plants, and screened various vegetative organs from these plants for NPT II activity by gel assay. Overall frequencies of 'IDNA-mediated gene fusions obtained were slightly lower, hut comparable to those obtained by Herman et al. (1990), and ranged from $20 \%$ to $30 \%$. The frequency of gene fusion obtained was similar regardless of whether the plants were transformed with vectors capable of transcription fusions (by incorporating in-frame stop codons between the npt II coding sequence and the right border) or translational fusions (by deleting the initiation codon from the promoterless npt II gene). Although they did not present data, Koncz et al. (1989) reported that approximately $50 \%$ of the flower samples they assayed also contained NPT II activity. Unlike previous studies, these authors transformed 3 different plant species with the same promocerless constructs, thus permitting more direct comparison of the frequencies of promoterless gene activation between species. Surprisingly, the probability of generating a T-DNAmediated gene fusion in tobacco and Arabidopsis were the same (23.5\% vs. $28.5 \%$ for transcriptional fusions; $24.4 \%$ vs. $30 \%$ for translational fusions). Considering the difference in total genomic DNA content, in repetitive DNA fraction, and in relative amount of DNA which is transcribed (see section 1.A.) between these plants, Koncz 
et al. (1989) proposed that their results indicated that the T-DNA integrated preferentially into transcribed regions of the plant genome. The high overall frequency of generating T-DNA-mediated gene fusions also supports this hypothesis.

Although direct selection for T-DNA-mediated gene fusions requires that the promoterless gene used encode a selectable phe irotype, this is not the case when a separate marker gene is used to recover transformants. Such strategy thus allows use of reporter genes such as GUS and lux, which do not confer selective growth advantages on cells but instead can be assayed with much greater sensitivity and versatility than NPT II. Recently, two studies exploiting GUS as a promoterless reporter have appeared (Kertbundit et al., 1991; Topping et al., 1991). A system based on promoterless lux genes has also been developed (A. Szalay, University of Alberta, personal communication). Individuals expressing promoterless GUS reporters have been identified using both histological staining (Kertbundit et al., 1991) and quantitative fluorogenic assays (Topping et al., 1991). However, detailed analysis of gene fusion expression has only been achieved by histological means (Kertbundit et al., 1991; Topping et al., 1991). Topping et al. (1991) did, nevertheless, find evidence for more than a 20 fold difference in GUS activity amongst independent transformants during their preliminary screen. Several examples of organ- and tissue-specific T-DNA-mediated gene fusions were reported by Kertbundit et al. (1991). As Topping et al. (1991) only screened leaves and roots of their plants for the presence of promoterless GUS activity, the extent of organ- or tissue-specificity of expression cannot be determined.

The relative frequencies of uncovering T-DNA-mediated GUS fusions were also quite high. Using a vector capable of generating both transcriptional and translational gene fusions, Topping et al. (1991) reported that more than $75 \%$ of the plants they screened contained GUS activity. When the frequencies of T-DNA- 
mediated gene fusions detected in the leaf and root were compared, there was a clear bias for T-DNA insertions expressed in the root (22\% vs. $75 \%$ ). Of the fusions expressed in the leaf, only $15 \%$ did not contain GUS activity in the root as well (Topping et al., 1991). These authors also demonstrated that their promoterless GUS gene, in the absence of integration, or when oriented so that the translational start codon was not near the border repeats (vector pBl101; Jefferson et al., 1987), is not activated.

Kertbundit et al. (1991) estimated the frequency of T-DNA-mediated GUS fusions using a vector capable of both transcriptional and translational fusions (pGV1047) and another construct capable of generating only translational fusions (pGV1048). Unlike Koncz et al. (1989), who reported similar frequencies of transcriptional and translational fusions to npt II in vivo, Kertbundit et al. (1991) observed a large difference in the proportion of transformants expressing these 2 types of fusions ( $54 \%$ transcriptional fusions vs. $1.6 \%$ translational fusions). Such results suggest that the majority of the gene fusions generated using pGV /i447 were transcriptional fusions (J.P. Hernalsteens, Vrie Universiteit Brussel, personal communication). The reasons for the apparent discrepancies between the results of Kertbundit et al. (1991) and Koncz et al. (1989) are unknown (Kertbundit et al., 1991)

\section{F.2.c. T-DNA-mediated enhancer fusions}

Vectors capable of generating enhancer fusions incorporate, at the extremity of the T-DNA, the coding region of a reporter gene fused to a minimal promoterproper element. As determined by transient assay (where few molecules integrate into the genome) such a chimaeric gene, by itself, is expressed at low levels in plant cells (Topping et al., 1991). However, following stable transformation by Agrobacterium-mediated gene transfer, transcription of the construct may be 
activated by nearby enhancer elements (Goldsbrough and Bevan, 1991; Topping et al., 1991). Such an approach is similar to those used to detect P-transposon or naked DNA integrations next to enhancers in Drosophila (for review, see Bellen et al., 1990) and mammalian cells (Allen et al., 1988; Friedrich and Soriano, 1991; Gossler et al., 1989; Hamada, 1986a; Hamada, 1986b), respectively.

As enhancers may potentiate gene transcription from a distance, the spatial requirements of enhancer fusions should be less stringent than those using promoterless genes, possibly resulting in higher frequencies of gene fusions. Overall, results from the different studies carried out in animal systems appear to support this hypothesis. In the one case where both types of gene fusions were generated in mammalian cells (Gossler et al., 1989) the frequency of obtaining enhancer fusions was higher than that of generating promoter fusions (6/60 vs. $10 / 6(0)$; note that only about $70 \%$ of putative transformants contained foreign DNA). However, similar results were not observed with T-DNA-mediated enhancer or promoter fusions, as the frequencies of gene fusions generated by either approach were comparable (73\% vs. $78 \%$; Topping et al., 1991). On average, enhancer fusions were, nevertheless, expressed at significantly higher levels than promoterless gene fusions (Topping et al., 1991). It is rioteworthy that the reporter gene used to generate gene fusions by Topping et al. (1991) incorporated a translational initiation codon, while that of Gossler et al. (1989) did not.

The same properties of enhancers which make enhancer fusions attractive may also be a drawback to the system. First, as these cis-acting elements act at a distance, it may be more difficult to isolate enhancers by using the iransformed DNA as a tag or by plasmid rescue. Second, the presence of several enhancers in a given location implies that expression of the reporter gene may reflect the influences from more than one enhancer. Finally, promoter-proper elements are not all equivalent and are sometimes not interchangeable (Castresana et al., 1988; 
for an example from a mammalian system, see Wefald et al., 199(0). Specific combinations of endogenous enhancers with the particular promoter-proper element fused to the reporter gene may potentially result in altered expression patterns. Analysis of P-element-mediated enhancer fusions in Dressophila suggests that none of the above possibilities are significant problems in this system (Bellen et al., 1990). However, these questions have yet to be addressed for T-DNA . zediated enhancer fusions. It may thus be noteworthy that none of the enhancer fusions characterized by Topping et al. (1991) appeared to contain additional sequences upstream of the GUS gene, as determined by Northern blot analysis. These results suggest that in the cases studied to date, the T-DNA had not integrated within a transcriptional unit.

\section{F.3. Molecular cloning and functional testing of T-DNA-mediated gene fusions}

As discussed in previous sections, it is possible, either by T-DNA tagging or plasmid rescue to recover integrated T-DNA sequences and the chromosomal sequences which flank them. Although several T-DNA-mediated gene fusions have now been generated, only 3 have been cloned (Kertbundit et al., 1991; Koncz et al., 1989). In all cases, cloned segments of chromosomal DNA adjacent to the T-DNA were found to contain all the cis-acting elements required for regulated expression of the T-DNA-mediated gene fusions.

Six target sites of integration which resulted in T-DNA-mediated gene fusions have also been cloned (Kertbundit et al., 1991; Mayerhofer et al., 1991). For one integration (Kertbundit et al., 1991) data is available only for sequences flanking the right border repeats. Results obtained by Mayerhofer et al. (1991) have already been discussed in a previous section (1.E.3.e.). Of the 7 insertions they studied, 3 corresponded to transcriptional fusions to pPCV621 (Koncz et al., 1989; see Table 1.2), 2 were translational fusions to pPCV6NFHyg (Koncz et al., 1989; see 
Table 1.2), while the other 2 did not express gene fusions. However, one of the last 2 T-DNA was inserted within a gene and induced a mutant phenotype (Koncz et al., 1990). In none of the above examples was the expression pattern of the wild-type locus compared with that of the T-DNA-mediated gene fusion.

\section{I.G. Rationale of the Present Study}

Models of T-DNA integration have been formulated which propose that the process is mediated by illegitimate recombination between some, as yet uncharacterized double-stranded or singled-stranded intermediate, and nicks or breaks in the chromosomal DNA. However, the distribution or location of such integration sites remain largely unknown. Limited data from in situ hybridization of metaphase chromosomes and physical mapping of the T-DNA indicate that integration is random at this level. Similarly, sequence analysis of short stretches of plant DNA adjacent to integrated T-DNA also suggests that there is no specificity for T-DNA integration. A more defined knowledge of chromosomal regions of TDNA integration would complement the large amount of information available on the structure and organization of integrated T-DNA and thus may help consolidate models of T-DNA integration. An alternative method of characterizing loci of TDNA integration which isn't based on physical analysis may provide new insights on the integration process.

Although predominantly designed to isolate new classes of cis-acting regulatory signals (Kertbundit et al., 1991; Teeri et aı., 1986; Topping et al., 1991), to ascertain the feasibility of inducing insertional mutations in plant genes by $T$ DNA integration (André et al., 1986; Koncz et al., 1989) or to study the process of T-DNA deletion (Herman et al., 1990), T-DNA-mediated gene fusions should also provide a means of characterizing the chromosomal sites into which T-DNA 
integrate. This strategy would involve transforming plant cells with specially designed vectors containing a promoterless reporter gene linked to the end of the TDNA and analyzing the resulting transgenic plants for activation of promoterless gene expression. The frequency at which T-DNA integrate into transcriptionally active DNA, as well as the specific spatial and temporal expression patterns of individual gene fusions could be used to categorize insertion loci. Given the technical simplicity and the high efficiency of Agrohacterium-mediated transformation protocols, large numbers of chromosomal integration regions may be rapidly characterized in this way. This is in contrast to analysis of target sites which require molecular cloning of chromosomal sequences flanking the T-DNA and subsequent isolation and analysis of the wild-type locus. However, use of the TDNA as a molecular tag may also be used for molecular characterization of specific in vivo gene fusions.

Analysis of T-DNA-mediated gene fusions, regardless of the specificity of their expression, is best achieved by uncoupling selection of transformants and activation of promoterless gene expression. For optimal versatility and sensitivity, GUS appears to be the best suited reporter gene presently available. Afthough TDNA-mediated gene fusions may be generated to promoterless genes linked to either border repeats, transfer is more precise at the right border, and consequently, fewer rearrangements or deletions are to be expected by incorporating a promoterless GUS gene at this location. Finally, plants transformed with pBIN19 vectors may contain several copies of the T-DNA, often found in tandem repeats. As multiple copies of T-DNA can be deleterious to gene expression and complicate molecular cloning of specific T-DNA and flanking chromosomal segments, a vector capable of inserting predominantly as single, intact copies is desirable. Vectors Jesigned by Koncz and Schell (1986) appear to be best suited for this purpose. Agrobacterium has now been used to genetically transform numerous plant 
species. However, highly efficient protocols exist for only a limited number of species. One of these is tobacco. The additional advantage of working with this species is that overall patterns of gene expression have been intensely studied throughout the life cycle of the plant. This will allow more meaningful comparisons to be made hetween the frequency of gene fusions obtained and the specific patterns of expression uncovered to those previously detected by methods of RNA/DNA hybridization. 


\section{CHAPTER 2 -MATERIALS AND METHODS}

\section{A. Bacterial Strains and Plasmids}

Bacterial strains used in this thesis are listed in Table 2.1. Plasmids used are listed in Table 2.2.

\section{A.1. Growth and storage conditions}

Unless otherwise noted, all Escherichia coli and Agrobacterium tumefucien. were grown in Luria Broth (LB; $10 \mathrm{~g} / 1$ Baciotryptone, $5 \mathrm{~g} / \mathrm{l}$ yeast extract, $5 \mathrm{~g} / \mathrm{l}$ $\mathrm{NaCl}$ ). Media were sterilized by autoclaving at $121^{\circ} \mathrm{C}$ for $17 \mathrm{~min}$. When desired, media were solidified by addition of $1.5 \%$ Bactoagar prior to sterilization. E. coli strains were grown at $37^{\circ} \mathrm{C}$, while $A$. tumefaciens strains were grown at $28-29^{\circ} \mathrm{C}$. Broth cultures were grown with moderate agitation (ca. $175 \mathrm{rpm}$ ). Antibiotics were added to the culture media following sterilization at concentrations indicated in Table 2.3. Unless otherwise stated, freshly prepared antibiotic solutions, dissolved in sterile, distilled water were used. Rifampicin was dissolved in meth nol. For agar-solidified media, antibiotics were added following sterilization, once the solution had cooled to $55^{\circ} \mathrm{C}$. Unless otherwise stated, antibiotics were not added to broth cultures of bacterial strains harbouring high copy-number plasmids.

Bacterial strains to ' $\mathfrak{x}$ ' tored were grown overnight in liquid media containing appropriate antibiotics, pelleted, and resuspended in $5 \mathrm{mM} \mathrm{MgSO}_{4}$ containing $40 \%(\mathrm{v} / \mathrm{v})$ glycerol. Cultures in glycerol were incubated overnight at $4^{\circ} \mathrm{C}$ prior to transfer to $-20^{\circ} \mathrm{C}$ for frequent use, or to $-80^{\circ} \mathrm{C}$ for long term storage. 


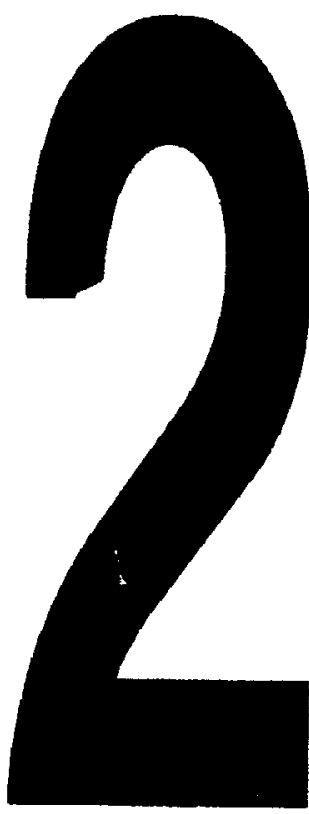

PM-1 33/2"X4" PHOTOGRAPHIC MICROCOPY TARGET NBS 1010a ANSI/ISO \#2 EOUIVALENT

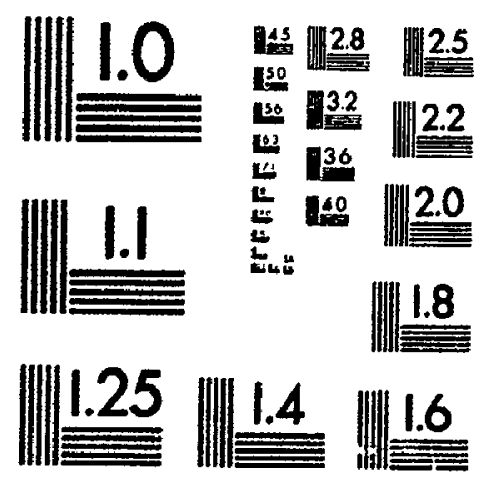

\section{PRECISIONSM RESOLUT!ON TARGETS}

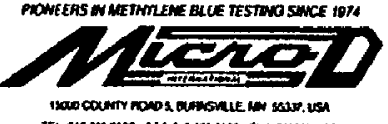

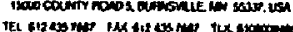


Table 2.1 List of bacterial strains used in this thesis.

$\begin{array}{lll}\text { Bacterial Genotype/phenotype Reference/Source } & \end{array}$

Escherichia coli $\mathrm{K} 12$

C600Rif thi-1 thr-1 leuB6 lacyl tonA21 SUpE44 $\lambda^{\circ}$ Rif'

CT2 thr leu thi lacY $\Delta$ trpE5 supE44 $\underline{\operatorname{ton} A 2} \lambda \underline{\operatorname{trf} A^{+}}$

DH5 $\alpha$ endA1 hsdR17 $\left(\overline{r_{k}}, \overline{m_{k}}\right)$ supE44 thi-1 $\lambda$ recal gyra96 rela1 $\phi 80 \mathrm{dl}$ ac Z $\triangle M 15$

LE392

hsdE514 $\left(\bar{r}_{k}, \overline{m_{k}}\right)$ supE44 supF58 lacYl or $\triangle($ laclZY $) 6$ galK2 galT22 metB1 trpR55 $\lambda$

WA802 lacY1 or $\Delta(\underline{1 a c}) 6$ supE44 galK2

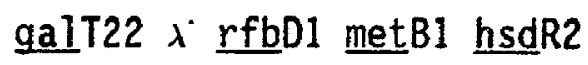
McrA' McrB'

Agrobacterium tumefaciens

GV3101 C58C1 Rif' lab strain; 6600 is Appleyard (1954)

Thomas et a1. (1981)

BRL (Burlington, Ont)

Promega (Madison, WI)

Raleigh et al. (1988)
Van Larebeke et al. (1974) 
Table 2.2. List of plasmids used in this thesis.

\begin{tabular}{|c|c|c|c|c|}
\hline Plasmids & $\begin{array}{c}\text { Bacteriat } \\
\text { markers }\end{array}$ & $\begin{array}{l}\text { Plant } \\
\text { markers }\end{array}$ & Relevant features & Reference/Source \\
\hline PBI 101 & $\mathrm{~km}^{r}$ & $\mathrm{Km}^{\mathrm{r}}$, GUS & $\begin{array}{l}\text { promoterless GUS-nos3: cassette } \\
\text { pBIN19 derivative }\end{array}$ & $\begin{array}{l}\text { Jefferson et al. (1987) } \\
\text { Clontech }\end{array}$ \\
\hline p81121 & $\mathrm{Km}^{\mathrm{r}}$ & $K m^{r}$, GUS & $\begin{array}{l}\text { 5'CaMV-35s-GUS-nos3' gene } \\
\text { pBIN19 derivative }\end{array}$ & $\begin{array}{l}\text { Jefferson et al. (1987) } \\
\text { Clontech }\end{array}$ \\
\hline pBIN19 & $\mathrm{Km}^{\mathrm{r}}$ & $\mathrm{Km}^{\mathrm{r}}$ & $\begin{array}{l}\text { RK2 replicon } \\
\text { binary T-ONA vector }\end{array}$ & Bevan (1984) \\
\hline PBRK4013 & $\mathrm{Cb}^{r}$ & & $\begin{array}{l}\text { Incp } \\
\text { conjugative helper plasmid }\end{array}$ & Hanel (1987) \\
\hline PGEM4Z & $\mathrm{Cb}^{r}$ & & bacteriophage Sp6/T7 promoters & Promega \\
\hline PGV928 & $C b^{r}, S m / S p^{r}$ & $\mathrm{Km}^{r}$ & $\begin{array}{l}\text { pBR322 replicon } \\
\text { T-DNA co-integrate vector }\end{array}$ & Andre et al. (1986) \\
\hline pGV928K & $\mathrm{Cb}^{r}, \mathrm{Sm} / \mathrm{Sp}^{r}, \mathrm{Km}^{r}$ & $\mathrm{Km}^{r}$ & nptIl gene of TaC4-KIXX in pGV928 & this study \\
\hline PNP90 & $\mathrm{Gm}^{\mathrm{r}}$ & & $\begin{array}{l}\text { T-DNA-less pT iC58 } \\
\text { binary helper plasmid }\end{array}$ & Koncz and Schel( 1986$)$ \\
\hline PWP90RK & $\mathrm{Km}, \mathrm{Gm}{ }^{r}$ & & $\begin{array}{l}\text { pMP90 with } \frac{\text { IncP }}{\text { binary helper plasmid }} \text { tratrf } \\
\text { plas }\end{array}$ & Koncz and Schell (1986) \\
\hline pnos-GUS & $\mathrm{Km}^{\mathrm{r}}$ & $\mathrm{Km}^{\mathrm{r}}$, Gus & $\begin{array}{l}\text { 5'nos-Gus-nos3' gene } \\
\text { pBI101 derivative }\end{array}$ & J. Hattori \\
\hline PPCV001 & $\mathrm{Cb}^{\mathrm{r}}$ & $\mathrm{Km}^{\mathrm{r}}$ & $\begin{array}{l}\text { PBR322/nini-RK2 replicon, } \\
\text { binary } T \text {-DNA vector }\end{array}$ & Koncz and Schell (1986) \\
\hline PPRF 101 & $\mathrm{Cb}^{r}$ & & $\begin{array}{l}\text { GUS-nos3: cassette from pBI } 101 \\
\text { in pUC19 }\end{array}$ & this study \\
\hline PPRF 102 & $\mathrm{cb}^{r}$ & & $\begin{array}{l}\text { mini-RK2 cassette from pPCV001 } \\
\text { in puC1318 }\end{array}$ & this study \\
\hline PPRF107 & $\mathrm{Cb}^{r}, \mathrm{Sm} / \mathrm{Sp} \mathrm{p}^{r}$ & & $\begin{array}{l}\text { aph1 gene-T-DNA right border } \\
\text { from pGV928 in puc19 }\end{array}$ & this study \\
\hline PPRF108 & $\mathrm{Cb}^{r}, \mathrm{Sm} / \mathrm{Sp}^{r}$ & & $\begin{array}{l}\operatorname{mini}-R K 2 \text { cassette of PPRF } 102 \\
\text { in PPRF } 107\end{array}$ & this study \\
\hline PPRF113 & $\mathrm{Cb}^{r}, \mathrm{Sm} / \mathrm{Sp} \mathrm{p}^{r}, \mathrm{Km}$ & $\mathrm{Km}^{r}$ & $\begin{array}{l}\text { aph1 gene-T-DNA right border } \\
\text { mini-RK2 cassette of pPRF } 108 \\
\text { in pGV928 }\end{array}$ & this study \\
\hline PPRF120 & $\mathrm{Cb}^{r}, \mathrm{Sm} / \mathrm{Sp} \mathrm{s}^{r}$ & $\mathrm{~K} \mathrm{n}^{r}$, gus & $\begin{array}{l}\text { promoterless GUS-nos3' cassette } \\
\text { linked to T-DNA right border } \\
\text { mini-RK2 repl icon } \\
\text { binary T-DNA vector }\end{array}$ & this study \\
\hline PRK2013 & $\mathrm{Km}^{r}$ & & $\begin{array}{l}\text { IncP } \\
\text { conjugative helper plasmid }\end{array}$ & $\begin{array}{l}\text { Figurski and Helinski } \\
\text { (1979) }\end{array}$ \\
\hline PRK2073 & $\mathrm{Sp}^{r}$ & & $\begin{array}{l}\text { Incp } \\
\text { conjugative helper plasmid }\end{array}$ & Leong et al. (1982) \\
\hline pr218-1 & $\mathrm{Cb}^{r}$ & & $\begin{array}{l}\text { GUS gene and } 2.5 \mathrm{~kb} \text { flanking } \\
\text { chromosomal DNA from plant T218 } \\
\text { inserted in ECO R1 of puct9 }\end{array}$ & this study \\
\hline pr:18-2 & $\mathrm{Cb}^{r}$ & & as pT218-1, but other orientation & this study \\
\hline
\end{tabular}




\begin{tabular}{|c|c|c|}
\hline pr218-3 & $\mathrm{Cb}^{r}$ & \\
\hline pт218-5 & $\mathrm{Cb}^{r}$ & \\
\hline pr218-6 & $\mathrm{Cb}^{\mathrm{r}}$ & \\
\hline pr218-7 & $\mathrm{Cb}^{r}$ & \\
\hline pr 218-8 & $\mathrm{Cb}^{r}$ & \\
\hline pr218-C1-i & Krnt & $\mathrm{Km}^{\mathrm{r}}$, GUS \\
\hline pr218-c4-2 & $\mathrm{Km}^{r}$ & $\mathrm{Km}^{r}$, GUS \\
\hline pr218-c5-3 & $\mathrm{K} \mathbf{m}^{r}$ & $\mathrm{~km}^{r}$, GUS \\
\hline pт218-c6-2 & $\mathrm{Km}^{r}$ & $\mathrm{Km}^{r}$, GUS \\
\hline puc19 & $\mathrm{Cb}^{r}$ & \\
\hline puc179 & $\mathrm{Cb}^{r}$ & \\
\hline puc1318 & $\mathrm{Cb}^{r}$ & \\
\hline
\end{tabular}

360 bp Xba 1/Sal 1 fragment of pr218-2 in puct19

contains tobacco chromosomal DNA

500 bp Xba 1 fragment of pr218-1 this study in pucts

600 bp Xba 1 fragment of pr218-1 this study in pucts

$1 \mathrm{~kb}$ xbs 1 fragment of pr218- 1 this study in pucis

800 bp Xba 1 fragment of pr218-1 this study in PGEM4Z

GUS gene plus 500 bp upstream

plant chromosomal ONA from

plant $T 218$ in Hind 111/Eco R1

of PBIN19, binary vector

GUS gene plus $2.5 \mathrm{~kb}$ upstream

plant chromosomal DNA from

plant $T 218$ in ECO R1 of pBIN19

binary vector

GUS gene plus 360 bp upstrean plant chronosomat DNA from plant $T 218$ in Xba 1/Eco $R 1$ of pBIN19, binary vector

cus gene plus $1 \mathrm{~kb}$ upstream plant chromosomal DNA from plant $T 218$ in Xba 1/Eco R1 of pBtw19, binary vector

high copy number cloning vector

puc19 with $M 13$ replicon

Norrander et at. (1983)

Vieira and Messing (1987)

Káy and McPherson (1987) 
Table 2.3. Concentration of antibiotics used with E. coli and Agrobacterium tumefaciens.

\begin{tabular}{|c|c|c|}
\hline \multirow[t]{2}{*}{ Antibiotic } & \multicolumn{2}{|c|}{ Concentration $(\mu \mathrm{g} / \mathrm{m} \mathrm{l})$} \\
\hline & E. coli & A. tumefaciens \\
\hline Carbenicillin & $100-250$ & 150 \\
\hline Gentamycin & 100 & 100 \\
\hline Kanamycin & 50 & 150 \\
\hline Rifampicin & -- & $100-200$ \\
\hline Spectinomycin & 20 & - \\
\hline
\end{tabular}




\section{B. Bacterial Conjugation}

Bacterial conjugation was used for three purposes: (1) to test whether various intermediates in plasmid construction were transfer proficient $\left(\mathrm{Tra}^{+}\right),(2)$ to mobilize binary vectors from $E$. coli to $A$. tumefaciens, and (3) to assess the integrity of plasmid pPRF120 following transfer to $A$. tumefaciens.

\section{B.1. Conjugation between E. coli strains}

Ten $\mu \mathrm{l}$ of an overnight culture of donor cells, $10 \mu \mathrm{l}$ of recipient cells, and $10 \mu \mathrm{l}$ of cells containing a helper plasmid were spotted on a quadrant of an LB plate. The helper plasmid pRK2013 (Figurski and Helinski, 1979) was used when transconjugants were selected on medium containing carbenicillin and pBRK4013 (Hamel, 1987) was used when the selection medium contained kanamycin. Ten $10 \mu \mathrm{l}$ of donor, recipient and helper cells were separately spotted onto a quadrant of an LB plate as controls, as were cells of the donor and recipient (without helper), cells of the donor and helper (without recipient) and cells of the helper and recipient (without donor). After incubation at $37^{\circ} \mathrm{C}$ for $2-3 \mathrm{hr}$, cells from the mating mixture and the controls were streaked onto media selective for the recipient strain containing the plasmid, and counterselecting for the donor, helper, and recipient cells not inheriting the plasmid. The presence of colonies on these plates after $24 \mathrm{hr}$ incubation at $37^{\circ} \mathrm{C}$ was interpreted as a positive result.

\section{B.2.. Transfer of binary plasmids from E. coli to A. tumefaciens GV3101}

Ten ml of a late iog-phase culture of Agrobacterium were centrifuged for 10 min in a desk-top centrifuge, washed in saline $(0.9 \% \mathrm{w} / \mathrm{v} \mathrm{NaCl})$, centrifuged again, and resuspended in $1 \mathrm{ml}$ of saline. One hundred $\mu$ of concentrated Agrobacterium (recipient) cells were mixed with $100 \mu$ l of an overnight culture of donor cells and $100 \mu$ of an overnight culture of helper strain on a sterile cellulose acetate filter 
placed on an LB plate. For transfer of pPRF120, pRK2073 (Leong et al., 1982) was used as helper, while for transfer of pBIN19 derivatives, pBRK4013 (Hamel, 1987) was used. Cells were incubated at $28^{\circ} \mathrm{C}$ for $24-36 \mathrm{hr}$, at which time the filters were removed from the plates and transferred to a disposable $15 \mathrm{ml}$ Falcon tube containing $1 \mathrm{ml}$ of saline. Cells were resuspended by vortexing. The mixture was diluted (usually up to $10^{-5}$ ) and $100 \mu$ l aliquots were plated on appropriate selective media. For pPRF120 transfer to A. tumefaciens GV3101 (pMP90RK) or GV3101CT, transconjugants were selected on DM1 medium $(5 \mathrm{~g} / \mathrm{l}$ cellobiose, $1 \mathrm{~g} / \mathrm{I}$ $\mathrm{NH}_{4} \mathrm{Cl}, 0.3 \mathrm{~g} / \mathrm{I} \mathrm{MgSO} 4.7 \mathrm{H}_{2} \mathrm{O}, 3.0 \mathrm{~g} / 1 \mathrm{~K}_{2} \mathrm{HPO}_{4}, 1.0 \mathrm{~g} / 1 \mathrm{NaH}_{2} \mathrm{PO}_{4}, 100 \mathrm{mg} / 1$ bromothymol blue; Close et al., 1985) supplemented with rifampicin, kanamycin, gentamycin and carbenicillin at concentrations listed in Table 2.3. Agrobacterium GV3101 (pMP90) transconjugants harbouring pBIN19 derivatives were selected on LB medium supplemented with rifampicin, gentamycin, and kanamycin. Individual colonies which grew on these plates were purified by streaking onto selective media. Controls for these mating experiments were essentially the same as described in section 2.B.1., except that $100 \mu$ l of cells were used, and each control treatment was plated on cellulose acetate filter paper. Undiluted and diluted aliquots of the controls were plated onto selective media, and occasionally onto non-selective medium to measure cell viability.

\section{B.3. Transfer of pPRF120 from Agrobacterium to $\underline{E}$ coli}

To assess the integrity of pPRF120 following transfer to Agrobacterium GV3101 (pMP90RK), the plasmid was mobilized to $E$. coli DH5 $\alpha$ and analyzed by restriction digestion. One hundred $\mu l$ of late log phase culture of Agrobacterium harbouring pPRF120 was mixed with $100 \mu$ l of $E$. coli DH5 $\alpha$ on a sterile cellulose acetate filter placed onto LB medium and incubated 24 to $36 \mathrm{hr}$ at $28^{\circ} \mathrm{C}$. Cells were washed from the filter and diluted in saline as described in section 2.B.2., plated on 
LB medium supplemented with carbenicillin and incubated overnight at $37^{\circ} \mathrm{C}$. Resulting $E$. coli transconjugants were purified by streaking onto selective media.

\section{C. Preparation of Competent Cells and Bacterial Transformation}

Competent cells were prepared by one of two methods. The method of Cohen et al. (1972) was used during the early stages of the research (mostly for pPRF120 construction) while methods outlined by Hanahan (1985) were used in the latter part of the research. For both methods, all manipulations were performed at $4^{\circ} \mathrm{C}$ and all solutions were cooled to $4^{\circ} \mathrm{C}$ before use.

\section{C.1. Preparation of competent cells (Cohen et al., 1972)}

Cells were grown to exponential phase, cooled to $4^{\circ} \mathrm{C}$, centrifuged for $5 \mathrm{~min}$ at $10,000 \mathrm{rpm}$, and resuspended in 0.5 volume of $100 \mathrm{mM} \mathrm{MgCl}$. The cells were centrifuged as above, resuspended in 0.5 volume $75 \mathrm{mM} \mathrm{CaCl}_{2}$, and incubated at $4^{\circ} \mathrm{C}$ for $30 \mathrm{~min}$ to several hours. The cells were pelleted by centrifugation and resuspended in 0.1 volume $\mathrm{CaCl}_{2}$. The competent cells were kept at $4^{\circ} \mathrm{C}$ and used for up to one week.

\section{C.2. Preparation of competent cells (Hanahan, 1985)}

Two procedures listed in Hanahan (1985) were used. The first was the "Standard High Efficiency Transformation" (Table 2, Hanahan, 1985) method, and the second was the "Frozen Storage of Competent Cells; Protocol 2" (Table 7, Hanahan, 1985). These protocols were followed exactly as described. Cultures of 4$7 \times 10^{7}$ viable cells (Table 2, step 2) corresponded to an absorption of 0.25 at 550 $\mathrm{nm}$, while those of 6-9 $10^{7}$ viable cells (Table 7, step 3) had an absorption of 0.35 at $550 \mathrm{~nm}$. Frozen competent cells were always flash-frozen in a dry ice/ethanol bath. 
Fresh competent cells were used immediately, while frozen cells were used over a period of several months.

\section{C.3. Transformation of competent cells}

Approximately 10-100 ng of plasmid DNA was transformed into competent cells. This corresponded to roughly $1 / 5$ to $1 / 4$ of the ligation mixture (the procedures used for DNA ligation are outlined in section 2.G.). DNA was added to 100-200 $\mu \mathrm{l}$ of competent cells in a $1.5 \mathrm{ml}$ microfuge tube, or when high levels of transformation were sought, cells were placed in a $15 \mathrm{ml}$ Falcon polypropylene tube (\#2059). The mixture was incubated on ice for 30 to $60 \mathrm{~min}$ and heat-pulsed either at $37^{\circ} \mathrm{C}$ for $5 \mathrm{~min}$, or at $42^{\circ} \mathrm{C}$ for $90 \mathrm{sec}$. The cells were returned on ice for $2 \mathrm{~min}$, and $900 \mu \mathrm{l}$ of $\mathrm{SOC}$ medium $(2 \mathrm{~g} / \mathrm{l} \mathrm{Bactoagar}, 0.5 \mathrm{~g} / 1$ yeast extract, $10 \mathrm{mM} \mathrm{NaCl}, 2.5$ $\mathrm{mM} \mathrm{KCl}, 10 \mathrm{mM} \mathrm{MgCl}_{2}, 10 \mathrm{mM} \mathrm{MgSO} 4,20 \mathrm{mM}$ glucose, prepared according to Hanahan, 1985) was added to the tube. After incubation for 30 to 60 min with moderate aeration $(150 \mathrm{rpm})$ at $37^{\circ} \mathrm{C}, 10$ to $100 \mu \mathrm{l}$ aliquots were plated on selective media and incubated for $24 \mathrm{hr}$ at $37^{\circ} \mathrm{C}$. The following controls were performed: (1) competent cells that had not received transforming DNA, but were otherwise treated in the same manner as above were used as negative control (2) the efficiency of the competent cells was assessed by transforming the cells with a known quantity (1-10 ng) of CsCl-purified plasmid DNA (3) the efficiency of the restriction digests and ligation were assessed by transforming competent cells with DNA which had been treated exactly as the experimental DNA, except that the ligase enzyme had been omitted from the ligation reaction. 


\section{D. DNA Extraction Protocols}

\section{D.1. Rapid extraction of Plasmid DNA}

Two methods of rapid extraction were used. The boiling method of Holmes and Quigley (1981) was used for high copy-number plasmids, while the alkaline lysis method (Birnboim and Doly, 1979) was used to extract wide-host range plasmids from E. coli and Agrobacterium cells.

\section{D.1.a. Holmes and Quigley's boiling method}

One $\mathrm{ml}$ of an overnight culture was centrifuged for $30 \mathrm{sec}$ in a microfuge. The pellet was dislodged by vortexing and resuspended in $200 \mu \mathrm{l}$ of STET buffer (8\% $\mathrm{w} / \mathrm{v}$ sucrose, $5 \% \mathrm{v} / \mathrm{v}$ Triton-X-100, $50 \mathrm{mM}$ Tris- $\mathrm{HCl}, \mathrm{pH} 8.0,50 \mathrm{mM}$ ethylenediaminetetra-acetic acid, disodium salt (EDTA), pH 8.0). Twenty $\mu$ l of a freshly prepared lysozyme solution $(10 \mathrm{mg} / \mathrm{ml})$ was added, and the cells were immediately incubated in a boiling bath of water for 40 to $50 \mathrm{sec}$. After centrifugation at $4^{\circ} \mathrm{C}$ for $30 \mathrm{~min}$, the gelatinous pellet was removed and the DNA was precipitated with an equal volume of cold $\left(-20^{\circ} \mathrm{C}\right)$ isopropanol, The solution was incubated at $-20^{\circ} \mathrm{C}$ for $30 \mathrm{~min}$ and centrifuged for $15 \mathrm{~min}$. The DNA pellet was washed with $300-500 \mu l$ ice-cold $70 \%$ ethanol and dried at $37^{\circ} \mathrm{C}$. The DNA was resuspended in $100 \mu \mathrm{l}$ TE buffer (10 mM Tris- $\mathrm{HCl}$, pH 8.0, 1 mM EDTA, pH 8.0).

\section{D.1.b. Rapid DNA isolation by alkaline lysis}

One $\mathrm{ml}$ of an overnight culture was transferred to a microtube and centrifuged for 30 sec. The cells were resuspended in $100 \mu \mathrm{l}$ of $25 \mathrm{mM}$ Tris-HCl, pH 8.0, $10 \mathrm{mM}$ EDTA, pH 8.0, $50 \mathrm{mM}$ glucose and incubated for $5 \mathrm{~min}$ at room temperature. Two hundred $\mu$ l of freshly-prepared alkaline/SDS solution ( $0.2 \mathrm{M}$ $\mathrm{NaOH}, 1.0 \% \mathrm{w} / \mathrm{v}$ sodium dodecyl sulfate [SDS]) was added, the tubes mixed by inversion, and incubated on ice for $5 \mathrm{~min}$. One hundred and fifty $\mu \mathrm{l}$ of $3 \mathrm{M} \mathrm{K}$-acetate 
was added, the tubes were mixed by inversion and incubated on ice for $5 \mathrm{~min}$. After centrifugation for $15 \mathrm{~min}$ at $4^{\circ} \mathrm{C}$, the supernatant was transferred to a fresh microtube and extracted with $400 \mu$ l of phenol/chloroform-isoamylalcohol (ultrapure phenol, BRL, Burlington, Ontario, saturated in water, containing $0.1 \% \mathrm{w} / \mathrm{v} 8-$ hydroxyquinoline and 0.2\% v/v B-mercaptoethanol; [25:24:1]). The aqueous and organic phases were thoroughly mixed and the contents centrifuged for $10 \mathrm{~min}$ in a microfuge. The aqueous phase was transferred to a fresh microtube containing 1.0 $\mathrm{ml}$ ice-cold $95 \%$ ethanol. After incubation of $6 \mathrm{~min}$ at $-80^{\circ} \mathrm{C}$, the tube was centrifuged for $30 \mathrm{~min}$ at $4^{\circ} \mathrm{C}$. The DNA pellet was washed $2 \mathrm{X}$ in $70 \%$ ice-cold ethanol, once in $95 \%$ ethanol, dried at $37^{\circ} \mathrm{C}$, and redissolved in $20 \mu \mathrm{l} \mathrm{TE}$.

\section{D.2. Large scale plasmid DNA extraction}

\section{D.2.a. Large scale isolation of high-copy number plasmid DNA}

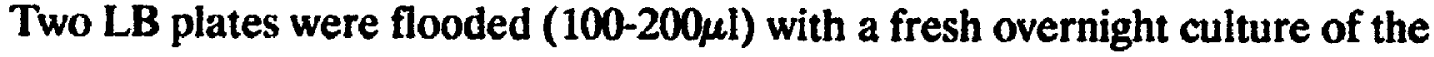
appropriate strain and incubated for 12 to $16 \mathrm{hr}$ at $37^{\circ} \mathrm{C}$. Three $\mathrm{ml}$ of saline was added to each plate and the cells were scraped off with a sterile glass spreader. Alternatively, a $50 \mathrm{ml}$ liquid culture of the appropriate strain was grown overnight in a 250 or $500 \mathrm{ml}$ Erlenmeyer flask. Cells were centrifuged at 10,000 rpm for $5 \mathrm{~min}$ and redissolved in $1 \mathrm{ml}$ of sucrose buffer $(50 \mathrm{mM}$ Tris- $\mathrm{HCl}, \mathrm{pH} 8.0$ containing $25 \%$ w/v sucrose). Three hundred $\mu$ l each of $0.25 \mathrm{M}$ EDTA, $\mathrm{pH} 8.0$, and $4 \mathrm{mg} / \mathrm{ml}$ lysozyme solution (freshly made) were added. The solution was mixed by inversion, $2.5 \mathrm{ml}$ of Triton-X lytic solution ( $50 \mathrm{mM}$ Tris-HCl, pH 8.0, 60 mM EDTA, pH 8.0, $2 \% \mathrm{v} / \mathrm{v}$ Triton-X-100) was added and the solution mixed by gentle inversion. After a 5 min incubation on ice, lysed cells were centrifuged at $15,000 \mathrm{rpm}$ for $45 \mathrm{~min}$ at $4^{\circ} \mathrm{C}$. Five $\mathrm{g} \mathrm{CsCl}$ and $0.8 \mathrm{ml}$ of a $4 \mathrm{mg} / \mathrm{ml}$ ethidium bromide $(\mathrm{EtBr})$ solution were added to $4.2 \mathrm{ml}$ of the cell lysate. The mixture was added to a Beckman Quick-seal ultracentrifuge tube. The remainder of the tube was filled with light paraffin oil and 
the tube was sealed with a Beckman tube heat-sealer. The DNA was banded by centrifugation at $60,000 \mathrm{rpm}$ for $16 \mathrm{hr}$. After centrifugation, the plasmid DNA (present in the lower band) was collected by needle and syringe under U.V. light and extracted with water-saturated $n$-butanol to remove EtBr. The DNA solution was dialysed against $1 \mathrm{mM}$ Tris- $\mathrm{HCl}, \mathrm{pH} 8.0,1 \mathrm{mM} \mathrm{NaCl}, 1 \mathrm{mM}$ EDTA, $\mathrm{pH} 8.0$ at $4^{\circ} \mathrm{C}$ for $2 \mathrm{hr}$ to overnight, and concentrated by ethanol precipitation (section 2.E.). Alternatively, the DNA was precipitated by addition of 2 volumes of sterile distilled water followed by 2 volumes of ice-cold $95 \%$ ethanol. After incubation for at least $30 \mathrm{~min}$ at $-20^{\circ} \mathrm{C}$, the DNA was recovered by centrifugation for $30 \mathrm{~min}$ in a microfuge. The DNA pellet was resuspended in TE buffer and then quantified by U.V. absorption at $260 \mathrm{~nm}$ (absorption of $1.00=40 \mu \mathrm{g} / \mathrm{ml}$ DNA)

\section{D.2.b. Large scale isolation of wide host-range plasmid DNA}

Six LB plates were flooded $(100-200 \mu \mathrm{l})$ with a fresh overnight culture of the appropriate strain and incubated for 12 to $16 \mathrm{hr}$ at $37^{\circ} \mathrm{C}$. Three $\mathrm{ml}$ of sucrose buffer was added to each plate and the cells were scraped off with a sterile glass spreader. Cell suspensions from 3 plates were pooled into a $40 \mathrm{ml}$ polycarbonate centrifuge tube to which $10 \mathrm{ml}$ sucrose buffer, $4 \mathrm{ml} 0.25 \mathrm{M}$ EDTA, pH 8.0 and $1 \mathrm{ml}$ of a 4 $\mathrm{mg} / \mathrm{ml}$ lysozyme solution (freshly prepared) were added. Four $\mathrm{ml}$ of Triton-X solution was added and the solution mixed by gentle inversion. After $15 \mathrm{~min}$ incubation at $37^{\circ} \mathrm{C}$, lysed cells were centrifuged at $15,000 \mathrm{rpm}$ for 45 min at $4^{\circ} \mathrm{C}$. DNA was purified by $\mathrm{CsCl}$ centrifugation as described in section 2.D.2.a.

\section{D.3. Isolation of lambda DNA}

The plate lysate method of Sambrook et al. (1989), modified by L. Robert and S. Bird (Plant Research Centre, Agriculture Canada) was used. A single, wellisolated plaque was picked using a Pasteur pipette and placed in $1 \mathrm{ml}$ of phage 
buffer ( $20 \mathrm{mM}$ Tris- $\mathrm{HCl}, \mathrm{pH} 7.5,100 \mathrm{mM} \mathrm{NaCl}, 10 \mathrm{mM} \mathrm{MgSO}_{4}$ ) containing a dr' $\mathrm{p}$ of chloroform. The tube containing the agarose plug was vortexed and left at room temperature for $\mathbf{3 0}$ min to allow diffusion of the phage, after which time the agarose and debris were removed by centrifugation in a microfuge at $7,000 \mathrm{rpm}$ for $3 \mathrm{~min}$. Fifty to $100 \mu$ of the supernatant was mixed with $100 \mu l$ of $E$. coli strain LB392 (Promega, Madison, WI) and incubated at $37^{\circ} \mathrm{C}$ for $20 \mathrm{~min}$. Two and one half $\mathrm{ml}$ of molten top agarose (TA; $10 \mathrm{~g} / \mathrm{l} \mathrm{Bactotryptone,} 5 \mathrm{~g} / \mathrm{l} \mathrm{NaCl}, 6 \mathrm{~g} / \mathrm{l}$ agarose, $10 \mathrm{mM}$ $\mathrm{MgSO}_{4}$ [added after sterilization, just prior to use]; $42^{\circ} \mathrm{C}$ ) was added to the tube, and the contents were spread over the surface of a freshly poured plate of LB medium solidified with $1.5 \%$ agarose. After incubation at $37^{\circ} \mathrm{C}$ for $9-11 \mathrm{hr}, 6 \mathrm{ml}$ of lambda diluent ( $10 \mathrm{mM}$ Tris- $\mathrm{HCl}, \mathrm{pH} 7.5,10 \mathrm{mM} \mathrm{MgSO}_{4}$ ) was added to the surface of the plate, which was then gently shaken for $2 \mathrm{hr}$ at room temperature. The supernatant was transferred to a centrifuge tube and the bacterial debris removed by centrifugation at $8,000 \mathrm{rpm}$ for $10 \mathrm{~min}$ at $4^{\circ} \mathrm{C}$. The supernatant was transferred to a fresh tube and treated with RNAaseA (10 $\mu \mathrm{g})$ and DNAsel $(10 \mu \mathrm{g})$ for $45 \mathrm{~min}$ at $37^{\circ} \mathrm{C}$. An equal volume of a $\mathrm{PEG} / \mathrm{NaCl}$ solution $(20 \% \mathrm{w} / \mathrm{v}$ polyethylene glycol $8,000,2 \mathrm{M} \mathrm{NaCl}$ in lambda diluent) was added, the tube mixed by vortexing, and incubated for $1 \mathrm{hr}$ in an ice bath. The precipitated bacteriophage were recovered by centrifugation at $10,000 \mathrm{~g}$ for $10 \mathrm{~min}$ at $4^{\circ} \mathrm{C}$. The tubes were well dried by inverting them on a paper towel to allow all the fluid to drain away and redissolved in $500 \mu$ l TE. Five $5 \mu$ l of $10 \%$ SDS was added and the tubes incubated for 5 min at $68^{\circ} \mathrm{C}$. The solution was then extracted once with 1 volume phenol, once with 1 volume phenol:chloroform:isoamylalcohol (25:24:1), and once with 1 volume chloroform:isoamylalcohol (24:1). After thoroughly mixing the aqueous and organic phases, the tubes were centrifuged for $5 \mathrm{~min}$ following each extraction. An equal volume of isopropanol was added to the tubes, which were incubated at $-80^{\circ} \mathrm{C}$ for 15 min. The tubes were then centrifuged for $\mathbf{3 0} \mathrm{min}$ at room temperature to recover 
phage DNA. The pellet was washed in ice-cold $70 \%$ ethanol, dried at room temperature, and redissolved in $100 \mu \mathrm{TE}$.

\section{D.4. Isolation of total plant DNA}

The method used to purify plant DNA was adapted from the one of Sanders et al. (1987; Dr. R. Rutledge, Petawawa National Forestry Institute, Chalk River, personal communication). Using a pestle and mortar, 1 to $2.5 \mathrm{~g}$ of freeze-dried leaf material was pulverized to a fine powder in the presence of $0.2 \mathrm{~g}$ alumina per $\mathrm{g}$ tissue. Ten ml of extraction buffer ( $50 \mathrm{mM}$ Tris-HCl, pH 8.0, $50 \mathrm{mM}$ EDTA, pH 8.0, $50 \mathrm{mM} \mathrm{NaCl}, 1 \% \mathrm{w} / \mathrm{v}$-laurolysarcosine, $400 \mu \mathrm{g} / \mathrm{ml} \mathrm{EtBr}$ ) was added and tissue and ground to ens"re that the powdered material was well suspended. After centrifugation at $5,000 \mathrm{rpm}$ for $5 \mathrm{~min}$ to remove cellular debris, $1.0 \mathrm{~g} \mathrm{CsCl}$ per $\mathrm{ml}$ supernatant was added and dissolved. The solution was added to a Quick-seal ultracentrifuge tube which was sealed and centrifuged for $16 \mathrm{hr}$ at $60,000 \mathrm{rpm}$. The DNA was harvested and extracted with n-butanol as described in section 2.D.a. Two volumes of water was added to the tube and the solution mixed by gentle inversion. Two volumes of ice-cold ethanol (95\%) was gently added and the DNA was recovered by gentle swirling with a Pasteur pipette which was bent at the end as to form a hook. The DNA was dipped in $70 \%$ ethanol and redissolved overnight in TE. The quality of the DNA was determined by running an aliquot (ca. $100 \mathrm{ng}$ ) of undigested DNA on an agarose gel.

\section{D.5. Isolation of DNA fragments}

For most applications, restriction fragments were isolated from agarose gels using the GENECLEAN kit, as recommended by the manufacturer (BIO 101 Inc, LaJolla, CA.), although they were also occasionally isolated from low-meltingtemperature agarose as described in Sambrook et al. (1989). 


\section{D.5.a. Isolation of DNA using GENECLEAN}

DNA was isolated from TAE (40 mM Tris- $\mathrm{HCl}, \mathrm{pH} 8.0,20 \mathrm{mM}$ Na acetate, 2 mM EDTA, $\mathrm{pH}$ 8.0) agarose gels. The concentration of purified fragments was estimated by running an aliquot on an agarose gel next to known quantity of lambda DNA digested with Hind III.

\section{D.5.b. Isolation of DNA using low-melting-temperature agarose}

DNA digested with appropriate enzymes was separated on a 1\% TAE lowmelting-temperature agarose (SEA PREP, ultra-low-gelling-temperature agarose, FMC Co., Rockland, ME) gel containing $0.5 \mu \mathrm{g} / \mathrm{ml} \mathrm{EtBr}$. The gel was poured and run ( $<50$ volts) at $4^{\circ} \mathrm{C}$. DNA was visualized on a long wavelength U.V. transilluminator. Desired bands were cut from the gel, transferred to a microfuge tube and heated at $70^{\circ} \mathrm{C}$ for $10-15 \mathrm{~min}$ to melt the agarose. The tube was transferred to $37^{\circ} \mathrm{C}$ and used directly for random priming. DNA in low-meltingtemperature agarose was stored for short periods of time at $4^{\circ} \mathrm{C}$ and heated to $70^{\circ} \mathrm{C}$ prior to use.

\section{E. Ethanol Precipitation of DNA}

DNA was precipitated by addition of $1 / 5$ volume $10 \mathrm{M} \mathrm{NH}_{4}$ acetate and 2 volumes ice-cold $95 \%$ ethanol. After incubation in an ice bath or $-20^{\circ} \mathrm{C}$ for at least $30 \mathrm{~min}$, the DNA was collected by centrifugation in a microfuge tube for $30 \mathrm{~min}$. The pellet was washed with ice-cold $70 \%$ ethanol and dried at $37^{\circ} \mathrm{C}$ or in a Speed Vac Concentrator (Savant Instruments, Farmingdale, NY). 


\section{F. Restriction Digestion}

\section{F.1. Restriction digestion of plasmid DNA}

Plasmid DNA isolated by rapid extraction or $\mathrm{CsCl}$ gradient was digested in a $20 \mu \mathrm{l}$ volume using buffers provided by the manufacturer. Approximately 5 units of restriction enzyme was added per $\mu$ g DNA. With the exception of Sma 1 digests which were performed at $30^{\circ} \mathrm{C}$, digestion with all other enzymes were performed at $37^{\circ} \mathrm{C}$ for 1.5 to $2 \mathrm{hr}$. When the DNA was to be digested with enzymes having different buffer requirements, it was ethanol precipitated between digests and resuspended in distilled water. Alternatively, if the enzymes had a different requirement for $\mathrm{NaCl}$ concentration, the DNA was first digested with the enzyme requiring less salt. The appropriate amount of $\mathrm{NaCl}$ was then added to the solution, and the DNA was digested with the second enzyme. This was only performed when the first enzyme was inactive or partly active in the second buffer. To avoid possible artifacts, enzymes capable of non-specific or "Star" activity were always used last.

\section{F.2. Restriction digestion of plant DNA}

Plant DNA was digested using buffers supplied by the manufacturer supplemented with $2.5 \mathrm{mM}$ spermidine trihydrochoride. DNA was digested at a concentration of approximately $100 \mathrm{ng} / \mu \mathrm{l}$ for several hr (3-6) at $37^{\circ} \mathrm{C}$. The digests were mixed intermittently by gentle tapping. The digested DNA was concentrated by ethanol precipitation prior to agarose gel electrophoresis.

\section{G. Ligation of DNA}

Thirty to $300 \mathrm{ng}$ of vector DNA was ligated with a three-fold molar excess of insert DNA. Ligations were performed in a $20 \mu \mathrm{l}$ volume using buffer supplied by the manufacturer and 1 (Weiss) unit of T4 DNA ligase (BRL, Burlington, Ontario). 
Ligation reactions were incubated at $12-15^{\circ} \mathrm{C}$ overnight. Ligation conditions used for construction of the partial T218 genomic library are detailed in section 2.K.

\section{H. DNA Sequencing}

DNA was sequenced using the dideoxy chain termination method of Sanger et al. (1977). All sequencing was performed using double-stranded $\mathrm{CsCl}$-purified plasmid DNA templates with kits purchased from U.S. Biochemical (Cleveland, Ohio) or Promega (Madison, WI) using [ $\left.\alpha^{35} \mathrm{~S}\right]-\mathrm{dATP}(1000 \mathrm{Ci} / \mathrm{mmol})$ as radioactive label. DNA inserted into pUC derivatives were sequenced from either ends using a universal primer (UP) hybridizing at -40 (Regional DNA Synthesis Laboratory, University of Calgary, Calgary, Alta.) and a reverse primer (PF1) hybridizing at -67. DNA inserted into pGEM4Z (Promega, Madison, WI) were sequenced using T7 and SP6 primers. A primer specific to the 5' end of the GUS gene (PF2) as well as several other primers hybridizing to sequences within the fragments to be analyzed were used to complete the sequences obtained from the UP and PF1. Primer PF1 and PF2 were synthesized by Dr. R. Watson (Plant Research Centre, Agriculture Canada, Ottawa, Ontario). All other PF-series primers were synthesized by Dr. J. Hattori (Plant Research Centre, Agriculture Canada, Ottawa, Ontario).

Nucleotides were resolved on a $6 \%$ denaturing polyacrylamide gel (ultrapure grade; BRL, Burlington, Ontario). One half-strength TBE (1X TBE is $89 \mathrm{mM}$ Trisma base, $2.5 \mathrm{mM}$ EDTA, pH 8.0,89 mM boric acid) was used as electrophoresis buffer. After electrophoresis, the gel was dried on Whatman $3 \mathrm{MM}$ paper on a gel drier at $80^{\circ} \mathrm{C}$. Dried gels were exposed to Kodak X-Omatic AR film at room temperature for 24 to $72 \mathrm{hr}$. 


\subsection{Preparation of Radioactive Probes}

Isolated restriction fragments were radiolabelled by the random primer method (Feinberg and Vogelstein, 1983) using kits purchased from BRL.

(Burlington, Ontario) or Stratagene (Palo Alto, CA). [ $\alpha^{32}$ P $]$-dCTP $(3,000$ $\mathrm{Ci} / \mathrm{mmol}$ ) was used as radioactive label. Unincorporated nucleotides were removed by chromatography through Sephadex G-50 (Nick Column, Pharmacia, Montreal, PQ). Probes were denatured for $10 \mathrm{~min}$ in boiling water, and placed on ice for 5 min before being added to the prehybridization solution (section 2.J.1.b.).

Molecular weight markers for Southern blots were radiolabelled by endfilling Hind III ends of lambda DNA using the Klenow fragment. To $1 \mu \mathrm{g}$ lambda DNA digested with Hind III, the following were added: 1/10 volume React 2 buffer (50 mM Tris- $\mathrm{HCl}$, pH 8.0, $10 \mathrm{mM} \mathrm{MgCl} 2,50 \mathrm{mM} \mathrm{NaCl}$; BRL, Burlington, Ontario), $0.1 \mathrm{mM}$ of each dATP, dGTP, dTTP, $10 \mu \mathrm{Ci}\left[\alpha^{32} \mathrm{P}\right]-\mathrm{dCTP}(3,000 \mathrm{Ci} / \mathrm{mmol}), 1$ unit Klenow fragment (BRL, Burlington, Ontario). After incubation at room temperature for $10 \mathrm{~min}$, the reaction was stopped by addition of $0.5 \mathrm{M}$ EDTA $(1 \mu \mathrm{l})$ and the unincorporated nucleotides were removed by Nick Column (Pharmacia, Montreal, PQ) chromatography.

\section{J. DNA Hybridization Techniques}

\section{J.1. Southern blot hybridization}

Southern blot analysis was performed as described in Rutledge et al. (1991).

\section{J.1.a. Agarose gel electrophoresis and Southern blotting}

Five $\mu \mathrm{g}$ of genomic LNA digested to completion were fractionated on a $0.8 \%$ TAE agarose gel at low voltage (30-40 volts). End-labelled lambda DNA (5,000 cpm Cerenkov) was used as molecular weight marker. After the dye front had 
migrated approximately $8 \mathrm{~cm}$ (usually overnight), the gel was stained in $\mathrm{EtBr}$, rinsed in water and photographed. The DNA was denatured by soaking the gel with moderate agitation in 2-3 volumes of $0.5 \mathrm{M} \mathrm{NaOH}, 1.5 \mathrm{M} \mathrm{NaCl}$ for $45 \mathrm{~min}$. After

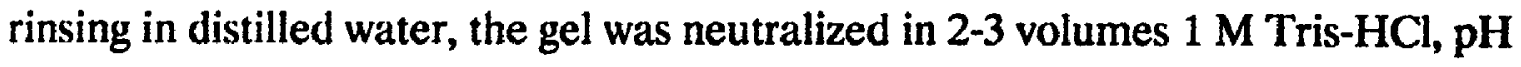
7.0, $1.5 \mathrm{M} \mathrm{NaCl}(2 \times 25 \mathrm{~min})$. The DNA was blotted onto a nylon membrane (Nytran; Schleicher and Schuell, Keene, NH) as follows: The gel was transferred onto 4 layers of Whatman 3MM blotting paper soaked in 20 X SSC ( $3 \mathrm{M} \mathrm{NaCl}, 0.3$ $M$ Nazcitrate), and a piece of Nytran membrane, cut to the size of the gel and soaked in 5 X SSC, was placed over the gel. Two pieces of Whatman 3MM paper, cut to the size of the gel - the bottom one suaked in $20 \times \mathrm{XSC}$, were placed on top of the nylon membrare, and one to 2 inches of paper towels was layered on top of the filter paper. The assemblage was topped with a light weight and wrapped in Saran wrap. After overnight blotting, DNA was immobilized onto the membrane by U.V. irradiation for 2 min on a transilluminator, and rinsed in 5 X SSC.

\section{J.1.b. Hybridization and autoradiography}

Membranes were prehybridized for 1 to several $\mathrm{hr}$ at $65^{\circ} \mathrm{C}$ in $1 \% \mathrm{w} / \mathrm{v} \mathrm{N}$ lauroylsarcosine, $1 \mathrm{M} \mathrm{NaCl}, 1 \mathrm{mM}$ EDTA, pH 8.0, $50 \mathrm{mM}$ Tris-HCl, pH 8.0, 50 $\mu \mathrm{g} / \mathrm{ml}$ yeast RNA in heat-sealable bags (ca. $100 \mu \mathrm{l} / \mathrm{cm}^{2}$ ) and hybridized overnight at the same temperature, in the same solution containing radiolabelled probes (section 2.I.) at concentrations of $8 \times 10^{5}-1 \times 10^{6} \mathrm{cpm} / \mathrm{ml}$ hybridization buffer. Membranes were washed twice ( 2 X $15 \mathrm{~min}$, room temperature) in $1 \mathrm{XSSC}, 0.1 \mathrm{M}$ $\mathrm{NaPO}_{4}$ buffer, $\mathrm{pH} 7.0,0.1 \% \mathrm{w} / \mathrm{v} \mathrm{N}$-lauroylsarcosine, twice $(2 \times 15 \mathrm{~min}$, room temperature) in $0.2 \mathrm{M} \mathrm{NaCl}, 0.5 \% \mathrm{w} / \mathrm{v} \mathrm{N}$-lauroylsarcosine, $1 \mathrm{X} \mathrm{TE}$, and twice ( $2 \mathrm{X}$ $30 \mathrm{~min}$ ) in $0.5 \% \mathrm{w} / \mathrm{v} \mathrm{N}$-lauroylsarcosine, $1 \mathrm{X}$ TE. Unless otherwise stated, the final wash was performed at $60-65^{\circ} \mathrm{C}$. Membranes were exposed to Kodak X-Omatic AR film at $-80^{\circ} \mathrm{C}$ in Kodak X-Omatic cassettes with regular intensifying screens. 
The probe was eluted from the nylon membrane by boiling for $20 \mathrm{~min}$ in 0.01 X SSC, $0.1 \mathrm{mM} \mathrm{NaPO}_{4}$ buffer, pH 7.0, 0.01 mM EDTA, pH 8.0, 0.5\% w/v Nlauroylsarcosine and rinsed in 2 X SSC.

\section{J.2. Plaque Hybridization}

For primary screening, approximately $100,0 \mathrm{CO}$ plaque-forming-units (pfu) were mixed with $500 \mu \mathrm{l}$ of an overnight culture of WA802 (Raleigh et al., 1988) cells and incubated for $30 \mathrm{~min}$ at $37^{\circ} \mathrm{C}$. The suspension was added to $25 \mathrm{ml}$ molten TA $\left(42^{\circ} \mathrm{C}\right.$ ) and spread onto a $200 \times 300 \mathrm{~mm}$ Pyrex dish containing $350 \mathrm{ml} \mathrm{LB}$ agar.

After incubation at $37^{\circ} \mathrm{C}$ for $10-12 \mathrm{hr}$, the dish was transferred to $4^{\circ} \mathrm{C}$ for $1 \mathrm{hr}$ prior to lifting with Nytran membrane (in duplicate). The membranes were transferred, phage side up, onto Whatman $3 \mathrm{MM}$ filter paper soaked in denaturing solution for $10 \mathrm{~min}$ and then with neutralizing solution for $2 \times 5 \mathrm{~min}$. After being transferred to a filter soaked with 5 X SSC for $5 \mathrm{~min}$, the DNA was immobilized onto the membrane by U.V. irradiation for $2 \mathrm{~min}$ on a transilluminator. The membrane was then submersed in a solution of $5 \mathrm{XSSC}$ and unwanted agarose particles were removed by rubbing with a gloved hand.

For secondary screening, the area of the Pyrex dish corresponding to a hybridization signal was removed using the large end of a Pasteur pipette, transferred to a microfuge tube containing $500 \mu \mathrm{l}$ phage buffer, and eluted from the agarose and plated as described in section 2.D.3. Plates containing between 100 to 300 pfu were transferred to $4^{\circ} \mathrm{C}$ for $1 \mathrm{hr}$ and lifted (in duplicate) as described above for the primary screening.

Membranes were prehybridized, hybridized, washed and autoradiographed as described for Southern blot hybridization (section 2.J.1.b). 
2.K. Construction of a Partial Genomic Library from Transgenic Plant T218 Fifteen $\mu \mathrm{g}$ of total DNA isolated from plant T218 was digested with Eco R1 as described in section 2.F.2. and resolved on a 0.8\% TAE agarose gel. After staining in $\mathrm{EtBr}$ and rinsing in water, the gel was visualized under long-wavelength U.V. irradiation. The DNA size fraction between 4 to $6 \mathrm{~kb}$ (estimated by comparison to a lambda Hind III marker) was cut from the gel and isolated using GENECLEAN. Approximately $150-200$ ng of size-fractionated DNA was ligated to $0.5 \mu \mathrm{g}$ dephosphorylated LambdaGEM2 arms (digested with Eco R1) for $4 \mathrm{hr}$ at $25^{\circ} \mathrm{C}$ essentially as recommended by the manufacturer (Promega, Madison, WI). The ligated DNA was packaged in vitro for $2 \mathrm{hr}$ at room temperature using the Packagene system as recommended by Promega, except that only $1 / 2(25 \mu \mathrm{l})$ of a Packagene extract was used. The phage titre was assessed according to the recommendations of the manufacturer (Promega, Madison, WI).

\section{L. Vector Construction}

Most cloning steps were performed using plasmids of the pUC series (Norrander et al., 1983). Recombinant plasmids were identified by insertional inactivation of lac Z using blue/white selection. This was accomplished on LB plates containing carbenicillin to which the following amounts of chromogenic substrate and lac inducer were spread at the surface: $40 \mu \mathrm{l}(20 \mathrm{mg} / \mathrm{ml}) 5$-bromo-4-chloro-3indolyl-B-galactoside (X-GAL) and $4 \mu \mathrm{l}(200 \mathrm{mg} / \mathrm{ml})$ isopropyl- $B$-Dthiogalactopyranoside (IPTG). When the fragment inserted into the pUC plasmid encoded for an easily tested phenotype (e.g. resistance to antibiotic, $\mathrm{Tra}^{+}$, or wide host-range origin of replication) the putative recombinant colonies were functionally tested for these phenotypes. In cases where carbenicillin selection was not possible (i.e. subcloning a fragment from one pUC derivative to another), appropriate 
restriction fragment were isolated from agarose gels by GENECLEAN prior to ligation and transformation. Restriction digest analyses were used to confirm the nature of the inserted fragment and to determine its orientation.

\section{L.1 Construction of pPRF120}

Details of plasmid construction are illustrated in Figure 2.1. Plasmid pGV928 (André et al., 1986) was digested with Acc 1 and treated with T4 DNA polymerase ( $5 \mathrm{~min}$, room temperature) in the presence of AATP and UTTP to endfill protruding "AT" ends of the Acc 1 sites, but not the "CG" ends of the Sal $1 / A c c 1$ sites. A $2.0 \mathrm{~Kb}$ Acc 1 (end-filled)-Sal $1 / A c c 1$ fragment containing the aminoglycoside phosphotransferase 1 (aph 1) gene and the right border repeat was then subcloned into pUC18 digested with Sma 1-Acc 1 to create pPRF107. In order to incorporate the origin of replication and origin of transfer from the wide hostrange IncP group plasmid RK2 into pPRF107, a 2.2 Kb Pvu II-Kpn 1 fragment from pPCV001 (Koncz and Schell, 1986) carrying these sequences was first subcloned into pUC1318 (Kay and McPherson, 1987) to add appropriate restriction enzyme sites at both ends of the fragment. The resulting plasmid, pPRF102 was then cleaved with Eco R1 and Kpn 1, and the smaller $2.2 \mathrm{~Kb}$ fragment was isolated from an agarose gel using GENECLEAN and inserted into the corresponding sites of pPRF107, thus creating pPRF108. The T-DNA right border, aph 1 gene and RK2 cassette, contained on a $4.4 \mathrm{~Kb}$ Sal 1-Eco R1 restriction fragment from pPRF108 were then ligated with a $3.3 \mathrm{~Kb}$ Sal 1-Eco $\mathrm{R} 1$ fragment from pGV928K containing the T-DNA left border repeat and a chimaeric gene consisting of the promoter from nopaline synthase, the coding segment of $n p t$ II and the polyadenylation signal sequence of octopine synthase (5'nos-npt II-ocs3') to create pPRF113. Plasmid pGV928K was derived from pGV928 by inserting the npt II gene from pUC4-KIXX (Pharmacia, Montreal, PQ) into the Sma 1 site. Digestion of pPRF113 with Sma 1, 
Figure 2.1. Construction of pPRF120. Details of plasmid construction are given in section 2.L.1. Abbreviations used are: aph1, aminoglycoside phosphotransferase 1 gene enending resistance to the antibiotics streptomycin and spectinomycin; bla, Blactamase gene encoding resistance to carbenicillin; npt II, neomycin phosphotransferase gene encoding resistance to kanamycin; npt II', chimaeric 5'nosnjt II-ocs3' gene encoding resistance to kanamycin in plant tissues; ori, origin of replication of pMB1; oriV, origin of replication of RK2; oriT, origin of transfer of RK2; L.B, closed triangle, T-DNA left border repeat; RB, open triangle, T-DNA right border repeat; Large frag, Small frag, indicate isolation of larger or smaller plasmid fragments from agarose gels; A, Acc 1; B, Bam H1; H, Hind III; K, Kpn 1; P, Pst 1; R, Eco R1; S, Sal 1; Sm, Sma 1; Sp, Sph 1; T, Sst 1; X, Xba 1. Except for the triangles representing the T-DNA border repeats, all plasmid maps in this thesis are to scale. 


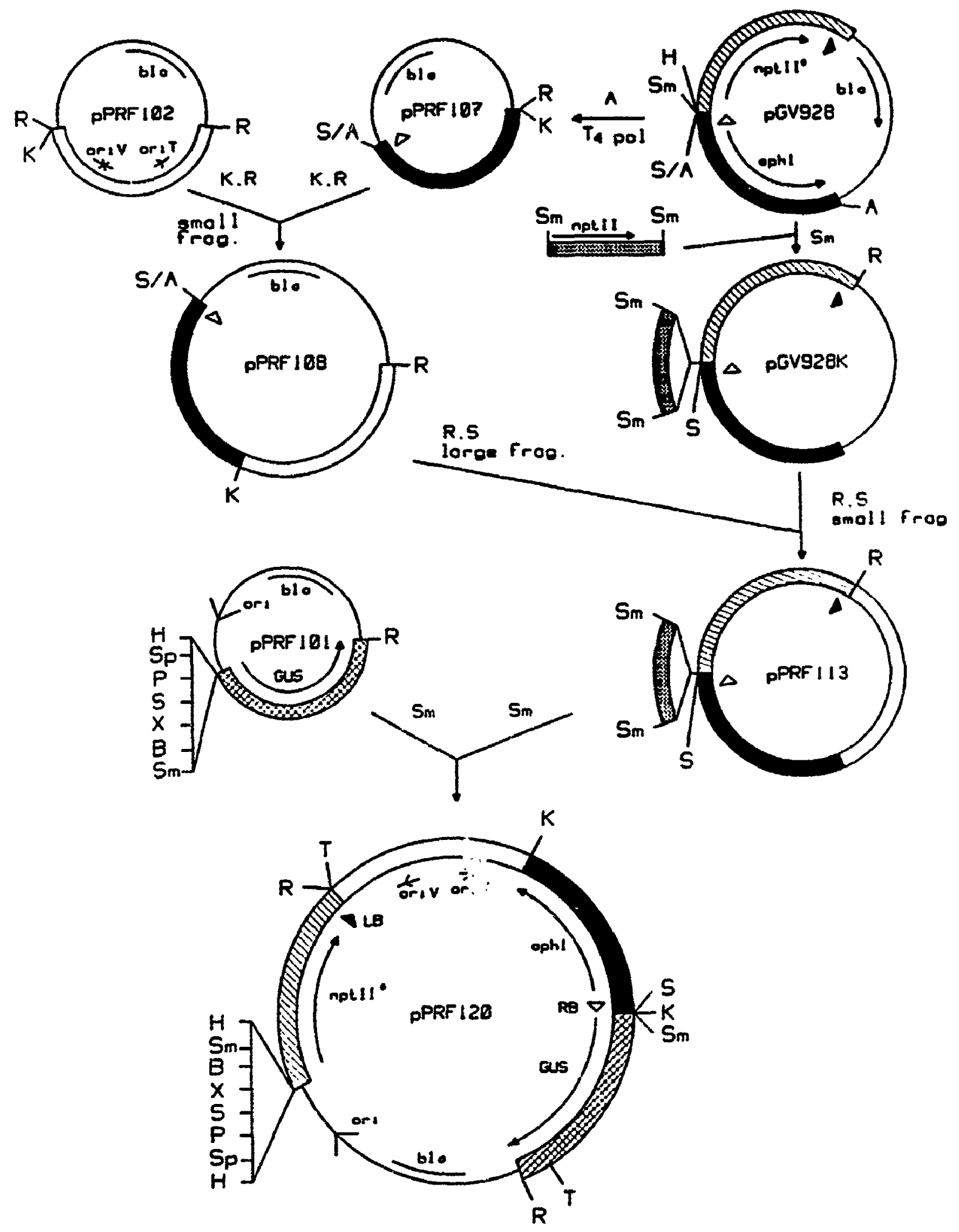


followed by ligation with Sma 1-cleaved pPRF101, a pUC19 subclone containing the chimaeric GUS-nos 3' gene from pBI101 (Clontech, Palo Alto, CA) on a $2.2 \mathbf{~ K b}$ Hind III-Eco R1 fragment, yielded pPRF120. All plasmids were maintained in $E$. coli strain DH5a, except for pPRF113 which was maintained in strain CT2 (Thomas et al., 1981).

\section{L.2. Construction of vectors for sequencing the T218 gene fusion}

Several restriction fragments from the $2.5 \mathrm{~kb}$ chromosomal DNA flanking the promoterless GUS gene of plant T218 were subcloned into plasmid vectors for sequencing purposes. In one case (pT218-3), the restriction fragment was also used as a hybridization probe. Three $X b a 1$ fragments from pT218-1 were subcloned into pUC19 as described in section 2.L. These were named pT218-5 (500 bp insert), pT218-6 (600 bp insert), and pT218-7 (1 kb insert). Plasmid pT218-5 represents the fragment farthest from the GUS gene. One of the Xba 1 sites used in the subcloning of this fragment is derived from the pUC19 multiple cloning site of pT218-1 and is not present in plant $T 218$. In addition to the $X b a 1$ subclones, the $X b a 1 / S a l 1$ fragment immediately upstream of the GUS gene and spanning the T-DNA/plant DNA junction was subcloned in pUC119 to create pT218-3. A 800 bp Sna B1 fragment containing $380 \mathrm{bp}$ from the 5 ' end of the GUS gene and $415 \mathrm{bp}$ of flanking chromosomal DNA was subcloned into the Finc II site of pGEM4Z (Promega, Madison, WI). This derivative was named pT218-8 and the orientation of the insert was determined by sequencing using the T7 and SP6 primers (Promega, Madison, WI).

\section{L.3. Construction of binary vectors for functional testing of the T218 gene fusion}

All fragments were inserted into the multiple cloning site of pBIN19, which is identical to that of pUC19 (Bevan et al., 1984). The entire segment which was 
recovered from the T218 genomic library was inserted into pBIN19 as a $4.7 \mathrm{~kb}$ Eco R1 fragment. The orientation of the insert was determined by Xba 1 and Xha $1 / E c o$ $\mathbf{R} 1$ digests. The recombinant plasmid in which the GUS gene is farthest from the multiple cloning site of pBIN19 was named pT218-C4-2. The orientation of the GUS gene in this vector, and of all the vectors described below, is the same as the one in pBI101 and pBI121 (Jefferson et al., 1987). A deleted derivative of pT218-2, containing only $360 \mathrm{bp}$ of flanking tobacco chromosomal DNA was inserted into pBIN19 as a Xba 1/Eco R1 fragment. This derivative was named pT218-C5-3.

Plasmid pT218-C5-3 was used to create a deletion derivative containing 500 bp of flanking chromosomal DNA. This was accomplished by substituting the plant chromosomal DNA portion of pT218-C5-3, which extends 360 bp to a Xha 1 site, with that of pT218-8, which extends 500 bp to the Sna B1 site. As the Sna B1 site found in the T218 chromosomal DNA was destroyed by insertion into the Hinc II site of pGEM4Z (section 2.L.2.), the 500 bp fragment was inserted into pT218-C5-3 as a Hind III/ Sma 1 fragment. The Hind III site is present in the multiple cloning site of pGEM4Z, while the Sma 1 site is localized in the T-DNA portion of pT218-8, between the GUS gene and the T-DNA/plant DNA junction. Substitution of the $360 \mathrm{bp}$ fragment also results in the incorporation of a $\mathrm{Bam} \mathrm{H} 1$ site in the multiple cloning site. Due to the nature of restriction sites used to insert the original Xba 1/Eco $\mathrm{R} 1$ fragment into $\mathrm{pBIN19,}$ the Bam $\mathrm{H} 1$ site is not present in pT218-C5-3. Thus the presence of the Bam $\mathrm{H} 1$ site was used to identify plasmids containing the $500 \mathrm{bp}$ fragment. Additional digests with Eco R1/Sal 1 and Eco R1/Bum H1 were performed to confirm the nature of the inserts. The resulting plasmid was named pT218-C1-2.

The final deletion derivative which was constructed contains approximately 1 $\mathrm{kb}$ of flanking tobacco chromosomal DNA and extends to the third $X b a 1$ site from the T-DNA/plant DNA junction. Plasmid pT218-1 was partially digested with $X b a$ 
1 as follows: Plasmid pT218-1 was digested to completion with Eco R1 using React 3 buffer ( $50 \mathrm{mM}$ Tris-HCl, pH 8.0, $10 \mathrm{mM} \mathrm{MgCl}, 100 \mathrm{mM} \mathrm{NaCl}$; BRL, Burlington, Ont.). The enzyme Xba 1 retains only $30 \%$ of its activity in this buffer (BRL, Burlington, Ont.). One unit Xba 1 per $\mu \mathrm{g}$ pT218-1 DNA was added directly to the Eco $R 1$ digest and aliquots were removed after 20, 50, 80 and 110 min. Fractions of these aliquots were run on agarose gels to determine the extent to digestion at the different time points, and those yielding partial digestion $(20-80 \mathrm{~min})$ were pooled and loaded on an agarose gel. The band of approximately $3 \mathrm{~kb}$ was isolated and ligated with pBIN19 DNA digested with Eco R1/Xba 1 to create pT218-C6-2. Putative pT218-C6-2 plasmids were analyzed by restriction digest using Eco R1/Sal 1.

\section{M. Growth and Transformation of Plant Tissues}

Nicotiana tabacum L. cv Petit Havana SR1, originally obtained from Dr. B. Bowen, Agrigenetics, Madison, WI, was used throughout this thesis. For comparative Southern blot analyses, DNA was also isolated from leaves of Nicotiana sylvestris and Nicotiana tomentosiformis. Leaf samples were a gift from Mr. Eric Bevis, Imperial Tobacco, Montreal, PQ. The plants were grown in the greenhouses at the Central Experimental Farm, Agriculture Canada, Ottawa, Ont. A tobacco suspension culture which was used as a feeder layer in the Agrobacteriummediated transformation protocol was also obtained from Mr. Bevis.

\section{M.1. Growth conditions}

\section{M.1.a. Greenhouse conditions}

Untransforined and transgenic tobacco plants were grown in greenhouses at the Central Experimental Farm, Agriculture Canada, Ottawa, Ont. The greenhouse 
temperature varied between $20-35^{\circ} \mathrm{C}$ in the summer and was maintained at approximately $25^{\circ} \mathrm{C}$ in the other seasons.

Due to the large number of transgenic plants which were generated in this thesis, different greenhouse facilities were used. Growth conditions varied between each greenhouse. However, with the exception of tissue samples harvested for the initial screen of flower and seed tissues, all plants which were studied in detail were grown in the same greenhouse under the conditions listed below.

Plants were potted in a soil mixture of soil:peat:moss:sand:perlite (1:2:1:1) with traces of lime and superphosphate. Plants were watered twice daily, and fertilized daily with $1 / 10$ strength Hoagland's solution (except weekends) and weekly with N-P-K (20:20:20). Plants were grown under natural sun light supplemented with fluorescent lights set for a $16 \mathrm{hr}$ photoperiod.

\section{M.1.b. In vitro growth conditions}

Plant tissues were grown in an environmentally controlled growth room at $25^{\circ} \mathrm{C}$ with continuous illumination (fluorescent and incandescent lights, 400 $\mu \mathrm{E} / \mathrm{n}^{2} / \mathrm{s}$ ) or in Conviron growth cabinet (Control Environments, Vaudreuil, PQ) growth chambers with a $16 \mathrm{hr}$ photoperiod of $400 \mu \mathrm{E} / \mathrm{nr}^{2} / \mathrm{s}$. Leaf discs and germinating seedlings were grown in $100 \times 25 \mathrm{~mm}$ Petri dishes sealed with Parafilm, while shoot cultures and plants were grown in GA-7 Magenta boxes (Magenta Corporation, Chicago, IL))

\section{M.2. Tissue Culture}

\section{M.2.a. Media composition}

The basal medium used throughout this thesis consisted of MS salts (Murashige and Skoog, 1962) with B5 vitamins (Gamborg et al., 1968), supplemented with $2 \% \mathrm{w} / \mathrm{v}$ sucrose and $0.8 \% \mathrm{w} / \mathrm{v}$ Difco Bactoagar, pH 5.7 (MSO 
medium). Transgenic shoots were regenerated on MSB5 medium supplemented with $1 \mu \mathrm{g} / \mathrm{ml}$ 6-benzylaminopurine (BA), $0.1 \mu \mathrm{g} / \mathrm{ml} \alpha$-naphthalene acetic acid (NAA), $3 \% \mathrm{w} / \mathrm{v}$ sucrose, $0.8 \% \mathrm{w} / \mathrm{v}$ Bactoagar (MS104 medium) containing $100 \mu \mathrm{g} / \mathrm{ml}$ kanamycin sulfate (Sigma, St. Louis, MO) and $500 \mu \mathrm{g} / \mathrm{ml}$ cefotaxime (Claforan, Roussel, Montreal, PQ). The tobacco suspension culture was grown in liquid MSB5 medium supplemented with $2 \mathrm{mg} / \mathrm{ml}$ 2, 4-dichlorophenoxyacetic acid (MSD2).

\section{M.2.b. Shoot culture}

A continuous supply of sterile, in vitro-grown plants was maintained as explant source for genetic transformation. These were propagated by transferring terminal or axillary buds along with a segment of stem to fresh medium every 3-4 weeks.

Regenerated shoots from tobacco leaf discs following Agrobacteriummediated transformation were excised and transferred to MS0 medium supplemented with $100 \mu \mathrm{g} / \mathrm{ml}$ kanamycin sulfate and $500 \mu \mathrm{g} / \mathrm{ml}$ cefotaxime. Only shoots of 5-10 mm, having distinct stems were excised. Care was taken not to transfer any callus material.

\section{M.2.c. Cell suspension culture}

The tobacco cell suspension culture was grown in $125 \mathrm{ml}$ Erlenmeyer flasks covered with aluminium foil containing $25-40 \mathrm{ml}$ MSD2 medium. Flasks were shaken continuously at $150 \mathrm{rpm}$. Cell suspensions were transferred every 1-2 weeks as follows: The cells were allowed to settle for approximately $15 \mathrm{~min}$, after which time the supernatant was removed, and 5-10 $\mathrm{ml}$ of the cell suspension transferred to a flask containing $25 \mathrm{ml}$ fresh medium. Suspensions were used in feeder layers 4-6 days after transfer. 


\section{M.3. Agrobacterium-mediated transformation}

The leaf disc method (Horsch et al., 1985) was used to transform explants prepared from plants grown either in vitro or in the greenhouse. For explants from in vitro-grown plants, leaf strips of $10 \mathrm{~mm}^{2}$ were excised and cultured for 2 days on nurse cultures consisting of $3 \mathrm{ml} \mathrm{N}$. tabacum cell suspension plated on the surface of MS104 medium and covered with two layers of sterile Whatman \#2 filter paper. The leaf pieces were then dipped in a 2 day culture of the appropriate Agrobacterium strain for 30-60 sec, blotted onto sterile filter paper, and returned to the nurse culture for a 2 day co-culture. Leaves collected from plants grown in the greenhouse were sterilized for $20 \mathrm{~min}$ in a $10 \%$ bleach solution $(0.6 \%$ sodium hypochlorite; Javex, Bristol-Myers) and rinsed several times in sterile distilled water. Discs were cut from the leaves using a paper puncher, cultured on MS104 medium, without the nurse culture, for 3 days, and infected with Agrobacterium as described above. Following Agrobacterium cocultivation, the leaf pieces were transferred to fresh MS104 medium supplemented with $500 \mu \mathrm{g} / \mathrm{ml}$ cefotaxime and $100 \mu \mathrm{g} / \mathrm{ml}$ kanamycin. Tissues were transferred to fresh medium every three weeks. In order to ensure that each regenerating shoot represented an independent transformation event, leaf disc sectors yielding shoots or callus growth were dissected apart early in development, and no more than one shoot was excised per callus. Shoots were rooted on MSO medium supplemented with $500 \mu \mathrm{g} / \mathrm{ml}$ cefotaxime and $100 \mu \mathrm{g} / \mathrm{ml}$ kanamycin as described above (section 2.M.2.c.). Upon transfer to the greenhouse, rooted shoots were covered with a plastic bag for one week to allow adaptation to conditions of lower humidity.

\section{M.4. Seedling germination and analysis of kanamycin segregation}

Seeds from self-pollinated transgenic plants were placed in filter paper bags and surface sterilized in $70 \%$ ethanol for $1 \mathrm{~min}$ and in 2-3 1 of undiluted Javex 
bleach (6\% sodium hypochlorite) containing a few drops of Tween 20 for $25 \mathrm{~min}$. Seeds were then washed several times with sterile distilled water, dried under laminar flow, and placed in Petri dishes containing MSO medium supplemented with $100 \mu \mathrm{g} / \mathrm{ml}$ kanamycin. The numbers of green (kanamycin resistant) to bleached (kanamycin sensitive) plantlets were counted after 4-6 weeks, and analyzed using the chi-squared test with one degree of freedom at significance level of $P=0.05$.

\section{N. Plant Pollination}

In order to maximize self-fertilization, a wax-paper bag was placed over flower heads prior to pollen anthesis. For genetic crosses, flowers were emasculated before the stigma emerged from the corolla, and hand-pollinated with pollen from the desired plant. A piece of dialysis tubing, stapled at the end, was placed over the flower to prevent further pollination. The dialysis tubing was removed several days latter to allow for capsule growth.

\subsection{B-Glucuronidase Assays}

Quantitative fluorogenic and histological GUS assays were performed according to Jefferson (1987) with modifications.

\subsubsection{Fluorogenic assay}

\subsection{1.a. Tissue collection}

Approximately 50-150 mg of tissue was collected, weighed, and immediately placed in liquid nitrogen. Samples which were not homogenized on the same day were stored at $-80^{\circ} \mathrm{C}$ until use. For the initial screening of transgenic plants, the following tissues, all collected from the original transgenic plants were analyzed. 
Leaves from regenerated shoots grown in vitro, flowers corresponding to developmental stages 4 and 5 of Koltunow et al. (1990) and beige seeds, approximately 12-16 DPA (Chen et al., 1988). Flowers and seeds were collected from plants grown in the greenhouse. For detailed, quantitative analysis of GUS activity, leaf, stem and root tissue were collected from kanamycin resistant (selffertilized) $\mathbf{R}_{1}$ progeny of the different transformants grown in vitro. Floral tissues were harvested at developmental stages 8-10 (Koltunow et al., 1990) from the original transgenic plants grown in the greenhouse. Flowers of these plants were tagged and developing seeds were collected from capsules at 10 and 20 DPA. Embryos in the developing seeds at 10 DPA are at the globular stage, while at approximately 20 DPA they are at the cotyledon stage (personal observation and J. DeMoor, Department of Biology, Carleton University, personal communication). Drawings of embryos at different times during seed development is presented in Figure 2.2.

\subsection{1.b. Tissue homogenization}

Samples were removed from $-80^{\circ} \mathrm{C}$ and immediately placed in liquid nitrogen. Samples to be homogenized were removed one at a time. With the exception of seed samples, the tissue was ground to small pieces in a microfuge tube using a ground glass pestle. Ice-cold extraction buffer ( $50 \mathrm{mM} \mathrm{NaPO}_{4}$ buffer, $\mathrm{pH}$ 7.0, $10 \mathrm{mM}$ ß-mercaptoethanol, $10 \mathrm{mM}$ EDTA, pH 8.0, 0.1\% w/v Nlauroylsarcosine, $0.1 \% \mathrm{v} / \mathrm{v}$ Triton-X-100) was added at approximately $3 \mu \mathrm{l} / \mathrm{mg}$ tissue, and the tissue was homogenized using an OMNI 1000 hand-held homogenizer (OMNI International, Waterbury, $\mathrm{CN}$ ) until pieces of tissue were no longer visible (ca. 20-30 sec). Cellular debris was removed by centrifugation (microfuge) at $4^{\circ} \mathrm{C}$ for $10 \mathrm{~min}$ and the supernatant transferred to a fresh microtube. The extracts were either assayed directly, or placed in liquid nitrogen and stored at $-80^{\circ} \mathrm{C}$ until use. 
Figure 2.2. Development of zygotic embryos in tobacco. 


\section{EMBRYO DEVELOPMENT}

\section{A. Nicotiana tabacum}

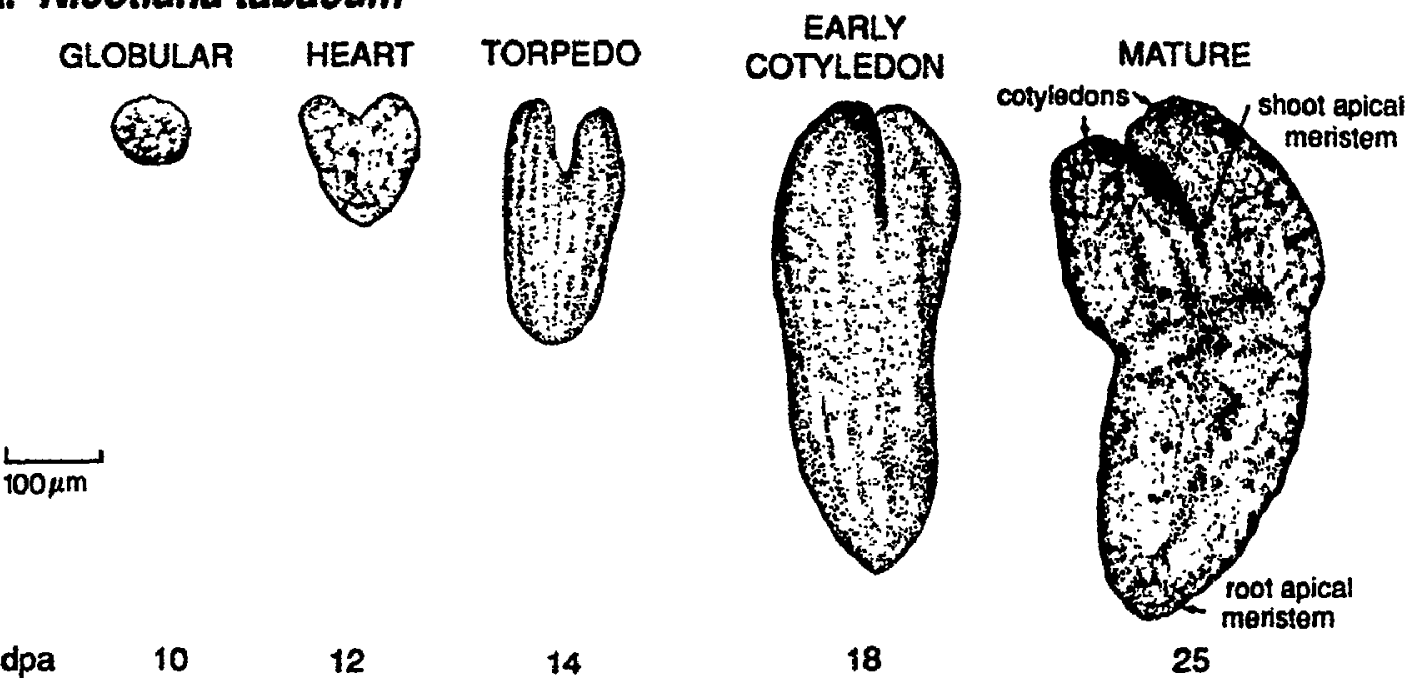




\subsection{1.c. GUS assay protocol}

Samples were assayed in extraction buffer containing $1 \mathrm{mM}$ 4-methyl umbelliferyl-ß-D-glucuronide (MUG; Sigma, St. Louis, MO). Five hundred $\mu \mathrm{l}$ assay buffer in a microtube was pre-warmed at $37^{\circ} \mathrm{C}$ for a few min. Extracts were removed from $-80^{\circ} \mathrm{C}$, thawed and vortexed to ensure even suspension. Fifty $\mu l$ extract was added to the assay buffer, thoroughly mixed by inversion, and returned to a $37^{\circ} \mathrm{C}$ water bath. At different times, including time " 0 ", $100 \mu$ laliquots were removed, transferred to a $2 \mathrm{ml}$ tube containing $1.9 \mathrm{ml}$ of stop buffer $(0.2 \mathrm{M}$ $\mathrm{Na}_{2} \mathrm{CO}_{3}$ ) and mixed. For the initial screening, samples were taken at time " 0 " and at one additional time point, usually between $4-7 \mathrm{hr}$. For more detailed fluorogenic analyses, 3 to 4 time points, taken at 60 or $90 \mathrm{~min}$ intervals were taken. Stopped reactions were stored away from direct sunlight until quantified by fluorometry.

\subsection{1.d. Determination of GUS activity}

Fluorescence was measured using a Hoefer TKO Fluorometer (emission 365 $\mathrm{nm}$; detection $460 \mathrm{~nm}$ ) calibrated with 100 and $500 \mathrm{nM}$ sodium methyl umbelliferone (Sigma, St. Louis, MO). Relative fluorescence values were converted to $\mathrm{nM}$ MU, then nmoles or pmoles MU. Activity is expressed in nmole or pmole per unit time (min) per unit protein (mg). Protein concentration in the extracts were determined using the Bio-Rad (Bradford) Protein Assay kit with bovine serum albumin (Sigma, St. Louis, MO) as standard.

\subsubsection{Histological GUS assay}

Tissue samples analyzed by histological assay were collected at developmental stages comparable to those used for the fluorogenic assay. Whole seedlings and a combination of different hand-cut sections were analyzed for each organ. These included leaf slices, epidermal strips, transverse and longitudinal stem 
and flower sections, whole roots, whole seeds, halved seed sections and excised embryos. Sections were incubated overnight at $37^{\circ} \mathrm{C}$ in $100 \mathrm{mM} \mathrm{NaPO}_{4}$ buffer, pH 7.0, $10 \mathrm{mM}$ EDTA, pH 8.0, $0.5 \mathrm{mM} \mathrm{K}_{3}\left[\mathrm{Fe}(\mathrm{CN})_{6}\right], 0.5 \mathrm{mM} \mathrm{K}_{4}\left[\mathrm{Fe}(\mathrm{CN})_{6}\right] \mathrm{H}_{2} \mathrm{O}$, containing $1 \mathrm{mg} / \mathrm{ml}$ of the chromogenic substrate, 5-bromo-4-chloro-3-indolyl glucuronide (X-GLUC; Clontech, Palo Alto, CA). Flowers were assayed in the same buffer containing $20 \%(\mathrm{v} / \mathrm{v})$ methanol to eliminate endogenous staining in anthers (Kosugi et al., 1990). After 2-3 rinses in $50 \mathrm{mM} \mathrm{NaPO}_{4}$ buffer, $\mathrm{pH} 7.0$, the material was fixed overnight in $1 \%$ glutaraldehyde in phosphate buffer $\mathrm{pH} 7.0$ at $4^{\circ} \mathrm{C}$. After several rinses in phosphate buffer, green tissue was gradually placed in a series of ethanol solutions of increasing concentration to clear pigments. In some cases, the plantlets were dried on filter paper to enhance visualization of the stain. 


\section{CHAPTER 3 - RESULTS}

\section{A. Design and Construction of pPRF120: A Binary Vector Capable of Identifying T-DNA Insertions into Transcribed DNA.}

To generate T-DNA-mediated gene fusions, and thus detect T-DNA integrations within transcriptionally active DNA, a vector containing a promoterless GUS gene linked to the right border repeat was designed. Details of plasmid construction are presented in Figure 2.1. Several vector components originated from the intermediate vector pGV928 (André et al., 1986). This plasmid is nearly isogenic to the one used by André et al. (1986) to generate T-DNA-mediated gene fusions, except that the npt II gene in pGV928 is under the transcriptional control of the nos promoter. In pPRF120, this gene was exploited to recover kanamycinresistant transgenic plants. Plasmid pGV928 also contains a synthetic T-DNA right border flanked by several closely linked recognition sites for restriction enzymes into which a promoterless GUS gene was eventually inserted. However, prior to this step, pGV928 was converted from a co-integrate type vector to a binary type. Due to the lack of convenient restriction sites in pGV928, a simple replacement of the pBR322-based replicon with one of broader bacterial host-range was not possible. As an alternative, a multi-step approach was designed to accomplish this goal. The strategy was to ligate only a portion of pGV928 with a fragment containing a wide-host replicon, in such a way that additional restriction enzyme sites were incorporated at the ends of the restriction fragments. These new sites were then exploited to reconstitute a derivative of pGV928 containing a broad hostrange replicon. The resulting plasmid, pPRF113, contains a conditional wide-host range replicon from plasmid RK2 (incompatibility group P; $\operatorname{IncP}$ ). This replicon is 
said to be conditional because it requires trans-acting replicating factors $(t r f)$ for stable maintenance in Gram negative bacteria. Use of the conditional mini-RK2 cassette allows the size of the replicon fragment to be kept to a minimum. Other plasmid derivatives containing the mini-RK2 cassette (pPCV001, pPRF102) that were used in this study also incorporated a pMB1 replicon, and could thus be maintained in the absence of trf genes. However, the conditional RK2 cassette is the only replicon present in pPRF113. Attempts to transform this plasmid in E. coli strains lacking trf genes failed to yield any kanamycin-resistant colonies (data not shown). Consequently, pPRF113 was maintained in the E. coli strain CT2 (Thomas et al., 1981) which contains a trf gene encoding a factor, $\mathrm{Tfr}^{+}$, integrated into the chromosome. An additional difference between pGV928 and pPRF113 is the presence of a $1.2 \mathrm{~Kb}$ Sma 1 insert containing an $n p t$ II gene in the latter. Addition of the kanamycin resistance marker was necessary as the aph 1 gene from pGV928 was found to be ineffective at selecting for transformants on the basis of spectinomycin resistance. The T-DNA portion of pPRF113 is identical to that of pGV928K (Figure 2.1.), and with the exception of the $1.2 \mathrm{~kb}$ npt $\mathrm{Il}$ insert, is the same as that of pGV928. Sma I was chosen as restriction site for incorporating the npt II gene as the next step in pPRF120 construction involved inserting a linearized pUC19 derivative containing the GUS-nos 3' cassette from pBI101 into this site, thus replacing the fragment carrying the npt II gene. Plating of cells harbouring the resulting plasmid on medium containing kanamycin revealed that they were, in fact, sensitive to this antibiotic (data not shown). Plasmid pPRF120 has the promoterless GUS gene from pPRF101 closely linked to the right border repeat. Doublestranded sequencing of the GUS-right border area confirmed that the initiation codon for GUS is located $42 \mathrm{bp}$ from the T-DNA right border repeat (Figure 3.1). There are no "TATA"-like elements or stop codons present in this sequence so that both transcriptional and translational gene fusions may be generated. Concurrently, 
Figure 3.1. Sequence of the T-DNA right border area of pPRF120. The nucleotide sequence of the region of pPRF120 between the 5 end of the GUS gene and the TDNA right border repeat was determined using a sequencing primer hybridizing to the $S$ ' end of the GUS coding region (indicated by arrow). Sequences close to, and spanning the priming site are as published by Jefferson et al. (1986) and were not determined here. The location of T-DNA right border repeat and restriction sites are indicated. 
T-DNA RIGHT BORDER

A A T T A A A G G T TA A T C T G T C A G A C T C G

SaI 1

Kpn 1

Sma 1

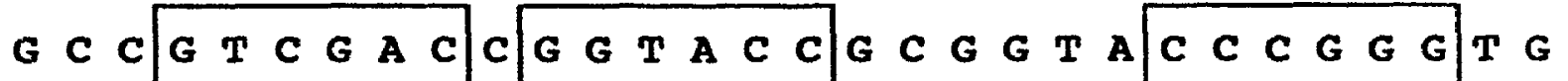

TTCA G T C C T TATGTTACG T C T T TAGA A A Het Leu Arg Pro Val Glu GUS CODING REGION 
insertion of pPRF101 into the Sma I site of pPRF113 resulted in the incorporation of a carbenicillin resistance marker, a narrow-host range, high copy-number origin of replication, and a multiple cloning site into the T-DNA of pPRF120.

Localization of these sequences within the T-DNA portion should permit molecular cloning of the promoterless GUS gene and flanking chromosomal segments by plasmid rescue. Plasmid pPRF120 has a molecular weight of $11.5 \mathrm{~kb}$ and has bacterial markers for resistance to carbenicillin and spectinomycin. As part of the mini-RK2 cassette, the vector also contains an IncP origin of transfer (oriT), permitting mobilization to other Gram negative bacteria including $A$. tumefaciens.

\section{B. Occurrence of T-DNA-mediated gene fusions in tobacco plants transformed with pPRF120}

Plasmid pPRF120 was mobilized to Agrobacterium strain GV3101 (pMP90RK) by triparental mating. The Ti-helper plasmid pMP90RK contains the trf and transfer (tra) genes needed for pPRF120 maintenance and transfer, confers resistance to the antibiotics gentamycin and kanamycin, and provides the virulence functions for T-DNA transfer (i.e. binary system; Koncz and Schell, 1986). pPRF120 can also be used in conjunction with other Ti plasmids, as Agrobacterium strains containing trf genes integrated into the chromosome also exist (Koncz and Schell, 1986). Integrity of pPRF120 in Agrobacterium was assessed by transferring the plasmid to $E$. coli DH5 $\alpha$ by biparental matings and analyzing the plasmid content of 24 separate transconjugants by restriction mapping using Sst 1 and Eco R1/Sal 1 . In all cases, restriction patterns obtained were identical to that of PPRF120 prior to transfer to Agrobacterium (data not shown), indicating that the plasmid has not undergone any extensive structural rearrangements.

Cultures of Agrobacterium harbouring pPRF120 were used to infect tobacco 
leaf discs and approximately 1,000 kanamycin-resistant $(100 \mu \mathrm{g} / \mathrm{ml})$ transgenic plants were recovered. Control (untransformed) discs cultured on medium containing this concentration of kanamycin never formed shoots (data not shown). In contrast, shoots were occasionally observed on control discs grown in the presence of $\mathbf{5 0}$ $\mu \mathrm{g} / \mathrm{ml}$ kanamycin (data not shown). As shoots regenerated from the same calli are often the result of the same transformation event (Jones et al., 1987), care was taken to excise no more than one shoot per callus.

As selection of transformants was independent of promoterless gene activation, the population of transgenic plants had to be analyzed for GUS activity in order to identify individuals expressing T-DNA-mediated gene fusions. The strategy which was adopted for this purpose is shown diagrammatically in Figure 3.2. In addition to searching for organ-specific and developmentally-regulated gene fusions, the approach also incorporated a screen for in vivo fusions induced by exposure to cold temperature. Although these two phases of analysis overlapped experimentally, they will be considered separately below.

\section{B.1. Screening for cold-inducible T-DNA-mediated gene fusions}

Plant tissues exposed to low temperatures respond by synthesizing distinct species of mRNA and proteins (Thomashow, 1990). To test whether it was possible to uncover cold-inducible cis-acting regulatory elements by T-DNA-mediated gene fusions, leaf tissue was collected from in vitro-grown plants prior to, and following a $36 \mathrm{hr}$ incubation at $4^{\circ} \mathrm{C}$ (Figure 3.2). This period of time is sufficient for induction of de novo protein synthesis in leaves of other plant species (Thomashow, 1990). Material was collected from all 940 transformants and analyzed using the fluorogenic GUS assay (Jefferson, 1987). Extracts from untransformed leaves were also assayed to determine the extent of intrinsic background fluorescence unrelated 
Figure 3.2. Flow diagram illustrating the strategy employed to screen pPRF120 transformants for the presence of T-DNA-mediated GUS gene fusions. A summary of results obtained is presented in Table 3.1 


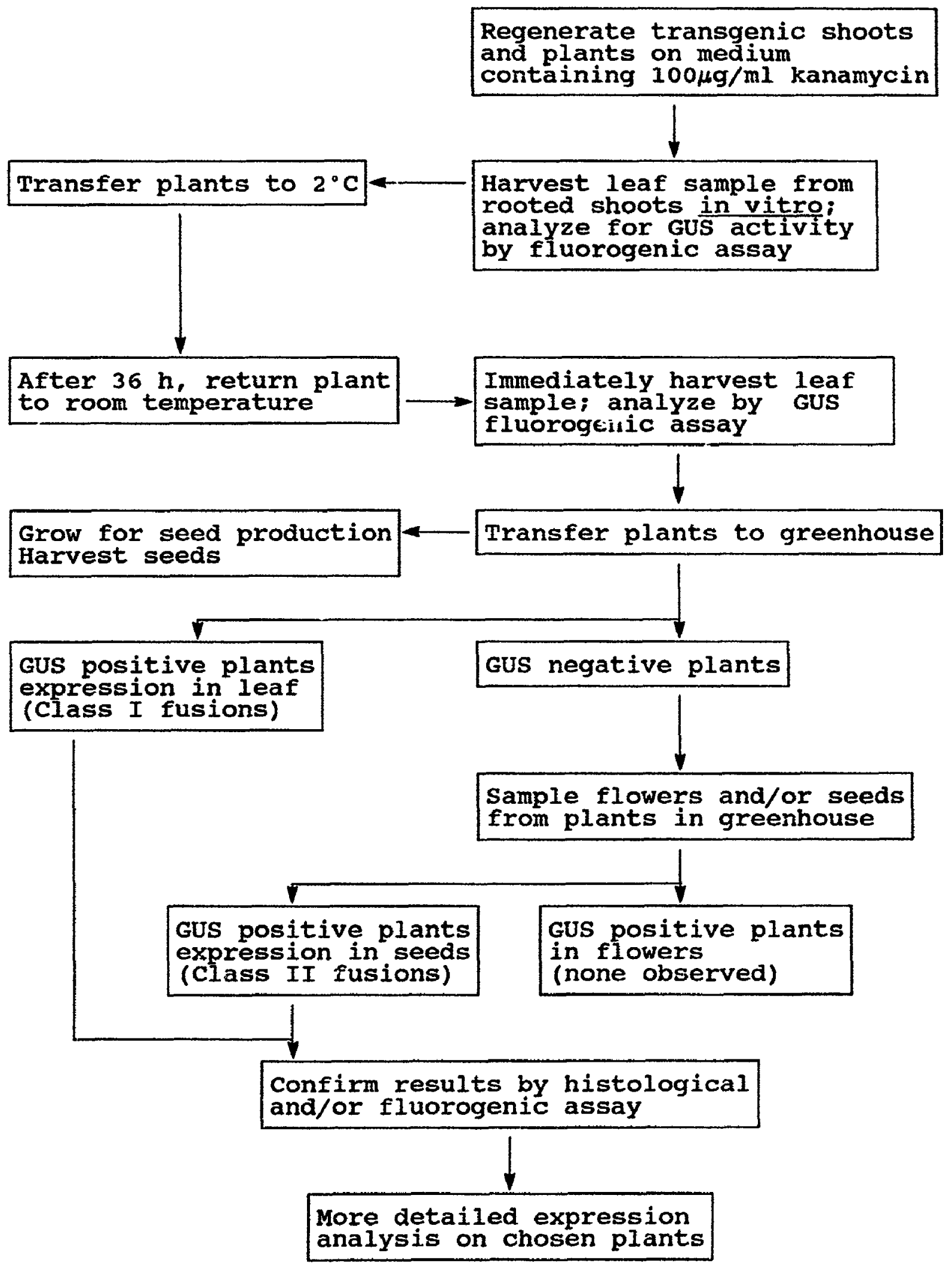


to GUS. In leaves, this value was $7 \pm 3$ pmole $\mathrm{MU} / \mathrm{min} / \mathrm{mg}$ protein. Transformants containing more than $\mathbf{5}$ times the activity of untransformed tissues were identified as putative candidates expressing T-DNA-mediated GUS fusions. Fluorescence measured in untransformed extracts never exceeded this level.

The level of fluorescence produced by 893 of the leaf extracts were within the range of untransformed extracts. Based on the criterion listed above, these do not express T-DNA-mediated gene fusions. GUS activity was detected in leaves from 57 individuals, or approximately $6 \%$ of the population. For plants which contained borderline levels of GUS activity, additional fluorogenic assays or histological staining with X-GLUC were performed. None of the 57 plants expressed GUS only after the cold treatment. Consequently, it was concluded that none of the gene fusions identified were cold-inducible.

Gene fusions first detected in leaf tissues will be referred to as Class I fusions. Expression patterns of Class I fusions were characterized in greater detail by fluorogenic and histological assays. The strategy used to study these, and specific results obtained are considered in future sections (3.D.).

\section{B.2. Screening for T-DNA-mediated gene fusions differentially expressed during plant development}

As plant gene expression is highly regulated (Section 1.B.), it was anticipated that in some cases, the T-DNA may have integrated next to cis-acting elements which were not expressed in leaf tissues. To test this hypothesis, and to determine the relative probability of generating T-DNA-mediated gene fusions in various plant tissues, flower and seed samples from several hundred plants which did not express GUS in the leaf were collected and analyzed for promoterless gene activation (Figure 3.2). The large size of the transformed population made it impractical to screen all organs for GUS activity. Instead of testing several tissues from a small 
proportion of the population, it was decided to analyze only a few tissues from many of the plants. Flowers and seeds were chosen for several reasons. (A), these tissues are not present during the tissue culture phase of growth. Consequently, gene fusions specinically expressed in flowers or seeds would have been difficult, if not impossible to uncover using the selection approach of André et al. (1986) or Teeri et al. (1986). Thus, the feasibility of generating gene fusions 'a floral and seed tissues had not been determined in these studies. (B), screening of leaf, flowers and seeds permitted the study of gene fusion expression throughout the different stages of the plant life cycle. (C), tissues in the leaves, flowers and seeds are distinct at the functional, biochemical, structural and developmental levels. (D), putative cisacting regulatory elements expressed in the flower and seeds could be of potential agricultural use. Of the 220 plants which were tested in developing seeds, 5 were found to coniain GUS activity. This class is referred to as Class II fusions and represents approximately $2 \%$ of the total number of individuals ang!, zed. GUS activity did not exceed background levels in any of the 330 flowers tested. Results obtained from this initial screening of pPRF120 transformants are s:Im marized in Table 3.1

\section{C. Analysis of pPRF120 T-DNA Segregation and Structure in Transgenic Plants}

Prior to characterizing expression patterns of GUS fusions in more detail, the copy number and structure of integrated pPRF120 T-DNA was assessed by Southern blct hybridization and segregation analysis of a T-DNA encoded marker, kanamycin resistance. Two groups of plants transformed with pPRF120 and containing 25 and 27 individuals each were studied. Group 1 consisted of kanamycin resistant plants which had not been screened for GUS expression at the 
Table 3.1. Summary of results from initial screening of pPRF120 transformants for GUS activity.

\begin{tabular}{|c|c|c|c|c|}
\hline $\begin{array}{c}\text { Tissue } \\
\text { Analyzed }\end{array}$ & $\begin{array}{l}\text { Number } \\
\text { Analyzed }\end{array}$ & $\begin{array}{l}\text { Number of } \\
\text { GUS positive }\end{array}$ & $\begin{array}{c}\text { Frequency of } \\
\text { Occurrence }\end{array}$ & $\begin{array}{l}\text { Type of } \\
\text { Fusion }\end{array}$ \\
\hline $\begin{array}{l}\text { Leaf } \\
\left(25^{\circ} \mathrm{C}\right)\end{array}$ & 940 & 57 & $6 \%$ & Class I \\
\hline $\begin{array}{l}\text { Leaf }{ }^{2} \\
\left(4^{\circ} \mathrm{C}\right)\end{array}$ & 910 & $0^{3}$ & $0 \%$ & \\
\hline Seeds $^{4}$ & 220 & 5 & $2 \%$ & Class II \\
\hline Flowers ${ }^{5}$ & 330 & 0 & $0 \%$ & \\
\hline
\end{tabular}

1 Tissues collected from plants grown in vitro

2 plants, grown in vitro, were incubated at $4^{\circ} \mathrm{C}$ for $36 \mathrm{hr}$ Samples were collected immediately after return to room temperature.

3 Indicates that none of the plants expressed Gus specifically as a result of the cold treatment.

4 Seeds, ca. 12-16 days post-anthesis, collected from plants grown in the greenhouse.

5 whole flowers, corresponding to stages 4 and 5 as described by Koltunow et al. (1990), collected from plants grown in the greenhouse. 
time of harvest. Subsequent analysis of these plants revealed that 5 of them (T198, T459; T475; T1018; T1243) possessed GUS activity. Group 2 plants were all screened for GUS activity prior to Southern analysis and found to express the promoterless GUS construct. In the following subsections, results from segregation of kanamycin resistance and Southern blot analyses are presented. The data obtained from these two approaches are then summarized, and compared to results observed for plants transformed with derivatives of the widely used binary vector pBIN19 (Bevan, 1984; Jefferson et al., 1987).

\section{C.1. Segregation of kanamycin resistance}

Self-fertilized seeds from untransformed SR1 tobacco and pPRF120 transformants were surface-sterilized, germinated on MS0 medium supplemented with $100 \mu \mathrm{g} / \mathrm{ml}$ kanamycin sulfate, and the resulting number of kanamycin resistant and kanamycin sensitive seedlings was counted (see Materials and Methods, section 2.M.4.). At this concentration of kanamycin, seeds from untransformed plants germinated only to become bleached after $2-3$ weeks. These seedlings usually possessed two bleached cotyledons, but rarely produce true leaves (data not shown). In contrast, almost all the seeds from pPRF120-transformed plants yielded some seedlings which remained green and developed into plants containing several morphologically normal leaves. Seeds from untransformed plants and selected transformed plants produced only green seedlings when plated in the absence of kanamycin (data not shown), indicating that the patterns of bleached to green seedlings observed on medium containing kanamycin is due to resistance or sensitivity to this antibiotic. The exact ratios of kanamycin resistant to kanamycin sensitive seedlings produced by Group 1 plants is presented in Table 3.2, while those observed in Group 2 plants are included in Table 3.3. The segregation ratios observed in plants from these two groups are very similar, with more than $80 \%$ of 
Table 3.2. Analysis of pPRF120-encoded kanamycin resistance in the progeny of Group 1 plants.

\begin{tabular}{lrrccc}
\hline Transformant & ${ }^{\#} \mathrm{Km}^{\mathrm{r}}$ & ${ }^{\#} \mathrm{Km}^{\mathrm{s}}$ & $\begin{array}{c}\text { Observed } \\
\text { Ratio }\end{array}$ & $\begin{array}{c}\text { Expected } \\
\text { Ratio }\end{array}$ & Chi $^{2(1)}$ \\
\hline \multicolumn{5}{c}{ Single } \\
T70 & \multicolumn{5}{c}{ Dominant Gene } \\
T192 & 204 & 72 & $2.8: 1$ & $3: 1$ & 0.17 \\
T198 & 145 & 59 & $2.5: 1$ & $3: 1$ & 1.67 \\
T289 & 129 & 38 & $3.4: 1$ & $3: 1$ & 0.45 \\
T349 & 116 & 43 & $2.7: 1$ & $3: 1$ & 0.35 \\
T392 & 155 & 46 & $3.3: 1$ & $3: 1$ & 0.38 \\
T443 & 265 & 24 & $2.7: 1$ & $3: 1$ & 0.18 \\
T459 & 84 & 28 & $3: 1$ & $3: 1$ & 0.00 \\
T462 & 283 & 88 & $3.2: 1$ & $3: 1$ & 0.32 \\
T470 & 83 & 28 & $3: 1$ & 0.35 \\
T475 & 109 & 25 & $4.4: 1$ & $3: 1$ & 2.87 \\
T636 & 331 & 95 & $3.5: 1$ & $3: 1$ & 1.66 \\
T642 & 193 & 60 & $3.2: 1$ & $3: 1$ & 0.22 \\
T667 & 184 & 61 & $3: 1$ & $3: 1$ & 0.00 \\
T710 & 138 & 51 & $2.7: 1$ & $3: 1$ & 0.40 \\
T842 & 107 & 40 & $2.7: 1$ & $3: 1$ & 0.38 \\
T935 & 118 & 32 & $3.7: 1$ & $3: 1$ & 1.07 \\
T1010 & 70 & 25 & $2.8: 1$ & $3: 1$ & 0.09 \\
T1136 & 222 & 78 & $2.8: 1$ & $3: 1$ & 0.16 \\
T1218 & 119 & 45 & $2.6: 1$ & $3: 1$ & 0.52 \\
T1243 & 77 & 24 & $3.2: 1$ & $3: 1$ & 0.08 \\
& 251 & 88 & $2.9: 1$ & $3: 1$ & 0.17
\end{tabular}

Two Independent Dominant Genes

$\begin{array}{llllll}\text { T1018 } & 242 & 15 & 16: 1 & 15: 1 & 0.07\end{array}$

Possible Homozygous Recessive Lethal

T819

$330 \quad 143$

$2.3: 1$

$2: 1$

2.07

All Sensitive

T873

N.A. N.A.

$0: 1$

$0: 1$

N.A.

Anomalous Ratios

T558

$333 \quad 85$

$3.9: 1$

$4: 1$

0.03

1 expected ratio not significantly different from observed ratio at the $95 \%$ confidence interval.

N.A. not applicable 
Table 3.3. Analysis of pPRF120-encoded kanamycin resistance in the progeny of Group 2 plants.

\begin{tabular}{|c|c|c|c|c|c|}
\hline Transformant & ${ }^{\#} \mathrm{Km}^{\mathrm{r}}$ & ${ }^{\#} \mathbf{K m}^{\mathbf{s}}$ & $\begin{array}{c}\text { Observed } \\
\text { Ratio }\end{array}$ & $\begin{array}{l}\text { Expected } \\
\text { Ratio }\end{array}$ & $\mathrm{Chi}^{2(1)}$ \\
\hline \multicolumn{6}{|c|}{ Single Dominant Gene } \\
\hline $\begin{array}{l}\text { T24 } \\
T 30 \\
T 61 \\
T 62 \\
T 116 \\
T 165 \\
T 218 \\
T 252 \\
T 338 \\
T 348 \\
T 356 \\
T 371 \\
T 411 \\
T 418 \\
T ! 303 \\
T 612 \\
T 668 \\
T 777 \\
\text { T804 } \\
\text { T919 } \\
\text { T926 } \\
\text { T1019 } \\
\text { T1041 } \\
\text { T1275 }\end{array}$ & $\begin{array}{r}110 \\
283 \\
102 \\
86 \\
252 \\
618 \\
198 \\
400 \\
335 \\
120 \\
162 \\
105 \\
5 \\
71 \\
133 \\
714 \\
57 \\
402 \\
415 \\
208 \\
435 \\
23 \\
710 \\
262\end{array}$ & $\begin{array}{r}33 \\
106 \\
28 \\
28 \\
66 \\
193 \\
54 \\
131 \\
125 \\
38 \\
40 \\
27 \\
2 \\
14 \\
45 \\
226 \\
15 \\
134 \\
120 \\
61 \\
152 \\
8 \\
232 \\
88\end{array}$ & $\begin{array}{r}3.3: 1 \\
2.7: 1 \\
3.6: 1 \\
3.1: 1 \\
3.8: 1 \\
3.2: 1 \\
3.7: 1 \\
3.1: 1 \\
2.9: 1 \\
3.2: 1 \\
4.1: 1 \\
3.9: 1 \\
2.5: 1 \\
5: 1 \\
3: 1 \\
3.2: 1 \\
3.8: 1 \\
3: 1 \\
3.5: 1 \\
3.4: 1 \\
2.9: 1 \\
2.9: 1 \\
3.1: 1 \\
3: 1\end{array}$ & $\begin{array}{l}3: 1 \\
3: 1 \\
3: 1 \\
3: 1 \\
3: 1 \\
3: 1 \\
3: 1 \\
3: 1 \\
3: 1 \\
3: 1 \\
3: 1 \\
3: 1 \\
3: 1 \\
3: 1 \\
3: 1 \\
3: 1 \\
3: 1 \\
3: 1 \\
3: 1 \\
3: 1 \\
3: 1 \\
3: 1 \\
3: 1 \\
3: 1\end{array}$ & $\begin{array}{l}0.28 \\
1.05 \\
0.83 \\
0.01 \\
3.06 \\
0.63 \\
1.71 \\
0.03 \\
0.28 \\
0.76 \\
2.91 \\
1.45 \\
0.22 * \\
3.30 \\
0.01 \\
0.46 \\
0.67 \\
0.00 \\
1.88 \\
0.77 \\
0.25 \\
0.01 * \\
0.07 \\
0.00\end{array}$ \\
\hline
\end{tabular}

Two Independent Dominant Genes
T97
$174 \quad 10$
$17: 1$
$15: 1$
0.21

Possible Homozygous Recessive Lethal

$\begin{array}{lrrrrr}T 463 & 152 & 69 & 2.2: 1 & 2: 1 & 0.45 \\ \text { T1253 } & 359 & 155 & 2.3: 1 & 2: 1 & 2.36\end{array}$

Anomalous Ratios

\begin{tabular}{lrrrrr} 
T439 & 457 & 90 & $5.1: 1$ & $5: 1$ & 0.02 \\
T1169 & 272 & 189 & $1.4: 1$ & $3: 2$ & 0.19 \\
\hline
\end{tabular}

1 expected ratio not significantly different from observed ratio at the $95 \%$ confidence interval.

* indicates plants which were not included in analyses due to the low number of seedilings which were counted. 
individuals segregating for the presence of a single locus which is inherited in a Mendelian fashion. The segregation patterns of the remaining plants are consistent with the presence of either two unlinked loci (T97; T1018), two closely linked loci (T439; T558), no T-DNA insertion (T873), or one homozygous lethal locus (T463; T819; T1253). Data obtained with the remaining plant (T1169) could not be interpreted within the context of any of the above possibilities. In a previous report (Heberle-Bors et al., 1988) individuals which segregated for the presence of a single, homozygous lethal T-DNA locus in one generation did not continue to do so in subsequent generations. To investigate the possibility that pPRF120 integration had caused a lethal insertional mutation in the transformants segregating with a 2:1 $\left(\mathrm{Km}^{\mathrm{r}}: \mathrm{Km}^{\mathrm{S}}\right)$ ratio, several of the kanamycin-resistant seedlings from plant $\mathrm{T} 819$ were transferred to the greenhouse and allowed to set seeds. These were covered with a bag to ensure self fertilization. Patterns of kanamycin segregation were analyzed in the resulting seedlings ( $R_{2}$ generation). Data is presented in Table 3.4. As indicated by the presence of $\mathbf{R}_{\mathbf{1}}$ individuals which produced only kanamycin resistant progeny (T819-1; T819-7; T819-8), plants homozygous for the T819 T-DNA insertion can be recovered. Thus, the T-DNA insertion in plant T819 is not homozygous lethal, as was initially suspected by the (2:1) kanamycin segregation ratio.

\section{C.2. Copy number and organization of pPRF120 T-DNA}

Southern blot analyses using GUS and npt II coding sequence probes were carried out on Group 1 and Group 2 plants to determine the number of integrated T-DNA copies and to assess the extent of T-DNA rearrangements. A schematic representation of pPRF120 T-DNA showing the location of the sequences used as probes is illustrated in Figure 3.3. In all cases, DNA was digested with Eco R1, which recognizes a unique site in the pPRF123 T-DNA. Resulting hybridization 
Table 3.4. Analysis of pPRF120-encoded kanamycin resistance in the $R_{2}$ generation of plant $T 819$.

\begin{tabular}{lccccc}
\hline Transformant & ${ }^{\#} \mathrm{Km}^{\mathrm{r}}$ & ${ }^{\mathrm{Km}_{\mathrm{Km}}}$ & $\begin{array}{c}\text { Observed } \\
\text { Ratio }\end{array}$ & $\begin{array}{c}\text { Expected } \\
\text { Ratio }\end{array}$ & $\mathrm{Chi}^{2(1)}$ \\
\hline T819-1 & 82 & 0 & $1: 0$ & $1: 0$ & $\mathrm{~N} . \mathrm{A} \cdot \mathbf{2}^{2}$ \\
T819-2 & 44 & 19 & $2.3: 1$ & $3: 1$ & $0.9^{3}$ \\
T819-4 & 24 & 6 & $4: 1$ & $3: 1$ & 0.4 \\
T819-6 & 36 & 15 & $2.4: 1$ & $3: 1$ & $0.5^{3}$ \\
T819-7 & 76 & 0 & $1: 0$ & $1: 0$ & N.A. \\
T819-8 & 61 & 0 & $1: 0$ & $1: 0$ & N.A.4 \\
T819-9 & 34 & 11 & $3.1: 1$ & $3: 1$ & 0.0 \\
T819-11 & 6 & 2 & $3: 1$ & $3: 1$ & 0.0 \\
\hline
\end{tabular}

1 expected ratio not significantly different from observed ratio at the $95 \%$ confidence interval.

2 not applicable

3 not significantly different from $2: 1$ ratio

4 not significantly different from $15: 1$ ratio 
Figure 3.3. Map of the T-DNA portion of pPRF120. Areas of the GUS and npt II genes used as hybridization probes are shown as \#1 and \#2, respectively. The distance between the Eco R1 site and the right (RB) and left (LB) T-DNA border repeats are also indicated. Other symbols used are the same as in Figure 2.1. 


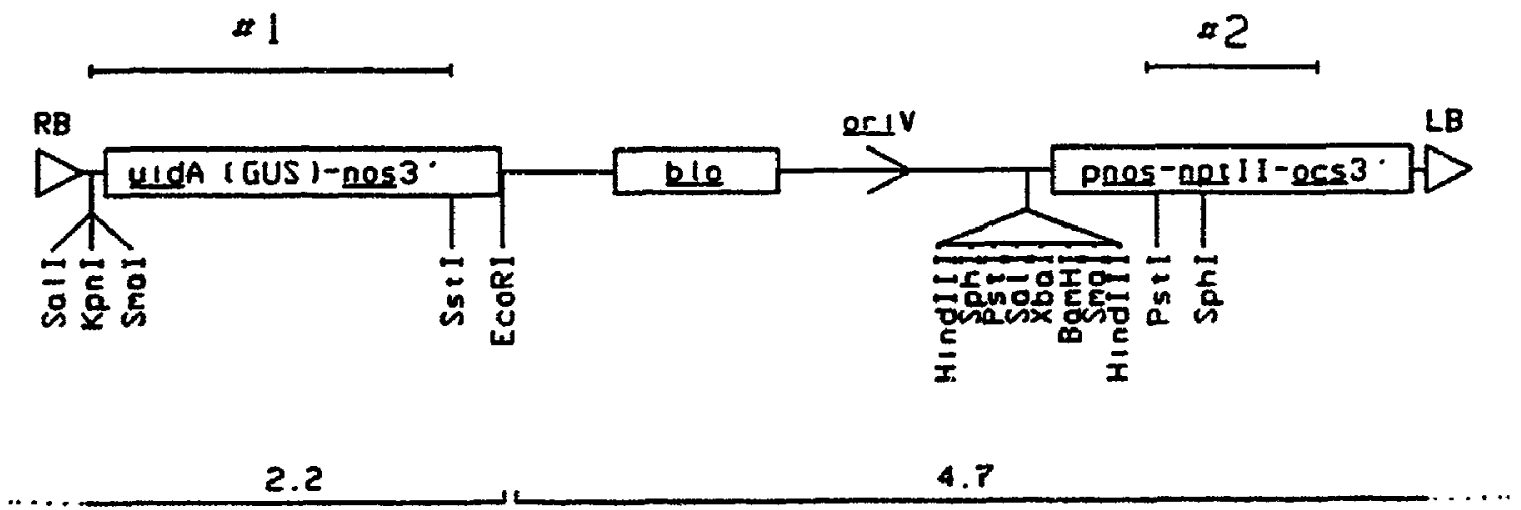

500 bp 
fragments observed on autoradiographs are thus composed of both T-DNA and flanking tobacco DNA sequences. The length of these fragments vary, depending on the location of the nearest Eco R1 site flanking the integrated T-DNA. Consequently, the number of T-DNA inserts was expected to equal the number of bands detected. Results obtained with Group 1 and Group 2 plants are presented in Figure 3.4 and Figure 3.5, respectively. Consistent with results from kanamycin segregation analyses, most plants contain only one hybridization band (see below). The size of the bands is variable, as expected for integrations at different sites, and in all cases equals or exceeds the distance between the internal Eco R1 site and the ends of the T-DNA (2.2 kb for the GUS probe; $4.7 \mathrm{~kb}$ for the $n p t$ II probe). DNA from an untransformed tobacco plant failed to hybridize to either probes (Figure 3.4).

All of the plants which segregated for the presence of a single T-DNA locus (3:1, 2:1 or $\left.<2: 1 \mathrm{Km}^{\mathrm{r}}: \mathrm{Km}^{\mathrm{S}}\right)$ contained single hybridization bands when hybridized with the npt II probe (Table 3.2; Table 3.3; Figure 3.4; Figure 3.5; summarized in Table 3.5, Classes 2-6). These individuals account for more than $85 \%$ of the plants analyzed. The most prevalent class $(80 \%)$ represents transformants containing unique GUS and npt II bands, and segregate 3:1 for kanamycir: resistance (Table 3.5, Class 2). Two plants (4\%), T642 and T819, revealed npt II bands but failed to hybridize to the GUS probe (Figure 3.4; Table 3.5, Class 5 and 6), suggesting that their T-DNA has undergone extensive deletions at the right border. The one plant which failed to produce kanamycin resistant seedlings (T873) was also the only plant which did not hybridize to the npt II probe (Figure 3.4; Table 3.5, Class 1). In addition, this plant failed to hybridize to the GUS coding sequence probe, suggesting that it did not contain any T-DNA sequences. It may represent either a non-transformed plant which grew despite the presence of kanamycin in the medium, or a transformed plant which has lost the T-DNA. The remaining 6 plants 
Figure 3.4. Southern blot analysis of Group 1 plants. DNA from plants which had not been analyzed for the presence of T-DNA-mediated gene fusions was digested with Eco R1 and hybridized using probes specific to the GUS coding region (GUS) and the npt II coding region (NPT II). A map of the pPRF120 T-DNA and the location of the fragments used as probes are included in Figure 3.3. Hybridization results of DNA from an untransformed plant (UNT.) is also presented. Molecular weight markers are in kilobase pairs. 

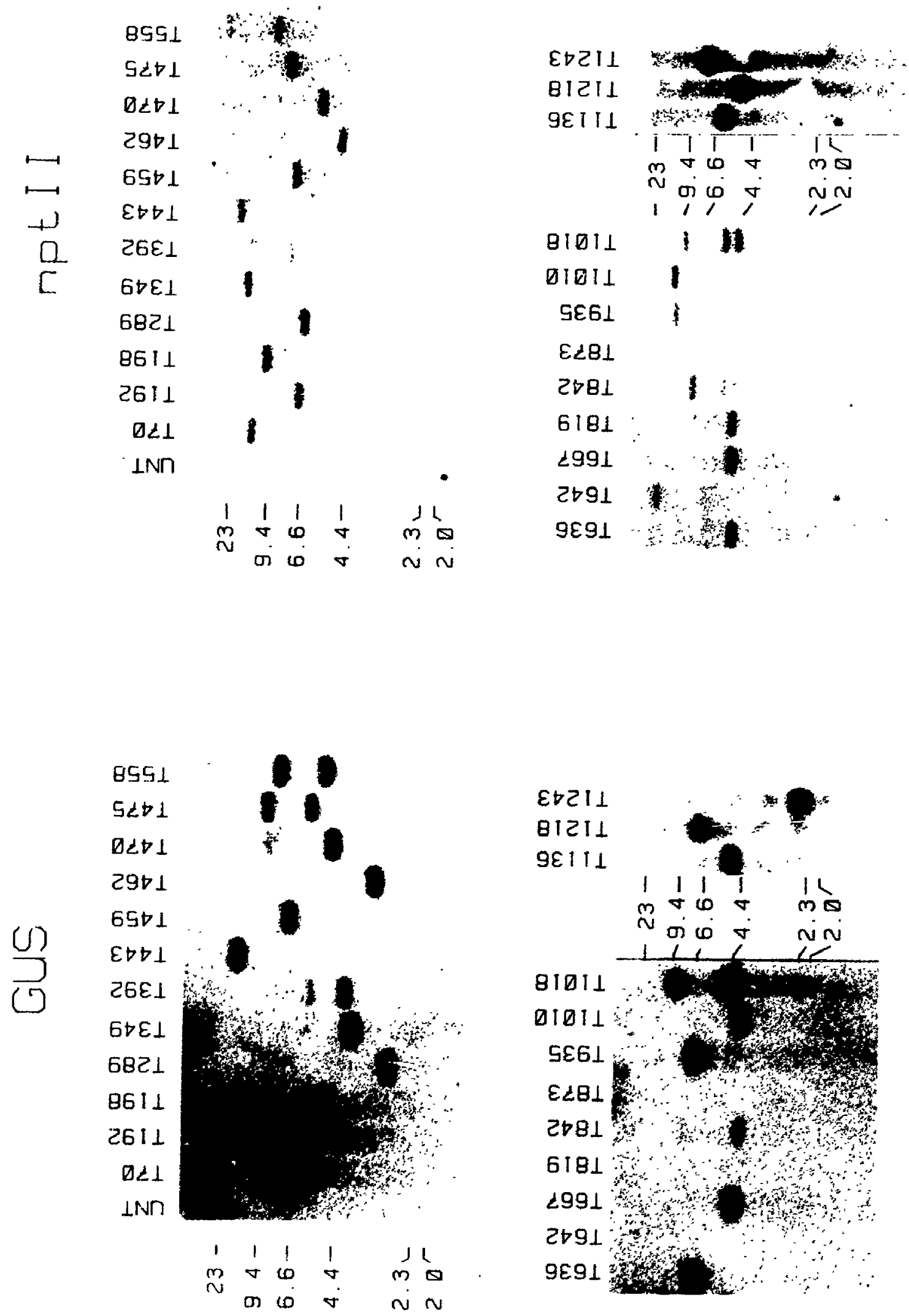
Figure 3.5. Southern blot analysis of Group 2 plants. DNA from plants which expressed a T-DNA-mediated gene fusion was digested with Eco R1 and hybridized using probes specific to the GUS coding region (GUS) and the npt Il coding region (NPT II). A map of the pPRF120 T-DNA and the location of the fragments used as probes are included in Figure 3.3. Molecular weight markers are in kilobase pairs. 

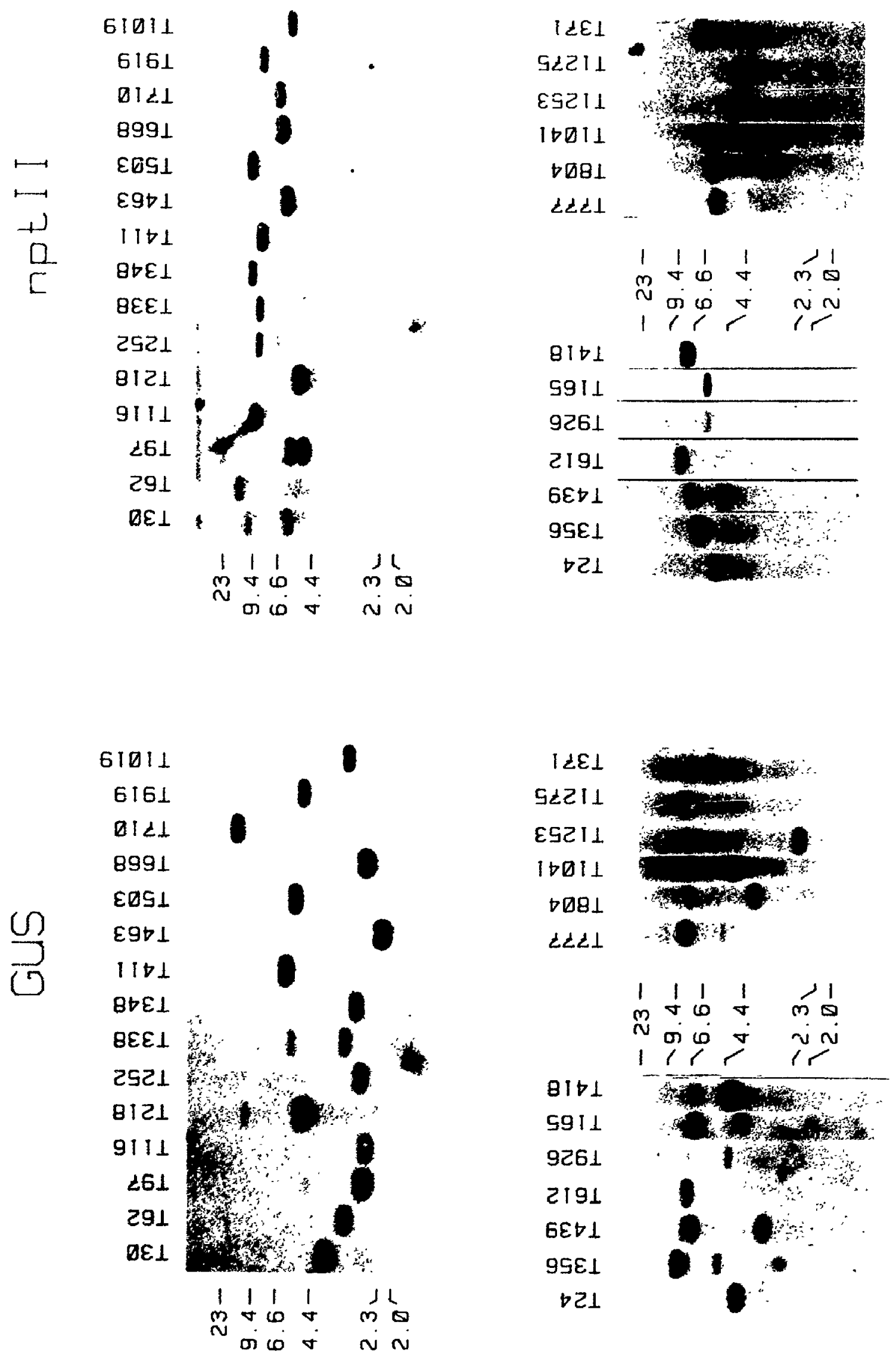


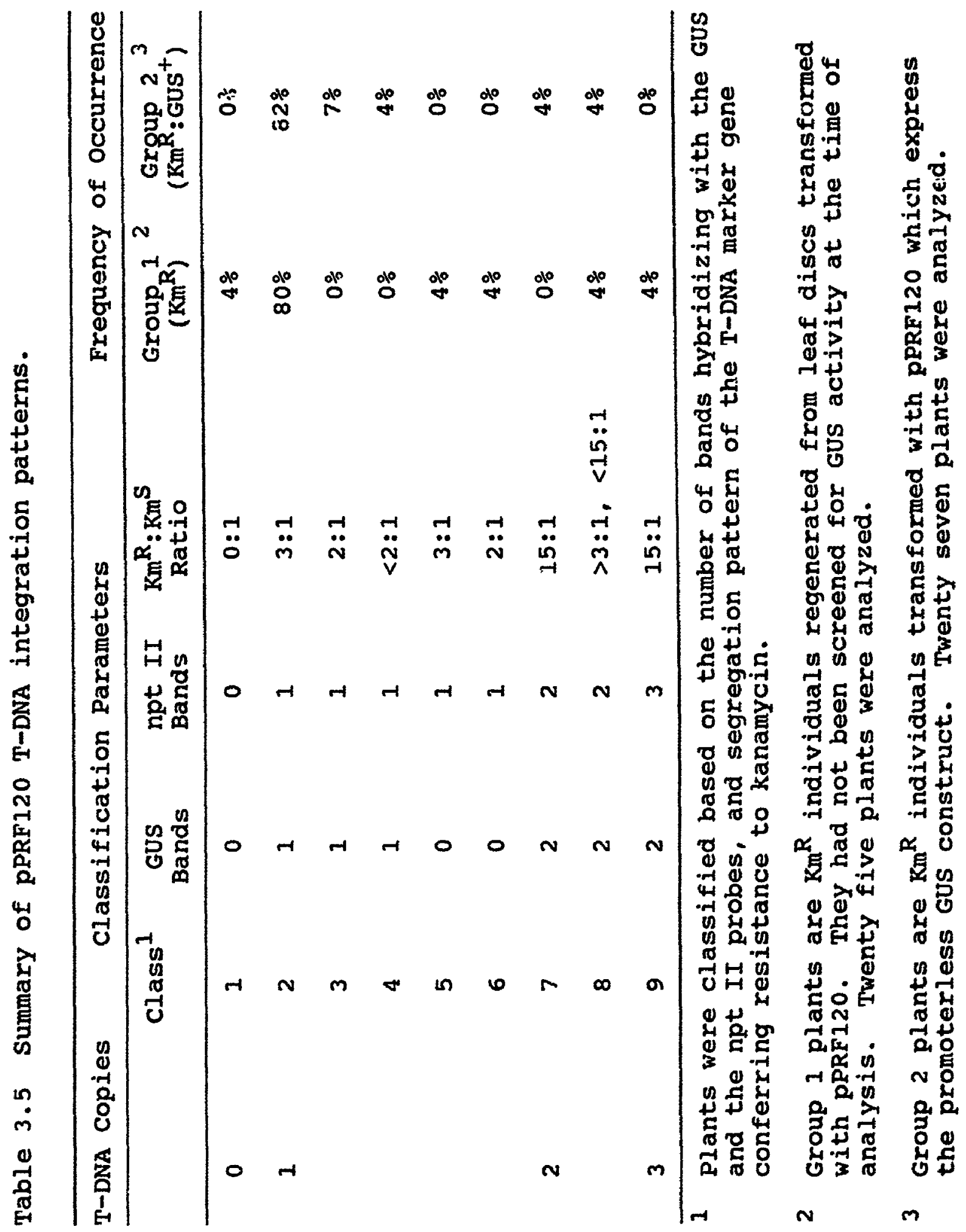


(12\%) analyzed contained either 2 or 3 copies of the T-DNA (Table 3.5, Classes 79). One plant (T1018) appeared to have different copy numbers of the GUS and npt II genes (Table 3.5, Class 9). These results were confirmed by Southern hybridization using different restriction enzymes ( $\mathrm{Xba} 1$ and $H$ ind III, data not shown). In addition, Southern blotting of DNA digested with these two restriction enzymes confirmed that plant T97 contains 2 copies of both the GUS and npt II regions. Apparently, the single band observed in the Eco R1 digest hybridized with the GUS probe represents a doublet (Figure 3.5). Segregation analyses of plants containing more than 1 copy of the T-DNA indicates that these are integrated at no more than 2 different chromosomal loci (Table 3.2; Table 3.3; Table 3.5, Classes 79). Based on the kanamycin segregation ratios, the 2 T-DNA copies in plants T439 and T558 appear to be closely linked (Table 3.5, Class 8).

\section{C.3. Kanamycin segregation and Southern blot analysis of pBIN19 derivatives}

Patterns of integration of PPRF120 were compared to those of derivatives of the widely used binary vector, pBIN19. Plants transformed with the three plasmids, pBI101, pBI121, and pnos-GUS, were studied. The 3 vectors differ only in the nature of the promoter cassette inserted upstream of the GUS coding sequence (Figure 3.6-B). Three independent transformants were studied for each of these vectors. Results from kanamycin segregation in $R_{1}$ seedlings are presented in Táble 3.6. Altnough the number of individuals analyzed with each vector is too small to permit meaningful comparisons to be made, the general trend suggests that more plants contain T-DNA inserts at multiple loci than was observed with pPRF120 (Table 3.2; Table 3.3). Multiple copies of the T-DNA in pBIN19 derivatives was confirmed by Southern blot analyses. These analyses were performed as indicated for plants transformed with pPRF120, except that DNA was isolated from 3 kanamycin-resistant progeny of each transformant, and digested with Hind III 
Figure 3.6. Southern blot analysis of plants transformed with derivatives of pBIN19. (A) Southern blot analysis with a GUS-specific probe of plants transformed with pBI101 $(\phi 1, \phi 2)$, pnos-GUS (N2), or pBI121 $(C 4, C 7)$. Molecular weight markers are in kilobase pairs.

(B) Map of the T-DNA region of pBI101, pnos-GUS, and pBI121. The portion of the T-DNA which was used as hybridization probe is labelled \#1. PNOS, nopaline synthase promoter; P35S, cauliflower mosaic virus 35S promoter. Other symbols used are the same as in Figure 2.1. 
A.

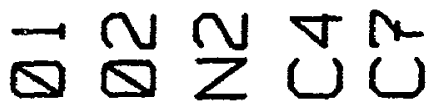

$$
\begin{aligned}
& \begin{array}{l}
23.1- \\
9.4- \\
6.6 r \\
4.4- \\
2.3- \\
2.0
\end{array}
\end{aligned}
$$

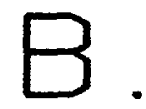

(pnos-GUS )

$|p B||2| \mid$ (pBIIOI)

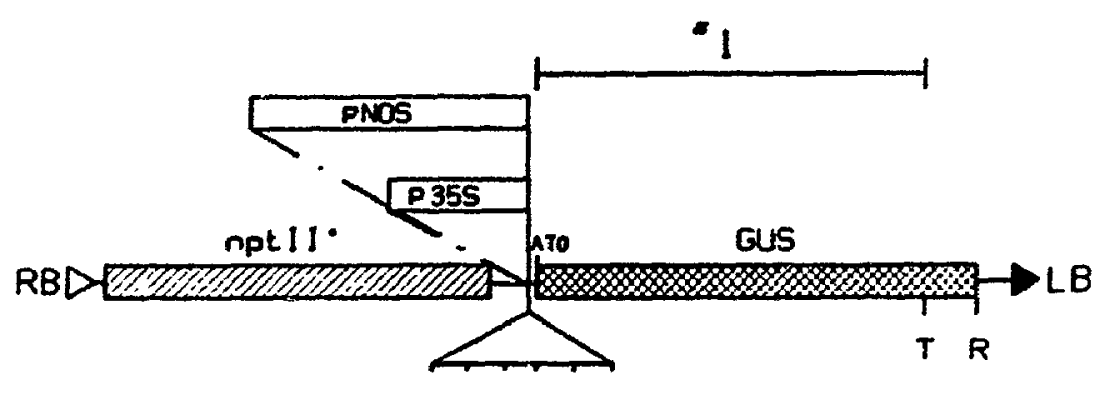

HPSXB Sm 
Table 3.6 . Analysis of kanamycin resistance in the progeny of plants transformed with the pBIN19 derivatives pBI101. pBI121 and pnos-GUS.

Transformant ${ }^{\#} \mathrm{Km}^{\mathrm{r}} \quad{ }^{\#} \mathrm{Km}^{\mathrm{s}} \quad \begin{gathered}\text { Observed } \\ \text { Ratio }\end{gathered} \begin{gathered}\text { Expected } \\ \text { Ratio }\end{gathered} \mathrm{Chi}^{2(1)}$

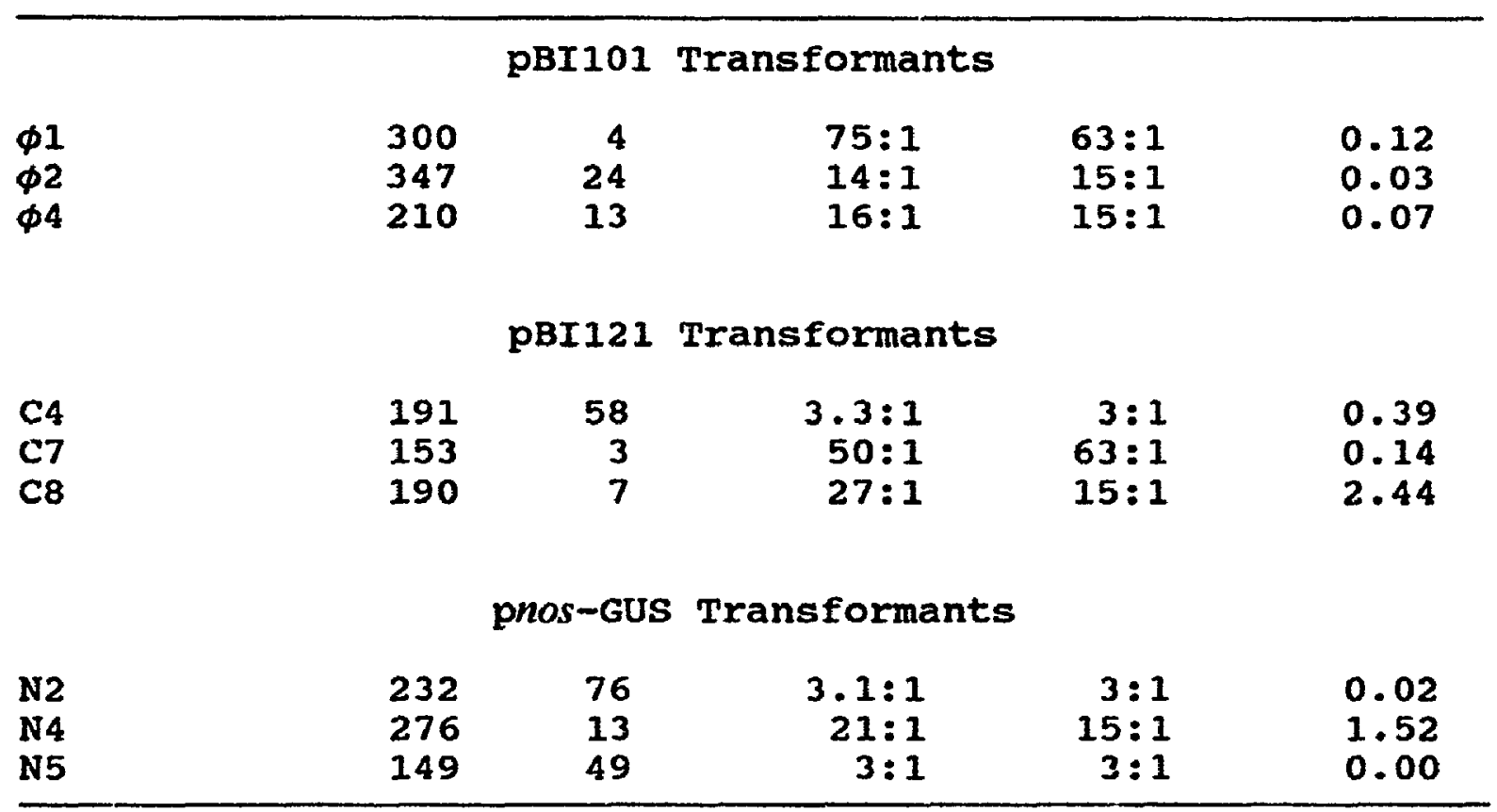

1 expected ratio not significantly different from observed ratio at the $95 \%$ confidence interval. 
instead of Eco R1. Hind III only cleaves the T-DNA in these plants once, with the left border fragment hybridizing to the GUS-specific probe. Results presented in Figure 3.6-A show typical data of Southern hybridization using the GUS-specific probe. The number of hybridizing bands detected varied from 1 to 5 , with the majority of the plants containing 2 or more bands (Figure 3.6; summarized in Table 3.7). In two plants ( $\phi 4$ and $C 7$ ) the number of hybridization bands exceeds the number of loci segregating for kanamycin resistance.

\section{D. Analysis of T-DNA-Mediated Gene Fusion Expression}

In addition to estimating the frequency at which the T-DNA integrates within transcriptionally active DNA, the expression patterns conferred onto the promoterless gene by flanking cis-acting elements can be used as a means of characterizing chromosomal regions into which the T-DNA has inserted. In this study, use of GUS as a promoterless reporter permitted detailed quantitative, as well as in situ analysis of gene fusion expression.

\section{D.1. Preliminary analysis of GUS expression}

The first step in the analysis of GUS expression was to confirm that the enhanced fluorescence detected in extracts of plants putatively expressing T-DNAmediated gene fusions was due to GUS-dependent production of methylumbelliferone. This was demonstrated by a series of assays in which the assay buffer contained both MUG and saccharo lactone (Sigma, St-Louis, MO, cat. no. S-0375), an inhibitor of B-glucuronidases (Jefferson, 1987). This treatment reduced the rate of fluorescence production to those of untransformed extracts (Figure 3.7). The omission of MUG from the assay buffer eliminated fluorescence production (data not shown). In addition, fluorescence was not reduced by 
Table 3.7. Summary of analysis of $T$-DNA integration in plants transformed with vectors derived from pBIN19.

\begin{tabular}{lccc}
\hline Vector & Plant & $\begin{array}{c}\text { GUS } \\
\text { Bands }\end{array}$ & $\begin{array}{c}\text { Number of } \\
\text { Loci }\end{array}$ \\
\hline pBI101 & $\phi 1$ & 3 & 3 \\
& $\phi 2$ & 2 & 2 \\
& $\phi 4$ & 3 & 2 \\
pBI121 & C4 & 1 & 1 \\
& C7 & 5 & 3 \\
& C8 & 2 & 2 \\
pnos-GUS & N2 & 2 & 1 \\
& N4 & 2 & 2 \\
& N5 & 1 & 1 \\
\hline
\end{tabular}


Figure 3.7. Effect of saccharo lactone on fluorescence production (nM methylumbelliferone) from transformed and untransformed leaf extracts. Assays were performed as detailed in section 2.0., except that the $\mathrm{pH}$ of the solution was changed from 7.0 to 6.0 to stabilize the inhibitor. Aliquots of assay reactions with and without saccharo lactone were removed after 1,2, and $3 \mathrm{hr}$, stopped by addition of sodium carbonate and quantified by fluorometry using methylumbelliferone as standard. Note the linear reaction kinetics for samples T30 and T61 in the absence of the inhibitor.

$\square$ T30 leaf (collected from a greenhouse-grown plant)

T30 leaf $+5 \mathrm{mM}$ saccharo lactone

$\Delta$ T61 leaf (collected from a greenhouse-grown plant)

$\Delta$ T61 leaf $+5 \mathrm{mM}$ saccharo lactone

O untransformed (SR1) leaf

- untransformed leaf + $5 \mathrm{mM}$ saccharo lactone 


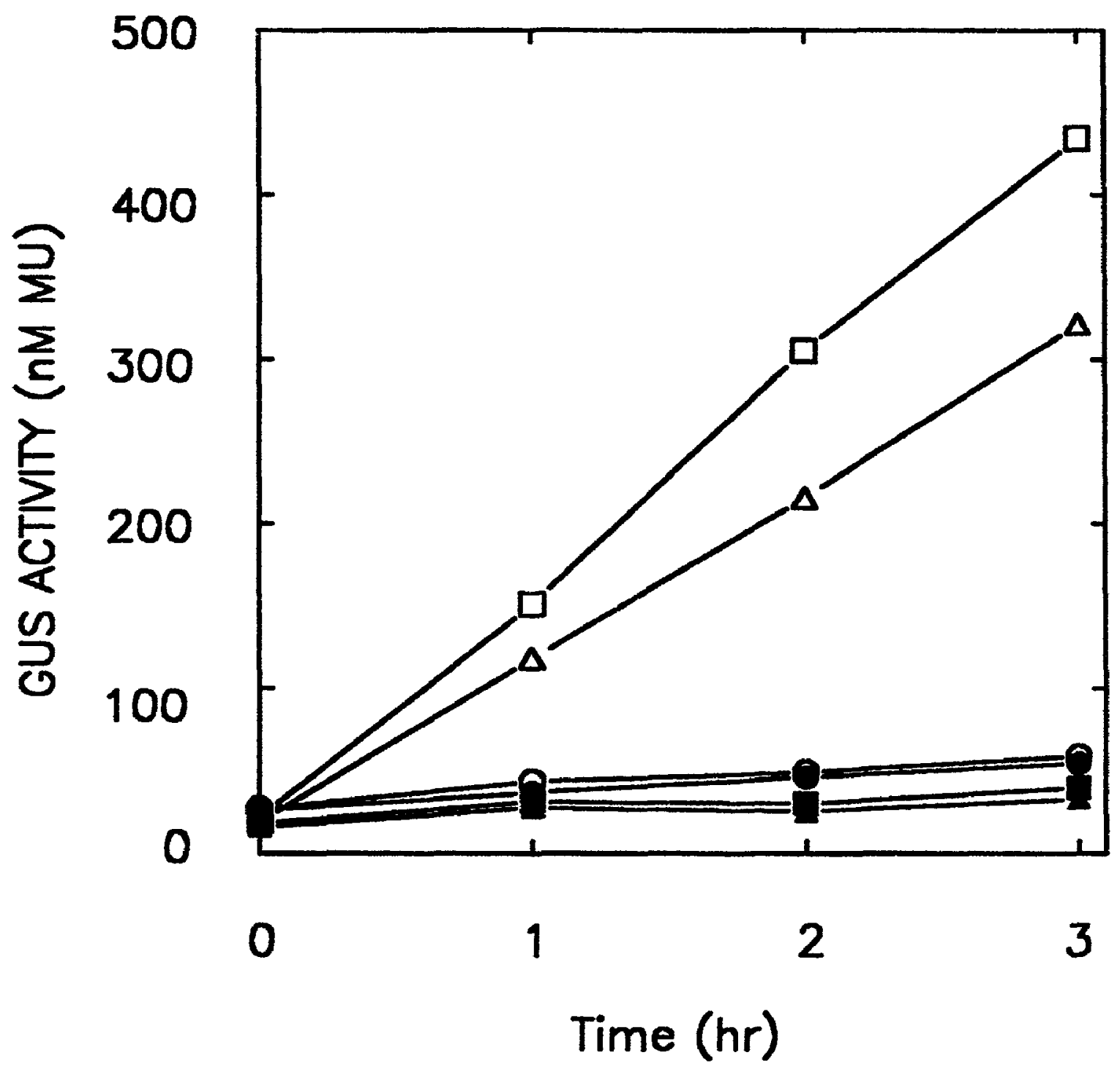


extraction of tissue with polyclar (insoluble polyvinyl pyrollicione) or activated charcoal, or chromatography through a Sephadex G-25 sieve, all treatments which can eliminate endogenous polyphenolics. These observations, along with the linear kinetics of the assay suggest that results obtained were not due to the presence of endogenous fluorescent compounds.

\section{D.1.a. Histological analysis of GUS activity in seedlings}

Patterns of GUS activity in 61 of the 62 plants expressing either a Class I or Class II fusion were analyzed in kanamycin resistant $\left(\mathbf{R}_{1}\right)$ seedlings by histological staining with X-GLUC. With the exception of a few plants, at least 6 kanamycin resistant progeny were tested to ensure that the patterns of GUS activity observed were reflective of gene fusion expression. Data are summarized in Table 3.8 and examples of some of the patterns observed are shown in Figure 3.8 and Figure 3.9. Expression of most gene fusions was detected in the leaf, stem and root of the seedlings (41\%; Table 3.8, subclass 1; Figure 3.8-A), or was restricted to the leaf and stem (30\%; Table 3.8, subclass 2; Figure 3.8-B). Seedlings from 6 of the transformants containing Class I gene fusions stained for GUS activity only in organs other than the leaf (Table 3.8, subclasses 3 and 4; Figure 3.8-C and -D), while seedlings from 7 individuals did not stain at all for GUS activity (Table 3.8, subclass 8; Figure 3.9-B). These results were unanticipated, as all other gene fusions were identified by their ability to be expressed in leaf tissue (see Figure 3.2). Such results are probably related to the greater sensitivity of the fluorogenic assay (Hobbs et al., 1990; Jefferson, 1987; see below).

Only two organ-specific Class I gene fusions were detected. These were both stem-specific (Table 3.8, subclass 4). In addition, seedlings from one of Class II gene fusions (T418) also expressed GUS in a stem-specific manner (Table 3.8, subclass 10). All other plants expressing Class II fusions did not stain for GUS 
Table 3.8. Patterns of GUS staining in kanamycin-resistant $R_{1}$ seedlings of pPRF120 transformants.

\begin{tabular}{|c|c|c|c|c|c|}
\hline Class & Subclass & organs staining & $g$ for GUS & Number of & Plants \\
\hline \multirow[t]{9}{*}{$\mathbf{I}$} & 1 & LEAF - STEM - & - ROOT & $25^{1}$ & \\
\hline & 2 & LEAF - STEM & & 18 & \\
\hline & 3 & STEM - & - ROOT & 4 & \\
\hline & 4 & STEM & & 2 & \\
\hline & 5 & LEAF & & 0 & \\
\hline & 6 & LEAF - & ROOT & 0 & \\
\hline & 7 & & ROOT & 0 & \\
\hline & 8 & NO ACTIVITY & DETECTED & 7 & \\
\hline & 9 & NOT ASSAYED & & $1^{2}$ & \\
\hline \multirow[t]{3}{*}{ II } & 10 & STEM & & 1 & \\
\hline & 11 & NO ACTIVITY I & DETECTED & 4 & \\
\hline & TOTAL & & & 62 & \\
\hline
\end{tabular}

1 Includes 2 individuals (T30; T919) that stained speci.'ically in vascular tissues of these organs and one (T804) which expressed GUS in vascular tissues of the leaf only

2 Represents plant T25 which did not produce seeds 
Figure 3.8 Patterns of GUS expression in the progeny of plants transformed with pPRF120. Seedlings were analyzed by histological assay using X-GLUC as described in section 2.0.2. Individuals analyzed were: (A) Tó12, (B) T348, (C) T1193, (D) T418, (E-G) T919. Bar = $5 \mathrm{~mm}$ of A-E and $1 \mathrm{~mm}$ for F and G. A-E, seedlings assayed 4-6 weeks after sowing; F, cross-section of midveins from in vitrogrown plants; $G$, cross-section of stems from in vitro-grown plants. 


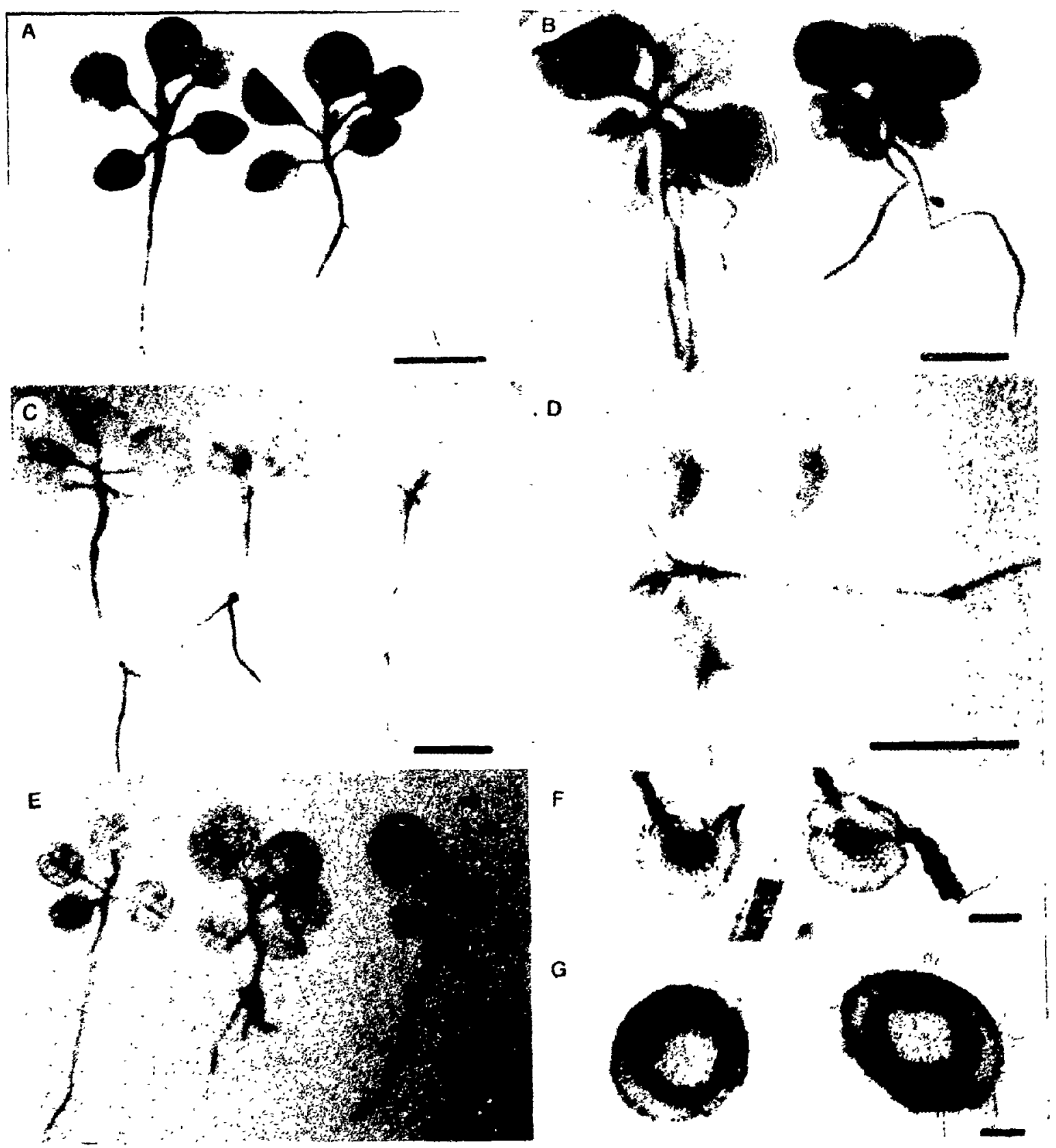


Figure 3.9. Histological analysis of GUS expression in seedlings of pPRF120 transformants showing variation in expression patterns. Seedlings were analyzed as described in section 2.0.2. (A) T62, (B) T1169, (C) T411, (D) T338. All plants, except T62 were placed on filter paper and photographed. Plant T62 was placed in a glass Petri dish and photographed using back-lighting which resulted in different colouration. Bar $=5 \mathrm{~mm}$. 

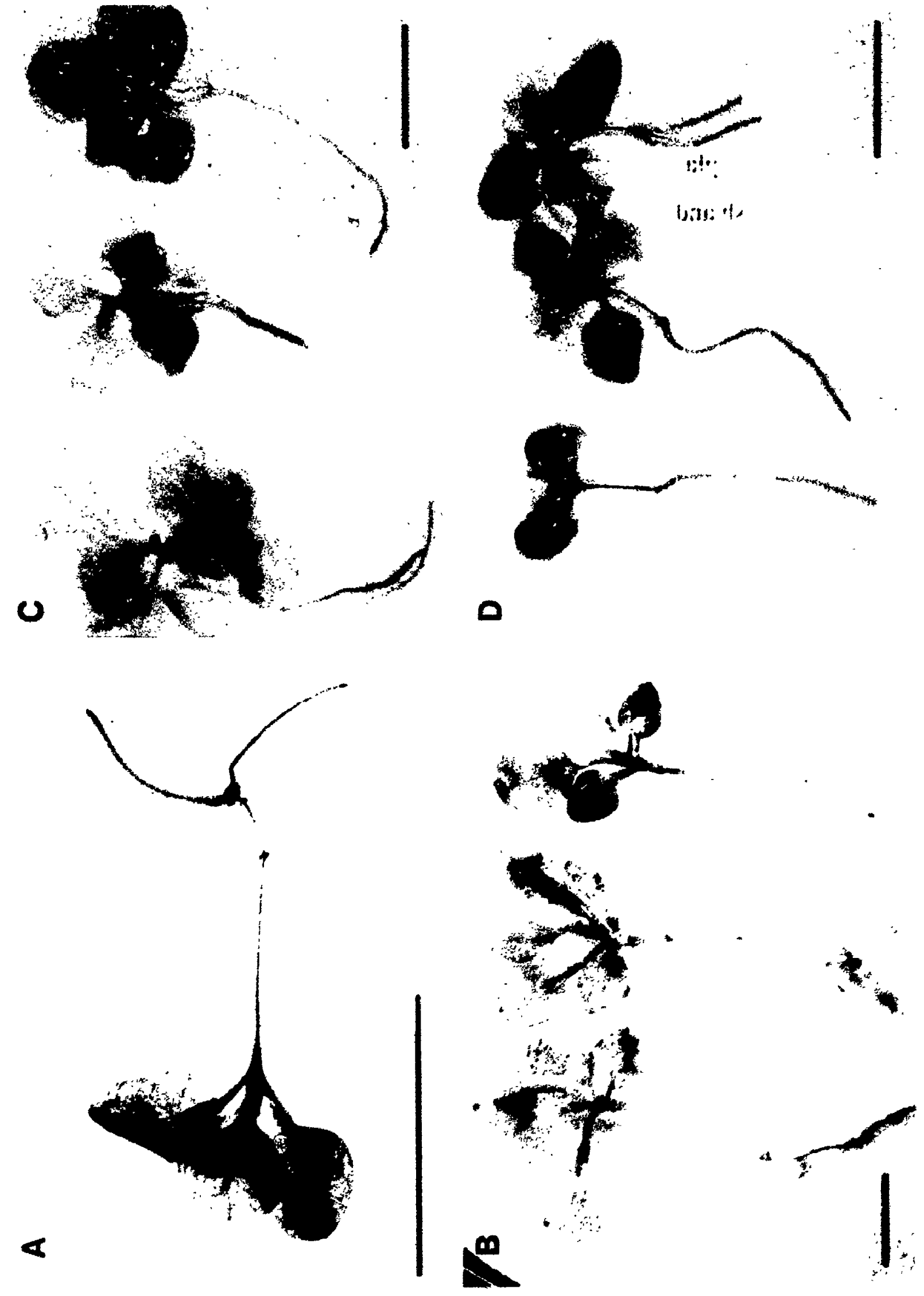
activity in seedlings and are represented in subclass 11 (Table 3.8; Figure 3.9-A). Leaf-specific and root-specific patterns of expression were not detected.

Histological staining also revealed the tissue- and cell-specificity of GUS activity. Vascular-specific expression was detected in the leaf, stem and root of two plants, T30 and T919 (Figure 3.8-E). One additional plant, T804, expressed GUS in the vascular tissue of the leaf only (data not shown). In the remaining plants, GUS staining showed no tissue-specificity. Many instances of constitutive expression at the cellular level were observed. In these cases, the indigo precipitate, indicative of GUS activity, was detectable throughout the different cell types of an organ (Figure 3.8-A, -B). "Constitutive" staining was not always evenly distributed. Some examples of the variability in staining intensities and patterns are presented in Figure 3.9. Seedlings of plant T1169 stained evenly throughout, except that the reaction was sometimes more intense near stomatal guard cells of the leaf (Figure 3.9-B) Leaves of seedlings from plants T411 (Figure 3.9-C) and T777 (Figure 3.10-R) showed more variation in patterns of GUS staining. With plant T411, several leaves did not stain for GUS activity, while other leaves contained large sectors which stained blue. GUS activity in the roots of these seedlings was only detectable in the area most distal to the stem, although it was not always observed in the root apex per se. Patterns of staining in leaves of T777 seedlings were also uneven, although the size of the staining sectors were much smaller than those observed in T411 leaves and the number of staining sectors is greater (Figure 3.10-R). Roots of T777 seedlings stain very intensely for the presence of GUS activity. Another unique pattern of staining was observed in leaves of T338 seedlings (Figure 3.9-D). In this case, GUS expression was only detected in the bottom pair of leaves. 
3.D.1.b. Quantitative analysis of GUS activity in vegetative organs of pPRF120 transformants

Although the results from histological analyses suggest that levels of GUS activity may vary in the different vegetative organs of plants expressing, T-DNAmediated gene fusions, this assay is not meant to be quantitative. Therefore, levels of GUS activity in the different vegetative organs of pPRF120 transformants were measured using quantitative fluorogenic assays. Organs from seven independent transformants were analyzed and levels of expression compared to those of known promoters fused to GUS. Samples were collected from kanamycin-resistant $\left(\mathbf{R}_{1}\right)$ progeny of the transformants grown in vitro to a developmental stage comparable to the one chosen for the initial screening. Results from these analyses are presented in Table 3.9. Consistent with the findings from the histological assays, all of the plants analyzed by fluorogenic assay express GUS in 2 or more organs. Four plants (T61, T629, T919, T1169) possess activity in the leaf, stem and root, whereas GUS expression in the remaining three plants (T81; T348; T463) is limited to leaf and stem tissues. The amount of GUS activity varies considerably, ranging from slightly more than 5-times the background in leaf, stem and root of plant T629 to more than 1,000-times the background only in the leaf of T1169. "1/ith the exception of T1169, the level of activity detected is comparable to those found in plants transformed with 5'nos-GUS (Table 3.10). The high level of GUS activity in plant T1169 is within the upper range of 5' CaMV 35S-GUS expression (Table 3.10). Leaves from plants transformed with $\mathrm{pBI} 101$, which contains a promoterless GUS gene oriented so that the initiation codon is not linked to a T-DNA border repeat, do not contain GUS activity (Table 3.10). The range of expression levels amongst different organs of individual plants also varied. For example, the leaf of plant T81 contains 5-times more activity than does the stem, and leaf tissue of T61 contains only one half as much activity as the stem. In contrast, little difference in activity could be 
Table 3.9. GUS activity (pmole MU/minute/mg protein) in different vegetative organs of untransformed tobacco plants and the progeny of seven plants transformed with pPRF120. Values represent the average \pm one standard deviation of nine samples for each of the untransformed organs and three samples for each of the transformed tissues, except for the roots of $T 61, T 919$ and $T 1169$ which represent the average value of two samples.

\begin{tabular}{lccc}
\hline Plant & $\begin{array}{c}\text { Leaf } \\
\text { Avg } \pm \text { std }\end{array}$ & $\begin{array}{c}\text { Stem } \\
\text { Avg } \pm \text { std }\end{array}$ & $\begin{array}{c}\text { Root } \\
\text { Avg } \pm \text { Std }\end{array}$ \\
\hline Untr. & $7 \pm 3$ & $7 \pm 3$ & $34 \pm 12$ \\
T61 & $107 \pm 8$ & $211 \pm 65$ & $367 \pm 93$ \\
T81 & $516 \pm 122$ & $99 \pm 49$ & $139 \pm 74$ \\
T348 & $122 \pm 23$ & $49 \pm 5$ & $82 \pm 26$ \\
T463 & $257 \pm 85$ & $90 \pm 24$ & $64 \pm 7$ \\
T629 & $43 \pm 22$ & $37 \pm 7$ & $243 \pm 3$ \\
T919 & $176 \pm 131$ & $440 \pm 13$ & $459 \pm 6$ \\
T1169 & $9430 \pm 4268$ & $6286 \pm 1018$ & $12690 \pm 489$ \\
\hline
\end{tabular}


Table 3.10. Gus activity in the leaves of progeny from independent transformants harboring either pBI101, phos-GUS, or pBI121. Values represent the average of 3 samples \pm one standard deviation of the mean. Units are the same as in Table 3.9 .

\begin{tabular}{cccc}
\hline PIant & $\begin{array}{c}\text { pBII01 } \\
\text { Avg } \pm \text { Std }\end{array}$ & $\begin{array}{c}\text { pnos-Gus } \\
\text { Avg } \pm \text { Std }\end{array}$ & $\begin{array}{c}\text { pBI121 } \\
\text { Avg } \pm \text { Std }\end{array}$ \\
\hline 1 & $9 \pm 0.3$ & $76 \pm 61$ & $18770 \pm 2450$ \\
2 & $11 \pm 2$ & $55 \pm 61$ & $774 \pm 441$ \\
3 & $10 \pm 1$ & $398 \pm 189$ & $8965 \pm 994$ \\
4 & & $387 \pm 533$ & $80 \pm 48$ \\
5 & & $43 \pm 46$ & \\
6 & & $3218 \pm 1160$ & \\
\hline
\end{tabular}


detected between the organs of plant T629. Leaf, stem, and root extracts from this plant all contain approximately 5 times more activity than untransformed controls. It is noteworthy that, although seedlings of plant T629 do not stain for GUS activity by histological assay, data from fluorogenic assays revealed that they consistently contain more than 5 times the background levels of GUS activity.

\section{D.2. Detailed expression analysis of T-DNA-mediated gene fusiope}

Patterns of GUS expression were more completely characterized in 14 Class I plants and in 4 of the 5 Class II plants. A total of 9 different tissues were analyzed; leaves, stems, roots, petals, anthers, ovaries, sepals, seeds 10 days post anthesis (DPA) and seeds 20 DPA. Details of sample collection are provided in Materials and Methods (section 2.0.1.a.). All of the plants which were analyzed in detail contain single, intact copies of the T-DNA, based on Southern blot analysis using GUS and npt II coding sequence probes, and segregation analysis of the kanamycinresistance marker (Figure 3.5; Table 3.3). Consequently, the observed patterns of GUS expression reflect the properties of individual gene fusions, and not the sum of expression resulting from multiple gene fusions.

Data from both histological and quantitative fluorogenic assays were combined to classify gene fusion expression patterns. Fluorogenic assays were used to determine the number and the type of organs in which a gene fusion was expressed and to compare levels of expression in different organs. Results from histological assays revealed cell- and tissue-specific patterns of gene expression within individual organs. Several patterns of gene expression have been reported in the literature, including constitutive, tissue- and organ-specific, and inducible patterns. Analysis of GUS activity in the pPRF120 transformants revealed that expression patterns of most gene fusions could not be readily classified in these torms. Consequently, the following classification system was developed. 
Unrestricted expression is defined as the detection of GUS activity in all tissues and organs examined by the fluorogenic and histological assays. Restricted expression is used to define those patterns of gene fusion expression where GUS activity failed to be detected in one or more organ or tissue. Thus, the term "restricted" is used solely to describe the spatial pattern of gene activity, and is not intended to implicate the role of any specific mechanism in gene regulation. Expression of gene fusions which were restricted to individual tissues or organs are further classified in terms of their tissue or organ specificity.

\section{D.2.a. Gene fusions expressed in an unrestricted pattern}

This expression pattern was rarely observed. Only one of the 18 plants which were studied in more detail (T1275) expressed GUS in all tissues and organs analyzed (Figure 3.10 A-I). Unrestricted expression of GUS was also observed in the vegetative organs of several other plants which were not studied in more detail. Additional analyses will be required to determine whether these gene fusions are also expressed in all floral organs and seed tissues. However, based solely on the analysis of vegetative organs, several plants revealed a restricted pattern of GUS expression (Table 3.8; Figure 3.8; Figure 3.9).

Levels of GUS activity measured in several tissues of plant T1275 are very high (Figure 3.10-A). Rates of activity in the leaf and root of this plant are within the upper range of 5' CaMV 35S-GUS expression previously detected in tobacco leaves (Table 3.10). Unrestricted expression of GUS in plant T1275 was visualized as a homogeneous blue precipitate in all tissues assayed. Examples from different vegetative organs, flowers, ovaries, seeds and embryos are provided in Figure 3.10 B-I.

It is noteworthy that, although levels of GUS activity detected in the ovaries of T1275 are rather low, this organ stained intensely blue by histological assay 
Figure 3.10. Fluorogenic and histological analyses of GUS expression in plants T1275 (A-I), T777 (J-R), and T30 (S-BB). The gene fusion of plant T1275 is expressed in an unrestricted pattern, that of $T 777$ in a restricted pattern, and that of T30 is tissue (vascular)-specific. For histograms, each bar represents the average \pm one standard deviation of three samples. Nine different tissues were analyzed: leaf (L), stem (S), root (R), anther (A), petal (P), ovary (O), sepal (Se), seeds 10 days post-anthesis (S1) and seeds 20 days post-anthesis (S2). For all measurements of GUS activity, the fraction attributed to intrinsic fluorescence, as determined by analysis of untransformed tissues, is shaded black on the graph. Absence of a black area at the bottom of a histogram indicates that the relative contribution of the background fluorescence is too small to be apparent. Note the different scales used in each histogram. For histological analyses of vegetative organs presented in Figures 3.10, 3.12 and 3.14, several samples from at least two different progeny were analyzed for each transformant. Scale bar $=5 \mathrm{~mm}$ for all photos except $\mathrm{D}, \mathrm{G}, \mathrm{H}, \mathrm{U}$, $W, Z$, and $A A$ where the bar equals $0.1 \mathrm{~mm} ; \mathrm{I}, \mathrm{O}$, and $\mathrm{P}$ where the bar equals 0.5 $\mathrm{mm}$ and $F, T$, and $B B$, where it equals $1 \mathrm{~mm} . \mathrm{B}, \mathrm{K}, \mathrm{T}=\mathrm{leaf} ; \mathrm{C}, \mathrm{L}, \mathrm{U}, \mathrm{V}=\mathrm{stem} ; \mathrm{D}$, $M, W=$ root; $E, N=$ flowers $F, Y=$ ovary; $G, H, O, Z=$ embryo; $I, P, A A=$ seed; $\mathrm{O}, \mathrm{R}, \mathrm{BB}=$ seedling; $\mathrm{X}=$ anther. Details of sample collection and assay conditions are presented in section 2.O. 

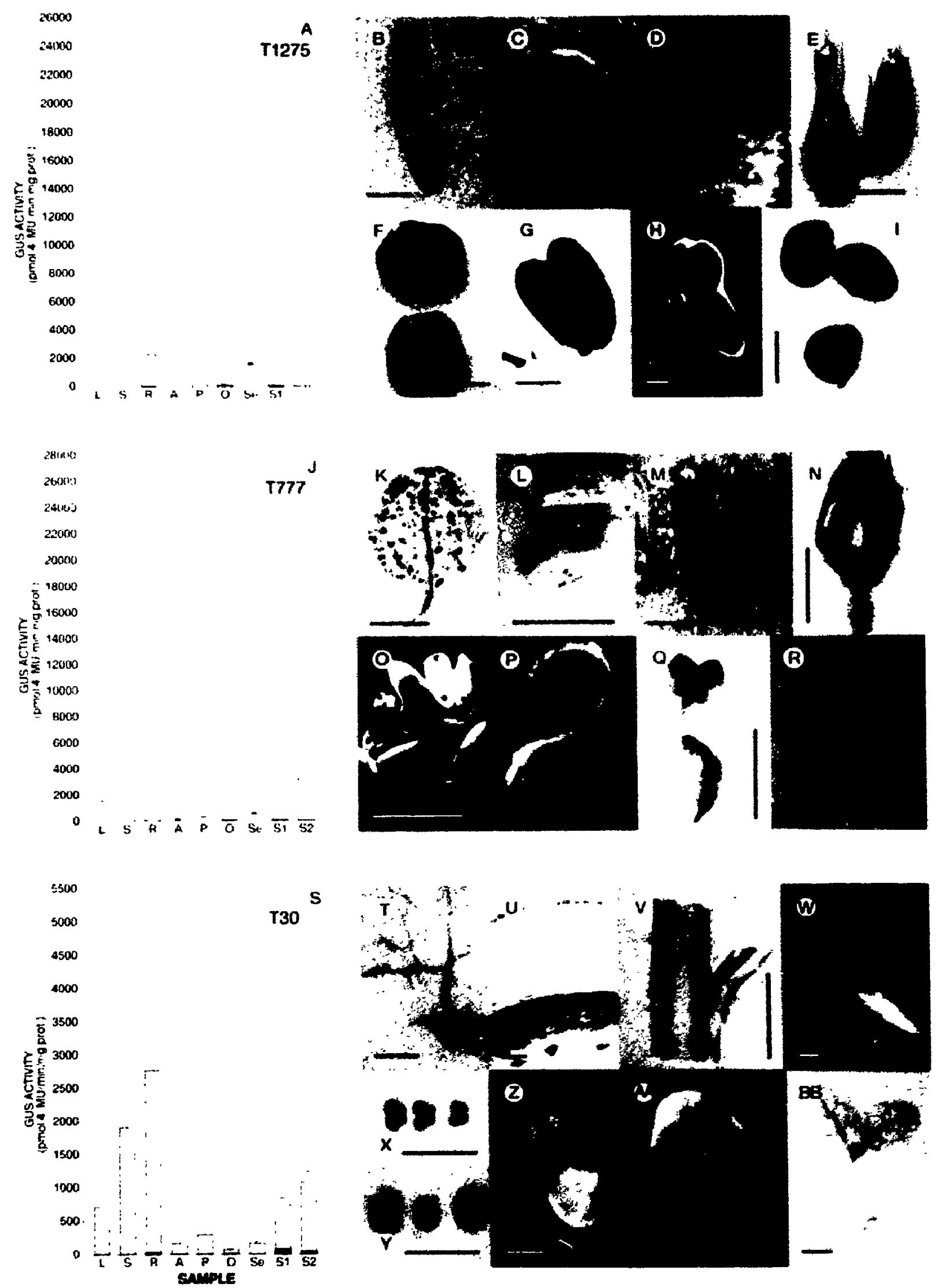
(Figure 3.10-E, F). Similar observations were made with floral organs from other transformants. Preliminary results suggest that these floral extracts may contain an inhibitor of GUS activity, which could account for such observations. Levels of GUS mRNA in tobacco flowers have recently been reported to be higher than expected based on fluorogenic assays (Topping et al., 1991). A better correlation between message levels and GUS activity was observed in the leaf and root. Although Topping et al. (1991) speculate that the apparent lower GUS activity in flowers may be related to inefficient translation, increased enzyme turnover or modification of the GUS protein, the phenomenon could also be related to the presence of an inhibitor of GUS activity. Presumably such an inhibitor would only be active after tissue extraction, as it does not appear to interfere with results of the histological assays.

\section{D.2.b. Gene fusions expressed in a restricted pattern}

Expression of most of the gene fusions identified in this study can be classified as restricted, including 12 of the 18 gene fusions which were characterized in more detail. In addition to T1275, three plants express GUS in all organs tested: T1253 (Figure 3.11), T777 (Figure $3.10 \mathrm{~J}-\mathrm{R}$ ), and T30 (Figure 3.10 S-BB). GUS activity in plant T30 is tissue-specific, and is described in a separate section (3.D.2.c.i.). Expression of the gene fusion in plant T1253 is very similar to that of plant T1275; levels of expression are very high, especially in the vegetative organs (Figure 3.11), and histological analyses indicates a homogeneous pattern of staining in all issues tested, except for seeds, where activity is observed in embryos, but not the endosperm or seed coat (data not shown). Although GUS "ctivity in plant T777 is also expressed in all organs (Figure 3.10 J-R), levels of expression are much higher in the roots than in other tissues. Relatively high rates of GUS activity were also detected in the seeds of this plant. As revealed by histological assay, the 
Figure 3.11. Quantitative analysis of GUS expression in plants containing T-DNAmediated gene fusions expressed in a restricted pattern. Each bar represents the average \pm one standard deviation of three samples, except for the leaf, stem and root of T338, which represent the average of 6 samples. Nine different tissues were analyzed: leaf (L), stem (S), root (R), anther (A), petal (Pe), ovary (O), sepal (Se), seeds 10 days post-anthesis (S1) and seeds 20 days post-anthesis (S2). For all measurements of GUS activity, the fraction attributed to intrinsic fluorescence, as determined by analysis of untransformed tissues, is shaded black on the graph. Absence of a shaded area at the bottom of a histogram bar indicates that the relative contribution of the background fluorescence is too small to be apparent. Note the different scales used in each histogram. 


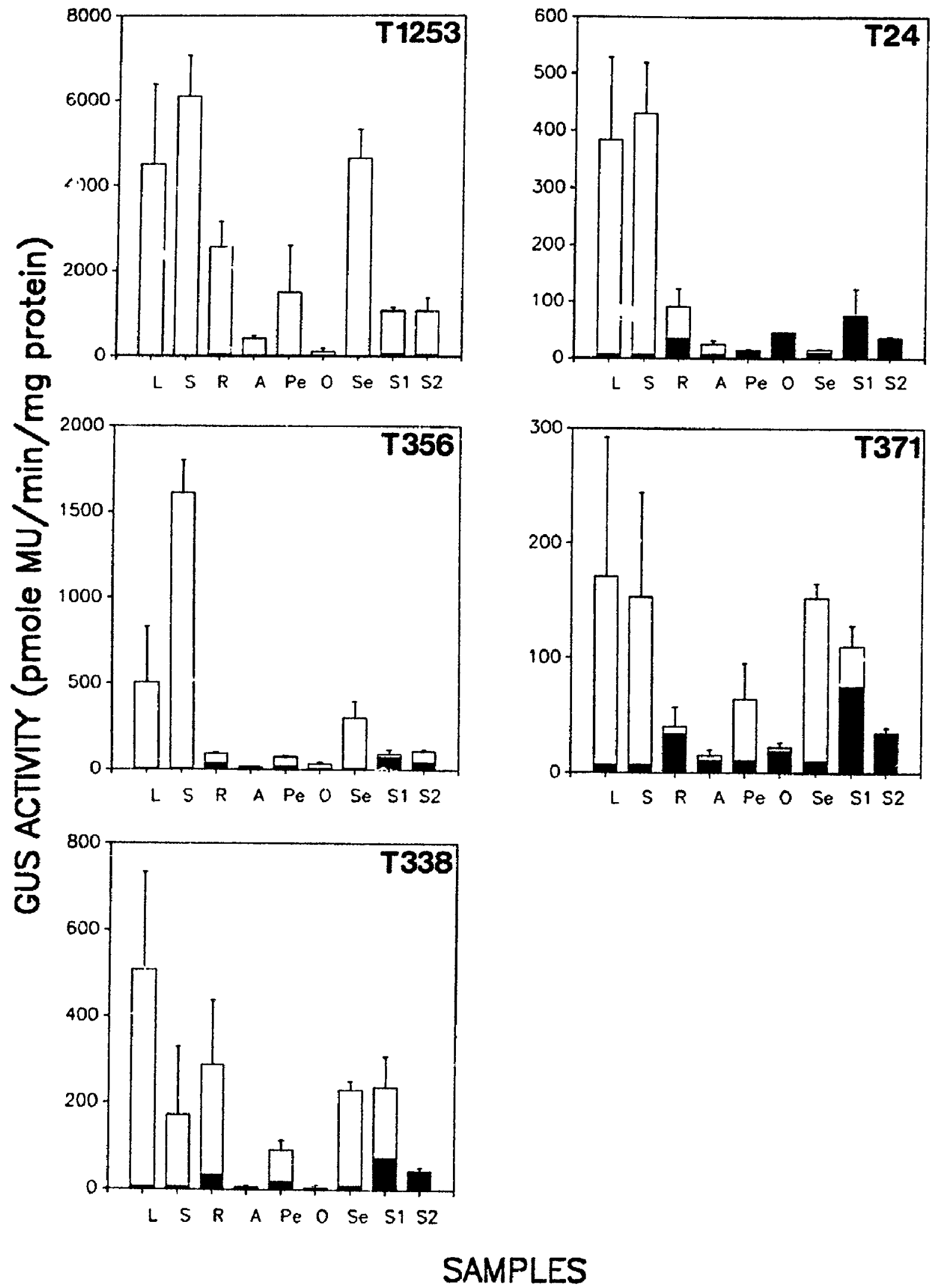


pattern of GUS activity within the different organs of $T 777$ is very different from the one observed in plants T1253 and T1275. The intensity of staining in tissue and seed sections of $\mathrm{T} 777$ is non-uniform, and frequently activity is only visible in patches of cells distributed in an apparent random manner (Figure 3.10 K-P, R). This expression pattern was detectable in the original transgenic plant as well as in at least 2 generations of selfed-progeny. GUS activity in the stem of $\mathrm{T} 777$ is predominantly, but not exclusively, detected in vascular tissues (Figure 3.10-L), while in roots and flowers (Figure 3.10-M, N), staining is often more homogeneous than in other tissues. Even, homogeneous expression of GUS was only visualized in young seedlings, prior to 10 days post-germination (Figure 3.10-O). The patchy pattern of staining was routinely observed in samples collected at this and subsequent time points (Figure 3.10*R).

All of the remaining Class I gene fusions which were studied in more detail failed to express GUS in one or more organs tested by fluorogenic assay. However, within a specific organ, it was possible to observe GUS activity in all tissues (Figure 3.12-B, F, H, K; Table 3.11). The number and types of organs in which these gene fusions are expressed, as well as the levels at which they are expressed in specific organs, vary considerably. The most organ-specific expression observed was in plant T24, where GUS activity is oniy detected in the leaf and stem (' igure 3.11). All other plants in this cat gory express GUS in numerous, but not all tissues (Figures 3.11-3.13; Table 3.11). The root or seeds are usually the tissues in which the gene fusions failed to be expressed. Levels of GUS activity could differ greatly in the various organs of a plant. In plants T198 (Figure 3.13) and T1041 (Figure 3.12-A), the highest levels of activity were detected in the roots. However, when compared to the levels expressed in roots of T777 (Figure 3.10-J), which also expressed GUS in a root-predominant fashion, those measured in T198 are more than 40 fold lower, while GUS activity in T1041 roots is three times lower. GUS activity in plants T356 
Figure 3.12. Fluorogenic and histological analyses of GUS expression in plants T1041 (A-D), T612 (E-H) and T804 (I-L). The gene fusions in these plants are all expressed in a restricted pattern. For histograms, each bar represents the average \pm one standard deviation of three samples. Nine different tissues were analyzed: leaf (I.), stem (S), root (R), anther (A), petal (P), ovary (O), sepal (Se), seeds 10 days post-anthesis (S1) and seeds 20 days post-anthesis (S2). For all measurements of GUS activity, the fraction attributed to intrinsic fluorescence, as determined by analysis of untransformed tissues, is shaded black on the graph. Absence of a black area at the bottom of a histogram indicates that the relative contribution of the background fluorescence is too small to be apparent. Note the different scales used in each histogram. Scale bar $=1 \mathrm{~mm}$, except for $B$ and $L$, where it equals $0.1 \mathrm{~mm}$. B, F, J = leaf; C, G, K = stem; D, H = root $L=$ embryo. Details of sample collection and assay conditions are presented in section 2.0. 

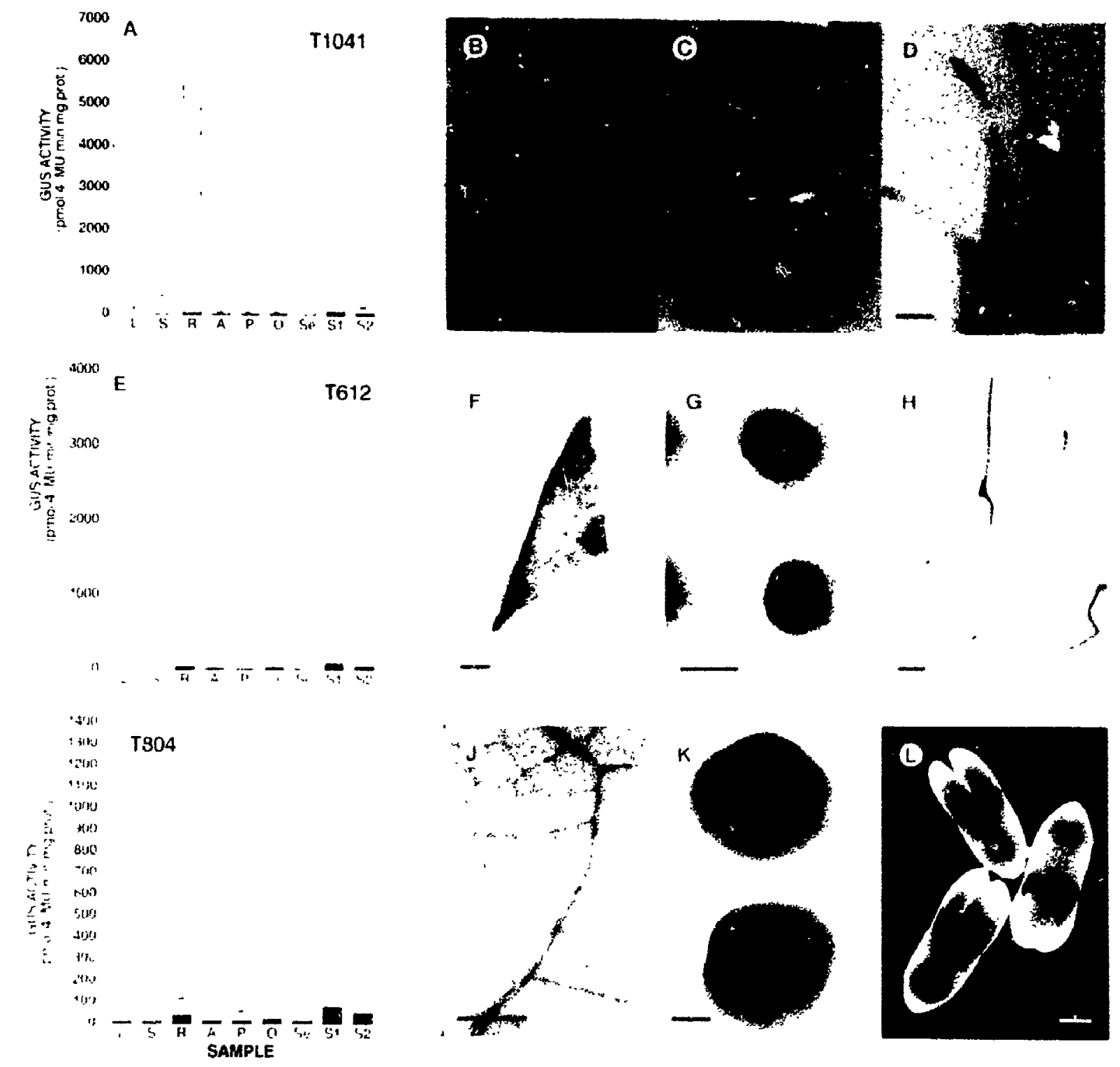
Table 3.11 Summary of histological analyses

\begin{tabular}{|c|c|c|c|c|c|c|c|c|c|}
\hline \multirow[b]{2}{*}{ PLANT } & \multicolumn{3}{|c|}{ VEGETATIVE } & \multicolumn{4}{|c|}{ FLORAL } & \multicolumn{2}{|c|}{ SEEDS } \\
\hline & LEAF & STEM & ROOT & PETAL & ANTHER & OVARY & SEPAL & $10 \mathrm{DPA}$ & $20 \mathrm{DPA}$ \\
\hline \multicolumn{10}{|c|}{ Unrestricted Expression } \\
\hline T1275 & Un $n^{l}$ & Un & Un & Un & Un & Un & Un & Un & Un \\
\hline \multicolumn{10}{|c|}{ Restricted Expression } \\
\hline T24 & Un & Un & ND & ND & ND & ND & ND & ND & ND \\
\hline T252 & Un & vc & ND & Un & ND & ND & ND & NA & NA \\
\hline T338 & Un & vc & ND & Un & Un & Un & Un & NA & NA \\
\hline T356 & Un & Un & ND & Un & Un & Un & Un & NA & NA \\
\hline T371 & Un & Un & ND & Un & ND & Un & Un & NA & NA \\
\hline T503 & Un & Vc & ND & Un & Un & Un & Un & ND & ND \\
\hline 1612 & Un & $\mathrm{Pi}$ & Un & Un & ND & Ma & Un & ND & ND \\
\hline $\mathrm{T} 777$ & $\mathrm{~Pa}$ & $\mathrm{~Pa}$ & $\mathrm{~Pa}$ & $\mathrm{~Pa}$ & $\mathrm{~Pa}$ & $\mathrm{~Pa}$ & $\mathrm{~Pa}$ & $\mathrm{~Pa}$ & $\mathrm{~Pa}$ \\
\hline T804 & $\boldsymbol{v}$ & Un & ND & Un & Un & Un & Un & Em & Em \\
\hline T1041 & Un & Oc & Un & Un & Un & Un & ND & ND & ND \\
\hline$T 1253$ & Un & Un & Un & Un & Un & Un & Un & Em & Em \\
\hline \multicolumn{10}{|c|}{ Tissue-Specific: Vascular-Specific } \\
\hline T30 & v & $v$ & $\mathbf{v}$ & vc & vc & vC & vc & Em & Em \\
\hline \multicolumn{10}{|c|}{ Seed-Specific } \\
\hline T165 & ND & ND & ND & ND & ND & ND & ND & En & ND \\
\hline $\mathrm{T} 218$ & ND & ND & ND & ND & ND & ND & ND & SC & ND \\
\hline T418 & ND & $V_{c}$ & ND & ND & ND & ov & ND & Em & ND \\
\hline
\end{tabular}

${ }_{\text {Abbreviations: Un, staining throughout sample }}$

Em, predominantly embryo-specific

En, endosperm-specific

$\mathrm{Ma}$, predominantly in the central area

$\mathrm{NA}$, not assayed

ND, not detected (no staining)

Oc, predominantly staining in outer cortex

Ov, staining in the ovules

$\mathrm{Pa}$, patchy

$\mathrm{Pi}$, predominantly staining in pith

SC, seed coat-specific

$V$, vascular-specific

$V C$, predominantly staining in vascular tissues 
Figure 3.13. Quantitative analysis of GUS expression in three Class I plants containing T-DNA-mediated gene fusions expressed in a restricted pattern and one plant containing a Class II gene fusion (T62). Each bar represents the average \pm one standard deviation of three samples. Nine different tissues were analyzed: leaf (L), stem (S), root (R), anther (A), petal (Pe), ovary (O), sepal (Se), seeds 10 days postanthesis (S1) and seeds 20 days post-anthesis (S2). For all measurements of GUS activity, the fraction attributed to intrinsic fluorescence, as determined by analysis of untransformed tissues, is shaded black on the graph. Note the different scales used in each histogram. 


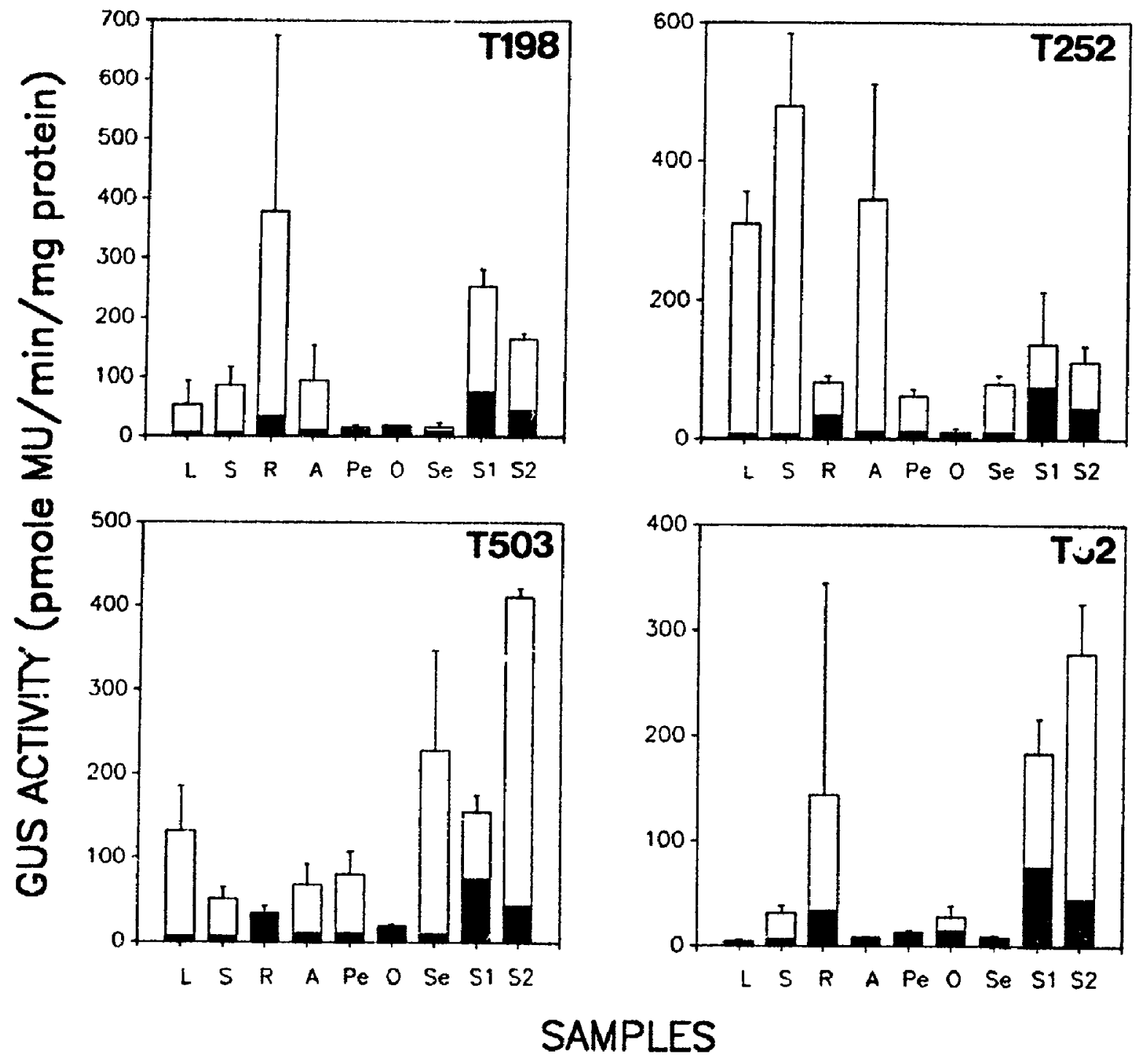


(Figure 3.11) and T612 (Figure 3.12-E) is highest in the stem, while in plant T804 (Figure 3.12-I), levels measured in the seeds are greater than those detected in vegetative and floral organs. Although fluorogenic assays failed to reveal the presence of GUS activity in many of the floral organs of plants with restricted GUS expression, histological analysis indicated that the gene fusions are expressed in these tissues (Table 3.11). Elevated levels of GUS activity were occasionally detected in floral organs, usually the sepals (plants T1253, T371, T338, Figure 3.11; T503, Figure 3.13). In one case, T252 (Figure 3.13), the level of GUS measured in the anthers was comparable to those detected in the leaf and stem.

At the histological level, GUS is expressed throughout all organs of T24, T356, and T371 which contained activity (Table 3.11; data not shown). In plant T198, GUS activity is also detectable throughout most tissue sections, but is more intense in the vascular bundles of the leaf, stem and roots, and at the root apex (data not shown). GUS expression in leaves and many floral organs of plants T252, T338, T503, and T1041 is also distributed throughout all tissue types (Figure 3.12; data not shown). However, expression in the stems of these plants is more tissuespecific. With plants T252, T338 and T503, vascular-specific patterns are often observed, although in many cases, faint staining is also apparent throughout the stem sections. GUS activity ir: the stem of T612 is concentrated in the central pith (Figure 3.12-G). Staining in the ovary of this plant is also concentrated in the central area (data not shown). Staining in the stem of T1041 is predominantly localized in the exterior edge of the outer cortex (Figure 3.12-C). A general characteristic of GUS staining in the stems of the above plants is that it is generally less restricted near the apex, and is often detected in nodes, in the general area corresponding to axillary meristems (data not shown). In roots of plant T1041, GUS activity is reduced or absent from the apical region, although it is detectable at the very tip of the root (Figure 3.12.D). Histological analysis of (T804) indicates that 
this gene fusion is expressed in a vascular-specific pattern in the leaf, but in the stem and floral organs, activity is distributed throughout the tissue sections (Figure 3.12-J, $\mathrm{K}$; data not shown). In seeds, the T804 gene fusion is expressed as a band in the upper embryonic axis (Figure 3.12-L). Faint staining is also detectable in the seed coat.

\section{D.2.c. Tissue-specific patterns of gene fusion expression}

Histological examination of GUS activity revealed that expression of some gene fusions is restricted to specific cells or tissues. Since one type of tissue can be found in more than one organ, tissue-specificity does not imply organ-specificity. No organ-specific patterns of expression were detected amongst the Class I gene fusions which were analyzed in more detail. In contrast, most of the Class II fusions are seed-specific. In at least two cases, seed-specific gene fusions are also expressed in specific tissues.

\section{D.2.c.i. Vascular-specific gene fusion expression}

An example of vascular-specific expression was previously reported in section 3.D.1.a. (T919; Figure 3.8 E-G). Of the 18 piants which were analyzed in more detail, one (T30) revealed a vascular-specific pattern of GUS expression. As determined by fluorogenic assay, the T30 gene fusion is expressed in all organs analyzed (Figure 3.10-S). However, in situ analysis of T30 expression by histological assay revealed it to be highly vascular-specific in vegetative organs (Figure 3.10 TW). More precise localization of GUS activity in leaf blades and stem cross-sections indicates that expression is restricted to the phloem (Figure 3.10-U; data not shown). In leaf epidermal strips, activity is occasionall $;$ detected in stomatal guard cells. Floral organs of T30 also contain predominantly vascular-specific patterns of GUS expression (Figure 3.10-X, Y), although faint staining was periodically 
detected throughout the sections analyzed. No evidence of vascular-specific gene expression was observed in seeds of T30. GUS activity in late heart-stage embryos collected at 12 DPA is restricted to a band across the middle of the embryo (Figure 3.10-Z), while in older seeds (20 DPA), GUS is expressed throughout the embryo (Figure 3.10-AA).

Since GUS expression in plant T30 is distributed throughout seed embryos but highly tissue-specific in vegetative organs, histological analyses were performed on germinating seeds to determine at which stage vascular-specific expression could be observed. As early as six days after sowing on sterile agar plates, GUS activity is localized to vascular tissues in emerging radicles. However, faint staining outside vascular tissues was occasionally visualized at this stage. As germination in tobacco is asynchronous (Avery, 1933 and personal observation), some seedlings analyzed after 6 days of germination had completely emerged from the seed and their cotyledons had expanded. GUS activity in these cotyledons is clearly vascularspecific (Figure 3.10-BB). Although staining continues to be vascular-specific throughout seedling development, faint staining was occasionally observed throughout cotyledons and leaves from older seedlings ( 20 days post-germination).

\section{D.2.c.ii. Embryo-specific gene fusion expression}

Plant T418 contains a Class II gene fusion which is expressed in seeds at 20 DPA (Figure 3.14-A). Although this gene fusion was not identified as a result of sc. zening leaf tissues, fluorogenic analysis indicates a borderline level of GUS activity in this organ (just below $5 \mathrm{X}$ untransforined levels). GUS activity is also detectable, at a much higher level, in stems of plant T418 (Figure 3.14-A). Within the stem and the seed, the T418 gene fusion is expressed in a tissue-specific fashion. In stems, GUS activity is principally vascular-specific (Figure 3.14-C). A less restricted pattern of staining was observed at the node, and included staining in the 
Figure 3.14. Fluorogenic and histological analyses of GUS expression in plants T418 (A-E), T165 (G-J), and T218 (L-P). These plants all express tissue-specific gene fusions. For histograms, each bar represents the average \pm one standard deviation of three samples. Nine different tissues were analyzed: leaf (L), stem (S), root ( $R$ ), anther $(A)$, petal $(P)$, ovary $(O)$, sepal (Se), seeds 10 days post-anthesis (S1) and seeds 20 days post-anthesis (S2). For all measurements of GUS activity, the fraction attributed to intrinsic fluorescence, as determined by analysis of untransformed tissues, is shaded black on the graph. Absence of a black area at the bottom of a histogram indicates that the relative contribution of the background fluorescence is too small to be apparent. Note the different scales used in each histogram. Histological analyses of a transformant harbouring the cloned T218 gene fusion (C4-2 \#10) is also presented (Q-S). Scale bar = $5 \mathrm{~mm}$, except for E, I, J, N-S where it equals $0.5 \mathrm{~mm}$, and $\mathrm{D}$, where the bar $=0.05 \mathrm{~mm}$. B = leaf; C $=$ stem; D, I, O, R = embryo; E, J, N, P, Q, S = seed; G, L = seedling; H, M = flower. Details of sample collection and assay conditions are presented in section 2.0 . 

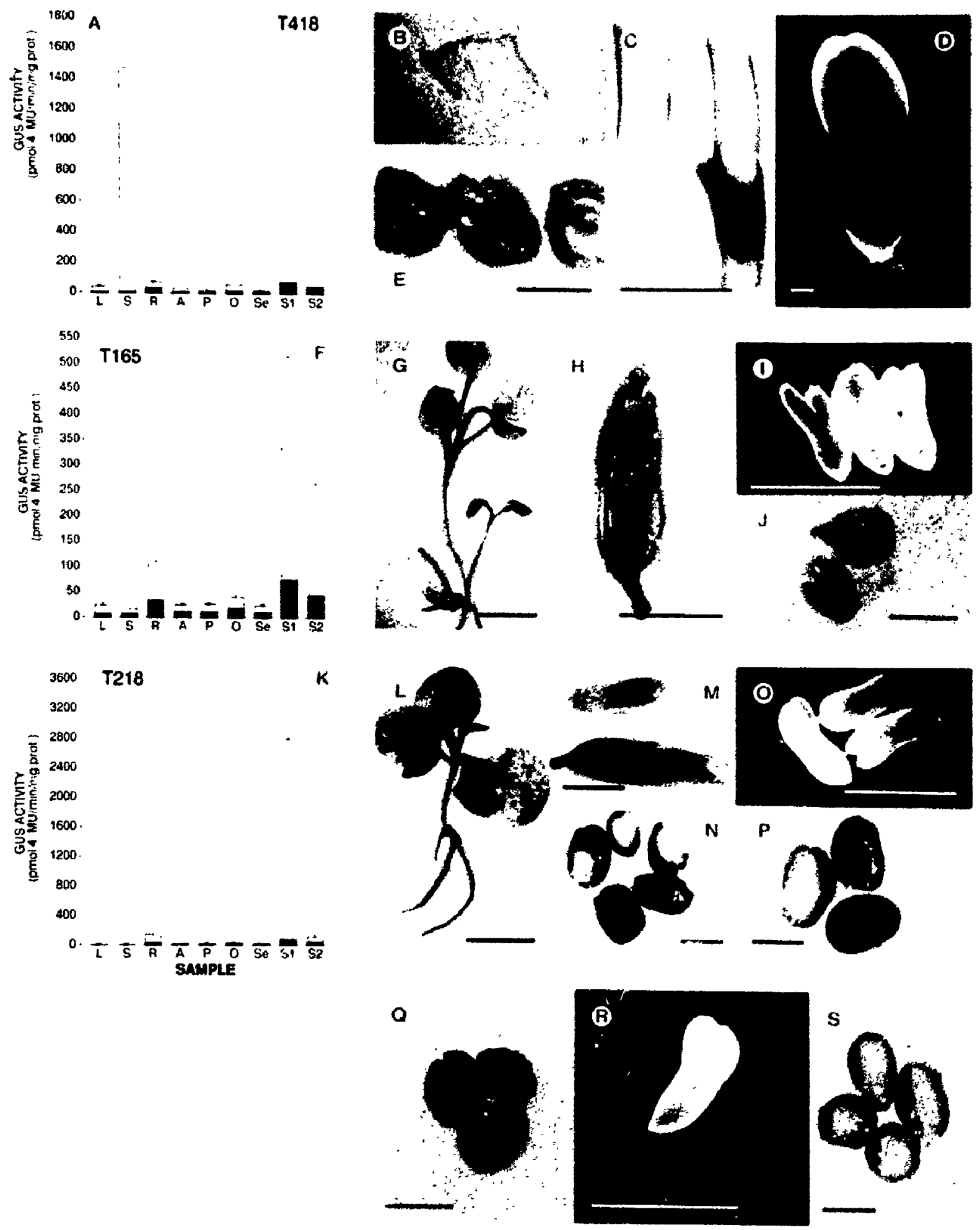
axillary meristem region (Figure 3.14). Histological analysis also revealed the presence of GUS activity in the ovary which appeared to be localized in the ovules (data not shown). GUS activity within seeds of T418 is localized to the embryonic axis (Figure 3.14-E). Staining was not observed in the cotyledons, the endosperms or the seed coat of this plant.

\section{D.2.c.iii. Endosperm-specific gene fusion expression}

The remaining three Class II fusions analyzed (T62, T165, T218) are all seedspecific (Figure 3.13; Figure 3.14 F-P). Although considered seed-specific, levels of GUS activity in the roots of plant T62 are just below the threshold limit of 5 times the untransformed controls. GUS activity in T62 root was never detected by histological assay (Figure 3.8; data not shown). The T62 gene fusion is expressed in seeds at 20 DPA. Further analysis of this fusion at the histological level was diffic ! : as staining was weak and infrequent. Consequently, the tissue-specificity of the T62 gene fusion was not assessed.

Levels of GUS activity measured in seeds of T165 are also relatively low (Figure 3.14-F). However, they exceed the threshold value at both 10 DPA and 20 DPA. Low levels of expression in T165 made it difficult to localize GUS activity in situ. However, faint staining was reproducibly detected in whole seeds and seed sections at 10-15 DPA (Figure 3.14-J). GUS activity appears to be localized in the endosperm. Consistent with this hypothesis is the observation that excised embryos do not stain for GUS activity (Figure 3.14-I). Activity also appears to be absent from the seed coat. Seeds analyzed by histological assay once the seed coat had been dissected away continue to stain for GUS activity (Figure 3.14-J).

\section{D.2.c.iv. Seed coat-specific gene fusion expression}

Expression of the GUS fusion in plant T218 is restricted to the seed coat at 
10-14 DPA (Figure 3.14 K-P; see section 3.D.3.). Fluorogenic and histological analyses failed to reveal the presence of GUS activity in seeds at 20 DPA (Figure 3.14-K, P). Embryos and the endosperm within whole seeds and seed sections (Figure 3.14-N), or embryos excised from seeds at 10-14 DPA and assayed separately (Figure 3.14-O), fail to stain for GUS activity. Scratching or scuffing of the outer surfaces of the seed coat resulted in displacement of the blue precipitate. Similar manipulations to the inner surface of the seed coat, accomplished after seed dissection, failed to achieve tr : same result, indicating that GUS activity in seeds of T218 is Incalized at or near the exterior surface.

\section{D.3. Further Characterization of the $\mathbf{T} 18$ Gene Fusion Expression}

The unique pattern of GUS expression detected in seeds of plant T218 suggested that this gene fusion may represent a good candidate for more detailed analyses at the molecular level. Prior to undertaking steps towards gene isolation, the expression pattern of T218 was characterized in greater detail. Two series of experiments were designed. The first was to confirm, by genetic means, that GUS expression was seed coat-specific; the second was to define more precisely the time course of T218 gene fusion expressiun during seed development.

\section{D.3.a. Genetic analysis GUS expression in T218 seeds}

Unlike the embryo and endosperm, which develop from female gametophytic tissues following double fertilization, the seed coat is formed by differentiation of the integuments (Essau, 1977). Therefore, the seed coat develops entirely from maternal sporophytic tissues, which implies that the genotype of the plant used to pollinate the flower does not affect gene expression in these cells. This feature of seed coat development was exploited to design a genetic test for the specificity of T218 gene fusion expression. Reciprocal genetic hybridizations were carried out 

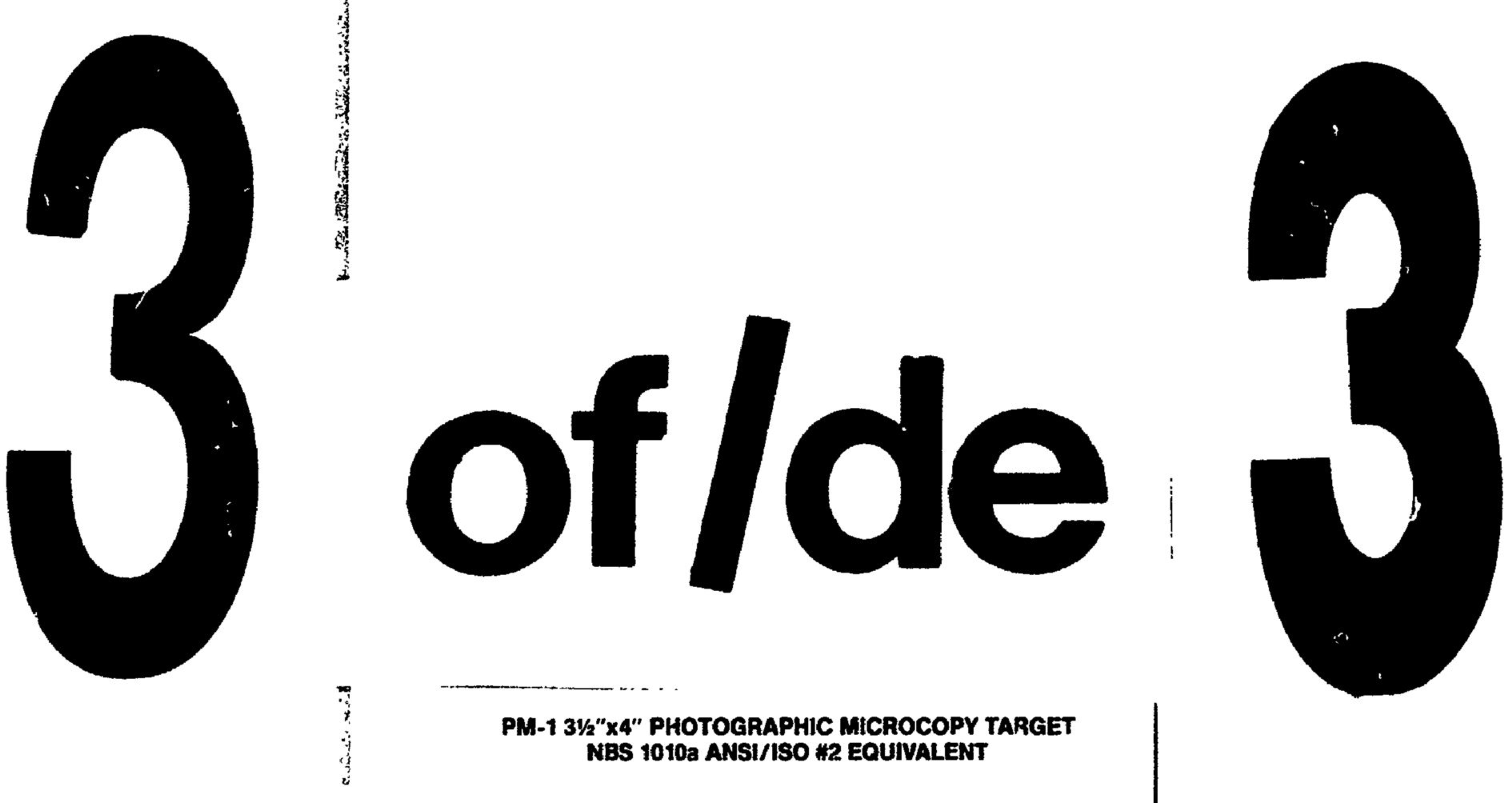

PM-1 31/2"x4" PHOTOGRAPHIC MTCROCOPY TARGET NBS $1010 a$ ANSI/ISO $* 2$ EQUIVALENT

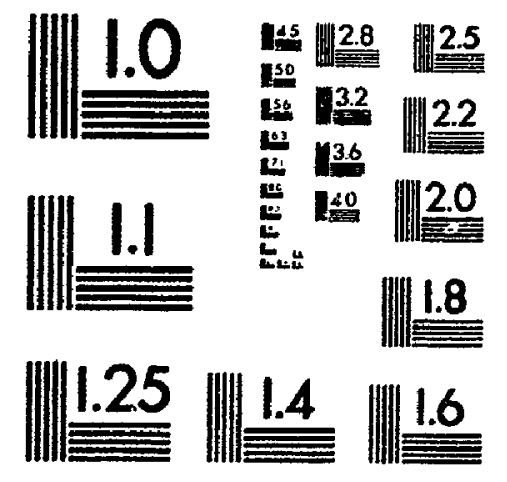

PRECISIONEM RESOLUTION TARGETS

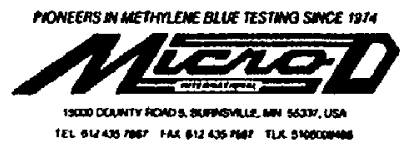


between plant T218 and untransformed SR1 tobacco as described in Materials and Methods section 2.N. If, as proposed, GUS expression in plant T218 is restricted to the seed coat, then seeds harvested from untransformed plants pollinated with T218 anthers should not contain GUS activity. However, should the T218 gene fusion also be expressed in the embryo or endosperm, activity would be detected in these hybrid seeds. Regardless of where the T218 gene fusion is expressed, GUS activity will be detectable in hybrid seeds resulting from pollination of T218 with untransformed pollen. When analyzed by histological assays, seeds of plant T218 pollinated with untransformed anthers continue to stain for GUS activity specifically in the seed coat (data not shown). In contrast, seeds derived from the reciprocal cross (urtransformed plants pollinated with T218 anthers) do not stain for GUS activity, indicating that gene expression in seeds of plant T218 is specific to the seed coat (data not shown). This conclusion is further substantiated by fluorogenic analyses, which demonstrate that seeds from untransformed plants pollinated with T218 anthers contain similar levels of GUS activity as untransformed (selffertilized) controls (Appendix 1). The observation that all, or almost all, seeds resulting from $\mathrm{T} 218$ self fertilization stain blue (data not shown) in the seed coat is also consistent with the view that staining is not dependent on fertilization of gametes. In such a case, a staining ratio of $3: 1$ would be expected with one functional copy (locus) of the T-DNA in a population of self-fertilized seeds.

Finally, within the context of the reciprocal genetic crosses, non-seed tissues from the tobacco fruits were analyzed for the presence of GUS activity. Results from fluorogenic assays indicate that the $\mathrm{T} 218$ gene fusion is not expressed in these tissues (Appendix 1). Histological staining of capsule cross-sections occasionally revealed the presence of blue staining in fruit tissues surrounding the seeds. However, activity is not detected if the seeds are removed from the capsules prior to analysis. 


\section{D.3.b. Time course of GUS expression in T218 seeds}

Flowers from plant T218 were tagged and seeds harvested after different time intervals to determine the pattern of GUS expression during seed development. When analyzed by fluorogenic assays (Figure 3.15) activity is first detectable at 9 DPA. Levels of expression continue to increase until 12 DPA, after which time they decrease. The last time point at which activity is observed is 17 DPA. Consistent with results presented in Figure 3.14-K, the T218 gene fusion is not expressed at 20 DPA (Figure 3.15). Histological analysis revealed the presence of GUS activity in seeds at 10,12 and 14 DPA. In all cases, activity appears to be restricted to the seed coat. As seeds harvested at 10 DPA contain liquid endosperm, it was difficult to analyze cross-sections of these seeds. However, analysis of whole seeds harvested at this time point revealed that they consistently stain for the presence of GUS activity. Subsequent dissection of these seeds indicates that the embryos and endosperm had not stained. Although it is possible that lack of staining in the embryo and endosperm may be related to problems of substrate penetration, it is noteworthy that endosperm of T165 as well as embryos of T1275 stain for GUS activity in the context of whole seeds. Furthermore, excised embryos from T218 seeds harvested at 10 DPA fail to stain for GUS activity, indicating, at the very least, that this gene fusion is not expressed in the embryo. Localization of GUS activity in seeds harvested at 12 or 14 DPA was more straightforward as the endosperm is at least partially solidified at these time points. Sections through these seeds demonstrate that GUS is localized to the seed coai (Figure 3.14-N; data not shown). Excised embryos dissected from seeds at 12 or 14 DPA do rist stain for GUS activity (Figure 3.14-O; data not shown). Similarly, GUS activity is not observed in seeds harvested at 17 or 20 DPA (Figure 3.14-P; data not shown). 
Figure 3.15. Analysis of promoterless GUS expression during seed development in plant T218. Each point represents the average \pm one standard deviation of three samples. Details of assay conditions are provided in section 2.0.1. 


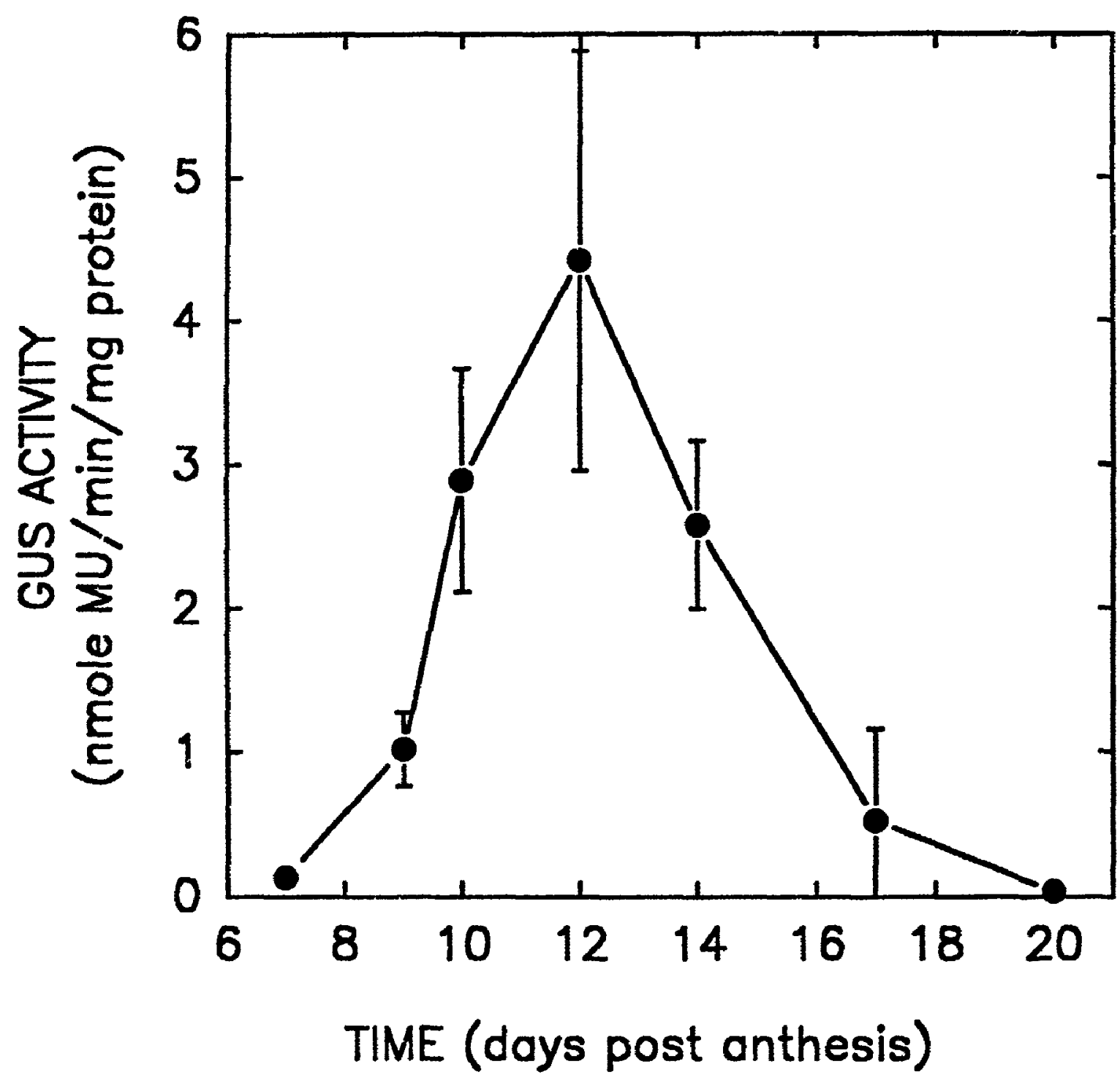




\section{E. Molecular Analysis of the T218 Gene Fusion}

The strategy developed in this thesis to study chromosomal regions of TDNA integration is based on the hypothesis that regulated expression the T-DNAmediated gene fusions is controlled by endogenous cis-acting elements localized in the plant DNA flanking the promoterless GUS gene, and not due to anomalous physiological or biochemical conditions existing within rare transgenic plants. To exclude the latter possibility, the chromosomal sequences flanking the promoterless GUS gene in plant T218 were recovered using T-DNA tagging and the ability of the isolated fragment to initiate regulated gene expression of the promoter GUS gene in transgenic plants was assessed. Although chromosomal flanking sequences could have been recovered from any of the plants, isolation and subsequent characterization of the $\mathrm{T} 218$ gene fusion are of particular interest as it is expressed specifically in the seed coat. Seed coat-specific genes have yet to be isolated. Consequently, in addition to confirming whether cis-acting elements responsible for GUS expression are localized in the DNA flanking the T-DNA, analysis of the T218 gene fusion offers an opportunity to study a unique class of cis-acting elements.

\section{E.1. Molecular cloning of the T218 gene fusion by T-DNA tagging}

Southern blot analysis of pPRF120 transformants using restriction enzymes which cleave only once within the T-DNA not only provides a means of estimating T-DNA copy number, it also allows one to assemble a map of the restriction sites flanking the T-DNA. Using this strategy, a restriction map of the sites flanking the T-DNA in plant T218 was constructed (Figure 3.16-B). When cleaved with Eco $\mathrm{R} 1 /$ Sal 1 , two restriction sites which flank the GUS gene in pPRF120, and hybridized with the GUS probe, a fragment of $2.2 \mathrm{~kb}$ is observed. This suggests that the Sal 1 site next to the right border of pPRF120 is intact, and that the end point of the T-DNA in plant T218 lies within 10 bp of the right border repeat (see Figure 3.1 
Figure 3.16. Southern blot analysis and restriction map of chromosomal DNA adjacent to the T-DNA in plant T218.

(A) Southern blot analysis of DNA digested with Eco R1 (lane 1), Sal 1/Eco R1 (lane 2), Xba 1 (lane 3), Hind III (lane 4) and Bam H1 (lane 5) and hybridized with a probe specific for the GUS coding region. Molecular weight markers are in kilobase pairs.

(B) Map of restriction sites flanking the T-DNA of plant T218. The map also incorporates data obtained from Southern blots of DNA digested with Eco R1 and hybridized to the npt II coding region probe in Plate 3.2. 


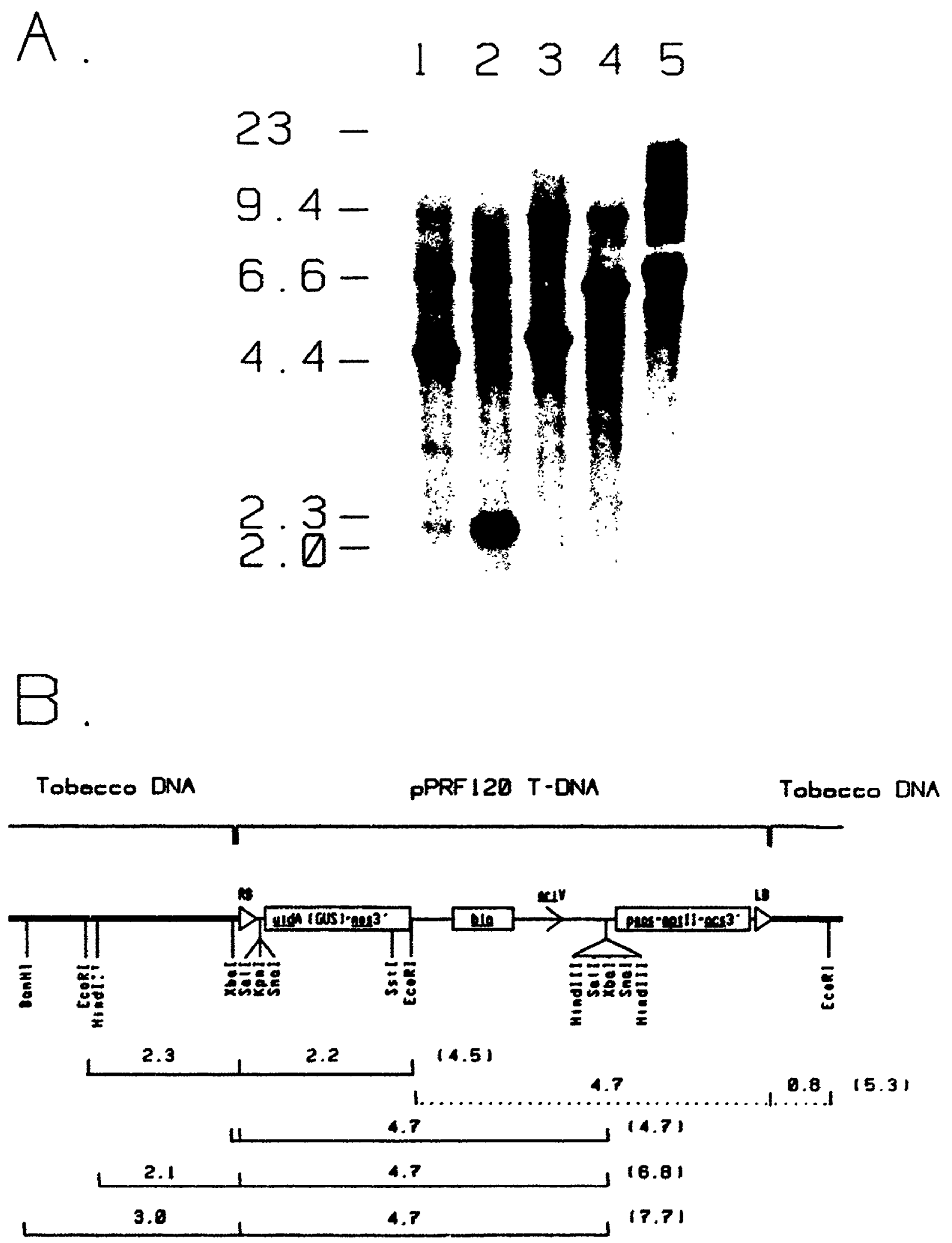


for sequence of pPRF120 right border region). The $X b a 1$ digest yielded a hybridization band of approximately $4.9 \mathrm{~kb}$ (Figure 3.16). As pPRF120 T-DNA contains a unique $X b a 1$ site situated $4.7 \mathrm{~kb}$ from the right border, this result indicates that the T-DNA has integrated a few hundred bp downstream of a Xba 1 site. The map also reveals the presence of an Eco R1 site approximately $2.3 \mathrm{~kb}$ upstream of the T-DNA right border. The $4.5 \mathrm{~kb}$ fragment observed in the Eco R1 digest is thus comprised of these $2.3 \mathrm{~kb}$ of flanking tobacco DNA and an additional $2.2 \mathrm{~kb}$ of T-DNA sequences. This fragment provided a good target for cloning of T218 flanking sequences for several reasons (1) the amount of flanking DNA recovered in this way is large enough to ensure, with good probability, that it will contain all cis-acting elements responsible for T218 GUS expression; (2) this size of fragment is within the range which may be inserted into lambda vectors specially designed to construct cDNA libraries; and (3) predigested (Eco R1) and phosphatase-treated vector arms of the bacteriophage vector LambdaGEM-2 (Promega) are commercially available, thus facilitating library construction. A partial library of Eco R1-digested T218 DNA, enriched for sequences of 4 to $6 \mathrm{~kb}$, was constructed in LambdaGEM-2, and screened by plaque hybridization using a nos3' fragment as probe (Figure 3.17). Sequences from the GUS gene could not be used as probes as this gene originates from $E$. coli. Details of library construction and screening are provided in Materials and Methods section 2.J.2. and 2.K. Of the approximately 125,000 plaques which were plated, one positive signal was detected in the primary screen. Following plaque purification, phage DNA was purified and digested with Eco R1. A single insert of $4.7 \mathrm{~kb}$ was observed in the chosen clone (data not shown). This fragment was subcloned in both orientations into plasmid pUC19 and characterized in more detail. The resulting derivatives were named pT218-1 (GUS gene farthest away from multiple cloning site) and pT218-2 (GUS gene next to multiple cloning site). 
Figure 3.17. Restriction map and strategy used to sequence the cloned T218 gene fusion.

(A) Restriction map showing the positioning of recognition sites for Eco R1, Hind III, Sal 1, Sma 1, Sna B1, and Xba 1. The location of sequences used as a probe to screen the T218 genomic library is indiated as \#1.

(B) Sequencing strategy for the T-DNA/plant DNA junction and the first $1.1 \mathrm{~kb}$ of flanking chromosomal DNA. The arrows represent the direction and the extent of sequencing from the positions indicated by the vertical lines. Plasmids pT218-3 and pT218-6 were used as templates for sequencing from the universal primer (UP) and the reverse primer (PF1), while plasmid DNA from pT218-8 was sequenced using the T7 primer (T7). Primers PF2-PF6 were used to sequence using pT218-2.

Sequences spanning restriction sites used for subcloning were all analyzed using the full length subclone. 

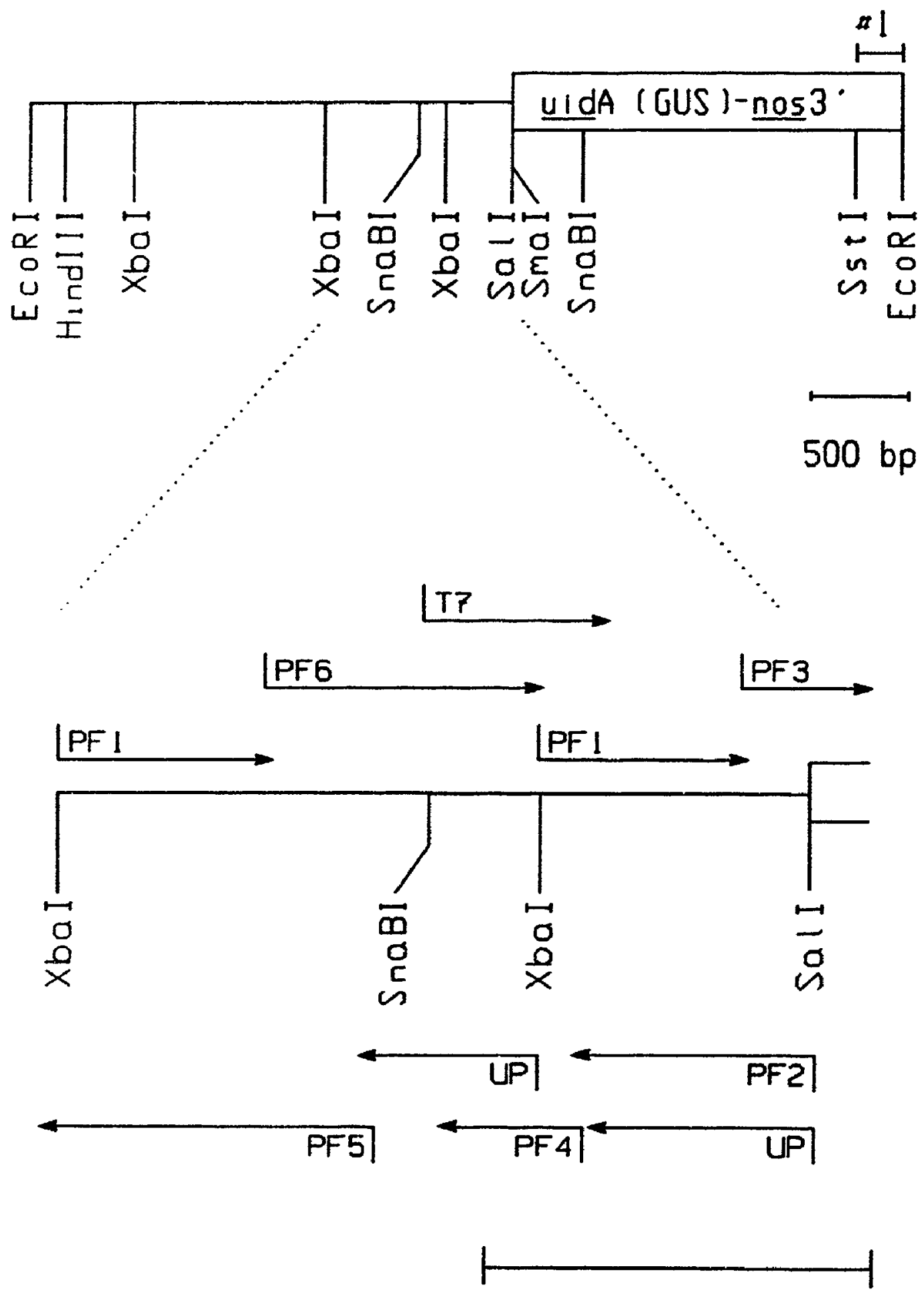

$500 \mathrm{bp}$ 
A restriction map of the cloned segment was generated to confirm its origin and to localize convenient sites for further manipulations (Figure 3.17). In addition to the total size of the insert, the location of the $X b a 1$ site and Hind III sites nearest to the right border region are the same as those predicted by genomic Southern blot analysis of T218 DNA (Figure 3.16). Restriction patterns of Eco R1/Sal, Eco $\mathrm{R} 1 /$ Sma 1, and Eco R1/Kpn 1 double digests are also consistent with the map of the pPRF120 GUS gene.

\section{E.2. Sequence analysis of the T218 gene fusion}

The nucleotide sequence of the T218 T-DNA/plant DNA junction and the adjacent $1 \mathrm{~kb}$ of flanking tobacco DNA was analyzed by the dideoxy chaintermination method (Sanger et al., 1977). The strategy used is summarized in Figure 3.17. The $600 \mathrm{bp} \mathrm{Xba} 1$ fragment, the $400 \mathrm{bp} \mathrm{Xba} \mathrm{1/Sal} 1$ fragment, and the 800 bp Sna B1 fragment of pT218-2 were subcloned into pUC19, pUC119 and pGEM4Z, respectively. The resulting plasmid derivatives were named pT218-6, pT218-3, and pT218-8. Double-stranded DNA templates were sequenced from either ends using a universal primer (UP), a reverse primer (PF1), or the T7 primer. Where needed, additional sequencing primers were synthesized to complete the analysis. The deduced sequence is shown in Figure 3.18. Comparison with the sequence of pPRF120 GUS/right border region shown in Figure 3.1 reveals that the end point of the T218 T-DNA is $8 \mathrm{bp}$ from the right border. This is only $2 \mathrm{bp}$ beyond the Sal 1 site. There are no additional base pair substitutions or rearrangements between the GUS "ATG" and the end of the T-DNA. There are also few direct or inverted repeats next to the T-DNA/plant DNA junction (Figure 3.18). However, the T-DNA end point does span one member of an 11 bp direct repeat (repeat \#6, Figure 3.18). The other member of this direct repeat is located $50 \mathrm{bp}$ within the T-DNA. There are an additional 5 direct repeats, and 4 inverted 
Figure 3.18. Nucleotide sequence of the T-DNA-mediated gene fusion T218. Nucleotides are numbered on the left-hand side. Nucleotide 1 represents the first nucleotide of the Xba 1 site located appruximately $1 \mathrm{~kb}$ from the GUS initiation codon, which is marked with an asterix. The amino acid sequence of the start of the GUS gene, as well as of the upstream ORF in frame with the GUS coding region is also indicated. The right end-point of the T-DNA is marked with a vertical arrow. The location of and direction of direct $(\# 1-\# 6)$ and inverted $(\# 7-\# 9, P)$ repeats are marked with arrows, while sequences capable of forming Z-DNA are labelled with a Z. Putative TATA and CAAT boxes within the vicinity of the GUS ATG are boxed. "P" indicates a palindrome. Sal, Sal 1; Sma, Sma 1; SnaB, Sna B1; Xba, Xha 1. The location of other, putative cis-acting elements are shown in Figure 3.19. 


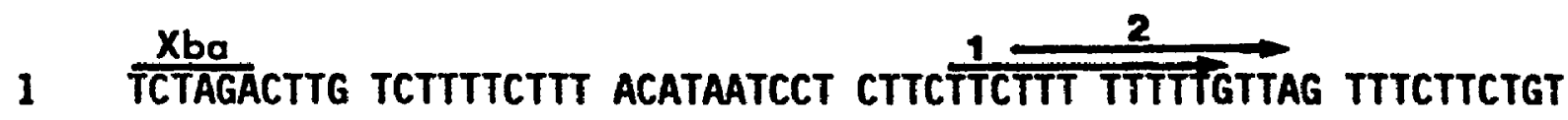

61 TTTATCCAAA AAACGAATTA TTGATTAAGA AATACACCAG ACAAGTTTTT TACTTCTTTT

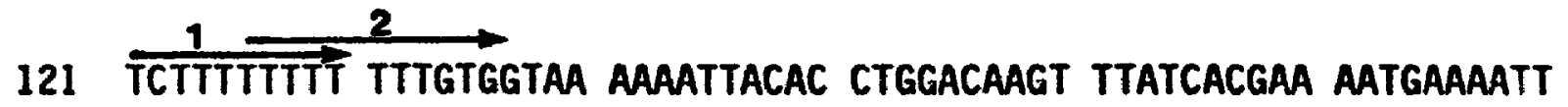
181 GCTATTTAAG GGATGTAGTT CCGGACTATT TGGAAGATAA GTGTTAACAA AATAAATAAA 241 TAAAAAGTTT ATACAGTTAG ATCTCTCTAT AACAGTCATC CTTATTTATA ACAATACTTTT

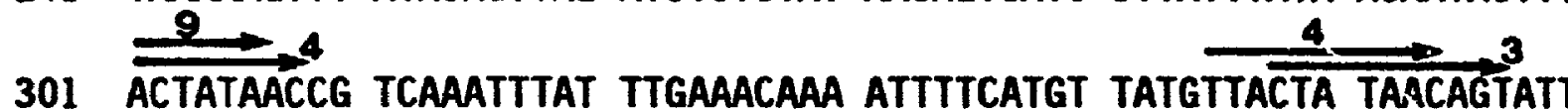

361 TTATTATAGC AACCAAAAAA TATCGAAACA GATACGATTG TTATAGAGCG ATTTGATTGT

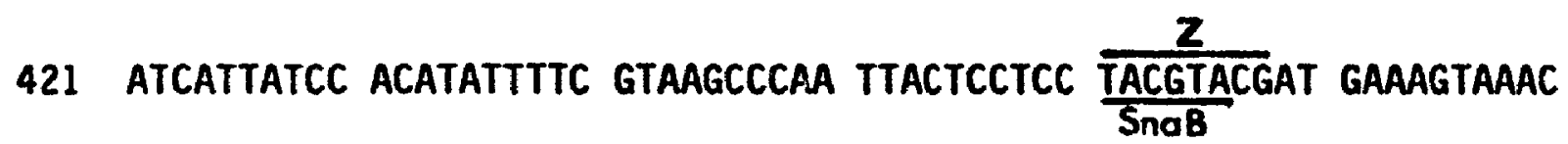
481 CAATTTAAAG TTGCAAAAAT CCAATAGATT TCAATACTTC TTCAACTGGC GTTATGTTAG

541 GTAATGACTC CTTTTTAACT TITCATCTTT AATTTGAAGT TTCTTTCATT AAAAGAAAGT $601 \frac{x b a}{\text { TTCTAGAGGA }} 5$ GAGTGTTTT AACACTTCTA GCTCTACTAT TATCTGTGTT $\frac{x b a}{T \text { TCTAGAGAA }}$ 661 AAATAGAAAA TGTGTCCACC TCAAAACAA CTAAAGGTG GCAAATCTIC ACCTATTTAT 721 TTTATITTGg ATTAATTAAg ATATAGTAAA GATGAGIIIAT AAACEgAGTT ITGGAGTTGA 781 TACAGTGAAT ITTAAGATGT GTACCGATTT AACTTTATTT ATGTTTCGCA CATATAAGAA 841 GTCCGATTTG GAAATACTAG ATTTIGTCAA TCA GGCAATT CATGTGGTTG AAGAATTTAA 901 GTIATATACA ATGATGATAT AAAGATATTT TATACTATTA GTGCAAATTA A TCG ATT $Z$ S I

$957 \bar{A} C T$ AAA AAT TAT TAT TCT ATT AAT ITA TGC TAT CGT GCC TCC $\frac{6}{\text { CCA ACC }}$ $\begin{array}{llllllllllllllll}T & K & N & Y & Y & S & I & N & L & C & T & R & A & S & P & T\end{array}$ $1005 \overrightarrow{\text { CGT CG. }}$. CCG CGG TAC CCG GGT GGT CAG TCC CTT ATG TTA CGT CCT GTA $\begin{array}{llllllllllllllll}R & R & P & R & Y & P & G & G & Q & S & L & M & L & R & P & V\end{array}$ 1053 GAA ACC CCA ACC CGT GAA ATC AAA CTC GA $\begin{array}{lllllllll}E & T & P & T & R & E & I & K & L\end{array}$ 
repeats of 10-12 bp within the tobacco chromosomal DNA. One of the inverted repeats is in the form of a perfect palindrome $(\mathrm{P})$ and is present approximately 50 bp from the T-DNA/plant DNA junction (Figure 3.18). In several cases, one member of a direct or inverted repeat partially overlaps a different repeat.

Analysis of the nucleotide sequence of the chromosomal DNA adjacent to the T-DNA right border allowed for the construction of a more precise restriction map. Of note is the presence of two closely linked $\mathrm{Xba} 1$ sites approximately $360 \mathrm{bp}$ from the GUS ATG. Only one site had been resolved by restriction mapping. These two sites are contained within a larger direct repeat of $42 \mathrm{bp}$ (\#5). No additional recognition sites for commonly used restriction enzymes were identified in the sequenced fragment.

The A + T content of the tobacco DNA isolated is approximately $66 \%$. In comparison, the average $A+T$ content of tobacco is approximately $60 \%$ (Zimmerman and Goldberg, 1977). Analysis of sequences flanking the T-DNA indicates that immediately upstream of, and in frame with, the GUS coding region is an open reading frame (ORF) of 29 amino acids. However, this ORF, as well as the others detected within the flanking DNA, is not initiated by a methionine codon. In addition, none of the "ATG" triplets identified in the upstream DNA correspond to the consensus translational start sequence for plants (the best match were 5 of $7 \mathrm{bp}$; data not shown). There are numerous putative "TATA" boxes in the adjacent plant DNA. The location of some of these are indicated in Figure 3.18, as is the location of a putative "CAAT" box. In addition, several sequences resembling binding sites for trans-acting factors can be detected in the upstream DNA. With the exception of a region homologous to the Box VI of $r b c S$ (Lam et al., 1990) at position 230, the most common motifs identified by the computer search were either short ones (4-6 bp) or those which allowed for the substitution of several base pairs within the consensus sequence (e.g. the GT-1 motif at 132; Figure 3.19). The sequence of 
Figure 3.19. Localization of putative cis-acting elements within the promoter region of the T218 gene fusion. The + or - symbols indicate the orientation of the boxed sequence relative to the published one. Within the context of the reference promoter, the recognition sequences have been shown to bind to nuclear factors by gel retardation assays or in vitro or in vivo footprinting. No functional testing has been performed in the context of the T218 promoter.

The "TTTTTTTT" motif at positions 38 and 123 are $100 \%$ homologous to a binding site located in the wound-responsive carrot extensin gene (Weising and Kahl, 1990).

The "TTGTGGTAAAAA" sequence at 132 matches the GT-1 box consensus sequence (G/TA/TGTGA/GA/TAAA/TA/GA/T) identified in the pea rbcS-3A gene by Schindler and Cashmore (1990).

The "AAGaTAAGT" sequence at 214 matches a binding site (AAGCTAAGT) located in the wound-responsive potato protease inhibitor Il gene (Weising and Kahl, 1990).

The "AAATAaATAAATAAAAAgtTT" sequence at 230 matches (18/21) the Box VI site (AAAATAGATAAATAAAAACATT) located in the promoter of the pea rbcS-3A gene by Lam et al. (1990). A tetramer of Box VI, when fused to the CaMV promoter " $\mathrm{A}$ " domain can potentiate transcription in transgenic tobacco Lam et al. (1990).

One A/T rich motif at 236 (TTTATTTTGTT) matches the "TTTATTTTGAT" sequence located in the sunflower helianthinin gene by Jordano et al. (1989).

Three "GATA" motifs (Gidoni et al., 1989) are found at 391, 423 and 429.

Two A/T rich motifs at 569 and 786 match the "TTAATTTTAAG" sequence found in the phaseolin promoter (Bustos et al., 1989).

Two direct repeats of $7 \mathrm{bp}$ located at 681 and 714 match (6/7) a G-box site (ACGTGGA) found in the parsley chalcone synthase gene (Block et al., 1990) 
Extensint

1 TCTAGACTTG TCTTTTCTTT ACATAATCCT CTTCTIC ITT TITTTGTTAG TTTCTTCTGT

61 TTTATCCAAA AAACGAATTA TTGATTAAGA AATACACCAG ACAAGTTTTT TACTTCTITT Extensint GT-1+

121 TC TTTTTTIT TIGTGGTAA AAAATTACAC CTGGACAAGT TTATCACGAA AATGAAATT

181 GCTATTTAAG GGATGTAGTT CCGgACTATT TGS PAGATAA GTGTTAACA AATAAATAAA BOX VI+

241 TAAAAGTTT ATACAGTTAG ATCTCTCTAT AACAGTCATC CTTATTTATA ACAATACTTT

301 ACTATAACCG TCAAATTTAT ITGAAACAAA ATTTTCATGT TATGTTACTA TAACAGTATT

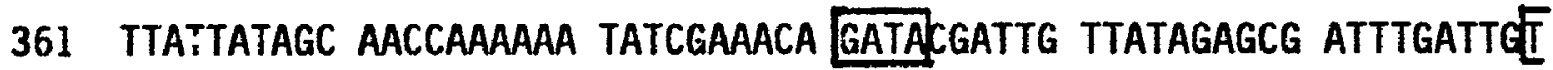
GATA-

421 ATGATIATCC ACATATTTTC GTAAGCCCAA TTACTCCTCC TACGTACGAT GAAGTAAAC

481 CAATTTAAAG ITGCAAAAAT CCAATAGATT TCAATACTTC ITCAACTGGC GTTATGTTAG A/T RICH+

541 GTAATGACTC CTTTTTAACT TTTCATCIIT AATTTGAAG TTCTTTCATT AAAAGAAAGT

601 TTCTAGAAGA GAAGTGTTTT AACACTTCTA GCTCTACTAT TATCTGTGTT TCTAGAAGAA

661 AAATAGAAAA TGTEICCACC TCAAAAACAA CTAAAGGTGG GCAAATCICC ACCT

721 TTTATTTTGG ATTAATTAAG ATATAGTAAA GATGAGTTAT AAACGGAGTT TTGGAGTTGA A/T Rich-

781 TACAGTIAAAT TTTAACATGT GTACCGATTT AACTTTATTT ATGTTTCGCA CATATAAGAA

841 GTCCGATTTG GAAATACTAG ATTTTGTCAA TCAGGCAATT CATGTGGTTG AAGAATTTAA

901 GTTATATACA ATGATGATAT AAAGAATTTT TATACTATTA GTGCAAATTA A TCG ATT

957 ACT AAA AAT TAT TAT TCT ATT AAT TTA TGC TAT CGT GCC TCC CCA ACC $\begin{array}{llllllllllllllll}T & K & N & Y & Y & S & I & N & L & C & T & R & A & S & P & T\end{array}$

1005 CGT CGA CCG CGG TAC CCG GGT GGT CAG TCC CTT ATG TTA CGT CCT GTA $\begin{array}{llllllllllllllll}R & R & P & R & Y & P & G & G & Q & S & L & M & L & R & P & V\end{array}$

1053 GAA ACC CCA ACC CGT GAA ATC AAA CTC GA

$$
\begin{array}{lllllllll}
E & T & P & T & R & E & I & K & L
\end{array}
$$


some of these motifs, their positions, and examples of other genes where they have been detected is presented in Figure 3.19. Four stretches of alternating purines and pyrimidines capable of adopting a Z-DNA conformation are also present in the chromosomal DNA flanking the T-DNA right border repeat of T218 (Figure 3.18). Three of these are $8 \mathrm{bp}$ in length, while the fourth, located between 827 and 836 spans $10 \mathrm{bp}$. One of the Z-DNA motifs overlaps a putative TATA box. The biological significance of any of these putative cis-acting sequences remains to be determined.

The sequenced fragment did not show significant homology tc. any of the eukaryotic genes present in the IBI genebank.

\section{E.3. Structural organization of the T218 locus in untransformed tobacco plants}

The chromosomal region into which the T-DNA has inserted in plant T218 was also characterized by Southern blot analysis using a segment of flanking tobacco DNA as probe. Untransformed SR1 DNA cleaved with various restriction enzymes yield single bands when hybridized with the $360 \mathrm{bp} \mathrm{Xba} \mathrm{1/Sal} 1$ fragment of pT218-3 (probe \#1 in Figure 3.20-C). The same pattern of hybridization was observed under conditions of high stringency washing $\left(0.2 \times \mathrm{XSC}, 60^{\circ} \mathrm{C}\right.$; Figure $\left.3.20-\mathrm{A}\right)$ and low stringency washing $\left(0.2 \mathrm{X} \mathrm{SSC}, 25^{\circ} \mathrm{C}\right.$; Figure $\left.3.20-\mathrm{B}\right)$, indicating that the region used as probe is unique within the tobacco genome. Faint hybridization bands are also visible on the autoradiographs presented in Figure 3.20-A and B, however, these were not observed in any reproducible pattern or number (compare tobacco in Figure 3.20-A and B, and data not shown). A restriction map showing the location of the Eco R1, Hind $\mathrm{III}_{\mathrm{s}}$ and $X b a 1$ sites surrounding the T-DNA integration site is presented in Figure 3.20-C. This map incorporates, and is consistent with, information obtained by Southern blot analysis of the T218 transformant using GUS and npt II probes (Figure 3.16), and with sequencing data (Figure 3.18). 
Figure 3.20. Southern blot analysis of tobacco, N. sylvestris, and N. tomentosiformis DNA using a probe derived from tobacco chromosomal DNA flanking the T218 right border repeat.

(A) Southern blot anaiysis of tobacco (N. tob), N. sylvestris (N. syl) and $N$.

tomentosiformis (N. tom) digested with Hind III (H), Xba 1 (X) and Eco R1 (E) and hybridized using the $360 \mathrm{bp} \mathrm{Xba} \mathrm{1/Sal} 1$ fragment of pT218-3 as probe (labelled \#1 on Figure 3.21-C). Filters were washed in $0.2 \times \mathrm{SSC}$ at $60^{\circ} \mathrm{C}$.

(B) Southern blot analysis of tobacco DNA digested with Hind III (H), Xba 1 (X), and Eco R1 (E), hybridized to the $360 \mathrm{bp} \mathrm{Xba} \mathrm{1/Sal} 1$ fragment of pT218-3 and washed under conditions of low stringency $\left(0.2 \times \mathrm{XSC}, 25^{\circ} \mathrm{C}\right)$. For (A) and (B), molecular weight markers are in kilobase pairs.

(C) Restriction map of the chromosomal locus into which pPRF120 T-DNA has integrated in plant T218. The position and orientation of T-DNA integration is also indicated on the map. Data from Southern blot analysis of plant T218 using the GUS and npt II probes, and from restriction mapping of the recovered T218 fragment were also used to generate the map. The location of the $\mathrm{Xba} 1 / \mathrm{Sal} 1$ fragment used as hybridization probe in Figure 3.21-A and -B is shown and labelled as \#1. 

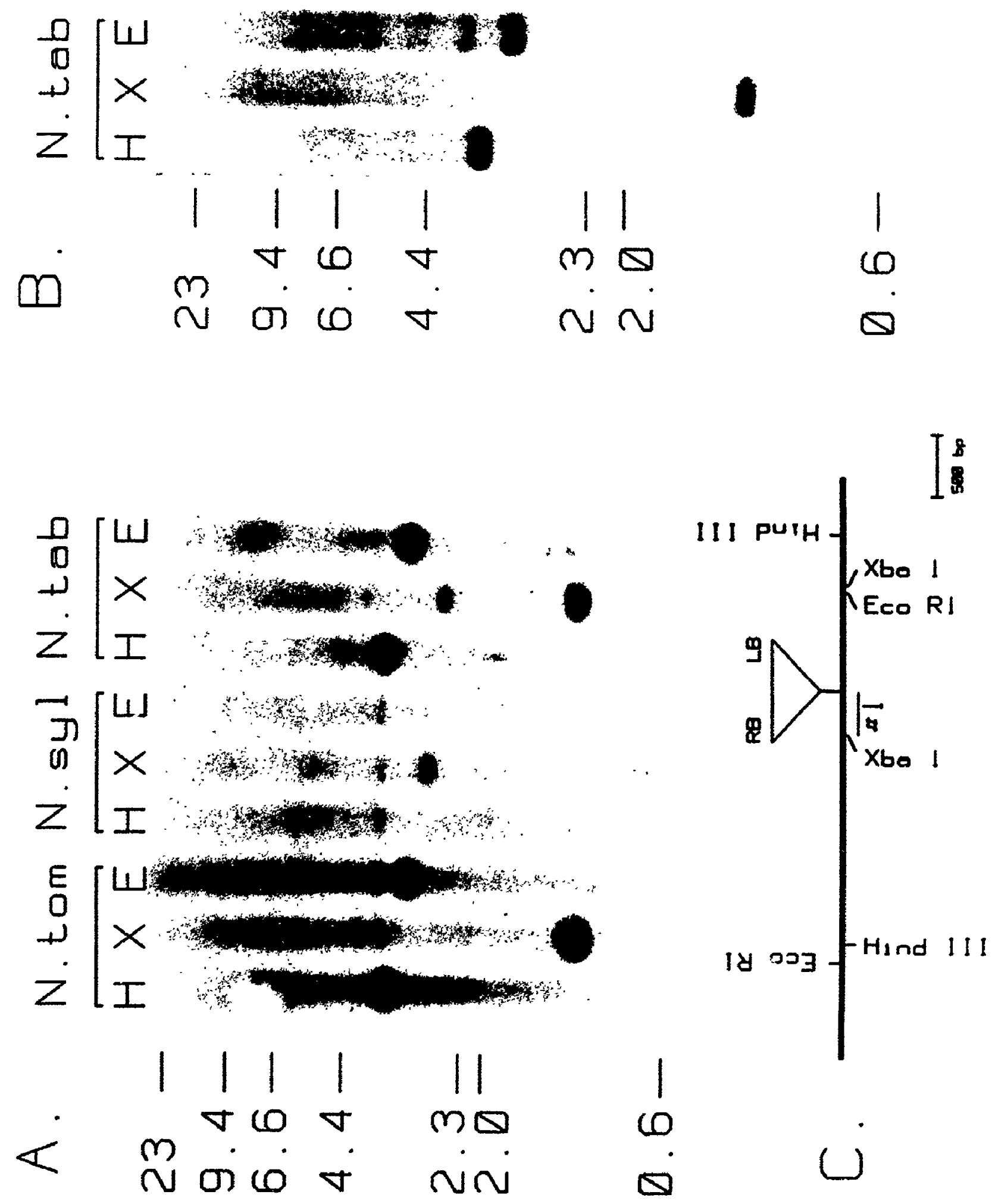
The genetic origin of the sequences flanking the T218 T-DNA was investigated by Southern blot analysis of $N$. sylvestris and $N$. tomentosiformis, the progenitors of tobacco (Okamuro and Goldberg, 1985). When filters were hybridized with the $360 \mathrm{bp} \mathrm{Xba} \mathrm{1/Sal} 1$ fragment of pT218-3 and washed under conditions of high stringency, single bands, identical in size to those observed in tobacco were detected in the $N$. tomentosiformis genome (Figure 3.20-A). Only faint hybridization bands are visible with DNA from $N$. sylvestris (Figure 3.20-A), suggesting that the chromosomal region into which the T218 T-DNA inserted originated from $N$. tomentosiformis. Based on sequence homology and conservation of restriction enzyme recognition sites, the corresponding sequences in tobacco and N. tomentosiformis have diverged very little since the initial hybridization event. Similarly, Okamuro and Goldberg (1985) reported that the single-copy fraction of tobacco was indistinguishable from its counterparts in the parental genomes.

\section{E.4. Expression analysis of the cloned $T 218$ gene fusion in transgenic plants}

To determine whether the cis-acting elements responsible for the seed coatspecific expression of the promoterless GUS gene in plant T218 are contained within the fragment isolated by T-DNA tagging, it was reintroduced into (untransformed) tobacco plants for functional testing. Based on the low frequency of homologous recombination in plants (Offringa et al., 1990), it is unlikely that the T-DNA containing the cloned derivative of the T218 gene fusion will integrate at the original "T218" locus. Consequently, it was hypothesized that the spatial and temporal patterns of GUS expression observed in the resulting transgenic plants will reflect the regulatory properties of the cloned T218 cis-acting elements.

\section{E.4.a. Experimental design and vector construction}

The entire $4.7 \mathrm{~kb}$ Eco $\mathrm{R} 1$ fragment which was recovered from plant T218 was 
introduced into the binary vector pBIN19 and transferred to untransformed tobacco. Thus, in addition to tobacco DNA, the segment to be tested also contains the intact GUS gene originating from PPRF120. However, the right border repeat from pPRF120 is no longer present (see Figure 3.18 for sequence information). In the resulting binary vector (named pT218-C4-2), the orientation of the GUS gene is the same as in pBI101 (Figure 3.21; Jefferson et al., 1987). It is noteworthy that endogenous tobacco sequences which flanked the T-DNA in plant T218 are contained entirely within the T-DNA of pT218-C4-2. Plasmid pT218-C4-2 was mobilized into Agrobacterium tumefaciens strain GV3101 (pMP90) (Koncz and Schell, 1986) and used to infect tobacco leaf discs as previously described for pPRF120 transformation. Ten independent kanamycin-resistant $(100 \mu \mathrm{g} / \mathrm{ml})$ transformants were regenerated and analyzed for GUS activity in the seeds and leaves. More detailed characterization of gene fusion expression was performed with one of the transformants.

As initial analysis of pT218-C4-2 transformants suggested that they expressed GUS in seeds (see below), a preliminary deletion analysis was undertaken to localize cis-acting regulatory elements more precisely within the $2.5 \mathrm{~kb}$ promoter segment. Using convenient restriction sites, three deleted derivatives were generated and inserted into pBIN19 (Figure 3.21). These were subsequently mobilized to Agrobacterium GV3101 (pMP90) and used to infect tobacco leaf discs. Six to 10 independent transformants for each of these vectors were regenerated.

\section{E.4.b. Expression analysis of the full-length $T 218$ gene fusion in transgenic plants}

Transgenic plants harbouring pT218-C4-2 were transferred to the greenhouse where seeds were cellected and analyzed for GUS activity at 10 DPA and 20 DPA by histological assay. All transformants expressed GUS specifically in the seed coat at 10 DPA (data not shown; Figure 3.14-Q shows an example at 14 
Figure 3.21. Schematic drawings of vectors used to functionally test the T218 gene fusion promoter. 'The entire $4.7 \mathrm{~kb}$ Eco $\mathrm{R} 1$ restriction fragment isolated by plaque hybridization (section 3.E.1.), or derivatives containing deletions within the upstream DNA were introduced into the multiple cloning site of pBIN19 to create pT218-C4-2 (full length clone), pT218-C1-2 (1 kb promoter), pT218-C6-2 (500 bp promoter), and pT218-C5-3 (360 bp promoter). Additional details on vector construction are presented in section 2.L.3. Restriction sites contained within the multiple cloning sites of the derivatives may not be the same as those indicated for pBIN19. The figure also shows an updated version of the restriction map for the cloned T218 DNA based on sequence analysis. 


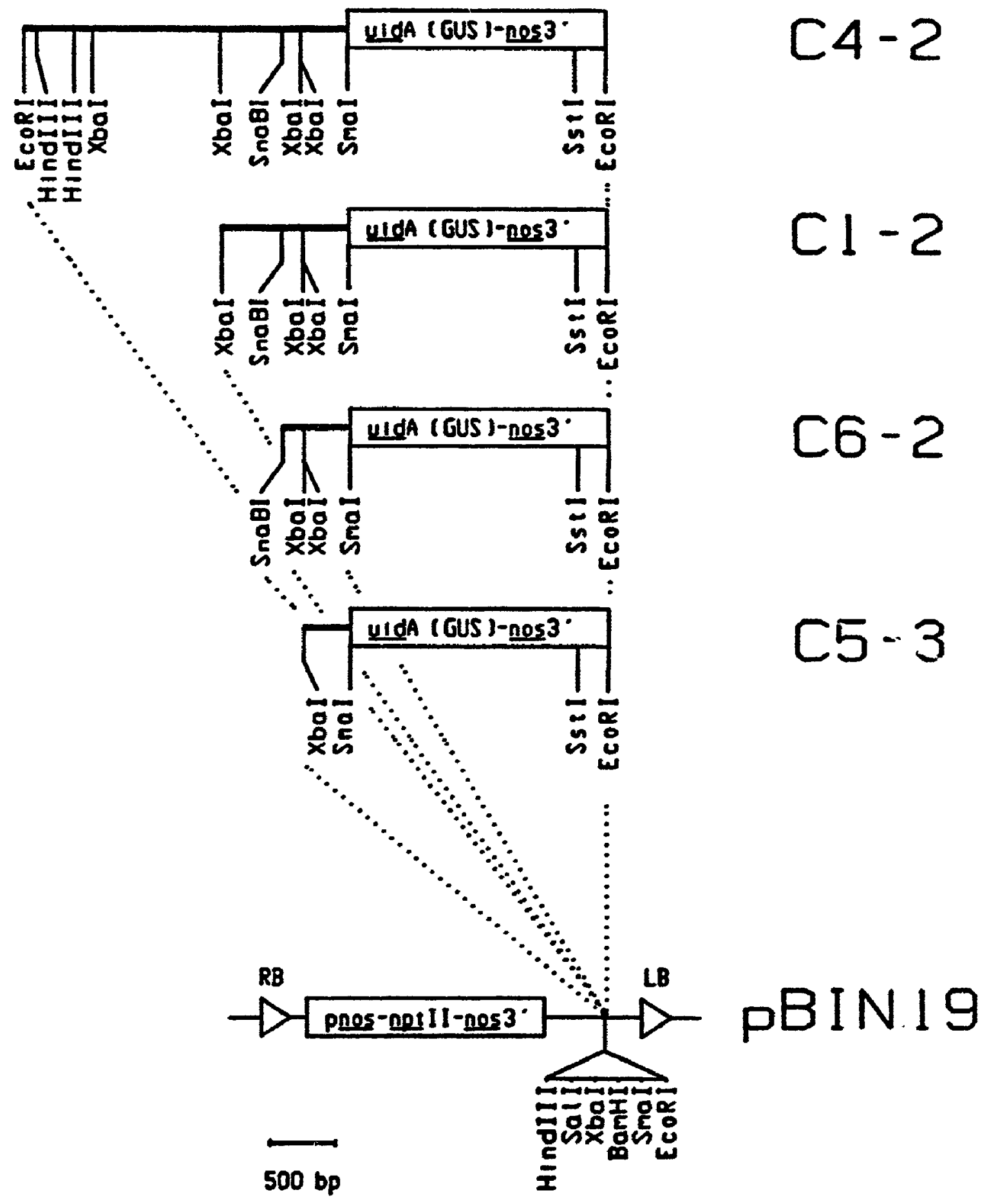


DPA). Excised embryos harvested from several of the transformants at 14 DPA failed to stain for GUS activity (Figure 3.14-R). GUS activity was also not detected in seeds at 20 DPA (Figure 3.14-S). Fluorogenic analyses of vegetative organs of several C4-2 plants indicate that these contain levels of GUS activity within the range of untransformed control. Reciprocal genetic crosses between two of the transformants (C4-2 \#5 and \#10) and untransformed plants revealed that most of the GUS activity was restricted to the seed coat (data not shown).

Southern blot analysis was performed on transformants harbouring pT218C4-2 to estimate T-DNA copy number, and to confirm that integration had occurred at different chromosomal sites. DNA was digested with Hind III, which cleaves the integrated T-DNA only once, and hybridized to the GUS coding sequence probe. As outlined in section 3.C.2., the size of the resulting hybridization fragments is thus dependent on the distance between the internal Hind III site and the nearest site flanking the T-DNA left border repeat. Data presented in Figure 3.22-A shows that the transformants contain from 1-4 copies of the GUS gene. As observed with other derivatives of pBIN19 (summarized in Table 3.7), many of the plants transformed with pT218-C4-2 (6 of 10) contain more than one T-DNA copy. A pattern of hybridization similar to the one above was observed when the $360 \mathrm{bp} \mathrm{Xba} 1 / \mathrm{Sal} 1$ fragment of pT218-3 is used as probe (Figure 3.22-B). With this probe, the endogenous copy of the "T218" flanking sequences also hybridizes. The endogenous band is $3.3 \mathrm{~kb}$ in size, as previously observed in untransformed tobacco (Figure 3.20; Figure 3.22-B). Additional bands observed in the pT218-C4-2 plants hybridized with the $X b a 1 /$ Sal 1 probe correspond in size and number to those observed with the GUS probe (Figure 3.22-A). The observation that the size of the GUS hybridization bands is different in every plant, and that the size of the endogenous T218 sequences remains the same, indicates that the T-DNA has integrated at different sites in these plants, none of which correspond to the original locus. All 
Figure 3.22. Southern blot analysis of tobacco plants transformed with pT218-C4-2. (A) Southern blot of DNA form an untransformed plant (UNTR.), plant T218, and ten independent transformants harbouring pT218-C4-2 (\#1-\#10) digested with Hind III and hybridized using a GUS coding region probe (labelled as \# 1 in Figure 3.22-C).

(B) Southern blot of DNA form an untransformed plant (UNTR.) and ten independent transformants harbouring pT218-C4-2 (\# 1-\#10) digesied witit Hind III and hybridized using a the $360 \mathrm{bp} X b a$ 1/Sal 1 fragment of pT218-3 as probe (labelled as \#2 in Figure 3.22-C). DNA from plant T218 digested with Eco R1 is also included on the blot. The endogenous tobacco DNA homologous to the probe hybridizes as a band of $3.3 \mathrm{~kb}$ in all the Hind III digests and as a $3.0 \mathrm{~kb}$ band in the Eco R1 digest (also see Figure 3.21). For (A) and (B), molecular weight markers are in kilobase pairs.

(C) Map of the T-DNA of pT218-C4-2 showing the location of restriction sites and of the areas used as hybridization probes. Chromosomal tobacco DNA recovered by T-DNA tagging of the T 218 gene fusion is represented by a thick line. 


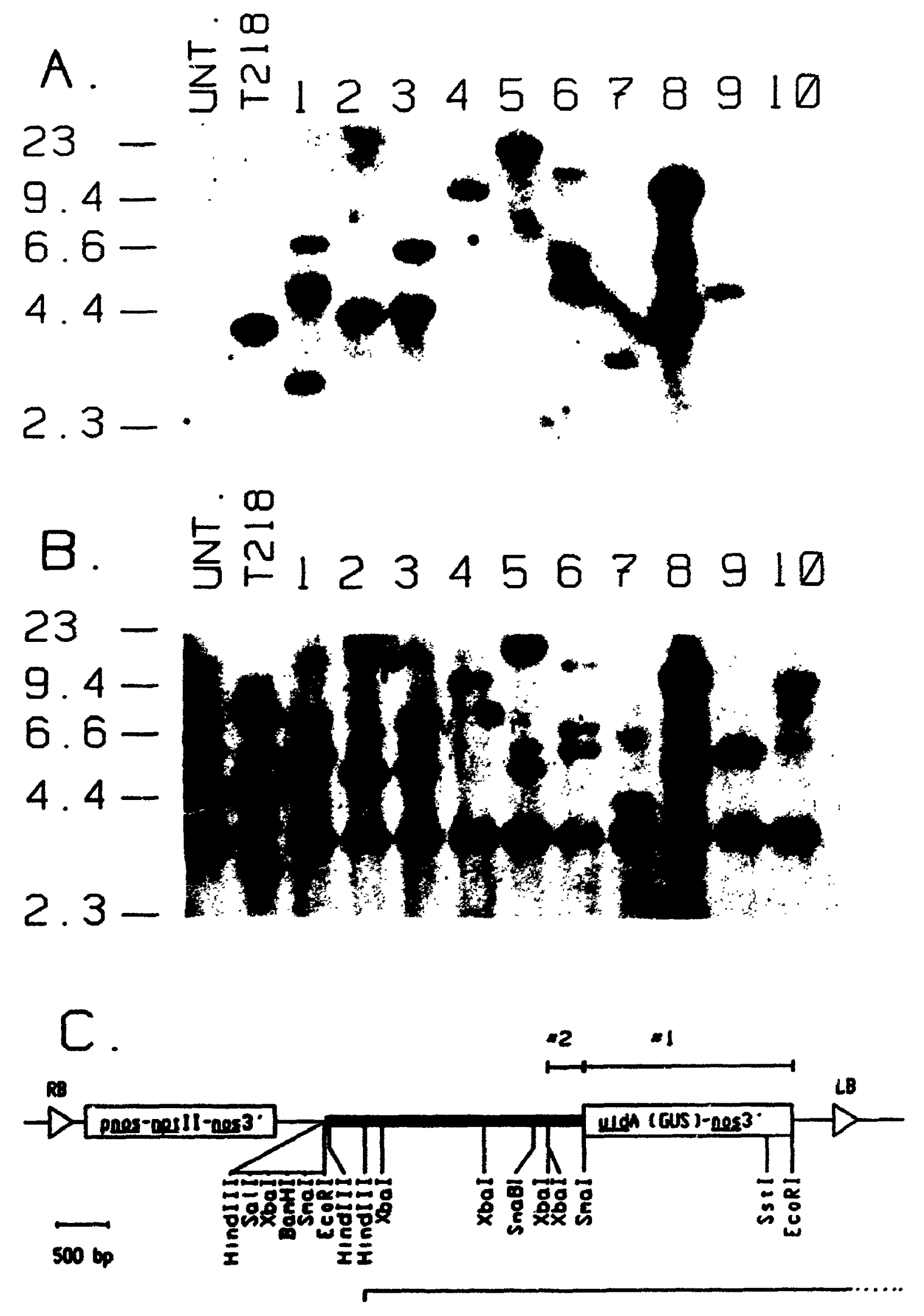


sequences responsible for the regulated expression of GUS in plant T218 must therefore be contained within the cloned fragment.

\section{E.4.c. Deletion analysis of the seed coat-specific promoter}

A variable amount of information is available on the deleted derivatives of the T218 promoter. The most complete analysis were performied on the shortest derivative (360 bp promoter; pT218-C5-3; Figure 3.21). Histological analysis of seeds harvested at 10 DPA and 20 DPA failed to reveal the presence of GUS activity in these seeds (data not shown). Southern blot analysis of these plants indicates that 9 of the 10 transformants contain at least one intact copy of the $T$ DNA (Figure 3.23). For these analyses, the plant DNA was digested with Eco R1 and $X b a 1$ which gencrates an internal fragment of $2.5 \mathrm{~kb}$. Thus, absence of expression in the C5-3 does not appear to be due to deletions or rearrangements in the inserted T-DNA. Presumably, lack of GUS activity in seeds of these plants results from the deletion of regulatory sequences from the T218 promoter.

The data available for each of the two remaining vectors, pT218-C1-2 and pT218-C6-2, is restricted to single transformants. Histological analyses of seeds from these plants at 12-14 DPA indicates that they are capable of expressing GUS. Based on the weak staining reaction, it appears that GUS is expressed at a much lower level than in the C4-2 plants (data not shown). 
Figure 3.23. Southern blot analysis of tobacco plants transformed with pT218-C5-3. (A) DNA from ten independent transformants, labelled \#1-\#10 were digested with Eco $\mathrm{R} 1 / \mathrm{Xba} 1$ and hybridized to the GUS coding region probe. Molecular weight markers are in kilobase pairs.

(B) Map of the pT218-C5-3 T-DNA showing the location of restriction sites and of the area used as hybridization probe. Chromosomal tobacco DNA recovered by TDNA tagging of the T218 gene fusion is represented by a thick line. The portion of the T-DNA which hybridizes to the GUS probe is indicated below the map. A map of the pT218-C5-3 T-DNA in relation to the pT218-C4-2 T-DNA is presented in Figure 3.20 . 


$$
\begin{aligned}
& \text { A. } 12345678910 \\
& 9.4= \\
& 6.6= \\
& 4.4- \\
& 2.3=-\infty-\infty-\infty-\infty-\infty \\
& 2.0=-\infty
\end{aligned}
$$

B.

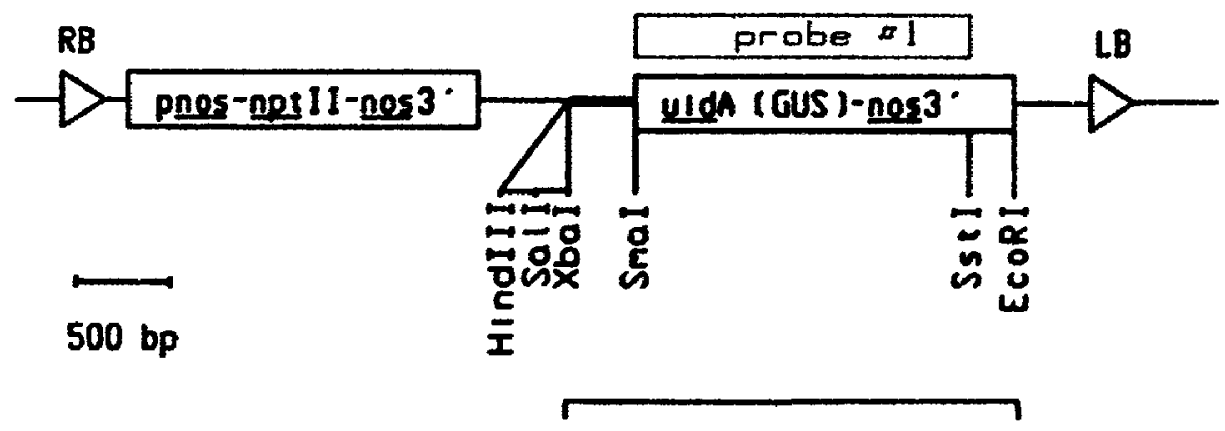




\section{CHAPTER 4 - DISCUSSION}

The goal of this thesis was to develop a strategy for characterizing chromosomal regions of T-DNA insertion based on their ability to activate a promoterless reporter gene linked to the extremity of the T-DNA. Several tobacco plants transformed with a T-DNA vector containing a promoterless GUS gene linked to the right border repeat (pPRF120) were found to reproducibly contain GUS activity when analyzed by either the fluorogenic or histological assay. As substantial levels of GUS activity were never detected in untransformed tissues, the data strongly suggest that GUS activity in these plants results from the activation of the promoterless reporter gene by neighbouring cis-acting regulatory elements residing in the tobacco chromosome. This possibility was demonstrated for one of the gene fusions by isolating, by T-DNA-tagging, the promoterless GUS gene and a segment of flanking chromosomal DNA, and functionally testing these in transgenic

plants. Results obtained revealed that the sequences responsible for the regulated expression of GUS in plant T218 are contained within the $2.5 \mathrm{~kb}$ of DNA which flank the right border repeat. Deletion of the flanking chromosomal sequences resulted in loss of GUS activity, further demonstrating that patterns of GUS expression which were detected in this plant were regulated by endogenous tobacco sequences which flank the T-DNA. Similarly, molecular cloning and functional testing of other gene fusions have all demonstrated that sequences responsible for controlling promoterless gene expression are contained within the chromosomal DNA adjacent to the 5' T-DNA (Kertbundit et al., 1991; Koncz et al., 1989). 


\section{A. Characteristics of pPRF120}

An important step of this research was to design a vector capable of detecting T-DNA integrations within transcriptionally active regions of the plant genome. The vector which was designed, called pPRF120, contains several features which make it an attractive choice for generating T-DNA-mediated gene fusions. These include the ability to predominantly integrate into the genome of plants as single, intact copies; the possibility of rapid and sensitive detection of promoterless gene activation in any tissues at any time in development; and the capacity for measuring relative strengths and revealing cell-specific patterns of expression.

Examination of both Southern blots and kanamycin segregation patterns revealed that the majority of plants transformed with pPRF120 contain only one intact copy of the T-DNA. In contrast, most plants transformed with derivatives of a widely used binary vector system, pBIN19, contain multiple T-DNA insertions. Several derivatives of pBIN19 were tested, including pBI101, pBI121, pnos-GUS, pT218-C4-2, and pT218-C5-3. Although the number of transformants tested for individual vectors was low, the overall trend strongly suggests that more than $50 \%$ of the plants transformed with pBIN19 derivatives contain multiple copies of the TDNA. Conditions used to infect, select and grow plants transformed with pPRF120 and derivatives of pBIN19 were identical, reducing variables suspected of affecting T-DNA integration (Deroles and Gardner, 1988a; Sukhapinda et al., 1987) and allowing a more direct comparison of the vectors. The pattern of pPRF120 integration into tobacco plants is clearly simpler. A predominance of multiple TDNA copies in plants transformed with pBIN19-based vectors has been reported by others (Bevan, 1984; Jefferson et al., 1987; Topping et al., 1991), indicating that this may be a general feature of the vector itself. Specific vector components of pPRF120 which may be responsible for the high proportion of single inserts observed remain unknown. 
There are several reasons why the presence of single T-DNA copies is desirable. First, it should facilitate tecovery of the T-DNA and flanking chromosomal sequences thought to contain cis-acting regulatory elements. This was demonstrated during the molecular cloning of the T218 gene fusion. The presence of a single T-DNA insert permitted the isolation of a DNA fraction of appropriate molecular weight to construct a partial gene bank enriched for the gene fusion, thus reducing the number of plaques which had to be screened. In the presence of multiple T-DNA copies, additional analyses would have been required to identify which of the T-DNA inserts represent gene fusions. As the pattern of reporter gene activity detected in plant organs represents the sum of all gene fusions which are expressed, the presence of single T-DNA inserts implies that the profile of only one T-DNA-mediated gene fusion is being studied. Therefore, potential additive (Masterson and Schell, 1989) or suppressive (reviewed in section 1.E.4.) interactions of different gene fusions, which may occur when multiple T-DNA insertions are present, are eliminated. Multiple copies of the T-DNA also complicate interpretations of the frequency of integrations within transcriptionally active regions of the genome. Current literature expresses the number of gene fusions generated on a "per plant" basis. However, the number of T-DNA copies in plants transformed with different vectors varies considerably. The more copies of the $T$ DNA present, the higher the probability of generating a gene fusion, regardless of the total number of plants analyzed. For example, the total number of T-DNA copies in 100 plants transformed with pPRF120 would be approximately 115 . In contrast, 100 plants transformed with the vector of Topping et al. (1991) would contain at least 216 copies of the T-DNA, based on segregation analysis of kanamycin resistance (summarized in Table 1.1). This is assuming that there is only one copy of the T-DNA per locus (i.e. no tandem repeats). and that all plants segregating for T-DNA inserts at 3 or more loci contain only 3 T-DNA copies. A 
more accurate method of reporting the frequency of T-DNA-mediated gene fusion would be on the basis of total T-DNA copies. However, this method of classification is complicated by the fact that it is not possible to resolve the presence of single or multiple gene fusions in plants containing multiple T-DNA inserts (Koncz et al., 1989). Consequently, in the absence of further analyses, such as segregating independent T-DNA copies from each other or molecular cloning and functional testing of individual gene fusions, it is not possible to accurately estimate the frequency at which the T-DNA integrates within transcriptionally active DNA in plants containing multiple copies of the T-DNA. It is also noteworthy that some of the T-DNA copies found within plants containing multiple insertions may not have the potential to express marker genes, thus further complicating data interpretation.

An interesting example of how multiple copies of the T-DNA may complicate studies of T-DNA-mediated gene fusions was recently reported at the Third International Congress of the International Society for Plant Molecular Biology, Tucson, AZ, by Kertbundit et al. (abstract \#293). These authors recovered a gene fusion by inverse PCR, and analyzed the DNA sequences flanking the promoterless GUS gene to discover that they corresponded to those of a truncated T-DNA copy. Such artifacts should be of particular concern in plants containing a high frequency of tandem T-DNA repeats.

Sensitive, detailed analyses of expression of in vivo gene fusions was achieved by incorporating GUS as the promoterless reporter. The advantages of GUS were reviewed in section 1.D. Unlike npt II assays exploited by Koncz et al. (1989), the GUS fluorogenic assay does not require chromatography or radioactive substrates. This enabled rapid, safe and cost-effective screening of reporter activity in leaves of close to 1,000 tobacco plants transformed with pPRF120, as well as in seeds and flowers of several hundred transformants. The resulting gene fusions were classified as Class I fusions and Class II fusions, respectively. Subsequently, a combination of 
both the fluorogenic and histological GUS assays was used to study different patterns of organ and cell-specific gene expression. Gene fusions expressed in a highly restricted manner, including seed coat-, embryo-, endosperm-, and vascularspecific, could be resolved. Expression levels of several gene fusions were measured in different tissues and could be readily compared to those of known promoters fused to GUS. However, comparisons of GUS activity between different gene fusions should be interpreted with caution, as there are several factors, including the distance between the GUS gene and the endogenous promoter and the presence of amino terminal fusions, which may affect the level of GUS transcript and activity. These factors would not affect levels of gene fusion expression within the different organs and tissues of an individual plant. Measurements of GUS activity in several plants transformed with pPRF120 indicated that levels of expression may vary considerably from organ to organ. Since this project was undertaken, other vectors incorporating promoterless GUS genes have been designed (Kertbundit et al., 1991; Topping et al., 1991). However, one of these is a pBIN19 derivative and plants transformed with this vector predominantly contain multiple T-DNA inserts (Topping et al., 1991; Table 1.1).

The use of GUS as promoterless reporter, coupled with the incorporation of a separate 5'nos-npt II-ocs3' marker into the T-DNA of pPRF120 permitted the selection of transformants regardless of their ability to express gene fusions. Potentially any tissue of the transgenic plants may be analyzed for expression of GUS, enabling the isolation of tissue-specific and developmentally regulated gene fusions. This was demonstrated by recovering at least 3 gene fusions which were expressed specifically in seeds. As these fusions are not expressed in any of the tissues which unierwent kanamycin selection, it is unlikely that they could have been recovered if a selective approach, such as those exploited by André et al. (1986) and Teeri et al. (1986), had been chosen. Uncoupling the recovery of 
transformants from gene fusion expression also permits one to directly estimate the fraction of transgenic plants which express T-DNA-mediated gene fusions.

\section{B. Characterization of Chromosomal Sites of T-DNA Integration Based on Promoterless Gene Activation}

DNA sequences contained within an organism's genome may be classified according to several properties. One of these is the ability to be transcribed into RNA. Transcribed sequences may be further categorized based on the level and the spatial and temporal pattern of their expression. As it is proposed that activation of promoterless reporter genes linked to the extremity of the T-DNA is dependent on T-DNA integration next to endogenous promoters, the proportion of insertions yielding gene fusions was used to estimate the frequency at which the T-DNA integrates within transcriptionally active regions of the plant genome. Similarly, regulation of T-DNA-mediated gene fusion expression is hypothesized to be controlled by endogenous plant promoters. Consequently, analysis of gene fusion expression was used to further characterize chromosomal sites of T-DNA integration.

\section{B.1. Frequency of T-DNA integration within transcriptionally active DNA}

Analysis of GUS activity in leaves of plants transformed with pPRF120 revealed that at least $6 \%$ expressed a T-DNA-mediated gene fusion (Class I). Activation of the promoterless GUS gene was not detected in leaves of the remaining plants, although based on Southern blot analysis on a fraction of the plants, the majority probably contained intact T-DNA copies. Failure of these plants to express GUS may b、 Explained in part by T-DNA integrations within transcribed DNA which did not result in GUS expression due to the relative positioning of the promoterless reporter with respect to nearby regulatory elements 
(see below), integrations outside of transcribed regions of the genome or integrations next to cis-acting elements which were not expressed in leaf tissues. The last alternative was tested by analyzing for GUS activity in flowers and seeds from several hundred plants which did not express a gene fusion in the leaf. Results indicate that some of the plants indeed express GUS in very specific tissues other than leaves such as seeds. Approximately $2 \%$ of the plants which were analyzed $(5 / 220)$ expressed this class of gene fusion (Class II). Extrapolation of these results to the entire sample size suggests that approximately $8 \%$ of the plants $(6 \%$ Class I + $2 \%$ Class II fusions) express the promoterless reporter gene in either the leaf or seed.

As briefly discussed in section 1.F.2.a., the frequency at which T-DNAmediated gene fusions are detected probably underestimates the number of T-DNA insertions within transcribed DNA. In order to more accurately determine the frequency at which the T-DNA inserts within transcriptionally active regions of the genome, it would be desirable to be able to estimate the fraction of insertions within transcribed DNA which yield gene fusions and those which do not. Vectors containing promoterless genes linked to either the left or right border repeats are equally effective at generating T-DNA-mediated fusions, indicating that T-DNA integration within a transcriptional unit is non-polar (Herman et al., 1990). Based on these observations, it may be concluded that, at a maximum, only $50 \%$ of inserts within transcriptionally active DNA will be detected by T-DNA-mediated gene fusions. Furthermore, the assay system designed in this thesis, as well as those used in related studies (Herman et al., 1990; Kertbundit et al., 1991; Koncz et al., 1990; Topping et al., 1991) depends on translation of the promoterless gene into a functional enzyme. Therefore, factors affecting protein translation such as reading frames, or those determining protein stability and enzymatic activity, such as the length of amino-terminal additions and the presence of potential cellular targeting 
information within such segments, will ultimately influence the possibility of detecting gene fusions. For example, targeting of a GUS fusion to subcellular regions where it will be glycosylated, such as the endoplasmic reticulum, will abolish enzymatic activity (Iturriaga et al., 1989).

The sequence separating the translational start codon of the promoterless GUS gene and the right border repeat of pPRF120 does not contain stop codons. Consequently, both transcriptional and translation gene fusions may be generated with this vector. Integrations of pPRF120 next to endogenous promoters, 5' of translated segments would result in transcriptional fusions, while insertions within the coding segment of an endogenous gene would generate translational fusions. Factors affecting the expression of one type of gene fusion may not necessarily be the same as those influencing expression of the other. For example, proper alignment of reading frames between the promoterless GUS gene and the endogenous gene is only relevant for translational fusions. The relative proportion of either type of gene fusion generated by pPRF120 integration was not assessed. The one gene fusion which was recovered (T218) does not appear to be a translation fusion as no ORF initiated by a consensus translational initiator codon rould be detected 5' of the T-DNA insertion. The presence of translational fusions could be determined by Western blot analysis using anti-GUS antibodies available from Clontech (Palo Alto, CA) or by in-gel fluorometric GUS assay (Jefferson et al., 1987; Putterill and Gardner, 1989).

RNA/DNA hybridization studies (Kamalay and Goldberg, 1980; Kamalay and Goldberg, 1984; Okamuro and Goldberg, 1989) indicate that the sequence complexity of RNA transcribed in the mature tobacco sporophyte corresponds to $18 \%$ of the genome. Of this, only $7 \%$ is expressed in leaves, the organ screened most thoroughly in this study. This value corresponds to the frequency of pPRF120 transformants which expressed the promoterless GUS gene. As discussed above, it 
is probable that screening for expression of reporter gene activity under-estimates the number of transformants containing T-DNA insertions within transcribed DNA. By compensating for the orientation and reading frame alone, as many as $36 \%$ of $\mathrm{T}$ DNA insertions may be within genes expressed in the leaf. Therefore, the frequency of gene fusions observed in this study is higher than was expected based on random integration of T-DNA throughout the genome, and suggests that the T-DNA preferentially integrates within transcribed regions of the genome.

The above conclusion is based on comparison of the frequency of gene fusions to the total amount of DNA transcribed in the tobacco genome. The results obtained are more dramatic if only the proportion of the genome encoding mRNA ( $2 \%$ in the leaf) is used as a reference. As locations of T-DNA insertion within transcriptional units have never been mapped, it is currently not known whether integrations throughout a transcribed region can be resolved by T-DNA-mediated gene fusions. For example, can integration events within introns be detected? Based on in vivo gene fusions generated in mammalian cells, the answer appears to be that they are not detected. Electroporation of a vector containing a fromoterless lac Z gene into mouse embryonic stem (ES) cells resulted in approximately $0.1 \% \mathrm{X}$ GAL positive, G418 resistant colonies (Friedrich and Soriano, 1991). When a splice acceptor site was added at the S' end of the lacZ gene, the proportion of X-GAL positive colonies increased to 4.6\%. Based on these results, Friedrich and Soriano (1991), concluded that the majority of insertions leading to promoterless gene activation occur within introns, but that these are not resolved unless the splice acceptor site is present in the vector. Consequently, the fraction of the tobacco genome into which T-DNA insertions will be resolved as gene fusions is difficult to estimate at the current time. 
Data available from other studies of T-DNA-mediated gene fusions also indicate that the T-DNA preferentially integrates within transcribed regions of the genome. This can be concluded from the high proportion of transgenic plants which express T-DNA-mediated gene fusions (Herman et a l., 1990; Kertbundit et al., 1991; Koncz et al., 1989; Topping et al., 1991) and the observation that plant species containing large differences in DNA content yield gene fusions at similar frequencies (Koncz et al., 1989). When compared to results obtained with other vectors capable of generating in vivo gene fusions (see Table 1.1), the percentage of plants transformed with pPRF120 which expressed the promoterless reporter gene is low. It is proposed that a combination of several factors, including vector design, screening strategy, and the average number of T-DNA copies per plant, rather than drastic differences in the specificity of T-DNA integration, account for the large variation in the frequencies of gene fusions reported in the literature. First, it is unlikely that the relative sensitivity of the reporter gene utilized is responsible for the differences in frequency reported. pPRF120-induced gene fusions were detected using the fluorogenic GUS assay. This assay is widely regarded as very sensitive (Jefferson, 1987; Jefferson et al., 1987), and was found to be slightly more sensitive than the npt II assay in transient gene expression assays of tobacco protoplasts (Töpfer et al., 1988). Topping et al. (1991), who reported a gene fusion rate of $78 \%$, also screened their plants with this assay. Kertbundit et al. (1991) exploited the GUS histological assay to screen for gene fusions. Although the histological assay has the potential advantage of identifying gene fusions having a highly restricted expression pattern (which may go undetected by fluorogenic assay due to the presence of an overwhelming amount of cells not expressing GUS in the cell extract), it is otherwise not as sensitive as the fluorogenic assay (Hobbs et al., 1990; Jefferson, 1987). This was also demonstrated in this study, as several tissues 
which contained GUS activity based on fluorogenic analysis failed to stain blue in the presence of X-GLUC. Therefore, it does not appear as though the assay system used to detect the T-DNA-mediated gene fusions per se can account for the lower frequencies obtained with pPRF120. Nevertheless, it is highly possible that interpretation of what constituted a positive result (i.e. reporter gene activity) may have differed from study to study, thus leading to discrepancies in results.

A second factor which may hypothetically account for the lower frequency of pPRF120-induced gene fusion is the limited number of tissues which were screened. Although it is probable that the frequency of gene fusions observed could increase upon screening additional organs, this cannot by itself explain the differences in results. Using different T-DNA vectors, Koncz et al (1989) screened the leaf, stem and root of 325 N. tabacum, N. plumbaginifolia and Arabidopsis thaliana plants and found that approximately $30 \%$ expressed $n p t$ II gene fusions. The percentage of the plants which expressed gene fusions in the leaf $(20 \%)$ was still higher than the value reported here (6\%). Similarly, Herman et al. (1990) reported that promoterless marker genes were activated in up to $50 \%$ of the protoplast-derived calli they analyzed. No other tissues were tested. The probability of generating gene fusions in seeds has not been assessed in any other study.

The third factor which was considered is the number of T-DNA insertions generated by the different vectors. Although plants transformed with pPRFi20 and vectors designed by Kertbundit et al. (1991) contain mostly single inserts, a large fraction of plants analyzed by Koncz et al. (1989) and Topping et al. (1991) contain multiple T-DNA inserts. Herman et al. (1990) do not report the average number of T-DNA copies present in the calli they studied. As previously discussed (section 4.A.) the presence of multiple T-DNA copies in a plant increases the probability that at least one of these will generate a gene fusion. However, an accurate assesiment of the proportion to T-DNA integrating within transcribed areas cannot 
be obtained in plants containing multiple T-DNA copies. The only conclusion which can be made is that at least one gene fusion is pir.sent, although in reality, one or several T-DNA inserts within the same plant may represent gene fusions. Therefore, the number of T-DNA copies could account, at least in part, for the differences in the frequencies of gene fusion observed. Differences in the T-DNA vectors, the transformation and selection protocols, and species used are other factors which very likely influence the results.

The presence of multiple copies of the T-DNA within a plant may also help explain why some of the reported frequencies of T-DNA-mediated gene fusions appear to be higher than would be predicted. For example, Topping et al. (1991) report that $78 \%$ of the leaves and roots they analyzed expressed the promoterless GUS gene. As one would expect at least $50 \%$ of insertions within transcriptionally active DNA to go undetected because of the relative orientation of the T-DNA with respect to the endogenous cis-acting elements, the numbers of Topping et al. (1991) would imply that the T-DNA has inserted within transcriptionally active DNA in over $150 \%$ of their plants. However, as half of the transformants contained insertions at 3 or more loci (Topping et al., 1991), this frequency of gene fusions is not impossible, and may coi respond to a frequency of less than $100 \%$ when expressed on the basis of T-DNA copy rather than transformants. Similarly, Koncz et al. (1989) reported that between 20 to $30 \%$ of the plants they analyzed expressed T-DNA-mediated translational fusions. As activation of the promoterless gene in these cases requires not only proper orientation of the T-DNA with respect to the endogenous transcriptional unit, but also an alignment in reading frames, these values again correspond to more than $100 \%$ of the plants containing a T-DNA insertion within transcriptionally active DNA. It is noteworthy that, unlike Koncz et al. (1989), Kertbundit et al. (1991) obtained considerably fewer gene fusions by transforming plants with a vector capable of generating translational gene fusions 
than one capable of generating both transcriptional and translational fusions.

As reviewed in section 1.E.3.f., models of T-DNA integration propose that it is mediated by illegitimate recombination. Consequently, it may be postulated that this process would be facilitated by the open chromatin structures characteristic of transcriptionally active regions, thereby accounting for preferential integration of the T-DNA within these areas. Other elements capable of inserting into eukaryotic chromosomes have also been shown to integrate preferentially within, or in the vicinity of, transcribed DNA. Mammalian retroviruses and retrotransposons found in Drosophila, yeast, and Dictostelium integrate preferentially into open chromatin, often in A/T rich regions (Mooslehner et al., 1990; Sandmeyer et al., 1990). Retrovirus integration is frequently associated with DNase I hypersensitive sites which exist at the 5' end of genes, while the integration sites of some yeast retrotransposons can often be mapped in the vicinity of genes transcribed by RNA polymerase III. An exception to the last class of targets are the ribosomal 5S genes (Sandmeyer et al., 1990). Similarly, the P-element of Drosophila, which is uot a retroelement, frequently integrates in the 5 upstream and untranslated regions of genes (Engels, 1988; Bownes, 1990). P-element insertions within heterochromatin are rare. There has only been one preliminary report of in vivo gene fusions mediated by DNA transferred to plant cells by methods of direct transfer (Klein et al., 1990). The data provided indicate that a vector containing a promoterless npt II gene linked to an extremity can yield one-third the number of kanamycin resistant protoplast-derived calli as a vector incorporating a constitutively-expressed $n p t$ II marker, suggesting preferential integration within transcriptionall: active regions. Therefore, preferential integration within transcribed or open chromatin is not unique to the T-DNA, and appears to occur with many genetic elements which insert into eukaryotic chromosomes.

Given the apparent correlation between open chromatin/gene transcription 
and T-DNA integration, it would be pertinent to determine whether the transcriptional state of a gene or transcriptional unit at the time of T-DNA insertion influences the process. This question is difficult to study, as not all cells within an explant are capable of being transformed (Janssen and Gardner, 1989). Furthermore, shoot regeneration requires that cells within the explant first "dedifferentiate" to a more meristematic state (Thorpe, 1980). Consequently, patterns of gene expression in cells at the time of T-DNA integration may not be the same as those of the original explant. However, the observation that some pPRF120-induced gene fusions are specifically expressed in highly differentiated cell types such as the endosperm and seed coat strongly suggests that the target sites of T-DNA integration need not be transcriptionally active at the time of infection.

Current literature provides no indication that gene fusions are expressed at a higher frequency in the tissues infected with Agrobacterium. Following transformation of $A$. thaliana root explants, Kertbundit et al. (1991) did not find a higher proportion of plants which expressed T-DNA-mediated gene fusions in this organ. In fact, their results may be interpreted to show that gene fusions expressed in roots are under-represented in the plants they analyzed, as no root-specific fusions were detected, and individuals which expressed GUS in the leaf, flower and stem were uncovered much more frequently than those which expressed GUS in these 3 structures as well as roots (48 vs. 7). Curiously, Topping et al. (1991) found that $75 \%$ of the tobacco plants they analyzed expressed a T-DNA-mediated GUS fusion in the roots. Unlike Kertbundit et al. (1991), these authors did not infect root tissue, but rather leaf discs. The frequency of GUS fusions expressed in leaves (22\%), however, was considerably lower than that in the root. As discussed by Topping et al. (1991), the higher percentage of fusions detected in the roots does not appear to be due to the presence of a greater number of genes expressed in this organ, or to the fact that regulatory signals controlling gene expression in the root 
are stronger than those in the leaf or other organs. These authors propose that cells in the roots and those found in the callus at the surface of the leaf discs are both active in cell division, and may express similar sets of genes. A greater number of root genes may thus be in the open conformation at the time of infection and $T$ DNA integration. It would be interesting to determine the frequency at which the vector designed by Topping et al. (1991) yields gene fusions in callus tissues. The results obtained in the present study indicate that the relative frequency of detecting gene fusions which are expressed in the leaf (infected tissue) is greater than that of generating fusions in seeds by a factor of $3(6 \%$ vs. $2 \%)$. Whether the difference in frequency is related to the transcriptional state of the chromosomal sites of integration at the time of infection remains to be confirmed. It is noteworthy that genes which are not transcriptionally active at a given time, or under a certain condition, may still be relatively "open" with respect to the bulk of tw: chromatin (Kahl et al., 1987; van Holde, 1989). Such chromatin has been : .ferred to as "competent", and may also represent preferential sites for T-DNA irtegration. A hypothesis similar to this one has been proposed by Topping et al. (1991). Preferential integration of the T-DNA within active or competent chromatin is also supported by observations, "N Weising et al. (1990) who reported that integrated TDNA elements are preferentially sensitive to nucleases regardless of the transcriptional state of the sequences contained therein (reviewed in sectic 1.E.3.d.). There has been at least one report linking the transcri ${ }_{2}^{-}$tional statgenes with preferential integration of mobile DNA. This was observed in Drosophila transformed with an enhancer-trap vector based on the P-element (Bownes, 1990). This transposon has been shown to actively transpose in gerin line cells, and correspondingly, a disproportionately large number of enthencer fusions detected by Bownes (1990) were expressed in these tissues. 


\section{B.2. Expression patterns of sites of T-DNA integration}

In addition to estimating the frequency at which the T-DNA integrates into transcribed areas of the genome, chromosomal sites of T-DNA integration were characterized by analyzing the patterns of GUS expression in various vegetative and floral organs, as well as developing seeds from 14 Class I gene fusions, and 4 Class 11 fusions, and comparing them to the overall patterns of gene expression observed in tobacco plants using RNA/DNA hybridization studies (reviewed in section 1.B.1.). Patterns of promoterless GUS activation indicate that the T-DNA may integrate within transcriptional units having widely different expression specificities, ranging from those expressed in all organs and tissues (defined as unrestricted expression) to those expressed specifically iri highly differentiated tissues such as the endosperm and seed coat. Individual gene fusions could be detected in tissues representing all stages of the life cycle, including vegetative organs, floral organs, and seeds, 1.ithout necessarily being expressed in all tissues and organs. This pattern was defined as restricted expression, and was ine most prevalent class of expression detected. Overall, patterns of gene expression revealed by T-DNA-mediated fusions are not inconsistent with those obtai 'ed ly analyzing mRNA pools in different organs of the tobacco plant (Okamuro and Goldberg, 1989). These studies estimate that approximately $30 \%$ of the mRNA constitute housekeepi Results obtained from these reciprocal crosses are presented in Appendix 1.ng genes which are expressed in all organs (Okamuro and Goldberg, 1989). This pattern of expression corresponds to the unrestricted expression pattern described above. Although the number of gene fusions expressing GUS in an unrestricted pattern (one) appears to be lower than expected ( $30 \%$ of 18 gene fusions studied in more detail), the techniques used by Okamuro and Goldberg (1989) could not resolve gene expression at the cellular level. Consequently, other gene fusions such as T30, T777, and T1253, which are expressed in all organs, would be classified as housekeeping 
genes by these methods. Okamuro and Goldberg (1989) also detected a class of transcripts which were expressed in what is defined in this thesis as a restricted pattern. These were shared by two or more, but not all, organs. Levels of these transcripts could vary considerably in different organs, and analysis of some of these mRNA by in situ hybridization has revealed evidence for tissue- and cell-specificity of expression. Approximately 25 to $40 \%$ of the mRNA detected by Okamuro and Goldberg (1989) were detected in 2 or more organs. Thus, the large number of restricted gene fusion expression patterns observed in this study is not inconsistent with the proportion of transcripts shared by two or more organs. The remaining class of transcripts detected by Okamuro and Goldberg (1989) were organ-specific. These varied in frequency from $23 \%$ to $40 \%$. The exceptions being the leaf and petal, which shared a specific subset of transcripts between each other, but did not possess organ-specific transcripts per se. In contrast to the results obtained by hybridization studies, no leaf-or leaf/petal-specific gene fusions were detected amongst the 57 Class I gene fusions analyzed in this study. However, several seedspecific fusions were uncovered amongst the Class II gene fusions. Other studies of T-DNA-mediated gene fusions have reported organ-specific, and more specifically, leaf-specific fusions (Koncz et al., 1989; Kertbundit et al., 1991), indicating that they may be generated. However, analysis of gene fusion expression in other studies have not been as intensive as those performed in this thesis, and it is possible that some of the organ-specific fusions detected in these studies are also expressed in some of the tissues which were not analyzed.

There are at least two possible reasons by which lack of leaf-specific gene fusions may be explained. First, hybridization analysis such as those carried out by Okamuro and Goldberg (1989) are capable of detecting transcripts which are expressed at very low levels. These studies have also revealed that the majority of the developmentally regulated transcripts are expressed at very low levels. 
Conseqquently, cis-acting elements associated with leaf-specific transcripts may be too weak to produce sufficient GUS enzyme for detection. It is perhaps noteworthy that truly organ-specific transcripts are difficult to recover using hybridization methods such as differential hybridization. Apparent organ-specific clones are occasionally expressed in other tissues, albeit often at considerably lower levels (see, for example Koltunow et al., 1990; Okamuro and Goldberg, 1989). A second alternative to explaining the lack of leaf-specific gene fusions is that many of the leaf-specific or organ-specific mRNA are regulated at the post-transcriptional level. Comparison of nuclear RNA pools between different tobacco organs failed to reveal large numbers of organ-specific, especially leaf-specific transcripts (Okamuro and Goldberg, 1989). Most of the nuclear RNA transcripts detected in the leaf (ca. 90\%) were also present in other organs analyzed by Okamuro and Goldberg (1989). Therefore, lack of leaf-specific gene fusions is consistent with overall patterns of nuclear RNA, not mRNA, expression in tobacco leaves.

Comparison of expression patterns between Class I and Class II gene fusions reveals that the latter appear to be more organ- and tissue-specific than the former. Given that most Class I fusions are expressed in a restricted pattern, it should have been possible to uncover Class II fusions expressed in a variety of organs other than the leaf. An interesting possibility is that the initial screening for gene fusions expressed in leaf tissue identified many of the fusions having broad expression specificities. and that subsequent analysis of other tissues for GUS activity may yield gene fusions having more restricted expression profiles.

When interpreting the patterns of T-DNA-mediated gene fusions, it was assumed that these paralleled those of the endogenous transcript into which the TDNA had integrated. Analysis of the chromosomal location of P-element-mediated enhancer fusions in Drosophila has revealed that in some cases, a known gene having the expression pattern similar or identical to the enhancer fusion mapped in 
the vicinity of the inserted element (Wilson et al., 1989; Bellen et al., 1990, and references therein). However, similar studies have yet to be carried out to show that the expression patterns of T-DNA-mediated gene fusions accurately reflect those of the endogenous transcript. Recovery and functional testing of the T218 gene fusion demonstrated that cis-acting elements required for regulated expression of the gene fusion are located in the chromosomal DNA flanking the GUS gene, but does not yield any information with respect to expression of the chromosomal sequences in the absence of the T-DNA. Studies which will eventually lead to the expression analysis of the endogenous transcripts are currently underway (J. Cosmopoulos, Carleton University, Ottawa, Ont., personal communication).

Hypothetically, there are at least two ways by which T-DNA insertion into a transcriptional unit may yield a T-DNA-mediated gene fusion which is not expressed in the same manner as the endogenous transcript. First, insertions near or within the promoter region itself may disrupt the integrity of cis-acting elements, thereby altering interactions of cis- and trans-acting elements and patterns of gene transcription. Rearrangements in the flanking chromosomal DNA resulting from TDNA integration (reviewed in section 1.E.3.c.) may also affect promoter integrity. Second, substitution of the endogenous transcript, or part of it, with the GUS-nos3' sequences may alter regulation of gene expression at the post-transcriptional level. Tobacco organs contain large amounts of nuclear RNA which are never found in the cytoplasm as mRNA (Kamalay and Goldberg, 1980; Kamalay and Goldberg, 1984; Goldberg et al., 1978; Okamuro and Goldberg, 1989). Presumably, posttranscriptional processes play an important role in establishing the mRNA population of a given organ. Without being otherwise disrupted, cis-acting elements normally regulating the expression of nuclear RNAs could conceivably give rise to a translatable GUS mRNA when fused to the promoterless GUS gene of pPRF120. However, in such cases, patterns of GUS expression would continue to reflect the 
transcriptional properties of the endogenous tobacco cis-acting elements.

\section{B.3. Additional questions relating to T-DNA integration specificity}

4.B.3.a. Why were no cold-inducible gene fusions detected?

Analysis of leaves from close to 1,000 pPRF120 transformants failed to detect the presence of cold-inducible gene fusions. As there are only a small number of genes which are induced by exposure of plants to cold temperature treatment (Thomashow, 1990), it is likely that the number of pPRF120 transformants which were screened for cold-inducible gene fusions was too small to ensure recovery of these types of cis-acting elements.

\section{B.3.b. Why were no gene fusions detected by analyzing flowers of pPRF120?}

Flowers from several hundred plants which did not express a Class I gene fusion were analyzed for GUS activity, but none were found to contain activity. Although it is possible that the probability of recovering these types of gene fusion is lower than that of detecting Class I or Class II gene fusions, analysis of floral tissues by the GUS fluorogenic assay must be interpreted with caution, as preliminary results appear to suggest that GUS activity is inhibited in these tissues. This preliminary evidence comes from thre $\varepsilon$ sources. First, several floral tissues which failed to produce significant levels of MU by fluorogenic assays stained for GUS activity by histological assay. Second, studies in which plant extracts were mixed indicate that addition of a floral tissue extract to a leaf extract containing GUS activity can reduce the rate of activity by up to $50 \%$. Third, extracts from floral tissues do not quench the fluorescence produced by a standard solution of MU any more than do leaf extracts. Consequently, if lack of GUS activity determined by fluorometry is not related to extract quenching, the results obtained could indicate that GUS may not be as stable or active in these extracts. Whether this is due to the 
presence in these tissues of a specific inhibitor of GUS, that would be released upon tissue extraction, remains to be determined. More analyses are required to confirm these observations. It is noteworthy that several substrates for GUS fluorogenic assays are commercially available from Molecular Probes, Inc. (Eugene, OR). As the alternative substrates have different excitation and emission wavelengths, they may be exploited to further analyze whether lack of activity using MUG is due to fluorescence quenching by the floral extracts. Comparisons of GUS mRNA levels and activity should also be helpful to determine whether gene fusions are expressed in tobacco flowers.

\section{B.3.c. Does the T-DNA show any site-specificity within transcribed DNA?}

Several elements capable of preferentially integrating within transcribed DNA show additional specificity for certain regions of a transcriptional unit. The specificity of retroelements and the P-transposable element within transcribed DNA regions was discussed in a previous section. Relatively little data is available on the site-specificity of T-DNA integration. However, information provided by Topping et al. (1991) and Kertbundit et al. (1991) suggests that the T-DNA may integrate within the 5' end of transcriptional units. First, Topping et al. (1991) report that they find no evidence that the enhancer fusions they generated resulted from $T$ DNA insertions within genes. This conclusion is based on Northern blot data showing that the size of enhancer fusion messages are the same as that of the normal GUS mRNA. However, given the resolution of Northern blotting, and the fact that these authors observed very high frequencies of gene fusions to a promoterless GUS gene in a separate study, the Northern blot results may be interpreted to show that the T-DNA integrates near the 5' end of genes. Lack of fusion transcripts could be explained either by integrations in non-transcribed promoter regions, or close to the 5' end resulting in short fusion transcripts that 
could not be resolved by the Northern blotting. Preferential integration of the TDNA downstream of promoter elements may possibly explain why Topping et al. (1991) observed similar (high) frequency of (promoterless) gene fusions and enhancer fusions. Given the more stringent spatial restrictions imposed on gene fusions to a promoterless reporter gene, one would otherwise predict that enhancer fusions should be generated more frequently.

Other observations suggesting that the T-DNA integrates close to the 5' end of genes comes from comparisons of the frequency of gene fusions generated by a vector capable of both transcriptional and translation gene fusions with one capable of generating only translational fusions (Kertbundit et al., 1991). Plants transformed with the latter vector yield considerably fewer gene fusions ( $1.6 \%$ vs. $54 \%$ ), suggesting that the majority of the fusions generated with the vector capable of both types of fusions represent transcriptional fusions. As there are no stop codons in the leader sequence of this vector, transcriptional fusions should be generated only when the T-DNA insertion is close to the 5' end of the endogenous gene. Insertions within the coding region of a transcript will result in translational fusions. Furthermore, insertions in the 5' non-coding region would not be resolved by a vector lacking a translational start site, possibly explaining the low frequency of gene fusions using the translational gene fusion vector. It is noteworthy that the above hypothesis is only valid if one considers that the T-DNA inserts only in structural genes. Additionally, it does not take into consideration the fact that Koncz et al. (1989) obtained similar rates of transcriptional and translational gene fusions. Walden et al. (1991) have speculated that the difference in the frequency of translational fusions observed by Koncz et al. (1989) and Kertbundit et al. (1991) is due to the inability of GUS to accommodate amino terminal fusions. However, this has yet to be shown experimentally. 
A question which is related to the site-specificity of T-DNA integration within a transcriptional unit is whether the location of insertion within the transcribed DNA has any influence on the expression of the promoterless reporter gene.

\section{B.3.d. What effect does kanamycin selection have on the distribution of T-DNA insertion?}

Although it has been proposed that regions of open chromatin constitute preferred sites of T-DNA integration because they are more favorable for illegitimate recombination, at least one alternative hypothesis has been proposed to explain preferential integration within regions of open chromatin. Weising et al. (1990) speculated that the reason why the T-DNA is observed to integrate within open chromatin is that integration events in other areas of the genome would not favor expression of the selectable markers used to recover transgenic plants. Cells containing inserts in such unfavorable locations would not survive under the selection pressure imposed. Therefore, according to this hypothesis, the high frequency at which T-DNA-mediated gene fusions are recovered in transgenic plants may not reflect a genuine affinity of the incoming T-DNA for open chromatin, but would rather be an artifact brought about by selection protocols which enrich for T-DNA inserts capable of expressing marker genes. However, results by Herman et al. (1990) show that the frequency of obtaining T-DNAmediated gene fusions is not greatly different in protoplast-derived calli which were first selected for expression of a constitutively-expressed marker gene from those which were not selected for transformation. These results argue against the theory of Weising et al. (1990). 
4.B.5.e. Is there a correlation between the frequency of T-DNA-mediated gene fusions and that of T-DNA-insertional mutagenesis?

Considering the high frequency at which the T-DNA integrates within transcribed DNA, few reports describing T-DNA-mediated insertional mutations have been published. Although plants transformed with pPRF120 were not systematically analyzed for the presence of mutant phenotypes, visual observation of the progeny of approximately 100 plants transformed with pPRF120 did not reveal any evidence of morphological mutations (data not shown). Many of the plants analyzed expressed the promoterless reporter gene and thus may have contained TDNA insertions within genes. A large number of transformation studies, including the present one, were performed with the allotetraploid N. tabacum, which may not be an ideal host for identification of T-DNA insertional mutations. Species better suited for this purpose, such as $A$. thaliana with its small, diploid genome, are susceptible to T-DNA transformation (Feldmann and Marks, 1987; Valvekens et al., 1988). T-DNA-induced mutations have now been identified in this organism (Feldmann, 1991; Feldmann et al., 1989; Koncz et al., 1990; Marks and Feldmann, 1989; Van Lijsebettens et al., 1990; Yanofsky et al., 1990), although the frequency at which these arise may be quite different, ranging from 0.2-1.0\% of plants (Koncz et al., 1990) to $19 \%$ of T-DNA inserts (Feldmann et al., 1989). The difference in frequency may be partly related to the thoroughness of the screening procedures developed. It is noteworthy that not all of the mutations observed by Feldmann and colleagues are linked to T-DNA insertion. These groups used the seed transformation protocol (Feldmann and Marks, 1987) which was proposed to prevent the possibility of tissue culture-induced mutations. Feldmann (1991) reports that $12 \%$ of the mutants are not tagged by a T-DNA insert. Errampalli et al. (1991) studied 18 embryonic lethal transgenic lines and concluded that only 9 of these were tagged. Presumably, the source of seeds used in the transformation 
protocol may affect the rate of spontaneous (untagged) mutations (Feldmann, 1991). A high number of morphological mutants identified following T-DNA transformation and regeneration through tissue culture appear to result from somaclonal variation and do not co-segregate with T-DNA-encoded markers (Van Lijsebettens et al., 1991).

The observation that the frequency of insertional mutations is lower than that of gene fusions is not unexpected, as mutational analyses with Drosophila and yeasts have demonstrated that as many as two-thirds of all genes are not essential for development (for more detailed discussion, see Friedrich and Soriano, 1991; Wilson et al., 1989). These results suggest that eukaryotic genomes are functionally redundant, this redundancy being brought about primarily by the presence of multigene families. In addition, the possibility that at least some of the T-DNA gene fusions may result from integrations within non-structural genes cannot be excluded at the present time (see next section).

In view of the fact that the T-DNA in plant T218 appears to have integrated within a unique DNA sequence, progeny of this plant were analyzed for the presence of insertional mutations. As the gene fusion in plant T218 is specifically expressed in the seed coat, seed coats from seeds harvested from the original transgenic would all have been hemizygous for the T-DNA insertion. The earliest generation in which the T218 T-DNA could be found in a homozygous state in the seed-coat is in seeds of the $R_{1}$ generation. Analysis of seeds from 12 kanamycin resistant $\mathbf{R}_{1}$ plants revealed that they all produced a normal amount of seeds which germinated and gave rise to phenotypically normal plants (data not shown). Segregation analysis of these seeds for the kanamycin-resistance marker indicated that several of the $\mathbf{R}_{1}$ plants were homozygous for the T-DNA (data not shown). Lack of detectable phenotype in plant T218 may be attributed to several factors. First, the T218 locus may encode a function which is not essential for seed 
formation. Second, the T-DNA, although integrated next to cis-acting elements capable of conferring seed coat-specific expression, may not be inserted within a structural gene. Currently, there is no evidence to suggest that the chromosomal region into which the T218 T-DNA has inserted contains a structural gene.

Sequence analysis of this locus prior to T-DNA insertion and Northern blot analysis would be needed to study this possibility. Third, it is possible that the T-DNA in plant T218 has inserted within a member of a multigene family. Although the results from the Southern blots argue against this hypothesis, the probe which was used may have been specific to one allele of the multigene family. It is noteworthy that sequence analysis failed to reveal the presence of a long open reading frame in the chromosomal DNA flanking the T218 fusion. Analysis using additional hybridization probes, more specifically coding region probes if they exist, are needed to confirm the uniqueness of this insertion site.

\section{B.3.e. Is it possible to resolve T-DNA-mediated gene fusions within transeribed regions which do not encode structural genes?}

In addition to mRNA, plant cells also contain other classes of RNA, including tRNA, and large amounts of rRNA (Flavell, 1986). In tobacco, there are between 1,000 to 1,500 copies of rRNA genes (reviewed in Long and Dawid, 1980). Transcriptionally active rDNA loci have been determined to be in an open chromatin structure (Flavell, 1986). If, as hypothesized the chromatin structure of a DNA region influences T-DNA integration, does rDNA represent a preferred site of integration, and second, can insertions within these regions be resolved by $T$ DNA-mediated gene fusions. Although it is difficult to answer these questions with the data available, it is noteworthy that rDNA genes are $\mathrm{C} / \mathrm{G}$ rich (Leweke and Hemleben, 1982). In contrast, sequences which flank the T-DNA have thus far been found to be A/T rich (Gheysen et al., 1987; Gheysen et al., 1991; Mayerhofer et al., 
1991; Zambryski, 1988). This includes the sequences flanking the T218 right border repeats, which is approximately $66 \% \mathrm{~A}+\mathrm{T}$. Consequently, there is no current evidence to suggest that the T-DNA has integrated within rDNA. As to whether insertions within rDNA would result in promoterless gene activation, several reports have shown that eukaryotic mRNA require the presence of a S' cap in order to be translated (see Rudenko et al., 1991). Transcripts other than those generated by RNA polymerase II lack this 5' cap structure. As rRNA is transcribed by RNA polymerase I, transcripts would lack the 5' cap.

\section{B.3.f. How could vectors for generating T-DNA-mediated gene fusions be improved?}

As it is possible to generate gene fusions to either the right or the left $T$ DNA borders, it would be interesting to design a vector with promoterless genes linked to both borders (e.g. GUS and $l u c$ ) and detırmine the frequency of uncovering fusions at either border and at both borders.

An interesting possibility would be to determine whether it is possible to develop a system which does not rely on protein activity. All vectors to date require transcription, translation, and the production of a functional enzyme in order to identify integrations within transcriptionally active regions of the genome. A more direct approach of studying these phenomena would be to analyze plant cells for the presence of the reporter gene transcript and determine how it compares to results obtained on the basis of reporter activity. Alternatively, a system based on the activation of a catalytic RNA molecule (ribozyme) may allow more efficient screening for gene fusions. However, ribozyme technology is only now emerging, and the feasibility and potential success of such an approach are difficult to predict. Nevertheless, current literature indicates that it should be possible to develop stitable in vitro as well as in vivo assays for the presence of ribozymes (Haseloff and 
Gerlach, 1988; Scanlon et al., 1991) based on RNA cleavage or splicing.

\section{C. Possible Influences of Flanking Chromosomal Sequences on Transgene Expression}

The possibility that chromosomal sites of T-DNA insertion affect the expression patterns of transferred genes ha" been proposed on several occasions (reviewed in section 1.E.4.). Results obtained in this study, as well as others with TDNA-mediated gene fusions, indicate that endogenous cis-acting regulatory elements are present in sequences flanking many T-DNA insertions, and thus may be capable of influencing the levels and patterns of genes located within the TDNA. However, direct evidence for this has never been shown. One approach which could be used to study the effects of flanking DNA on transgene expression is to analyze the pattern of S'nos-npt II-ocs3' expression in plants transformed with pPRF120 and determine if patterns observed correlate with those of the promoterless GUS gene in these plants. For example, plant T777 expresses GUS at very high levels in the roots, while plant T218 does not. As the npt II gene is under the control of the nos promoter in both plants, it should be expressed at similar levels in the roots of these plants. Enhanced levels of npt II activity (or transcript) in the roots of $T 777$ would suggest that flanking chromosomal sequences responsible for GUS activation are also capable of influencing expression of other transgenes. Should correlations between patterns of promoterless GUS gene activation and levels of $n p t$ II activity be observed with several different pPRF120 transformants, results would strongly suggest that the variable expression observed between independent transformants may be due to their chromosomal location.

It is noteworthy that some variability in levels of GUS expression within individual organs or tissues were observed in this study. As all analyses were 
performed on individual transgenic plants, these results demonstrate that all variation cannot be attributed to positional effects. Developmental regulation of the gene fusions and sampling differences may account for the variation.

\section{D. Use of T-DNA-Mediated Gene Fusions to Uncover Novel Cis-Acting Elements.}

Novels patterns of plant gene expression revealed by T-DNA-mediateci gene fusion may be used to uncover new classes of genes and cis-acting regulatory elements. Potential advantages of this approach are that, unlike differential hybridization, it is not biased by levels of transcription and thus may be better suited to uncover low abundance genes; it allows direct visualization of gene expression in planta and the possibility of uncovering cis-acting elements by T-DNA tagging or plasmid rescue. The potential of generating T-DNA insertional mutations may also allow characterization of tagged gene function. However, patterns of T-DNAmediated gene fusions reported to date suggest that the approach may not be the method of choice for isolating organ-specific or inducible genes, especially when genes expressed in a specific, pre-determined pattern are sought. Instead, it is proposed that T-DNA-mediated gene fusions are better suited to uncover patterns of gene expression not readily accessible by other current methods of gene isolation. These include gen:- expressed constitutively and those expressed within specific cells or tissues within an organ. For example, the vascular-specific pattern of expression in plant T30 would not have been uncovered by methods based on RNA hybridization as RNA isolation requires tissue homogenization. Similarly, it is possible to isolate seed-specific genes by methods of RNA hybridization, however, a considerable amount of additional analyses may be required to identify those expressed specifically in the endosperm or seed coat. In contrast, the GUS histological assay permits in situ visualization of gene fusions at the cell and tissue 
levels.

\section{D.1. Examples of novel patterns of gene expression revealed by T-DNA-mediated gene fusions}

An unrestricted pattern of GUS expression was detected in plant T1275. Levels of expression in vegetative organs were within the upper range of 5 'CaMV 35S-GUS expression. However, it does not show the tissue-specificity of the $35 \mathrm{~S}$ promoter, which is expressed preferentially within vascular tissues. Potentially, the cis-acting regulatory elements controlling GUS expression in plant T1275 may be exploited to express genes of choice at high levels in all tissues of transgenic plants.

An interesting phenomenon which was observed in several plants was that the cell-specific pattern of GUS expression could vary in different organs. For example, GUS expression in plant T804 is vascular-specific in the leaf but constitutive in the stem. Expression of GUS in plant T612 and T1041 are constitutive in the leaf but predominantly concentrated in the pith and outer cortex, respectively, in the stems of these plants.

The expression pattern of one gene fusion (T7/7) was irregular, and could not readily be classified on the basis of cell- or tissue-specificity. Instead GUS expression in this plant indicates that the gene fusion is shut-down in many cells early in seedling development. In situ localization of GUS expression in young seedlings revealed constitutive GUS activity, which switched to a "patchy" pattern in older seedlings, and in the various vegetative and floral organs, as well as seeds of mature plants. This expression pattern does not appear to be due to an unstable $T$ DNA insert which is lost in some cells or to the fact that T777 is a chimaeric transformant. The progeny of $T 777$ segregate in the 3:1, kanamycin resistant to sensitive, ratio expected for a single T-DNA insert and the patchy pattern of expression is detectable in all kanamycin resistant seedlings observed. Additionally, 
the hybridization signals of T777 DNA on Southern blots are of similar intensity as those obtained with plants which express GUS constitutively, indicating that the TDNA is not being lost in differentiated organs. Inactivation of transgenes during the normal course of development has been reported previously (reviewed in section 1.E.4.). However, the present observations appear to be unique in at least two ways. First, GUS activity in T777 was never completely shut-off in any given organ. GUS activity was always detected, but only in a fraction of the cells, which appeared to be randomly distributed throughout the organ. Second, the regulatory elements presumably controlling GUS expression in plant T777 are external to the T-DNA. Therefore, the pattern of gene expression observed is presumably reflective of the normal transcriptional properties of these sequences in untransformed tobacco.

Expression of GUS in plant $T 777$ may be influenced by the chromosomal domain within which the T-DNA has integrated. In mammalian cells, integration of foreign genes next to regions of heterochromatin, for example, has been shown to inactivate transgene expression in certain cell types (Reuter et al., 1990). The influence of chromosomal position on expression of the $T 777$ gene fusion may be tested by recovering the gene fusion and re-introducing it into untransformed tobacco plants, in much the same way as performed with the T218 gene fusion. These manipulations should result in insertion of the cloned gene fusion at different chromosomal locations in independent transformants. Should the same pattern of gene expression be visualized in these transformants, results would indicate that the pattern of GUS expression observed in plant T777 is controlled principally by the cis-acting elements flanking the T-DNA. In contrast, loss of the patchy, or variegated pattern would suggest that the sequences or factors other than the flanking cis-acting elements in plant $\mathbf{T 7 7 7}$ play an important role in regulating gene expression. 
Another unique pattern of gene expression which was revealed by T-DNAmediated gene fusion was seed coat-specificity. Regulatory elements from several seed-specific genes have been extensively characterized (Bustos et al., 1991; Edwards and Coruzzi, 1990; Goldberg et al., 1989; Okamuro and Goldberg, 1989). However, these all confer embryo- or endosperm-specific expression. Genes expressed in the seed coat have also been identified (for example, Lindstrom and Vodkin, 1991), although this is the first report of seed coat-specific expression. The seed coat, or testa, contains the embryo and stored nutrients, and may be involved in a number of functions including protection, seed dispersal and control of germination (Essau, 1977). The seed coat-specific fusion uncovered in plant T218 was expressed only at 10-14 DPA; no activity was detected in vegetative and floral organs, and seeds 20 DPA. This was demonstrated by histological and fluorogenic analysis of plant $T 218$, and was confirmed by genetic crosses involving plant $T 218$ and untransformed tobacco.

\section{D.2. Analysis of gene fusion $\mathrm{T} 218$ at the molecular level}

Although analysis of GUS expression in various organs of transgenic plants transformed with pPRF120 offers an opportunity to uncover novel patterns of gene expression, molecular cloning and analysis of gene fusions is required to gain a better understanding of the cis-acting elements controlling these expression patterns. In this thesis, the gene fusion from plant T218, which is expressed specifically in the seed coat, was isolated by T-DNA tagging, analyzed by DNA sequencing and functionally tested in transgenic tobacco.

Sequence analysis revealed the presence of several putative cis-acting elements in the chromosomal DNA flanking the GUS gene in plant T218. These included direct and inverted repeats, regions capable of forming Z-DNA, and sequences homologous to known plant cis-acting regulatory elements. However, the functional 
significance of these sequences has yet to be determined. As an initial step, the promoter region of the T218 gene fusion was deleted and functionally tested in transgenic tobacco. Results indicate that, although the full length, cloned gene fusion is expressed with the same spatial and temporal pattern as in the original plant, none of the 3 deleted derivatives tested retained full activity. Histological analysis of GUS expression in seeds of plants transformed with a construct containing $360 \mathrm{bp}$ of tobacco DNA flanking the GUS gene failed to reveal the presence of activity at 10 and $20 \mathrm{DPA}$. Preliminary analysis of seeds from plants transformed with promoter fragments of $500 \mathrm{bp}$ or $1 \mathrm{~kb}$ suggest that these are expressed at considerably lower levels than the full length promoter. However, data on the expression of the last two promoter derivatives are restricted to those obtained with single transformants. Additional analysis will be needed to confirm these results. Nevertheless, they suggest that sequences extending beyond $1 \mathrm{~kb}$ from the GUS translational start site are important for promoter function. Clearly, more analyses are required to define those cis-acting elements important for seed coatspecificity. Additional analyses should include characterization of the fusion transcript, the corresponding endogenous transcript, and comparison of their expression.

\section{E. Concluding Remarks}

Although integration within the plant genome appears to be randorn with respect to chromosomal location (Ambros et al., 1986; Chyi et al., 1986; Wallroth et al., 1986) and sequence specificity (Zambryski, 1988; Gheysen et al., 1987; Gheysen et al., 1991; Mayerhofer et al., 1991), data from T-DNA-mediated gene fusions indicate that it is biased for regions of the genome which are actively or potentially transcribed. It has been speculated that the open chromatin structure of such 
chromosomal areas may facilitate the process of illegitimate recombination between the T-DNA and the plant chromosome. Expression patterns of T-DNA-mediated gene fusions reveals that the T-DNA integrates next to cis-acting elements having strikingly different regulatory properties. The frequency at which different patterns of expression are observed is consistent with patterns of plant gene expression observed by the analysis of RNA populations. Thus, although the T-DNA preferentially integrates within transcribed regions of the genome, the data currently available do not suggest that it is biased to genes expressed in a particular fashion, or in specific cell types. The current literature can also not resolve whether the transcriptional state of a chromosomal area affects the ability of the T-DNA to integrate therein.

Analysis of gene fusions at the molecular level indicates that sequences required for promoterless gene activation are localized within the chromosomal DNA flanking the T-DNA. A considerable amount of additional information about insertion sites as well as the specificity of T-DNA integration should be obtained by molecular cloning and characterization of regions from untransformed plants corresponding to those into which the T-DNA has inserted. Such analyses may provide answers as to the specificity of T-DNA integration within a transcriptional unit and the feasibility of resolving gene fusions from T-DNA insertions in different areas within the transcribed region (e.g. 5' untranslated regions, introns, 3 ' regions). In addition, molecular characterization of the chromosomal sites of integration may help determine whether all gene fusions result from T-DNA insertions within structural genes.

Patterns of gene expression revealed by T-DNA-mediated gene fusions provide a means of uncovering novel classes of cis-acting elements and assessing the range of expression patterns which may be encoded by the plant genome. For example, aralysis of the T218 gene fusion may allow the identification of cis-acting 
elements involved in mediating gene expression in the seed coat. An interesting possibility is that analysis of regions flanking T-DNA-mediated gene fusions may reveal that sequences bearing no resemblance to the consensus regulatory elements currently thought to be involved in gene regulation are nevertheless capable of activating promoterless gene expression. Such sequences may or not be associated with "genes", transcripts or coding segments within the plant genome. 


\section{REFERENCES}

Allen, N.D., Cran, D.G., Barton, S.C., Hettle, S., Reik, W., and Surani, M.A. 1988. Transgenes as probes for active chromosomal domains in mouse development. Nature 333: 852-855.

Ambros, P., Matzke, A.J.M., and Matzke, M.A. 1986. Localization of Agrobacterium rhizogenes T-DNA in plant chromosomes by in situ hybridization. EMBO J. 5: 2073-2077.

An, G., Costa, M.A., Mitra, A., Ha, S.-B., and Máarton, L. 1988. Organ-specific and developmental regulation of the nopaline synthase promoter in transgenic tobacco plants. Plant Physiol. 88: 547-552.

An, G., Ebert, P.R., Yi, B.-Y., and Choi, C.-H. 1986. Both TATA box and upstream regions are required for the nopaline synthase promoter activity in transformed tobacco cells. Mol. Gen. Genet. 203: 245-250.

André, D., Colau, D., Schell, J., Van Montagu, M., and Hernalsteens, J.P. 1986. Gene tagging in plants by a T-DNA insertion mutagen that generates APH(3')IIplant gene fusions. Mol. Gen. Genet. 204: 512-518.

Appleyard, R.K. 1954. Segregation of new lysogenic types during growth of a doubly lysogenic strain derived from Escherichia coli K12. Genetics 39: 440.

Avery, G.S. 1933. Structure and germination of tobacco seed and the developmental anatomy of the seedling plant. Amer. J. Bot. 20: 309-327.

Bakkeren, G., Koukolikova-Nicola, Z., Grimsley, N., and Hohn, B. 1989. Recovery of Agrobacterium tumefaciens T-DNA molecules from whole plants early after transfer. Cell 57: 847-857.

Balcells, L., Swinburne, J., and Coupland, G. 1991. Transposons as tools for the isolation of plant genes. Trends Biotechnol. 9: 31-36.

Barnes, W.M. 1990. Variable patterns of expression of luciferase in transgenic tobacco leaves. Proc. Natl. Acad. Sci. USA 87: 9183-9187.

Battraw, M.J., and Hall, T.C. 1990. Histochemical analysis of CaMV 35S promoterB-glucuronidase gene expression in transgenic rice plants. Plant Mol. Biol. 15: 527538.

Bellen, H.J., Wilson, C., and Gehring, W.J. 1990. Dissecting the complexity of the nervous system by enhancer detection. BioEssays 12: 199-204.

Benfey, P.N., and Chua, N.-H. 1989. Regulated genes in transgenic plants. Science 244: 174-181.

Benfey, P.N., Ren, L., and Chua, N.-H. 1989. The CaMV 35S enhancer contains at least two domains which can confer different developmental and tissue-specific expression patterns. EMBO J. 8: 2195-2202. 
Benfey, P.N., Ren, L., and Chua, N.-H. 1990a. Tissue-specific expression from CaMV 35S enhancer subdomains in early stages of plant development. EMBO J. 9: 1677-1684.

Benfey, P.N., Ren, L., and Chua, N.-H. 1990b. Combinatorial and synergistic properties of CaMV $35 S$ enhancer subdomains. EMBO J. 9: 1685-1696.

Bevan, M. 1984. Binary Agrobacterium vectors for plant transformation. Nucl. Acid. Res. 12: 8711-8721.

Bhalla, P.L., and Dalling, M.J. 1984. Characteristics of a B-galactosidase associated with the stroma of chloroplasts prepared from mesophyll protoplasts of the primary leaf of wheat. Plant Physiol. 76: 92-95.

Bhattacharyya, M.K., Smith, A.M., Ellis, T.H.N., Hedley, C., and Martin, C. 1990. The wrinkled-seed character of pea described by Mendel is caused by a transposonlike insertion in a gene encoding starch-branching enzyme. Cell 60: 115-122.

Binns, A.N., and Thomashow, M.F. 1988. Cell biology of Agrobacterium infection and transformation of plants. Ann. Rev. Microbiol. 42: 575-606.

Birnboim, H.C., and Doly, J. 1979. A rapid alkaline extraction procedure for screening recombinant plasmid DNA. Nucl. Acids Res. 7: 1513-1520.

Block, A., Dangl, J.L., Hahlbrock, K., and Schulze-Lefert, P. 1990. Functional borders, genetic fine structure, and distance requirements of cis elements mediating light responsiveness of the parsley chalcone synthase promoter. Proc. Natl. Acad. Sci. USA 87: 5387-5391.

Bonnerot, C., Grimber. G., Briand, P., and Nicolas, J.-F. 1990. Patterns of expression of position-dependent integrated transgenes in mouse embryo. 1990. Proc. Natl. Acad. Sci. USA 87: 6331-6335.

Bownes, M. 1990. Preferential insertion of P elements $: 0$ genes expressed in the germ-line of Drosophila melanogaster. Mol. Gen. Genet. 222: 457-460.

Brasier, A.R. 1990. Reporter System Using Firefly Luciferase. In: Current Protocols in Molecular Biology, Suppl. 12, F.M. Ausubel, R. Brent, R.E. Kingston, D.D. Moore, J.A., Smith, J.D. Seidman, K. Struhl (eds), pp. 9.6.11-9.6.15., Wiley \& Sons, New York.

Brenner, D.G., Lin-Chao, S., and Cohen, S.N. 1989. Analysis of mammalian cell genetic regulation in situ by using retrovirus-derived "portable exons" carrying the Escherichia coli lacZ gene. Proc. Natl. Acad. Sci. USA 86: 5517-5521.

Budar, F., Thia-Toong, L., Van Montagu, M., and Hernalsteens, J.-P. 1986. Agrobacterium-mediated gene transfer results mainly in transgenic plants transmitting T-DNA as a single Mendelian factor. Genetics 114: 303-313.

Bustos, M.M., Begum, D., Kalkan, F.A., Battraw, M.J., and Hall, T.C. 1991. Positive and negative cis-acting DNA domains are required for spatial and temporal regulation of gene expression by a seed storage protein promoter. EMBO J. 10: 1469-1479. 
Bustos, M.M., Guiltinan, M.J., Jordano, J., Begum, D., Kalkan, F.A., and Hall, T.C. 1989. Regulation of $B$-glucuronidase expression in transgenic tobacco plants by an A/T-rich, cis-acting sequence found upstream of a french bean $B$-phaseolin gene. Plant Cell 1: 839-853.

Callis, J., Fromm, M., and Walbot, V. 1987. Introns increase gene expression in cultured maize cells. Genes Dev. 1: 1183-1200.

Carpenter, R., and Coen, E.S. 1990. Floral homeotic mutations produced by transposon-mutagenesis in Antirrhinum majus. Genes Dev. 4: 1483-1493.

Carrington, J.C., Freed, D.D., and Leinicke, A.J. 1991. Bipartite signal sequence mediates nuclear translocation of the plant potyviral nla protein. Plant Cell 3: 953962.

Casadaban, M.J., and Cohen, S.N. 1979. Lactose genes fused to exogenous promoters in one step using a Mu-lac bacteriophage: In vivo probe for transcriptional control sequences. Proc. Natl. Acad. Sci. USA 76: 4530-4533.

Castresana, C., de Carvalho, F., Gheysen, G., Habets, M., Inzé, D., and Van Montagu, M. 1990. Tissue-specific and pathogene-induced regulation of a Nicotiana plumbaginifolia B-1,3-glucanase gene. Plant Cell 2: 1131-1143.

Castresana, C., Garcia-Luque, I., Alonso, E., Malik, V.S., and Cashmore, A.R. 1988. Both positive and negative regulatory elements mediate expression of a photoregulated CAB gene from Nicotiana plumbaginifolia. EMBO J. 7: 1929-1936.

Chandlee, J.M. 1991. Analysis of developmentally interesting genes cloned from higher plants by insertional mutagenesis. Dev. Genet. 12: 261-271.

Chen, Z.-L., Pan, N.-S., and Beachy, R.N. 1988. A DNA sequence element that confers seed-specific enhancement to a constitutive pronoter. EMBO J. 7: 297302.

Christie, P.J., Ward, J.E., Gordon, M.P., and Nester, E.W. 1989. A gene required for transfer of T-DNA to plants encodes an ATPase with autophosphorylating activity. Proc. Natl. Acad. Sci. USA 86: 9677-9681.

Christou, P., Swain, W.F., Yang, N.-S., and McCabe, D.E. 1989. Inheritance and expression of foreign genes in transgenic soybean plants. Proc. Natl. Acad. Sci. USA 86: 7500-7504.

Chyi, Y.-S., Jorgensen, R.A., Goldstein, D., Tanksley, S.D., and Loaiza-Figueroa, F. 1986. Locations and stability of Agrobacterium-mediated T-DNA insertions in the Lycopersicon genome. Mol. Gen. Genet. 204: 64-69.

Close, T.J., Tait, R.C., and Kado, C.I. 1985. Regulation of Ti plasmid virulence genes by a chromosomal locus of Agrobacterium tumefaciens. J. Bacteriol. 164: 774781.

Coates, D., Taliercio, E.W., and Gelvin, S.B. 1987. Chromatin structure of integrated T-DNA in crown gall tumors. Plant Mol. Biol. 8: 159-168.

Coen, E.S., Romero, J.M., Doyle, S., Elliot, R., Murphy, G., and Carpenter, R. 1990. 
floricula: A homeotic gene required for flower development in Antirrhinum majus. Cell 63: 1311-1322.

Cohen, S.N., Chang, A.C.Y., and Hsu, L. 1972. Non-chromosomal antibiotic resistance in bacteria: Genetic transformation of Escherichia coli by R-factor DNA. Proc. Natl. Acad. Sci. U.S.A. 69: 2110-2114.

Collinge, D.B., and Slusarenko, A.J. 1987. Plant gene expression in response to pathogens. Plant Mol. Biol. 9: 389-410.

Cone, K.C., Schmidt, R.J., Burr, B., and Burr, F.A. 1988. Advantages and Limitations of using Spm as a Transposon Tag. In: Plant Transposable Elements, O. Nelsen (ed), pp. 149-159, Plenum Press, New York.

Conkling, M.A., Cheng., C.-1., Yamamoto, Y.T., and Goodman, H.M. 1990. Isolation of transcriptionally regulated root-specific g'enes from tobacco. Plant Physiol. 93: 1203-1211.

Czernilofsky, A.P., Hain, R., Herrera-Estrella, L., Lörz, H., Goyvaerts, E., Baker, B.J., and Schell, J. 1986. Fate of selectable marker DNA integrated into the genome of Nicotiana tabacum. DNA 5: 101-113.

Datla, R.S.S., Hammerlindl, J.K., Pelcher, L.E., Crosby, W.L., and Selvaraj, G. 1991. A bifunctional fusion between $B$-glucuronidase and neomycin phosphotransferase: A broad-spectrum marker enzyme for plants. Gene 101: 239246.

Datta, N., and Cashmore, A.R. 1989. Binding of a pea nuclear protein to promoters of certain photoregulated genes is modulated by phosphorylation. Plant Cell 1: 1069-1077.

De Almeida, E.R.P., Gossele, V., Muller, C.G., Dockx, J., Reynaerts, A., Botterman, J., Krebbers, E., and Timko, M.P. 1989. Transgenic expression of two marker genes under the control of an Arabidopsis rbcS promoter: Sequences encoding the Rubisco transit peptide increase expression levels. Mol. Gen. Genet. 218: 78-86.

De Block, M. Herrera-Estrella, L., Van Montagu, M., Schell, J., and Zambryski, P. 1984. Expression of foreign genes in regenerated plants and their progeny. EMBO J. 3: $1681-1689$.

De Block, M., and Debrouwer, D. 1991. Two T-DNA's co-transformed into Brassica napus by double Agrobacterium tumefaciens infection are mainly integrated at the same locus. Theor. Appl. Genet. 82: 257-263.

De Greve, H., Leemans, J., Hernalsteens, J.-P., Thia-Toong, L., Otten, L., Van Montagu, M., and Schell, J. 1982. Regeneration of normal and fertile plants that express opine synthase, from tobacco crown galls after deletion of tumourcontrolling functions. Nature 300: 752-755.

Dean, C., Favreau, M., Bond-Nutter, D., Bedbrook, J., and Dunsmuir, P, 1989. Sequences downstream of translation start regulate quantitative expression of two petunia $r b c$ S genes. Plant Cell 1: 201-208.

Dean, C., Jones, J., Favreau, M., Dunsmuir, P., and Berbrook, J. 1988. Influence of 
flanking sequences on variability in expression levels of an introduced gene in transgenic tobacco plants. Nucl. Acids Res. 16: 9267-9283.

Depicker, A., Herman, L., Jacobs, A., Schell, J., and Van Montagu, M. 1985. Frequencies of simultaneous tranformation with different T-DNAs and their relevance to the Agrobacterium/plant cell interaction. Mol. Gen. Genet. 201: 477484.

Deroles, S.C., and Gardner, R.C. 1988a. Expressiou and inheritance of kanamycir resistance in a large number of transgenic petunias generated by Agrobacteriummediated transformation. Plant Mol. Biol. 11: 355-364.

Deroles, S.C., and Gardner, R.C. 1988b. Analysis of the T-DNA structure in a large number of transgenic petunias generated by Agrobacterium-mediated transformation. Plant Mol. Biol. 11: 365-377.

Deshayes, A., Herrera-Estrella, L., and Caboche, M. 1985. Liposome-mediated transformantion of tobacco mesophyll protoplasts by an Escherichia coli plasmid. EMBO J. 4: 2731-2737.

Dixon, R.A., and Lamb, C.J. 1990. Molecular communication in interactions between plants and microbial pathogens. Ann. Rev. Plant Physiol. Mol. Biol. 41: 339-367.

Donald, R.G.K., and Cashmore, A.R. 1990. Mutation of either G box or I box sequences profoundly affects expression from the Arabıdopsis rbcS-1A promoter. EMBO J. 9: 1717-1726.

Döring, H.-P., and Starlinger, P. 1986. Molecular genetics of transposable elements in plants. Ann. Rev. Genet. 20: 175-200.

Dynan, W.S. 1989. Modularity in promoters and enhancers. Cell 58: 1-4.

Ebert, P.R., Ha, S.B., and An, G. 1987. Identification of an essential upstream element in the nopaline synthase promoter by stable and transient assays. Proc. Natl. Acad. Sci. USA 84: 5745-5749.

Edwards, J.W., and Coruzzi, G.M. 1990. Cell-specific gene expression in plants. Annu. Rev. Genet. 24: 275-303.

Elliston, K, and Messing, J. 1988. The molecular architecture of plant genes: A phylogenetic perspective. In: Architecture of Eukaryotic Genes, G. Kahl (Cd), pp. 21-56, VCH Publisher, New York.

Engels, W.R. 1988. P Element in Drosophila. In: Mobile DNA, D.E. Berg and M.M. Howe (eds), pp. 437-484, American Society for Microbiology, Washington, DC.

Errampalli, D., Patton, D., Castle, L., Mickelson, L., Hansen, K., Schnall, J., Feldmann, K, and Meinke, D. 1991. Embryonic lethals and T-DNA insertional mutagenesis in Arabidopsis. Plant Cell 3: 149-157.

Esau, K 1977. Anatomy of Seed Plants. Second Edition, John Wiley and Sons, New York, 550pp. 
Fang, R.-X., Nagy, F., Sivasubramaniam, S., and Chua, N.-H. 1989. Multiple cis regulatory elements for maximal expression of the cauliflower mosaic virus $35 \mathrm{~S}$ promoter in transgenic plants. Plant Cell 1: 141-150.

Farrell, L.B., and Beachy, R.N. 1990. Manipulation of B-glucuronidase for use as a reporter in vacuolar targeting studies. Plant Mol. Biol. 15: 821-825.

Federoff, N.V. 1989. About maize transposable elements and development. Cell 56: $181-191$.

Fedoroff, N.V. 1984. Transposable genetic elements in maize. Scientific American 250: 84-98.

Feinberg, A.P., and Vogelstein, B. 1983. A technique for radiolabelling DNA restriction endonuclease fragments to high specific activity. Anal. Biochem. 132: 613.

Feldmann, K.A., 1991. T-DNA insertion mutagenesis in Arabidopsis: Mutational spectrum. Plant Journal 1: 71-82.

Feldmann, K.A., and Marks, M.D. 1987. Agrobacterium-mediated transformation of gertrinating seeds of Arabidopsis thaliana: A non-tissue culture approach. Mol. Gen. Genet. 208: 1-9.

Feldmann, K.A., Marks, M.D., Christianson, M.L., and Quatrano, R.S. 1989. A dwarf mutant of Arabidopsis generated by T-DNA insertion mutagenesis. Science 243: $1351-1354$.

Ferreira, P.C.G., Hemerly, A.S., Villarroel, R., Van Montagu, M., and Inzé, D. 1991. The Arabidopsis functional homolog of the p34 $\mathrm{cdc} 2$ protein kinase. Plant Cell 3: 531-540.

Figurski, D.H., and Helinski, D.R. 1979. Replication of an origin-containing derivative of plasmid RK2 dependent on a plasmid function provided in trans. Proc. Natl. Acad. Sci. U.S.A. 76: 1648-1652.

Flavell, R.B. 1986. The structure and control of expression of ribosomal RNA genes. Oxf. Surv. Plant Mol. Cell Biol. 3: 252-274.

Forde, B.G., Freeman, J., Oliver, J.E., and Pineda, M. 1990. Nuclear factors interact with conserved $A$ /T-rich elements upstream of a nodule-enhanced glutamine synthetase gene from french bean. Plant Cell 2: 925-939.

Fraley, R.T., Rogers, S.G., and Horsch, R.B. 1986. Genetic transformation in higher plants. CRC Critical Reviews in Plant Sciences 4: 1-46.

Fraley, R.T., Rogers, S.G., Horsch, R.B., Eichholtz, D.A., Flick, J.S., Fink, C.L., Hoffmann, N.L., and Sanders, P.R. 1985. The SEV system: A new disarmed Ti plasmid vector system for plant transformation. Bio/Technology 3: 629-635.

Fraley, R.T., Rogers, S.G., Horsch, R.B., Sanders, P.R., Flick, J.S., Adams, S.P., Bittner, M.L., Brand, L.A., Fink, C.L., Fry, J.S., Galluppii, G.R., Goldberg, S.B., Hoffmatin, N.L., and Woo, S.C. 1983. Expression of bacterial genes in plant cells. 
Proc. Natl. Acad. Sci. USA 80: $48 C 3-4807$.

Friedrich, G., and Soriano, P. 1991. Promoter traps in embryonic stem cells: A genetic screen to identify and mutate developmental genes in mice. Genes Dev. 5: 1513-1523.

Futterer, J., Gordon, K., Sanfaçon, H., Bonneville, J.-M., and Hohn, T. 1990. Positive and negative control of translation by the leader sequence of cauliflower mosaic virus pregenomic 35S RNA. EMBO J. 9: 1697-1707.

Gallie, D.R., Feder, J.N., Schimke, R.T., and Walbot, V. 1991. Post-transcriptional regulation in higher eukaryotes: The role of the reporter gene in controlling expression. Mol. Gen. Genet. 228: 258-264.

Gamboig, O.L., Miller, R.A., and Ojima, K. 1978. Nutrient requirements of suspension cultures of soybean root cells. Exp. Cell Res. 50: 151-158.

Gheysen, G., Herman, L., Breyne, P., Gielen, J., Van Montagu, M., and Depicker, A. 1990. Cloning and sequence analysis of truncated T-DNA inserts from Nicotiana tabacum. Gene 94: 155-163.

Gheysen, G., Van Montagu, M., and Zambryski, P. 1987. Integ:ation of Agrobacterium tumefaciens transfer DNA (T-DNA) involves rearrangements of target plant DNA sequences. Proc. Natl. Acad. Sci. USA 84: 6169-6173.

Gheysen, G., Villarroel, R., and Van Montagu, M. 1991. Illegitimate recombination in plants: A model for T-DNA integration. Genes Dev. 5: 287-297.

Gidoni, D., Bond-Nutter, D., Brosio, P., Jones, J., Bedbrook, J., and Dunsmuir, P. 1988. Coordinated expression between two photosynthetic petunia genes in transgenic plants. Mol. Gen. Genet. 211: 507-514.

Gidoni, D., Brosio, P., Bond-Nutter, D., Bedbrook, J., and Dunsmuir, P. 1989. Novel cis-acting elements in petunia cab gene promoters. Mol. Gen. Genet. 215: 337-344.

Gierl, A., Saedler, H., and Peterson, P.A. 1989. Maize transposable elements. Ann. Rev. Genet. 23: 71-85.

Gilmartin, P.M., Sarokin, L., Memelink, J., and Chua, N.-H. 1990. Molecular light switches for plant genes. Plant Cell 2: 369-378.

Giuliano, G., Hoffman, N.E., Ko, K., Scolnik, P.A., and Cashmore, A.R. 1988. A light-entrained circadian clock controls transcription of several plant genes. EMBO J. 7: 3635-3642.

Goldberg, R.B., Barker, S.J., and Perez-Grau, L. 1989. P.egulation of gene expression during plant embryogenesis. Cell 56: 149-160.

Goldberg, R.B., Hoschek, G., Kamalay, J.C., and Timberlake, W.E. 1978. Sequence complexity of nuclear and polysomal RNA in leaves of the tobacco plant. Cell 14: 123-131.

Goldberg, R.B., Hoschek, G., Tam, S.H., Ditta, G.S., and Breidenbach, R.W. 1981. 
Abundance, diversity, and regulation of mRNA sequence sets in soybean embryogenesis. Dev. Biol. 83: 201-217.

Goldsbrough, A., and Bevan, M. 1991. New patterns of gene activity in plants detected using an Agrobacterium vector. Plant Mol. Biol. 16: 263-269.

Goring, D.R., Thomson, L., and Rothstein, S.J. 1991. Transformation of a partial nopaline synthase gene into tobacco suppresses the expression of a resident wildtype gene. Proc. Natl. Acad. Sci. USA 88: 1770-1774.

Gossler, A., Joy ner, A.L., Rossant, J., and Skarnes, W.C. 1989. Mouse embryonic stem cells and reporter constructs to detect developmentally regulated genes. Science 244: 463-465.

Grandbastien, M.-A., Spielmann, A., and Caboche, M. 1989. Tnt1, a mobile retroviral-like transposable element of tobacco isolated by plant cell genetics. Nature 337: 376-380.

Grirnsley, N., and Bisaro, D. 1987. Agroinfection. In: Plant DNA Infectious Agents, Th. Hohn and J. Schell (eds), pp. 87-107, Springer-Verlag/Wien, New York.

Guarente, L. 1988. UASs and enhancers: Common mechanism of transcriptional activation in yeast and mammals. Cell 52: 303-305.

Hain, R., Stabel, P., Czernilofsky, A.P., Steinbiß, H.H., Herrera-Estrella, L., and Schell, J. 1985. Uptake, integration, expression and genetic transmission of a selectable chimaeric gene by plant protoplasts. Mol. Gen. Genet. 199: 161-168.

Hake, S., Vollbrecht, E., and Freeling, M. 1989. Cloning Knotted, the dominant morphological mutant in maize using Ds2 as a transposon tag. EMBO J. 8: 15-22.

Hamada, H. 1986a. Activation of an enhancerless gene by chromosomal integration. Mol. Cell. Biol. 6: 4179-4184.

Hamada, H. $1986 \mathrm{~b}$. Random Isolation of gene activator elements from the human genome. Mol. Cell. Biol. 6: 4185-4194.

Hamel, A. 1987. Construction of plasmids for studying genetic events in Agrohacterium tumefaciens. M.Sc. Dissertation, Carleton University, Ottawa, Ontario.

Hanahan, D. 1985. Techniques for Transformation of $E$. coli. In: DNA Cloning: A Pratical Approach, Vol. 1, D.M. Golver (ed), pp. 109-135, IRL Press, Oxford.

Haring, M.A., Rommens, C.M.T., Nijkamp, H.J.J., and Hille, J. 1991a. The use of transgenic plants to understand transposition mechanisms and to develop transposon tagging strategies. Plant Mol. Biol. 16: 449-461.

Haring, M.A., Vroomen, M.J.T.-d., Nijkamp, H.J.J., and Hille, J. 1991b. Transactivation of an artificial dTam3 transposable element in transgenic tobacco plants. Plant Mol. Biol. 16: 39-47.

Hartings, H., Maddaloni, M., Lazzaroni, N., Di Fonzo, N., Motto, M., Salamini, F., and Thompson, $\mathrm{R}$. 1989. The $\mathrm{O} 2$ gene which regulates zein deposition in maize 
endosperm encodes a protein with structural homologies to transcriptional activators. EMBO J. 8: 2795-2801.

Haseloff, J., and Gerlach, W.L. 1988. Simple RNA enzymes with new and highly specific endoribonuclease activity. Nature 334: 585-591.

Hata, S., Ko'lchi, H., Suzuka, I., and Ishii, T. 1991. Isolation and characterization of cDNA clones for plant cyclins. EMBO J. 10: 2681-2688.

Heberle-Bors, E., Charvat, B., Thompson, D., Schernthaner, J.P., Barta, A., Matzke, A.J.M., and Matzke, M.A. 1988. Genetic analysis of T-DNA insertions into the tobacco genome. Flant Cell Reports 7: 571-574.

Hehl, R., and Baker, B. 1990. Properties of the maize transposable element activator in transgenic tobacco plants: A versatile inter-species genetic tool. Plant Cell 2: 709-721.

Helmer, G., Casadaban, M., Bevan, M., Kayes, L., and Chilton, M.-D. 1984. A new chimeric gene as a marker for plant transformation: The expression of Escherichia coli B-galactosidase in sunflower and tobacco cells. Bio/Technology 2: 520-527.

Herman, L., Jacobs, A., Van Montagu, M., and Depicker, A. 1990. Plant chromosome/marker gene fusion assay for study of normal and truncated T-DNA integration events. Mol. Gen. Genet. 224: 248-256.

Herman, P.L., and Marks, M.D. 1989. Trichome development in Arabidopsis thaliana. II. Isolation and complementation of the GLABROUSI gene. Plant Cell 1: 1051-1055.

Herrera-Estrella, L., Depicker, A., Van Montagu, M., and Schell, J. 1983.

Expression of chimaeric genes transferred inio plant cells using a Ti-plasmidderived vector. Nature 303: 209-213

Herrera-Estrella, L., Van de Broeck, G., Maenhaut, R., Van Montagu, M., Schell, J., Timko, M., and Cashmore, A. 1984. Light-inducible and chloroplast-associated expression of a chimaeric gene introduced into Nicotiana tabacum using a Ti plasmid vector. Nature 310: 115-120.

Herrmann, A., Schulz, W., and Hahlbrock, K. 1988. Two alleles of the single-copy chalcone synthase gene in parsley differ by a transposon-like element. Mol. Gen. Genet. 212: 93-98.

Hobbs, S.L.A., Kpodar, P., and DeLong, C.M.O. 1990. The effect of T-DNA copy number, position and methylation on reporter gene expression in tobacco transformants. Plant Mol. Biol. 15: 851-864.

Holmes, D.S., and Quigley, M. 1981. A rapid boiling method for the preparation of bacterial plasmids. Anal. Biochem. 114: 193-197.

Holsters, M., Villarroel, R., Gielen, J., Seurinck, J., De Greve, H., Van Montagu, M., and Schell, J. 1983. An analysis of the boundaries of the octopine TL-DNA in tumors induced by Agrobacterium tumefaciens. Mol. Gen. Genet. 190: 35-41.

Horsch, R.B., Fry, J.E., Hoffmann, N.L., Eichholtz, D., Rogers, S.G., and Fraley, 
R.T. 1985. A simple and general method for transferring genes into plants. Science 227: $1229-1231$.

Howard, E., and Citovsky, V. 1990. The emerging structure of the Agrobacterium TDNA transfer complex. BioEssays 12: 103-108.

Hu, C.-y., Chee, P.P., Chesney, R.H., Zhou, J.H., Miller, P.D., and O'Brien, W.T. 1990. Intrinsic GUS-Like Activity. In: Progress in Plant Cellular and Molecular Biology; Proceedings of the VIIth International Congress on Plant Tissue and Cell Culture, Amsterdam, The Netherlands, 24-29 June 1990, H.J.J. Nijkamp, L.H.W. Van der Plas, J. Van Aartrijk (eds), pp. 195-200, Kluwer Academic Publishers, Dordrecht.

Ingelbrecht, 1.L.W., Herman, L.M.F., Dekeyser, R.A., Van Montagu, M.C., and Depicker, A.G. 1989. Different 3' end regions strongly influence the level of gene expression in plant cells. Plant Cell 1: 671-680.

Iturriaga, G., Jefferson, R.A., and Bevan, M.W. 1989. Endoplasmic reticulum targetirg and glycosylation of hybrid proteins in transgenic tobacco. Plant Cell 1: $381-390$.

Izui, K., Ishijima, S., Yamaguchi, Y., Katagiri, F., Murata, T., Shigesada, K., Sugiyama, T., and Katsuki, H. 1986. Cloning and sequence analysis of cDNA encoding active phosphoenolpyruvate carboxylase of the C4-pathway from maize. Nucl. Acid Res. 14: 1615-1628.

Jackson, D., Culianez-Macia, F., Prescott, A.G., Roberts, K., and Martin, C. 1991. Expression patterns of myb genes from Antirrhinum flowers. Plant Cell 3: 115-125.

Jaenisch, R. 1988. Transgenic animals. Science 240: 1468-1474.

Janssen, B.-J., and Gardner, R.C. 1989. Localized transient expression of GUS in leaf discs following cocultivation with Agrobacterium. Plant Mol. Biol. 14: 61-72.

Jefferson, R., Goldsbrough, A., and Bevan, M. 1990. Transcriptional regulation of a patatin-1 gene in potato. Plant Mol. Biol. 14: 995-1006.

Jefferson, R.A. 1987. Assaying chimeric genes in plants: The GUS gene fusion system. Plant Mol. Biol. Rep. 5: 387-405.

Jefferson, R.A., Burgess, S.M., and Hirsh, D. 1986. B-glucuronidase from Escherichia coli as a gene-fusion marker. Proc. Natl. Acad. Sci. USA. 83: 8447-8451.

Jefferson, R.A., Kavanagh, T.A., and Bevan, M.W. 1987. GUS fusions: Bglucuronidase as a sensitive and versatile gene fusion marker in higher plants. EMBO J. 6: 3901-3907.

Johnson, P.F., and McKnight, S.L. 1989. Eukaryotic transcriptional regulatory proteins. Annu. Rev. Biochem. 58: 799-839.

Jones, J.D.G., Carland, F., Lim, E., Ralston, E., and Dooner, H.K. 1990. Preferential transposition of the maize element activator to linked chromosomal locations in tobacco. Plant Cell 2: 701-707. 
Jones, J.D.G., Dunsmuir, P., and Bedbrook, J. 1985. High level expression of introduced chimaeric genes in regenerated transformed plants. EMBO J. 4: 24112418.

Jones, J.D.G., Gilbert, D.E., Grady, K.L., and Jorgensen, R.A. 1987. T-DNA structure and gene expression in petunia plants transformed by Agrobacterium tumefaciens C58 derivatives. Mol. Gen. Genet. 207: 478-485.

Jordan, E.G., Timmis, J.N., and Trewavas, A.J. 1980. The plant nucleus. In: The Biochemistry of Plants, Vol 1, N.E. Tolbert (ed.), pp.489-588. Academic Press, New York.

Jordano, J., Almoguera, C., Thomas, T.L. 1989. A sunflower helianthinin gene upstream sequence ensemble contains an enhancer and sites of nuclear protein interaction. Plant Cell 1: 855-866.

Jorgensen, R. 1990. Altered gene expression in plants due to trans interactions between homologous genes. Trends Biotechnol. 8: 340-344.

Jorgensen, R. 1991. Beyond antisense - How do transgenes interact with homologous plant genes? Trends Biotechnol. 9: 266-267

Jorgensen, R., Snyder, C., and Jones, J.D.G. 1987. T-DNA is organized predominantly in inverted repeat structures in plants transformed with Agrobacterium iumefaciens C58 derivatives. Mol. Gen. Genet. 207: 471-477.

Kahl, G., Weising, K., Görz, A., Schäfer, W., and Hirasawa, E. 1987. Chromatin structure and plant gene expression. Dev. Genet. 8: 405-434.

Kamalay, J.C., and Goldberg, R.B. 1980. Regulation of structural gene expression in tobacco. Cell 19: 935-946.

Kamalay, J.C., and Goldberg, R.B. 1984. Organ-specific nuclear RNAs in tobacco. Proc. Natl. Acad. Sci. USA. 81: 2801-2805.

Kavanagh, T.A., Jefferson, R.A., and Bevan, M.W. 1988. Targeting a foreign protein to chloroplasts using fusions to the transit peptide of a chlorophyll $\mathrm{a} / \mathrm{b}$ protein. Mol. Gzn. Genet. 215: 38-45.

Kay, R., and McPherson, J. 1987. Hybrid pUC vectors for addition of new restriction enzyme sites to the ends of DNA fragments. Nucl. Acid Res. 15: 2778.

Keller, B., Schmid, J., and Lamb, C.J. 1989. Vascular expression of a bean cell wall glycine-rich protein- $\beta$-glucuronidase gene fusion in transgenic tobacco. EMBO J. 8: 1309-1314.

Kellum, R., and Schedl, P. 1991. A position-effect assay for boundaries of higher order chromosomal domains. Cell 64: 941-950.

Kertbundit, S., De Greve, H., Deboeck, F., Van Montagu, M., and Hernalsteens, J.P. 1991. In vivo random B-glucuronidase gene fusions in Arabidopsis thaliana. Proc. Natl. Acad. Sci. USA 88: 5212-5216.

Kleckner, N., Roth, J., and Botstein, D. 1977. Genetic engineering in vivo using 
translocatable drug-resistance elements. J. Mol. Biol. 116: 125-159.

Klee, H., and Estelle, M. 1991. Molecular genetic approaches to plant hormone biology. Ann. Rev. Plant Physiol. Plant Mol. Biol. 42: 529-551.

Klee, H., Horsch, R., and Rogers, S. 1987. Agrobacterium-mediated plant transformation and its further applications to plant biology. Ann. Rev. Plant Physiol. 38: 467-486.

Klein, B., Töpfer, R., Sohn, A., Schell, J., and Steinbiß, H.H. 1990. Promoterless Reporter Genes and their use in Plant Gene Transformation. In: Porgress in Plant Cellular and Molecular Biolcgy; Proceedings of the VIIth International Congress on Plant Tissue and Cell Culture, Amsterdam, The Netherlands, 24-29 June 1990, H.J.J. Nijkamp, L.H.W. Van der Plas, J. Van Aartrijk (eds), pp. 79-84, Kluwer Academic Publishers, Dordrecht.

Koltunow, A.M., Truettner, J., Cox, K.H., Wallroth, M., and Goldberg, R.B. 1990. Different temporal and spatial gene expression patterns occur during anther development. Plant Cell 2: 1201-1224.

Koncz, C., and Schell, J. 1986. The promoter of TL-DNA gene 5 controls the tissue-specific expression of chimaeric genes carried by a novel type of Agrobacterium binary vector. Mol. Gen. Genet. 204: 383-396.

Koncz, C., Martini, N., Koncz-Kalman, Z., Olsson, O., Radermacher, A., Szalay, A., and Schell, J. 1987. Genetic Tools for the Analysis of Gene Expression in Plants. In: Tailoring Genes for Crop Improvement, G. Bruening, J. Harada, T. Kosuge, and A. Hollaender (eds), pp. 197-209, Plenum Press, New York.

Koncz, C., Martini, N., Mayerhofer, R., Koncz-Kalman, Z., Körber, H., Redei, G.P., and Schell, J. 1989. High-frequency T-DNA-mediated gene tagging in plants. Proc. Natl. Acad. Sci. USA. 86: 8467-8471.

Koncz, C., Mayerhofer, R., Koncz-Kalman, Z., Nawrath, C., Reiss, B., Redel, G.P., and Schell, J. 1990. Isolation of a gene encoding a novel chloroplast protein by $T$ DNA tagging in Arabidopsis thatiana. EMBO J. 9: 1337-1346.

Konieczny, A., Voytas, D.F., Cummings, M.P., and Ausubel, F.M. 1991. A superfamily of Arabidopsis thaliana retrotransposons. Genetics 127: 801-809.

Kosugi, S., Ohashi, Y., Nakajima, K., and Arai, Y. 1990. An improved assay for Bglucuronidase in transformed cells: Methanol almost completely suppresses a putative endogenous B-glucuronidase activity. Plant Science 70: 133-140.

Koukolikova-Nicola, Z., Albright, L., and Hohn, B. 1987. The Mechanism of TDNA Transfer from Agrobacterium tumefaciens to the Plant Cell. In: Plant DNA Infectious Agents, Th. Hohn and J. Schell (eds), pp. 109-148, Springer-Verlag/Wien, New York Vienna.

Kroos, L., and Kaiser, D. 1984. Construction of Tn5 lac, a transposon that fuses lac Z expression to exogenous promoters, and its int:oduction into Myxococcus xanthus. Proc. Natl. Acad. Sci. USA 81: 5816-5820.

Kuhlemeier, C. Strittmatter, G., Ward, K., and Chua, N.-H. 1989. The pea rbcS-3A 
promoter mediates light responsiveness but not organ specificity. Plant Cell 1: 471 478.

Kuhlemeier, C., Fluhr, R., Green, P.J., and Chua, N.-H. 1987a. Sequences in the pea $r b c$ S-3A gene have homology to constitutive mammalian enhancers but function as negative regulatory elements. Genes Dev. 1: 247-255.

Kuhlemeier, C., Green, P.J., and Chua, N.-H. 1987b. Regulation of gene expression in higher plants. Ann. Rev. Plant Physiol. 38: 221-257.

Kwok, W.W., Nester, E.W., and Gordon, M.P. 1985. Unusual plasmid DNA organization in an octopine crown gall tumor. Nucl. Acids Res. 13: 459-471.

Lam, E., and Chua, N.-H. 1990. GT-1 binding site confers light responsive expression in transgenic tobacco. Science 248: 471-474.

Lam, E., Benfey, P.N., Gilmartin, P.M., Fang, R.-X., and Chua, N.-H. 1989. Sitespecific mutations alter in vitro factor binding and change promoter expression pattern in transgenic plants. Proc. Natl. Acad. Sci. USA 86: 7890-7894.

Lam, E., Kano-Murakami, Y., Gilmartin, P., Niner, B., and Chua, N.-H. 1990. A metal-dependent DNA-binding protein interacts with a constitutive element of a light-responsive promoter. Plant Cell 2: 857-866.

Lee, K.Y., Lund, P., Lowe, K., and Dunsmuir, P. 1990 . Homologous recombination in plant cells after Agrobacterium-mediated transformation. Plant Cell 2: 415-425.

Lemmers, M., De Beuckeleer, M., Holsters, M., Zambryski, P., Depicker, A., Hernalsteens, J.P., Van Montagu, M., and Schell, J. 1980. Internal organization, boundaries and integration of Ti-plasmid DNA in nopaline crown gall tumors. J. Mol. Biol. 144: 353-376.

Leong, S.A., Ditta, G.S., and Helinski, D.R. 1982. Heme biosynthesis in Rhizobium. J. Biol. Chem. 257: 8724-8730.

Leutwiler, L.S., Hough-Evans, B.R., and Meyerowitz, E.M. 1984. The DIA of Arabidopsis thaliana. Mol. Gen. Genet. 194: 15-23.

Leweke, B., and Hemleben, V. 1982. Organization of rDNA in Chromatin: Plants. In: The Cell Nucleus, Vol. XI, H. Bucsh (ed), pp. 225-253, Academic Press, New York.

Lindstrom, J.T., and Vodkin, L.O. 1991. A soybean cell wall protein is affected by seed color genotype. Plant Cell 3: 561-571.

Lipphardt, S., Brettschneider, R., Kreuzaler, F., Schell, J., and Dang, J.L. 1988. $U V$-inducible transient expression in parsley protoplasts identifies regulatory ciselements of a chimeric Antirrhinum majus chalcone synthase gene. EMBO J. 7: 4027-4033.

Long, E.O, and Dawid, I.B. 1980 . Repeated genes in eukaryotes. Ann. Rev. Biochem. 49: 727-764.

Maniatis, T., Goodbourn, S., and Fischer, J.A. 1987. Regulation of inducible and 
tissue-specific gene expression. Science 236: 1237-1245.

Mascarenhas, D., Mettler, I.J., Pierce, D.A., and Lowe, H.W. 1990. Intronmediated enhancement of heterologous gene expression in maize. Plant Mol. Biol. 15: 913-920.

Mascarenhas, J.P. 1989. The male gametophyte of flowering plants. Plant Cell 1: 657-664.

Masterson, R., and Schell, J. 1989. Transgenic plants and the study of plant development. In: Nucleic Acids and Molecular Biology, F. Eckstein and D.M.J. Lilley (eds) pp. 260-268, Vol 3. Springer-Verlag, Berlin.

Matsumoto, S., Ito, Y., Hosoi, T., Takahashi, Y., and Machida, Y. 1990. Integration of Agrobacterium T-DNA into a tobacco chromosome: Possible involvement of DNA homology between T-DNA and plant DNA. Mol. Gen. Genet. 224: 309-316.

Matzke, M.A., and Matzke, A.J.M. 1990. Gene interactions and epigenetic variation in transgenic plants. Dev, Genet. 11: 214-223.

Matzke, M.A., Primig, M., Trnovsky, J., and Matzke, A.J.M. 1989. Reversible methylation and inactivation of marker genes in sequentially transformed tobacco plants. EMBO J. 8: 643-649.

Mayerhofer, R., Koncz-Kalman, Z., Nawrath, C., Bakkeren, G., Cramen, A., Angelis, K., Redei, G.P., Schell, J., Hohn, B., and Koncz, C. 1991. T-DNA integration: A mode of illegitimate recombination in plants. EMBO J. 10: 697-704.

McClure, B.A., Hagen, G., Brown, C.S., Gee, M.A., and Guilfoyie, T.J. 1989. Transcription, organization, and sequence of an auxin-regulated gene cluster in soybean. Plant Cell 1: 229-22?

McKendree, W.L., Paul, A.-L., DeLisle, A.J., and Ferl, R.J. 1990. In vivo and in vitro characterization of protein interactions with the dyad G-box of the Arabidopsis Adh gene. Plant Cell 2: 207-214.

McKnight, S.L. 1991. Molecular zippers in gene regulation. Scientific American 264: 54-64.

McLaughlin, M., and Walbot, V. 1987. Cloning of a mutable $b z 2$ allele of maize by transposon tagging and differential hybridization. Genetics 117: 771-776.

Medford, J.I., Elmer, J.S., and Klee, H.J. 1991. Molecular cloning and characterization of genes expressed in shoot apical meristems. Plant Cell 3: 359370.

Mello, C.C., Kramer, J.M., Stinchcomb, D., and Ambros, V. 1991. Efficient gene transfer in C. elegans: extrachromosomal maintenance and integration of transforming sequences. EMBO J. 10: 3959-3970.

Miki, B.L.A., and lyer, V.N. 1990. Fundamentals of gene transfer in plants. In: Advanced Plant Physiology: Integration and Control of Carbon and Nitrogen Metabolism, D.T. Dennis and D.H. Turpin (eds), pp. 473-489, Longman Scientific and Technical, Essex. 
Mooslehner, K., Karls, U., and Harbers, K. 1990. Retroviral integration sites in transgenic Mov mice frequently map in the vicinity of transcribed DNA regions. J. Virol. 64: 3056-3058.

Morelli, G., Nagy, F., Fraley, R.T., Rogers, S.G., and Chua, N.-H. 1985. A short conserved sequence is involved in the light-inducibility of a gene encoding ribulose 1,5-bisphosphate carboxylase small subunit of pea. Nature 315: 200-204.

Murai, N., Li, Z., Kawagoe, Y., and Hayashimoto, A. 1991. Transposition of the maize activator element in transgenic rice plants. Nucl. Acid Res. 19: 617-622.

Murashige, T., and Skoog, F. 1962. A revised medium for rapid growth and bioassays with tobacco tissue cultures. Physiol. Plant. 15: 473-597.

Näär, A.M., Boutin, J.-M., Lipkin, S.M., Yu, V.C., Holloway, J.M., Glass, C.K., and Rosenfeld, M.G. 1991. The orientation and spacing of core DNA-binding motifs dictate selective transcriptional responses to three nuclear receptors. EMBO J. 1267-1279.

Nagy, F., Boutry, M., Hsu, M.-Y., Wong, M., and Chua, N.-H. 1987. The 5'proximal region of the wheat $C a b-1$ gene contains a 268 -bp enhancer-like sequence for phytochrome response. EMBO J. 6: 2537-2542.

Napoli, C., Lemieux, C., and Jorgensen, R. 1990. Introduction of a chimeric chalcone synthase gene into Petunia results in reversible co-suppression of homologous genes in trans. Plant Cell 2: 279-289.

Nester, E.W., Gordon, M.P., Amasino, R.M., and Yanofsky, M.F. 1984. Crown gall: A molecular and physiological analysis. Ann. Rev. Plant Physiol. 35: 387-413.

Norrander, J., Kempe, T., and Messing, J. 1983. Construction of improved M13 vectors using oligodeoxynucleotide-directed mutagenesis. Gene 26: 101-106.

Oeda, K. Salinas, J., and Chua, N.-H. 1991. A tobacco bZip transcription activator (TAF-1) binds to a G-box-like motif conserved in plant genes. EMBO J. 10: 17931802.

Offringa, R., de Groot, M.J.A., Haagsman, H.J., Does, M.P., van den Elzen, P.J.M., and Hooykaas, P.J.J. 1990. Extrachromosomal homologous recombination and gene targeting in plant cells after Agrobacterium mediated transformation. EMBO J. 9: $3077-3084$.

Okamuro, J.E., and Goldberg, R.B. 1985 . Tobacco single-copy DNA is highly homologous to sequences present in the genomes of its diploid progenitors. Mol. Gen. Genet. 198: 290-298.

Okamuro, J.K., and Goldberg, R.B. 1989. Regulation of plant gene expression: General principles. In: The Biochemisty of Plants, Vol. 15, A. Marcus (ed), pp 181, Academic Press, San Diego.

Ondek, B., Gloss, L., and Herr, W. 1988. The SV40 enhancer contains two distinct levels of organization. Nature 333: 40-45. 
Ooms, G., Bakker, A., Molendijk, L., Wullems, G.J., Gordon, M.P., Nester, E.W., and Schilperoort, R.A. 1982. T-DNA organization in homcgeneous and heterogeneous octopine-type crown gall tissues of Nicotiana tabacum. Cell 30: 589597.

Oppenheimer, D.G., Herman, P.L., Sivakumaran, S., Esch, J., and Marks, M.D. 1991. A myb gene required for leaf trichome differentiation in Arabidopsis is expressed in stipules. Cell 67: 483-493.

Ow, D.W., Wood, K.V., DeLuca, M., de Wet, J.R., Helinski, D.R., and Howell, S.H. 1986, Transient and stable expression of the firefly luciferase gene in plant cells and transgenic plants. Science 234: 856-859.

Palmiter, R.D., and Brinster, R.L. 1986. Germ-line transformation of mice. Ann. Rev. Genet. 20: 465-499.

Pang, P.P., and Meyerowitz, E.M. 1987. Arabidopsis thaliana: A model system for plant molecular biology. Bio/Technology 5: 1177-1181.

Paszkowski, J. 1989. Fate of Foreign DNA Introduced to Plant Cells. In: Genetic Engineering: Principles and Methods, Vol. 11, J.K. Setlow (ed), pp. 145-157, Plenum Press, New York.

Paul, A.-L., and Ferl, R.J. 1991. In vivo footprinting reveals unique cis-elements and different modes of hypoxic induction in maize $A d h 1$ and $A d h$ 2. Plant Cell 3: 159-168.

Paz-Ares, J., Ghosal, D., Wienand, U., Peterson, P.A., and Saedler, H. 1987. The regulatory $\mathrm{cl}$ locus of Zea mays encodes a protein with homology to myb protooncogene products and with structural similarities to transcriptional activators. EMBO J. 6: 3553-3558.

Peach, C., and Velten, J. 1991. Transgene expression variability (position effect) of CAT and GUS reporter genes driven by linked divergent T-DNA promoters. Plant Mol. Biol. 17: 49-60.

Peerbolte, R., Leenhouts, K., Hooykaas-van Slogteren, G.M.S., Hoge, J.H.C., Wullems, G.J., and Schilperoort, R.A. 1986a. Clones from a shooty tobacco crown gall tumor I: Deletions, rearrangements and amplifications resulting in irregular TDNA structures and organizations. Plant Mol. Biol. 7: 265-284.

Peerbolte, R., Leenhouts, K., Hooykaas-van Slogteren, Ü.M.S., Wullems, G.J., and Schilperoort, R.A. 1986b. Clones from a shooty tobacco crown gall tumor II: Irregular T-DNA structures and organization, T-DNA methylation and conditional expression of opine genes. Plant Mol. Biol. 7: 285-299.

Plegt, L., and Bino, R.J. 1989. B-glucuronidase activity during development of the male gametophyte from transgenic and non-transgenic plants. Mol. Gen. Genet. 216: 321-327.

Potrykus, 1. 1991. Gene transfer to plants: Assessment of published approaches and results. Annu. Rev. Plant Physiol. Plant Mol. Biol. 42: 205-225.

Potrykus, I.. Paszkowski, J., Saul, M.W., Petruska, J., and Shillito, R.D. 1985a. 
Molecular and general genetics of a hybrid foreign gene introduced into tobacco by direct gene transfer. Mol. Gen. Genet. 199: 169-177.

Potrykus, I., Saul, M.W., Petruska, J., Paszkowski, J., and Shillito, R.D. 1985b. Direct gene transfer to cells of a graminaceous monocot. Mol. Gen. Genet. 199: 183-188.

Potrykus, I., Shillito, R.D., Saul, M.W., and Paszkowski, J. 1985c. Direct gene transfer: State of the art future potential. Plant Mol. Biol. Rep. 3: 117-128.

Pouteau, S., Huttner, E., Grandbastien, M.A., and Caboche, M. 1991. Specific expression of the tobacco Tnt 1 retrotransposon in protoplasts. EMBO J. 10: 19111918.

Prat, S., Willmitzer, L., and Sanchez-Serrano, J.J. 1989. Nuclear proteins binding to a cauliflower mosaic virus 35S truncated promo:er. Mol. Gen. Genet. 217: 209214.

Putterill, J.J., and Gardner, R.C. 1989. Initiation of translation of the Bglucuronidase reporter gene at internal AUG codons in plant cells. Plant Science 62: 199-205.

Reuter, G., Giarre, M., Farah, J., Gausz, J., Spierer, A., and Spierer, P. 1990. Dependence of position-effect variegation in Drosophila on dose of a gene encoding an un ws kal zinc-finger protein. Nature 344: 219-223.

Rhod 4 s, P.R., and Vodkin, L.O. 1988. Organization of the Tgm family of transposable elements in soybean. Genetics 120: 597-604.

Riggs, C.D., and Bates, G.W. 1986. Stable transformation of tobacco by electroporation: Evidence for plasmid concatenation. Proc. Natl. Acad. Sci. USA 83: 5602-5606.

Roe, J.L., Sessions, A., Feldmann, K.A., and Zambryski, P. 1991. FM-98: A gene required during early floral development in Arabidopsis. In: Abrstacts 3rd International Congress of the International Society for Plant Molecular Biology, Tucson, Arizona, October 6-11, 1991, \#488.

Rogers, S.G., and Klee, H. 1987. Pathways to Plant Genetic Manipulation Employing Agrobacterium. In: Plant DNA Infectious Agents, Th. Hohn and J. Schell (eds), pp. 179-203, Springer-Verlag/Wien, New York.

Roth, B.A., Goff, S.A., Klein, T.M., and Fromm, M.E. 1991. C1- and R-dependent expression of the maize $B z 1$ gene requires sequences with homology to mammalian myb and myc binding sites. Plant Cell 3: 317-325.

Rudenko, G., Chung, H.-M.M., Pham, V.P., and Van der Ploeg, L.H.T. 1991. RNA polymerase I can mediate expression of CAT and neo protein-coding genes in Typanosoma brucei. EMBO J. 10: 3387-3397.

Rutledge, R.G., Quellet, T., Hattori, J., and Miki, B.L. 1991. Molecular characterization and genetic origin of the Brassica napus acetohydroxyacid synthase multigene family. Mol. Gen. Genet. 229: 31-40. 
Sachs, M.M., and Ho, T.-H.D. 1986. Alteration of gene expression during environmental stress in plants. Ann. Rev. Plant Physiol. 37: 363-376.

Sambrook, J., Fritsch, E.F., and Maniatis, T. 1989. Molecular Cloning: A Laboratory Manual. Second Edition, Cold Spring Harbor Laboratory Press, Cold Spring Harbor, NY.

Sanders, P.R., Winter, J.A., Barnason, A.R., Rogers, S.G., and Fraley, R.T. 1987. Comparison of cau'iflower mosaic virus $35 S$ and nopaline synthase promoters in transgenic plants. Nucl. Acid Res. 15: 1543-1558.

Sandmeyer, S.B., Hansen, L.J., and Chalker, D.L. 1990. Integration specificity of retrotransposons and retroviruses. Ann. Rev. Genet. 24: 491-518.

Sanger, F., Nicklin, S., and Coulson, A.R. 1977. DNA sequencing with chainterminating inhibitors. Proc. Natl. Acad. Sci. U.S.A. 74: 5463-5467.

Saul, M.W., and Potrykus, I. 1990. Direct gene transfer to protoplasts: Fate of the transferred genes. Dev. Genet. 11: 176-181.

Scanlon, K.J., Jiao, L., Funato, T., Wang, W., Tone, T., Rossi, J.J., and KashaniSabet, M. 1991. Ribozyme-mediated cleavage of c-fos mRNA reduces gene expression of DNA synthesis enzymes and metallothionein. Proc. Natl. Acad. Sci. USA 88: 10591-10595.

Schüffner, A.R., and Sheen, J. 1991. Maize rbcS promoter activity depends on sequence elements not found in dicot $r b c S$ promoters. Plant Cell 3: 997-1012.

Schauer, A.T. 1988. Visualizing gene expression with luciferase fusions. Trends Biotechnol. 6: 23-27.

Scheid, O.M., Paszkowski, J., and Potrykus, I. 1991. Reversible inactivation of a transgene in Arabidopsis thaliana. Mol. Gen. Genet. 228: 104-112.

Schell, J., and Van Montagu, M. 1983. The Ti plasmids as natural and as practical gene vectors for plants. Bio/Technology: 1: 175-180.

Schindler, U., and Cashmore, A.R. 1990. Photoregulated gene expression may involve ubiquitous DNA binding proteins. EMBO J. 9: 3415-3427.

Schmidt, R.J., Burr, F.A., and Burr, B. 1987. Transposon tagging and molecular analysis of the maize regulatory locus opaque-2. Science 238: 960-963.

Schneider, M., Ow, D.W., and Howell, S.H. 1990. The in vivo pattern of firefly luciferase expression in transgenic plants. Plant Mol. Biol. 14: 935-947.

Schulze-Lefert, P., Becker-André, M., Schulz, W., Hahlbrock, K., and Dangl, J.L. 1989a. Functional architecture of the light-responsive chalcone synthase promoter from parsley. Plant Cell 1: 707-714.

Schulze-Lefert, P., Dangl, J.L., Becker-André, M., Hahlbrock, K., and Schulz, W. $1989 \mathrm{~b}$. Inducible in vivo DNA footprints define sequences necessary for UV light activation of the parsley chalcone synthase gene. EMBO J. 8: 651-656. 
Schwarz-Sommer, Z., and Saedler, H. 1987. Can plant transposable elements generate novel regulatory systems? Mol. Gen. Genet. 209: 207-209.

Sheen, J. 1991. Molecular mechanisms underlying the differential expression of maize pyruvate, orthophosphate dikinase genes. Plant Cell 3: 225-245.

Sheridan, W.F. 1988. Maize developmental genetics: Genes of morphogenesis. Annu. Rev. Genet. 22: 353-385.

Simpson, R.B., O’Hara, P.J., Kwok, W., Montoya, A.L., Lichtenstein, C., Gordon, M.P., and Nester, E.W. 1982. DNA from the A6S/2 crown gall tumor contains scrambled Ti-plasmid sequences near its junctions with plant DNA. Cell 29: 10051014.

Singh, K., Dennis, E.S., Ellis, J.G., Llewellyn, D.J., Tokuhisa, J.G., Wahleithner, J.A., and Peacock, W.J. 1990. OCSBF-1, a maize ocs enhancer binding factor: Isolation and expression during development. Plant Cell 2: 891-903.

Smith, A.G., Gasser, C.S., Budelier, K.A., and Fraley, R.T. 1990. Identification and characterization of stamen- and tapetum-specific genes from tomato. Mol. Gen. Genet. 222: 9-16.

Sommer, H., Beltrán, J.-P., Huijser, P., Pape, H., Lönnig, W.-E., Saedler, H., and Schwarz-Sommer, Z. 1990. Deficiens, a homeotic gene invc .ed in the control of flower morphogenesis in Antirrhinum majus: The protein shows homology to transcription factors. EMBO J. 9: 605-613.

Sommer, H., Hehl, R. Krebbers, E., Piotrowiak, R., Lönning, W.-E., and Saedler, H. 1988. Transposable Elements of Antirrhinum majus. In: Plant Transposable Elements, O. Nelsen (ed), pp. 227-235, Plenum Press, New York.

Spielmann, A., and Simpson, R.B. 1986. T-DNA structure in transgenic tobacco plants with multiple independent integration sites. Mol. Gen. Genet. 205: 34-41.

Stachel, S.E., An, G., Flores, C., and Nester, E.W. 1985. A Tn3 lacZ. transposon for the random generation of $B$-galactosidase gene fusions: Application to the analysis of gene expression in Agrobacterium. EMBO J. 4: 891-898.

Stanford, A., Bevan, M., and Northcote, D. 1989. Differential expression within a family of novel wound-induced genes in potato. Mol. Gen. Genet. 215: 200-208.

Stougaard, J., Sardal, N.N., Grфn, A., Khüle, A., and Marcker, K.A. 1987. 5' analysis of the soybean leghaemoglobin $l b c 3$ gene: Regulatory elements required for promoter activity and organ specificity. EMBO. J. 6: 3565-3569.

Struhl, K. 1987. Promoters, activator proteins, and the mechanism of transcriptional initiation in yeast. Cell 49: 295-297.

Sukhapinda, K., Spivey, R., Simpson, R.B., and Shahin, E.A. 1987. Transgenic tomato (Lycopersicon esculentum $\mathrm{L}$.) transformed with a binary vector in Agrobacterium rhizogenes: Non-chimeric origin of callus clone and low copy numbers of integrated vector T-DNA. Mol. Gen. Genet. 206: 491-\$97.

Talanian, R.V., McKnight, C.J., and Kim, P.S. 1990. Sequence-specific DNA 
binding by a short peptide dimer. Science 249: 769-771.

Taylor, J.L., Jones, J.D.G., Sandler, S., Mueller, G.M., Bedbrook, J., and Dunsmuir, P. 1987. Optimizing the expression of chimeric genes in plant cells. Mol. Gen. Genet. 210: 572-577.

Teeri, T.H., Herrera-Estrella, L., Depicker, A., Van Montagu, M., and Palva, E.T. 1986. Indentification of plant promoters in situ by T-DNA-mediated transcriptional fusions to the npt-II gene. EMBO J. 5: 1755-1760.

Teeri, T.H., Lehväslaiho, H., Franck, M., Uotila, J., Heino, P., Palva, E.T., Van Montagu, M., and Herrera-Estrella, L. 1989. Gene fusions to lacZ reveal new expression patterns of chimeric genes in transgenic plants. EMBO J. 8: 343-350.

Terada, R., and Shimamoto, K. 1990. Expression of CaMV35S-GUS gene in transgenic rice plants. Mol. Gen. Genet. 220: 389-392.

Theologis, A. 1986. Rapid gene regulation by auxin. Ann. Rev. Plant Physiol. 37: 407-438.

Theres, N., Scheele, T., and Starlinger, P. 1987. Cloning of the Bz2 locus of Zea mays using the transposable element Ds as a gene tag. Mol. Gen. Genet. 209: 193197.

Thomas, C.M., Stalker, D.M., and Helinski, D.R. 1981. Replication and incompatibility properties of segments of the origin of the broad host range plasmid RK2. Mol. Gen. Genet. 181: 1-7.

Thomashow, M.F. 1990. Molecular genetics of cold-acclimation in higher plants. Adv. Genet. 28: 99-131.

Thomashow, M.F., Nutter, R., Postle, K., Chilton, M.-D., Blattner, F.R., Powell, A., Gordon, M.P., and Nester, E.W. 1980. Recombination between higher plant DNA and the Ti plasmid of Agrobacterium tumefaciens. Proc. Natl. Acad. Sci. USA 77: 6448-6452.

Thompson, W.F., and White, M.J. 1991. Physiological and molecular studies of light-regulated nuclear genes in higher plants. Annu. Rev. Plant Physiol. Plant Mol. Biol. 42: 423-466.

Thornburg, R.W., An, G., Cleveland, T.E., Johnson, R., and Ryan, C.A. 1987. Wound-inducible expression of a potato inhibitor II-chloramphenicol acetyltransferase gene fusion in transgenic tobacco plants. Proc. Natl. Acad. Sci. USA 84: 744-748.

Thorpe, T.A. 1980. Organogenesis in vitro: Structural, Physiological, and Biochemical Aspects. In: Perpectives in Plant Cell and Tissue Culture, International Review of Cytology, Suppl. 11A, I.K. Vasil (ed), pp. 71-111, Academic Press, Toronto.

Tokuhisa, J.G., Singh, K., Dennis, E.S., and Peacock, W.J. 1990. A DNA-binding protein factor recognizes two binding domains within the octopine synthase enhancer element. Plant Cell 2: 215-224. 
Töpfer, R., Pröls, M., Schell, J., and Steinbiß. H.-H. 1988. Transient gene expression in tobacco protoplasts: Il. Comparison of the reporter gene systems for CAT, NPT II, and GUS. Plant Cell Rep. 7: 225-228.

Topping, J.F., Wei, W., and Lindsey, K. 1991. Functional tagging of regulatory elements in the plant genome. Development 112: 1009-1019.

Valvekens, D., Van Montagu, M., and Van Lijsebettens, M. 1988. Agrohucterium tumefaciens-mediated transformation of Arabidopsis thaliana root explants by using kanamycin selection. Pro. Natl. Acad. Sci. USA. 85: 5536-5540.

van der Krol, A.R., Mur, L.A., Beld, M., Mol, J.N.M., and Stuitje, A.R. 1990. Flavonoid genes in Petunia: Addition of a limited number of gene copies may lead to a suppression of gene expression. Plant Cell 2: 291-299.

Van Haute, E., Joos, H., Maes, M., Warren, G., Van Montagu, M., and Schell, J. 1983. Intergenic transfer and exchange recombination of restriction fragments cloned in PBR322: a novel strategy for the reversed genetics of the Ti plasmids of Agrobacterium tumefaciens. EMBO J. 2: 411-417.

van Holde, K.E. 1989. Chromatin. Springer-Verlag, New York, 497pp.

Van Larebeke, N., Engler, G., Holsters, M., Van der Elsacker, S., Zaenen, J., Schilperoort, R.A., and Schell, J. 1974. Large plasmid in Agrobacterium tumefaciens essential for crown gall-inducing ability. Nature 252: 169-170.

Van Lijsebettens, M., Inzé, D., Schell, J., and Van Montagu, M. 1986. Transformed cell clones as a tool to study T-DNA integration mediated by Agrobacterium tumefaciens. J. Mol. Biol. 188: 129-145.

Van Lijsebettens, M., Vanderhaeghen, R., and Van Montagu, M. 1991. Insertional mutagenesis in Arabidopsis thaliana: Isolation of a T-DNA-linked mutation that alters leaf morphology. Theor. Appl. Genet. 81: 277-284.

Vieira, J., and Messing, J. 1987. Production of single-stranded plasmid DNA. Methods Enz. 153: 3-11.

Vinson, C.R., Sigler, P.P, and McKnight, S.L.. 1989. Scissors-grip model for DNA recognition by a family ff leucine zipper proteins. Science 246: 911-916.

Virts, E.L., and Gelvin, S.B. 1985. Analysis of transfer of tumor-inducing plasmids from Agrobacterium tumefaciens to Petunia protoplasts. J. Bacteriol. 162: 10301038.

Walbot, V., and Goldberg, R. 1979. Plant Genome Organization and Its Relationship to Classical Plant Genetics. In: Nucleic Acids in Plants, Vol. 1, T.C. Hall and J.W. Davies (eds), pp. 1-40, CRC Press, Boca Raton.

Walden, R., Hayashi, H., and Schell, J. 1991. 'T-DNA as a gene tag. Plant Journal 1: 281-288.

Wallroth, M., Gerats, A.G.M., Rogers, S.G., Fraley, R.T., and Horsch, R.B. 1986. Chromosomal localization of foreign genes in Petunia hybrida. Mol. Gen. Genet. 202: 6-15. 
Wasylyk, B. 1988. Enhancers and transcription factors in the control of gene expression. Biochimica et Biophysica Acta 951: 17-35.

Wefald, F.C., Devlin, B.H., and Williams, R.S. 1990. Functional heterogeneity of mammalian TATA-box sequences revealed by interaction with a cell-specific enhancer. Nature 344: 260-262.

Weil, C.F., and Wessler, S.R. 1990. The effects of plant transposable element insertion on transcription initiation and RNA processing. Annu. Rev. Plant Physiol. Plant Mol. Biol. 41: 527-552.

Weising, K., and Kahl, G. 1990. Towards an understandity of plant gene regulation: The action of nuclear factors. Z. Naturforsch. 46c: 1-11.

Weising, K., Bohn, H., and Kahl, G. 1990. Chromatin structure of transferred genes in transgenic plants. Devel. Genet. 11: 233-247.

Weising, K., Schell, J., and Kahl, G. 1988. Foreign genes in plants: Transfer, structure, expression, and applications. Ann. Rev. Genet. 22: 421-427.

Weisshaar, B., Armstrong, G.A., Block, A., da Costa e Silva, O., and Hahlbrock, K. 1991. Ligint-inducible and constitutively expressed DNA-binding proteins recognizing a plant promoter element with functional relevance in light responsiveness. EMBO J. 10: 1777-1786.

Wilson, C., Pearson, R.K., Bellen, H.J., O'Kane, C.J., Grossniklaus, U., and Gehring, W.J. 1989. P-element-mediated enhancer detection: An efficient method for isolating and characterizing developmentally regulated genes in Drosophila Genes Dev. 3: 1301-1313.

Xiang, X., Benson, K.F., and Chada, K. 1990. Mini-mouse: Disruption of the pygmy locus in a transgenic insertional mutant. Science 247: 967-969.

Yadav, N.S., Postle, K., Saiki, R.K., Thomashow, M.F., and Chilton, M.D. 1980. TDNA of a crown gall teratoma is covalently joined to host plant DNA. Nature 287: 458-461.

Yanofsky, M.F., Ma, H., Bowman, J.L., Drews, G.N., Feldmann, K.A., and Meyerowitz, E.M. 1990. The protein encoded by the Arabidopsis homeotic gene agaimous resembles transcription factors. Nature 346: 35-39.

Yoder, J.I. 1990. Rapid proliferation of the maize transposable element activator in transgenic tomato. Plant Cell 2: 723-730.

Zambryski, P. 1988. Basic processes underlying Agrobucterium-mediated DNA transfer to plant cells. Annu. Rev. Genet. 22: 1-30.

Zambryski, P. 1991. Single-strand nucleic acid:protein complexes involved in Agrobacterium or plant virus infection. Plenary Session, 3rd International Congress of the International Society for Plant Molecular Biology, Tucson, Arizona, October 6-11, 1991, Abstract \#8.

Zambryski, P., Depicker, A., Kruger, K., and Goodman, H.M. 1982. Tumor 
induction by Agrobacterium tumefaciens: Analysis of the boundaries of T-DNA. J. Mol. Appl. Genet. 1: 361-370.

Zambryski, P., Holsters, M., Kruger, K., Depicker, A., Schell, J., Van Montagu, M., and Goodman, H.M. 1980. Tumor DNA structure in plant cells transformed by $A$. tumefaciens. Science 209: 1385-1391.

Zambryski, P., Joos, H., Genetello, C., Leemans, J., Van Montagu, M., and Schell, J. 1983. Ti plasmid vector for the introduction of DNA into plant cells without alteration of their normal regeneration capacity. EMBO J. 2: 2143-2150.

Zambryski, P., Tempe, J., and Schell, J. 1989. Transfer and function of T-DNA genes from Agrobacterium Ti and Ri plasmids in plants. Cell 56: 193-201.

Zimmerman, J.L., and Goldberg, R.B. 1977. DNA sequence organization in the genome of Nicotiana tabacum. Chromosoma 59: 227-252. 
Appendix 1. Levels of GUS activity detected in seeds and placenta tissue from reciprocal genetic crosses between plant T218 and untransformed SRI tobacco. Results obtained with self-pollinated untransformed and $\mathrm{T} 218$ seeds are also presented. Note that GUS activity is presented on the basis of fresh weight as opposed to protein content.

\begin{tabular}{l}
\hline SAMPLE ANALYZED \\
$\begin{array}{c}\text { SAMPLE GUS ACTIVITY } \\
\text { SIZE }\end{array}$
\end{tabular} STANDARD DEVIATION

\begin{tabular}{|c|c|c|c|}
\hline $\begin{array}{l}\text { Untransformed } \\
\text { seeds } 10 \mathrm{DPA}\end{array}$ & 3 & 0.15 & 0.01 \\
\hline $\begin{array}{c}\text { untransformed } \\
\text { X } \\
\text { (seeds) }\end{array}$ & 3 & 0.37 & 0.17 \\
\hline $\begin{array}{c}9 \text { untransformed } \\
X \\
\text { ब'T21.8 } \\
\text { (placenta) }\end{array}$ & 3 & 0.07 & 0.02 \\
\hline $\begin{array}{c}\mathrm{C} 218 \\
\mathrm{x} \\
\begin{array}{c}\mathrm{T} \text { untransformed } \\
\text { (seeds) }\end{array}\end{array}$ & 2 & 6.55 & 2.65 \\
\hline $\begin{array}{c}\qquad \mathrm{T} 218 \\
\mathrm{x} \\
\substack{\text { untransformed } \\
(\text { placenta })}\end{array}$ & 2 & 0.07 & 0.03 \\
\hline $\begin{array}{c}\text { T218 (selfed) } \\
\text { (seeds) }\end{array}$ & 3 & 5.97 & 0.36 \\
\hline $\begin{array}{r}\text { T218 (selfed) } \\
\text { (placenta) }\end{array}$ & 1 & 0.09 & -- \\
\hline
\end{tabular}

1 pmole MU/min/mg fresh weight 

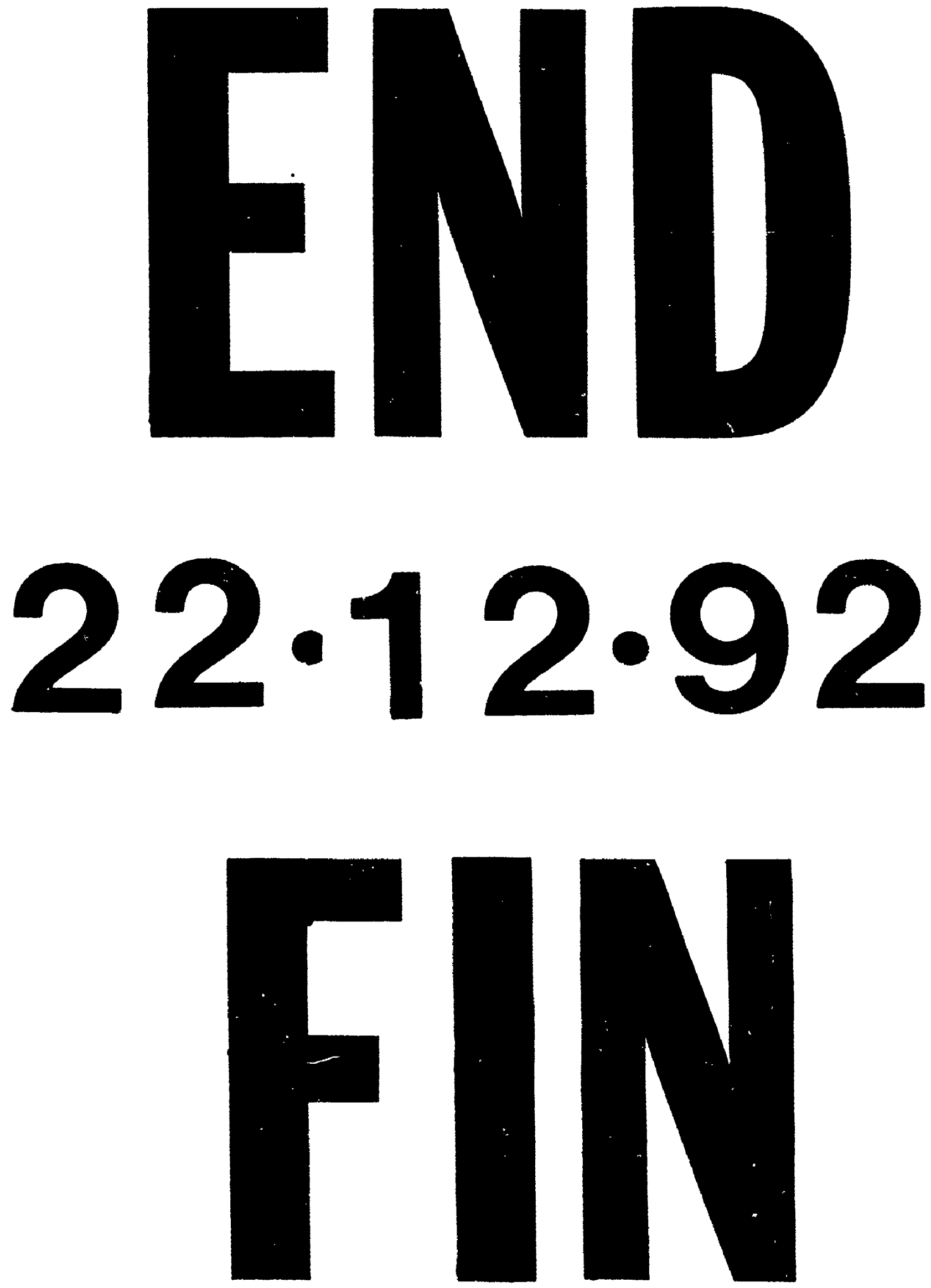